\title{
PARENTING AND FAMILY DIVERSITY ISSUES
}

DIANA LANG

Iowa State University Digital Press

Ames, Iowa 


\section{(ㅇ) (1) (2)}

Parenting and Family Diversity Issues by Diana Lang is licensed under a Creative Commons Attribution-NonCommercial-ShareAlike 4.0 International License, except where otherwise noted.

You are free to copy, share, adapt, remix, transform, and build upon the material for any purpose, even commercially, as long as you follow the terms of the license.

If you plan to reuse or adapt this text, please notify Dr. Lang by contacting her at dianab1@iastate.edu.

Suggested citation: Lang, D. (2020). Parenting and family diversity issues. Ames, IA: Iowa State University Digital Press. DOI: https://doi.org/10.31274/isudp.8

Published by the Iowa State University Digital Press, a division of the University Library at Iowa State University.

701 Morrill Rd, Ames, IA 50011, USA

E-mail:digipress@iastate.edu 


\section{CONTENTS}

About the Contributors

\section{Part I. Key Concepts}

Influences on Parenting

Diana Lang and Marissa L. Diener

Parenting Tasks: Roles, Goals, and Responsibilities

Diana Lang

The Primary Role of Families in Promoting Children's Development

Diana Lang

The Primary Role of Communities in Promoting Children's and Families' Development:

Evidence-Based, Best-Practice Recommendations

Diana Lang

ACEs

Diana Lang

\section{Part II. Parenting Theory}

1600s: Autocratic Parenting

Diana Lang

Early 1800s: Rousseau

Diana Lang

Late 1900s: Stanley Hall

Diana Lang

Late 1900s: Montessori

Diana Lang

1920s: Watson

Lumen Learning; Wikimedia contributors; and Diana Lang 
1930s: Vygotsky

Ana R. Leon; Jennfier Paris; Antoinette Ricardo; Dawn Rymond; and Diana Lang 1930s: Freud

Saylor Academy and Diana Lang

1940s: Spock

Wikimedia contributors and Diana Lang

1940s: Spitz

Wikimedia contributors and Diana Lang

1940s: Skinner

OpenStax and Diana Lang

1950s: Harlow, Bowlby, and Ainsworth

Lumen Learning and Diana Lang

1950s: Piaget

Dawn Rymond; Antoinette Ricardo; Jennfier Paris; Lumen Learning; and Diana Lang 1960s: Erikson

Jennfier Paris; Antoinette Ricardo; Dawn Rymond; Lumen Learning; and Diana Lang 1960s: Bandura

Mark E. Bouton and Diana Lang

1960s: Dreikurs

New World Encyclopedia; Wikimedia contributors; and Diana Lang

1970s: Bronfenbrenner

New World Encyclopedia; Wikimedia contributors; Jaime Ballard; Elizabeth Wieling;

Catherine Solheim; and Diana Lang

1980s: Galinsky

Marissa L. Diener and Diana Lang

\section{Part III. Family Theories}

The Double ABC-X Model of Family Stress

Jaime Ballard; Elizabeth Wieling; Catherine Solheim; and Diana Lang

Family Systems Theory

Diana Lang 
Systemic Family Development Theory

Diana Lang

Family Development Theory

Diana Lang

\section{Part IV. Parenting Styles}

Baumrind's Parenting Styles

Joel A Muraco; Wendy Ruiz; Rebecca Laff; Ross Thompson; and Diana Lang

Additional Parenting Styles

Diana Lang

\section{Part V. Child-Rearing Strategies}

Child-rearing and Guidance

Diana Lang

Active Listening

Diana Lang

Anticipatory Structure

Diana Lang

CALM

Diana Lang

Constructive Choices

Diana Lang

Four Pluses and a Wish

Diana Lang

Grounding

Diana Lang

I-messages

Diana Lang

Induction

Diana Lang 
Natural and Logical Consequences

Diana Lang

No-lose Method

Diana Lang

Problem Ownership

141

Diana Lang

Positive Language

143

Diana Lang

Redirecting

Diana Lang and Jack Maass

Reward-oriented Parenting and Positive Reinforcement

148

Diana Lang

Structure (with Flexibility): Routines, Rules, Directions

150

Diana Lang

Taking Away Privileges

153

Diana Lang

Time-ins and Time-outs

155

Diana Lang

Part VI. Child-rearing in a Variety of Contexts

Child Abuse, Neglect, and Foster Care

158

Diana Lang and Wikimedia contributors

Adoption

Diana Lang

Exceptionalities

167

Additional Topics that can Impact Parenting, Child-rearing, Families, and Child

178

Outcomes

Part VII. Developmental Milestones

Developmental Milestones and Positive Parenting Tips 
Infancy and Toddlerhood

Suzanne Valentine-French; Martha Lally; and Diana Lang

Early Childhood

Martha Lally; Suzanne Valentine-French; and Diana Lang

Middle and Late Childhood

Martha Lally; Suzanne Valentine-French; and Diana Lang Adolescence

Martha Lally; Suzanne Valentine-French; and Diana Lang

Emerging and Early Adulthood

Martha Lally and Suzanne Valentine-French 


\section{ABOUT THE CONTRIBUTORS}

This open textbook is a work in progress and will be improved and expanded over time. Version 1.0 has been compiled and written by the following contributors:

\section{Author}

\section{Diana L. Lang}

Dr. Lang is an Associate Teaching Professor at Iowa State University who teaches a variety of courses within the Department of Human Development and Family Studies. She is also a Certified Family Life Educator (CFLE) which is recognized in the U.S. and Canada for Family Life Education professions. Her areas of interest include adoption, parenting, parent-child communications, topic avoidance, individual and family development across the life span, policy, professional orientation and service learning, and human sexuality education. She is the proud parent of two adult children and is the volunteer executive director and founder of a non-profit organization that promotes adoption as a positive parenting option.

If you plan to reuse or adapt this text, please notify Dr. Lang by contacting her at baltimore.diana@gmail.com.

\section{Assistants \& Support}

\section{Alyssa L. Hanson}

Alyssa, a graduate student and teaching assistant in the Human Development and Family Studies Department at Iowa State University (2018-2021) provided assistance in the editing of this book.

\section{Abbey K. Elder}

Abbey Elder is the Open Access \& Scholarly Communication Librarian at Iowa State University who provided outstanding copyediting and production support during the development of this book. 


\section{PART I}

\section{KEY CONCEPTS}

\section{Introduction}

Parenting, child-rearing, care-giving, and parenting education are key concepts that can impact child outcomes. Therefore, it is imperative to provide definitions of each concept before learning about "parenting." I invite you to critically think about each concept and analyze how the information within this book can be applied to each of these words.

Parenting is a process of raising, promoting, and supporting the physical, emotional, social, and cognitive development of a child to adulthood and across the lifespan. ${ }^{1}$

Child-rearing is oftentimes defined interchangeably with parenting. However, there are many nonparental figures (e.g., society, day care providers, teachers, governments) who offer similar types of care without being a child's legal "parent." ${ }^{2}$

Care-giving is the act of assuming the main responsibilities for someone who cannot provide all basic needs for oneself. Examples might include a parent, day care provider, trained professional, or family member. ${ }^{3}$

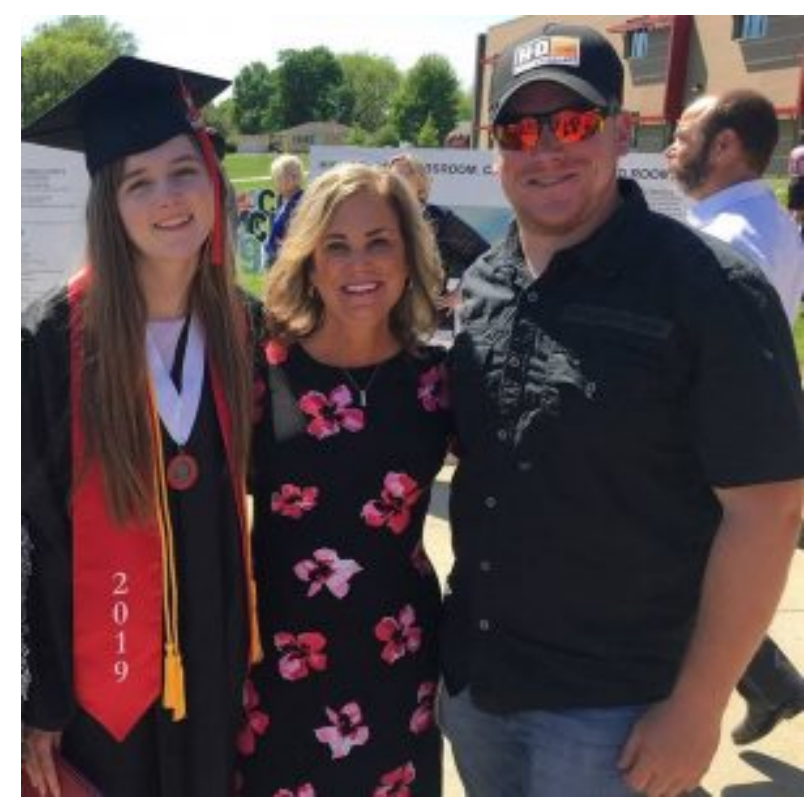

Figure 1. A family celebrating graduation.

Parenting education is a process that can help caregivers (and prospective caregivers) understand how to provide developmentally-appropriate care in a safe, loving, nurturing, and stable environment that contributes to a child's positive health and well-being. Successful parenting education provides participants with individualized, culturally-relevant knowledge, resources, strategies, tools, networking support, and guidance regarding best-practice approaches to childrearing. The goals of parenting education include caregivers learning and implementing this

1. Brooks, J. B. (2012). The process of parenting: Ninth edition. McGraw-Hill Higher Education.

2. Abrahan, H. (2017). A family is what you make it? Legal recognition and regulation of multiple parents. American University Journal of Gender, Social Policy er the Law, 25(4) https://ssrn.com/abstract=2925886

3. US Legal. (n.d.). Primary-caregiver doctrine law and legal definition. Retrieved from https://definitions.uslegal.com/p/primarycaregiver-doctrine/ 
information to facilitate a child's long-term, positive, emotional, social, physical, and cognitive development. ${ }^{4}$

Research continually shows that parenting practices can influence a child's social, emotional, and intellectual development, especially during the early years. ${ }^{5}$ Studies also demonstrate that parenting practices can impact a child's behavioral health, ability to focus (attention), and enhanced sense of security. ${ }^{6}$

Further, parenting processes and outcomes can be influenced by factors such as personality, biology, temperament, and the unique experiences of a parent and a child. Therefore, these processes should be examined within the contexts of social, economic, historical, and psychological factors related to individuals, families, communities, and cultures. ${ }^{7}$

Across the world, a variety of definitions exist for many topics concerning "parenting" and "family." For instance, the European Court of Human Rights jurisprudence recommends that "family" be defined on culturally-sensitive and case-by-case bases by giving consideration to the personal ties between the persons concerned. ${ }^{8}$

Further, it is fairly-well agreed upon that those who work with children and families embrace, respect, and understand that subjective definitions of these concepts (a) exist within and between individuals, cultures, and organizations (e.g., UNICEF, U.S. Census Bureau, etc.), (b) can change over time, and (c) are based on personal experiences, views, values, beliefs, historical time and place, culture, etc. ${ }^{9}$

\section{Throughout this entire book, it should be assumed that}

\section{the following terms are defined as follows:}

Parent: The words, "family member," "primary caregiver," and/or "parent" will be used interchangeably to denote the diverse groups of individuals who are primarily responsible for

4. Child Welfare Information Gateway. (2019). Parent Education to Strengthen Families and Prevent Child Maltreatment. Issue Briefs https://www.childwelfare.gov/pubs/issue-briefs/parented/

5. National Academies of Sciences, Engineering, and Medicine. (2016). Parenting Matters: Supporting Parents of Children Ages 0-8. Washington, DC: The National Academies Press. https://doi.org/10.17226/21868.

6. Child Welfare Information Gateway. (2019). Parent Education to Strengthen Families and Prevent Child Maltreatment. Issue Briefs https://www.childwelfare.gov/pubs/issue-briefs/parented/

7. Child Welfare Information Gateway. (2019). Parent Education to Strengthen Families and Prevent Child Maltreatment. Issue Briefs https://www.childwelfare.gov/pubs/issue-briefs/parented/

8. UNICEF. (2016) Refugee and Migrant Crisis in Europe: The Right of the Child to Family Reunification. Advocacy Brief. Retrieved from https://www.unicef.org/eca/sites/unicef.org.eca/files/ ADVOCACY_BRIEF_Family_Reunification_13_10_15.pdf

9. https://courses.lumenlearning.com/wm-introductiontosociology/chapter/defining-family/ 
rearing a child. These terms can include, but are not limited to, extended family members, guardians, fictive kin, foster families, close friends, those bonded by legal and/or biological ties, etc.

Family: Similarly, the words, "family" and "families" will be used to signify the diverse social and cultural constructions that may be derived from (a) values, beliefs, or relationship bonds (e.g., cohabitation), (b) blood, marriage, or legal ties (e.g., adoption), (c) social bonds (e.g., fostering, nurturing, or economic ties), and (d) decision-making related to day-to-day functioning ${ }^{10}$ Therefore, "family" may include, but is not limited to, extended family members, guardians, fictive kin, foster families, close friends, those joined by legal or biological ties, etc.

10. Sharma R. (2013). The family and family structure classification redefined for the current times. Journal of Family Medicine and Primary Care, 2(4), 306-310. https://doi.org/10.4103/2249-4863.123774 


\title{
INFLUENCES ON PARENTING
}

\author{
Diana Lang and Marissa L. Diener
}

Parenting is a complex process in which parents and children both impact one another. There are many reasons that parents behave the way they do. The multiple influences on parenting are still being explored. Proposed influences on parental behavior include:

1. parent characteristics,

2. child characteristics, and

3. contextual and sociocultural characteristics. ${ }^{1} 2$

\section{Parent Characteristics}

Parents bring unique traits and qualities to the parenting relationship that affect their decisions as parents. These characteristics include a parent's age, gender identity, personality, developmental history, beliefs, knowledge about parenting and child development, and mental and physical health. Parents' personalities also affect parenting behaviors. Parents who are more agreeable, conscientious, and outgoing are warmer and provide more structure to their children. Parents who are more agreeable, less anxious, and less negative also support their children's autonomy more than parents who are anxious and less agreeable. ${ }^{3}$ Parents who have these personality traits appear to be better able to respond to their children positively and provide a more consistent, structured environment for their children.

Parents' developmental histories, or their experiences as children, can also affect their parenting strategies. Parents may learn parenting practices from their own parents. Fathers whose own parents provided monitoring, consistent and age-appropriate discipline, and warmth are more likely to provide this constructive parenting to their own children. ${ }^{4}$ Patterns of negative parenting and ineffective discipline also appear from one generation to the next. However, parents who are

1. Belsky, J. (1984). The determinants of parenting: A process model. Child Development, 55(1), 83-96.

2. Demick, J. (1999). Parental development: Problem, theory, method, and practice. In Mosher, R. L., Youngman D. J., \& Day J. M. (Eds.), Human development across the life span: Educational and psychological applications (pp. 177-199). Praeger.

3. Prinzie, P., Stams, G. J., Dekovic, M., Reijntjes, A. H., \& Belsky, J. (2009). The relations between parents' Big Five personality factors and parenting: A meta-review. Journal of Personality and Social Psychology, 97(1), 351-362.

4. Kerr, D. C. R., Capaldi, D. M., Pears, K. C., \& Owen, L. D. (2009). A prospective three generational study of fathers' constructive parenting: Influences from family of origin, adolescent adjustment, and offspring temperament. Developmental Psychology, 45(1), 1257-1275. 
dissatisfied with their primary caregivers' approach may be more likely to change their parenting methods when they have children.

\section{Child Characteristics}

Parenting is bidirectional. Not only do parents and caregivers affect their children, but children influence their parents/primary caregivers as well. ${ }^{5}$ Child characteristics, such as gender identity, birth order, temperament, and health status, can affect child-rearing behaviors and roles. For example, an infant with an easy temperament may enable caregivers to feel more effective, as they are easily able to soothe the child and elicit smiling and cooing. On the other hand, a cranky or fussy infant can elicit fewer positive reactions from caregivers and may result in parents feeling less effective in the role. ${ }^{6}$ Over time, parents of more difficult children may become more punitive and less patient with their children. ${ }^{7}$ Many parents who have a fussy, difficult child have been found to be less satisfied

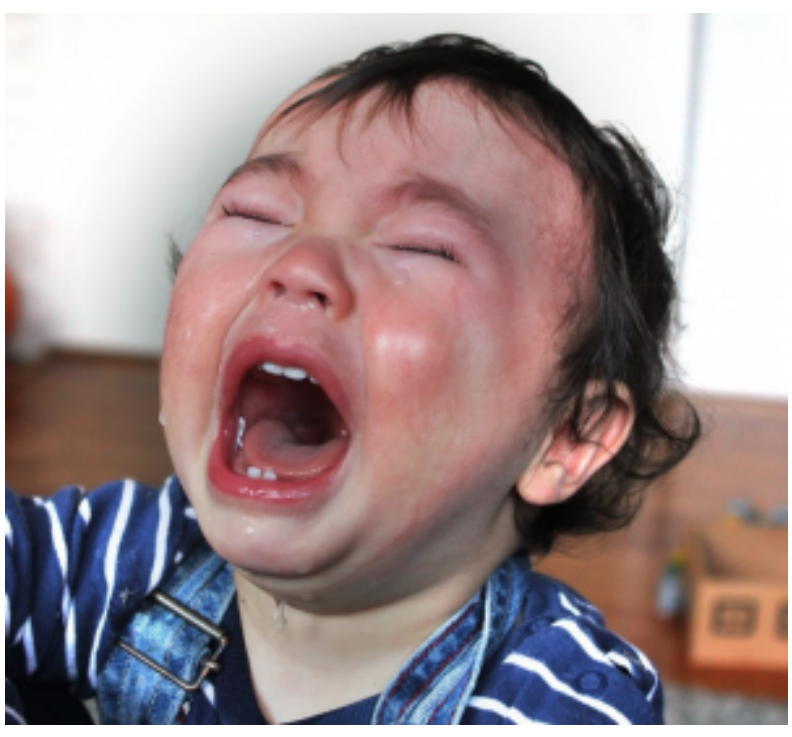

Figure 1. A child with a difficult temperament can have a significant impact on a parent. (Photo Credit: Harald Groven, $\underline{\text { CC BY-SA 2.0) }}$ with their relationships and have greater challenges in balancing work and family roles. ${ }^{9}$ Thus, child temperament is one of the child characteristics that influences how caregivers behave with their children.

Another child characteristic is the child's gender identity. Some parents assign different household chores to their children based on their child's gender identity. For example, older research has shown girls are more often responsible for caring for younger siblings and household chores, whereas boys are more likely to be asked to perform chores outside the home, such as mowing the

5. Child Characteristics is adapted from "The Developing Parent" by Marisa Diener, licensed CC BY NC SA.

6. Eisenberg, N., Hofer, C., Spinrad, T., Gershoff, E., Valiente, C., Losoya, S. L., Zhou, Q., Cumberland, A., Liew, J., Reiser, M., \& Maxon, E. (2008). Understanding parent-adolescent conflict discussions: Concurrent and across-time prediction from youths' dispositions and parenting. Monographs of the Society for Research in Child Development, 73(2), 1-160.

7. Clark, L. A., Kochanska, G., \& Ready, R. (2000). Mothers' personality and its interaction with child temperament as predictors of parenting behavior. Journal of Personality and Social Psychology, 79, 274-285.

8. Kiff, C. J., Lengua, L. J., \& Zalewski, M. (2011). Nature and nurturing: Parenting in the context of child temperament. Clinical Child and Family Psychology Review, 14(1), 251-301. https://doi.org/10.1007/s10567011-0093-4

9. Hyde, J. S., Else-Quest, N. M., \& Goldsmith, H. H. (2004). Children's temperament and behavior problems predict their employed mothers' work functioning. Child Development, 75, 580-594. 
lawn. ${ }^{10}$ Research has also demonstrated that some parents talk differently with their children based on their child's gender identity, such as providing more scientific explanations to their sons and using more emotion words with their daughters. ${ }^{11}$

\section{Contextual Factors and Sociocultural Characteristics}

The parent-child relationship does not occur in isolation. Sociocultural characteristics, including economic hardship, religion, politics, neighborhoods, schools, and social support, can also influence parenting. Parents who experience economic hardship tend to be more easily frustrated, depressed, and sad, and these emotional characteristics can affect their parenting skills. ${ }^{12}$ Culture can also impact parenting behaviors in fundamental ways. Although promoting the development of skills necessary to function effectively in one's community, to the best of one's abilities, is a universal goal of parenting, the specific skills necessary vary widely from culture to culture. Thus, parents have different goals for their children that partially depend on their culture. ${ }^{13}$ For example, parents vary in how much they emphasize goals for independence and individual achievements and goals involving maintaining harmonious relationships and being embedded in a strong network of social relationships.

\section{Video Example}

Watch Dr. Dan Siegel describe how caregivers can impact brain development.

10. Grusec, J. E., Goodnow, J. J., \& Cohen, L. (1996). Household work and the development of concern for others. Developmental Psychology, 32(6), 999-1007.

11. Crowley, K., Callanan, M. A., Tenenbaum, H. R., \& Allen, E. (2001). Parents explain more often to boys than to girls during shared scientific thinking. Psychological Science, 12(3), 258-261. https://doi.org/10.1111/1467-9280.00347

12. Conger, R. D., \& Conger, K. J. (2004). Resilience in Midwestern families: Selected findings from the first decade of a prospective, longitudinal study. Journal of Marriage and Family, 64(2): 361-373. https://doi.org/10.1111/ j.1741-3737.2002.00361.x

13. Tamis-LeMonda, C. S., Way, N., Hughes, D., Yoshikawa, H., Kalman, R. K., \& Niwa, E. Y. (2007). Parents' goals for children: The dynamic coexistence of individualism and collectivism in cultures and individuals. Social Development, 17(1), 183-209. https://doi.org/10.1111/j.1467-9507.2007.00419.x 


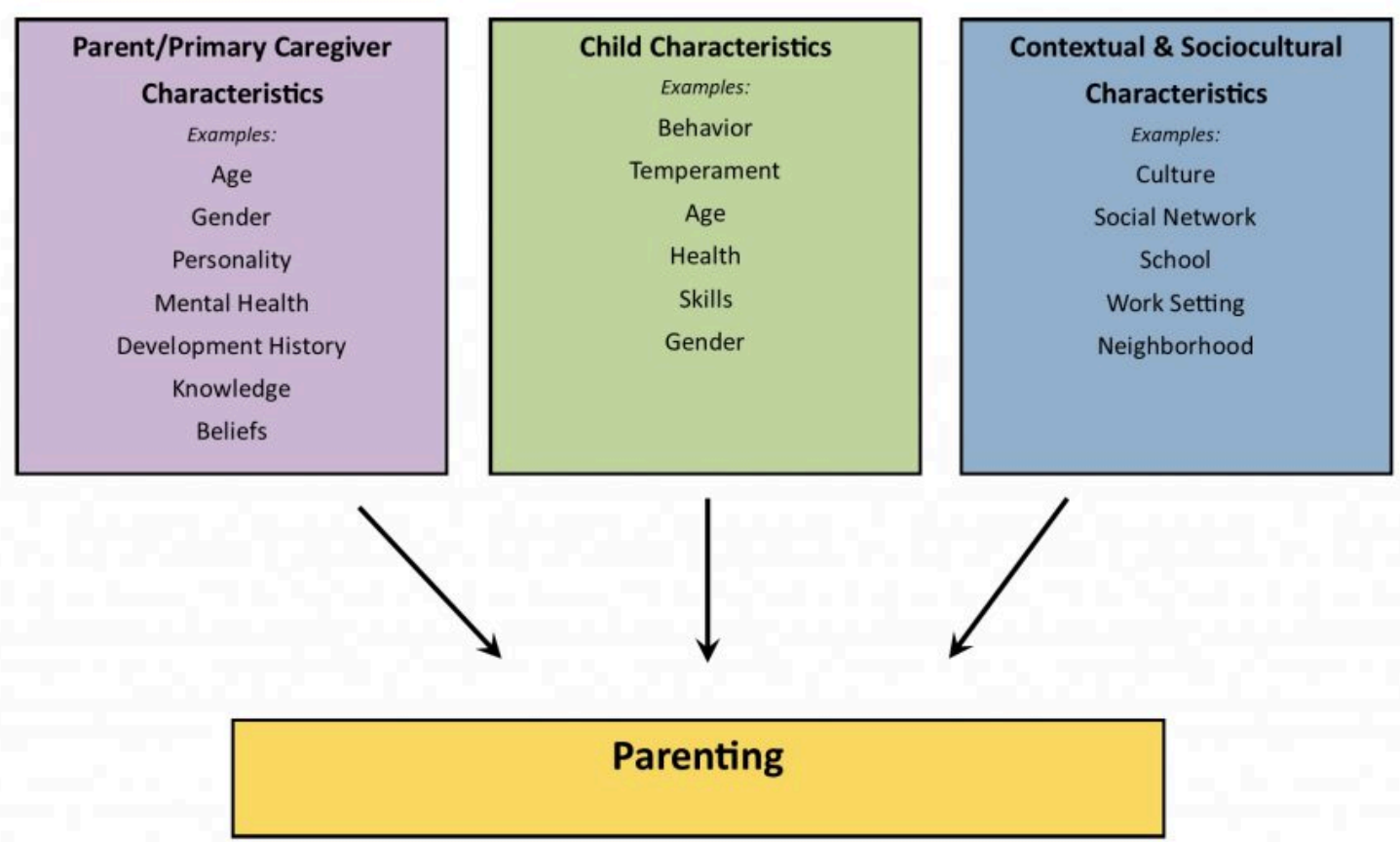

Figure 2. Influences on parenting can stem from internal factors such as the parent or child's characteristics or external, sociocultural characteristics.

These differences in parental goals can also be influenced by culture and immigration status. Other important contextual characteristics, such as the neighborhood, school, and social networks, can affect parenting, even though these settings do not always include both the child and the parent. ${ }^{14}$ For example, Latina mothers who perceived their neighborhood as more dangerous showed less warmth with their children, perhaps because of the greater stress associated with living in a threatening environment. ${ }^{15}$

\section{Summary: Many Factors Can Influence Parenting and Child Outcomes}

Parenting factors include characteristics of the primary caregiver, such as gender identity and personality, as well as characteristics of the child, such as age and temperament. Parenting styles

14. Bronfenbrenner, U. (1989). Ecological systems theory. Annals of Child Development, 6(1), 187-249.

15. Gonzalez-Backen, M. A., Updegraff, K. A., \& Umaña-Taylor, A. J. (2011). Mexican-origin adolescent mothers' stressors and psychosocial functioning: Examining ethnic identity affirmation and familism as moderators. Journal of Youth and Adolescence, 40(2), 140-157. https://doi.org/10.1007/s10964-010-9511-z 
provide reliable indicators of parenting functioning that predicts child well-being across a wide spectrum of environments and diverse communities. Caregivers who consistently engage in high responsiveness and appropriate demandingness with children are linked to more "quality" outcomes for youth.

The interaction among all these factors creates many different patterns of parenting behaviors. For instance, parenting influences a child's development as well as the development of the parent or primary caregiver. And, as parents face new challenges, they change their parenting strategies and construct new aspects of their identities. Furthermore, the goals and tasks of parents may change over time as their children develop. ${ }^{16}{ }^{17}$ However, the next page outlines typical parenting tasks, roles, goals, and responsibilities that extend across cultures and time.

16. Baumrind, D. (1991). The influence of parenting style on adolescent competence and substance use. Journal of Early Adolescence, 11, 56-95. 10.1177/0272431691111004

17. Barber, B. K. (1996). Parental psychological control: Revisiting a neglected construct. Child Development, 67, $3296-3319$. doi:10.2307/1131780 


\title{
PARENTING TASKS: ROLES, GOALS, AND RESPONSIBILITIES
}

\author{
Diana Lang
}

Despite contextual factors and varied goals associated with parenting, roles and responsibilities of parenthood are derived from national and international laws, policies, research, and practice. Below are well-agreed upon fundamental tasks of parenthood ${ }^{1}$ that extend across many cultures:

- Safety and sustenance: ensuring adequate food, housing, clothing, medical care, and protection from harm in a multitude of contexts (e.g., neighborhood, household structure)

- Socioemotional support: providing warm and positive responsivity, affection, communication, expectations, affirmations, encouragement, emotional regulation, guidance, discipline, and modeling of appropriate behaviors

- Stimulation/instruction: encouraging achievement and learning through exposure to developmentally-appropriate and culturallyenriching experiences

- Supervision: monitoring whereabouts, communications, activities; collecting

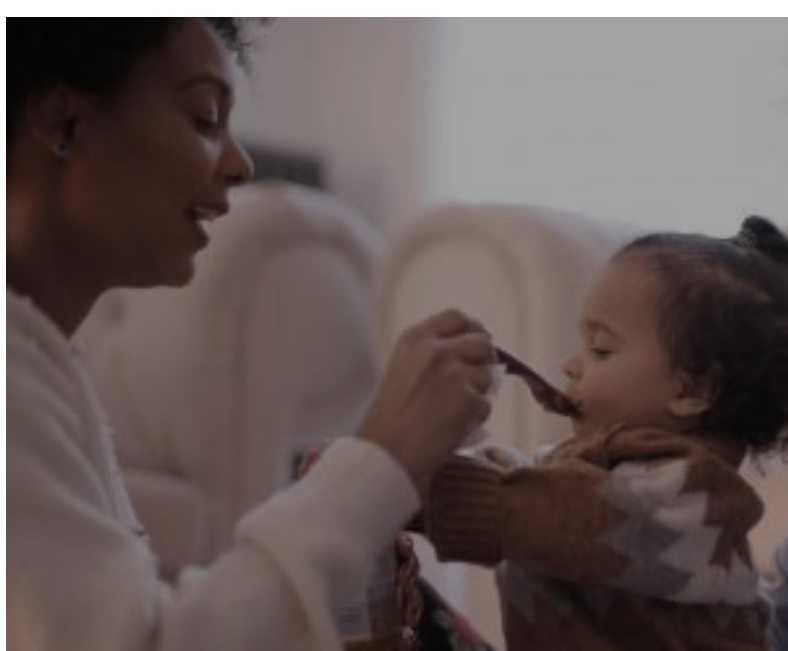

Figure 1. A parent feeding their child exhibits the "providing sustenance" task of parenting. (Photo Credit: $\underline{\text { Andrea Piacquadio, }}$ Pexels License) information from various sources; maintaining ongoing, reciprocal communications with children

- Structure: facilitating organized environments and activities via routines, rituals, scaffolding, and time management

- Socialization: supporting connections with communities, relatives, friends, peers, and institutions $^{2}$

1. Bradley, R. H. (2007). Parenting in the breach. How parents help children cope with developmentally challenging circumstances. Parenting: Science and Practice, 7(2), 99-148.

2. Laukkanan, E., Karppinen, S., Maattaa, K., \& Uusiautti, S. (2014). Emphases of parenting in the light of three comparison groups. International Education Studies, 7(3), 67-77. http://dx.doi.org/10.5539/ies.v7n3p67 


\title{
THE PRIMARY ROLE OF FAMILIES IN PROMOTING CHILDREN'S DEVELOPMENT
}

\author{
Diana Lang
}

The family is central in children's lives because it is through experiences with their families that children learn about themselves and the world around them. "Family member" is used here to define the people who are primarily responsible for a child, including parents, extended family members, guardians, and foster families. Family structures, processes, and functions must be assessed in order to understand the role family members have in child outcomes. ${ }^{1}$

\section{Family Structures}

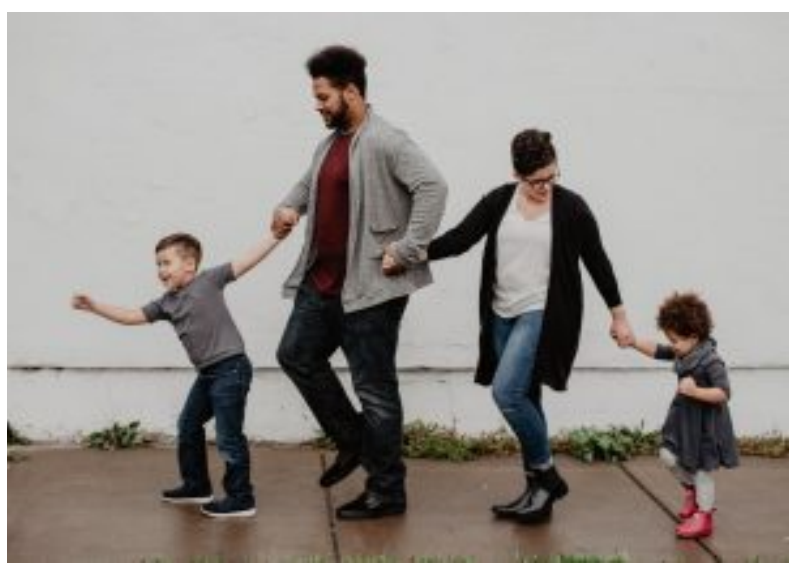

Figure 1. A family with two parents and two children. (Photo Credit: Emma Bauso, $\underline{\text { Pexels }}$ License)

"family structures":
"Family structures" delineate household members who are related by blood or legal ties; this concept typically assumes there is at least one child younger than 18 years of age residing in the household. Specific structures include two-parent, one-parent, and "living with neither parent" (e.g., grandparents or other relatives rearing a child, families providing foster care, and children living in institutionalized settings), blended families, single-parent plus partner families (cohabiting couples, for example), multigenerational families, binuclear families, and adoptive families.

The U.S. Census Bureau utilizes these definitions of

- Nuclear family: a child lives with two married biologically-related parents and with only full siblings, if siblings are present.

- Cohabiting families: a child's parent lives with at least one opposite-sex, non-related adult. This additional adult may or may not be the biological parent of the child.

- Same-sex cohabiting/married families: a child's parent lives with at least one same-sex, non-

1. Hammond, R., Cheney, P., \& Pearsey, R. (2015) Sociology of the Family. Rocky Ridge Press. http://freesociologybooks.com/ Sociology_Of_The_Family/01_Changes_and_Definitions.php 
related adult. The additional adult may or may not be the biological parent of the child.

- Stepfamilies and blended families (terms used interchangeably): children who live in a household formed through remarriage resulting in children living with one or no biologicallyrelated parents. The presence of a stepparent, stepsibling, or half-sibling designates a family as blended. ${ }^{2}$

\section{Family Processes}

"Family processes" are the ways in which families internally function to navigate cognitive, social, and emotional events. Examples include how families adapt, communicate, cope, problem solve, parent, rear children, make decisions, plan, and lead. ${ }^{3}$

\section{Family Functions}

Many "family functions" are similar to parenting tasks, goals, and responsibilities. However, it is important to understand how "family functions" and parenting tasks impact each other. The following is a list of somewhat universal family functions (e.g., almost all families in all countries worldwide have some of these in common):

- Economic support: providing basic needs, such as food, shelter, clothing, etc.

- Emotional support: providing love, comfort, intimacy, companionship, nurturing, belongingness, etc.

- Socialization of children: rearing children, parenting, helping children function to the best of their abilities within their society.

- Control of sexuality: defining and managing when and with whom (e.g., marriage) sexuality occurs.

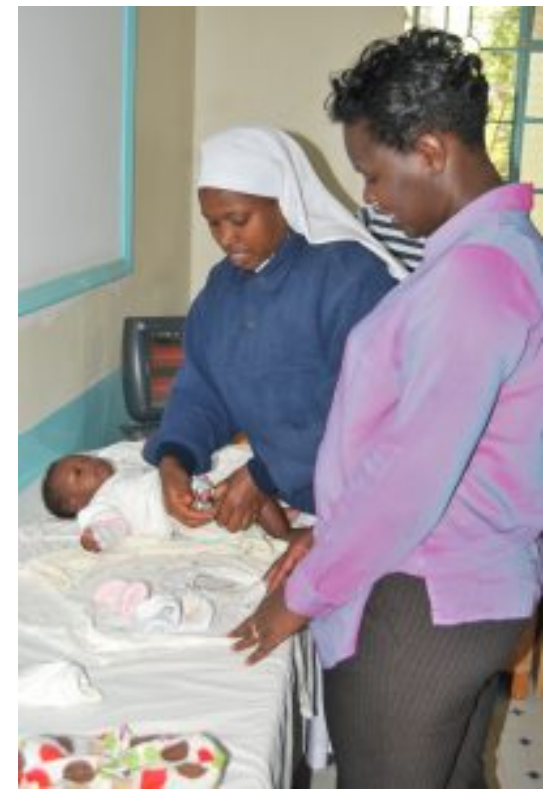

Figure 2. This infant getting immunization shots is being provided for in ways that not all families can afford. (Photo Credit: Maria Immaculata Hospital, CC BY-SA 4.0)

- Procreation: contributing to the continuation of society and offspring.

- Ascribed status: providing a social identity (e.g., social class, race, ethnicity, kinship, religion, etc.) ${ }^{4}$

2. United States Census Bureau. (2019). Historical living arrangements of children. Retrieved from https://www.census.gov/data/ tables/time-series/demo/families/children.html

3. Pasley, K., \& Petren, R. E. (2015). Family structure. In Encyclopedia of Family Studies, C. L. Shehan (Ed.) John Wiley \& Sons, Inc. https://doi.org/10.1002/9781119085621.wbefs016 
4. Hammond, R., Cheney, P., \& Pearsey, R.(2015). Sociology of the Family in Introduction to Sociology Textbook. Rocky Ridge Press. Retrieved from http://freesociologybooks.com/Sociology_Of_The_Family/01_Changes_and_Definitions.php 


\section{THE PRIMARY ROLE OF COMMUNITIES IN PROMOTING CHILDREN'S AND FAMILIES' DEVELOPMENT: EVIDENCE-BASED, BEST-PRACTICE RECOMMENDATIONS}

Diana Lang

Many caregivers seek or need information, education, and/or assistance in rearing children. "It takes a village" is a common mantra used in relation to parenting and child-rearing. This means that entire communities of people help shape children's development and can foster safe, healthy environments and positive child outcomes. Programs, educational institutions, community organizations, and those who work with children and families can also support children's healthy growth and development within the family by creating continuity between primary caregivers and the "village." For optimal outcomes, it is important for all members of the "village" to find, assess, analyze, and implement high-quality, up-to-date, evidence-based, best-practice recommendations to strengthen children and families.

Evidence-based parenting programs and practices are those that are supported and welldocumented by up-to-date scientific research. Key indicators must demonstrate that practices have strengthened families, prevented youth and/or family problems, and/or promoted family and child well-being via validated research studies. ${ }^{1}$ Read this PDF: Family Engagement Best-Practice Tips for Everyone Who Works with Children or Families.

\section{Video Examples}

The videos within this link depict strength-based family engagement approaches that promote positive relationships and outcomes for children and families.

Best Practices in Family \& Community Engagement Video Series

1. Child Welfare Information Gateway. (2019). Parent education to strengthen families and reduce the risk of maltreatment.

Washington, DC: U.S. Department of Health and Human Services, Children's Bureau. 
14 THE PRIMARY ROLE OF COMMUNITIES IN PROMOTING CHILDREN'S AND FAMILIES' DEVELOPMENT: EVIDENCE-BASED, BEST-PRACTICE RECOMMENDATIONS

Best-practice recommendations are methods, approaches, or techniques that are regarded as superior to other alternatives because research demonstrates they produce the most favorable outcomes when compared with other methods, approaches, or techniques. ${ }^{2}$

\section{Links to best-practice approach recommendations}

- Media recommendations from the American Academy of Pediatrics

- Vaccination recommendations from the Centers for Disease Control and Prevention

\section{Further Reading}

Read this PDF to learn more about evidence-based, best-practice approach recommendations regarding specific programs, competencies, and the key elements of effective parenting education programs:

Child Welfare Information Gateway. (2019). Parent education to strengthen families and reduce the risk of maltreatment $|p d f|$. Washington, DC: U.S. Department of Health and Human Services, Children's Bureau.

The following section contains evidence-based, best-practice recommendations for the prevention and education of adverse childhood experiences (ACEs). 


\title{
ACES
}

\author{
Diana Lang
}

\section{Adverse Childhood Experiences (ACEs)}

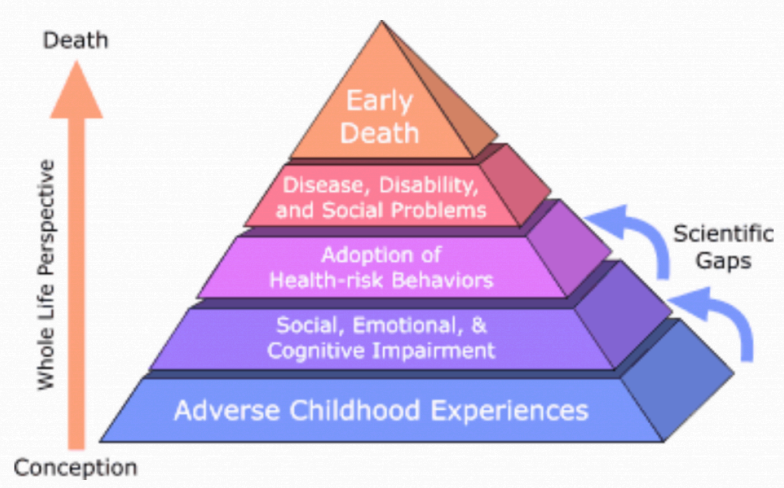

The term Adverse Childhood Experiences (ACEs) is defined as a traumatic experience that happens to someone before the age of 18 years that the person "recalls" as an adult. ${ }^{1}$

ACEs can include sexual, psychological, or physical abuse. ACEs have been linked to premature death and various health conditions and risks. ${ }^{2}$

\section{ACEs score}

To determine your own ACEs score, visit this website

Several studies have shown that ACEs are associated with health-related risk factors such as substance abuse, risky sexual behavior, obesity, cardiovascular disease, cancer, and diabetes. ${ }^{3}$ Having multiple ACEs is an important risk factor for several unfavorable health outcomes, including early

1. Centers for Disease Control and Prevention. (2019). About adverse childhood experiences. Retrieved from https://www.cdc.gov/ violenceprevention/childabuseandneglect/acestudy/aboutace.html

2. Center on the Developing Child at Harvard University. (n.d.). What are ACEs? And how do they relate to toxic stress? Retrieved from https://developingchild.harvard.edu/resources/aces-and-toxic-stress-frequently-asked-questions/

3. Ximenes, R. B. B., Ximenes, J. C. M., Nascimento, S. L., Roddy, S. M., \& Leite, A. J. M. (2019). Relationship between maternal adverse childhood experiences and infant development: A systematic review. Medicine, 98(10) doi: 10.1097/

MD.0000000000014644 
death. The research suggests that the impact of these adverse experiences in childhood on adult health status is strong and cumulative. ${ }^{4}$

Best-practice recommendations for preventing ACEs entail reducing child abuse and neglect by:

- Strengthening economic supports to families,

- Supporting parents via education about positive parenting techniques,

- Providing high-quality care and education immediately following a child's birth,

- Improving parenting skills to enhance healthy child development and well-being, and

- Providing early interventions to reduce adverse effects and to prevent future risks. ${ }^{5}$

\section{Video Examples}

Watch Dr. Bruce Perry talk about reducing the effects of trauma.

Additional video examples can be viewed on the CDC's YouTube channel.

Watch Dr. Dan Siegel discuss the brain's ability to repair after trauma.

\section{Further Reading}

Center for Disease Control and Prevention: Adverse Childhood Experiences Handout [PDF]

Center for Disease Control and Prevention: Adverse Childhood Experiences website

More information will be addressed within the Child Abuse, Neglect, and Corporal Punishment content.

4. Ximenes, R. B. B., Ximenes, J. C. M., Nascimento, S. L., Roddy, S. M., \& Leite, A. J. M. (2019). Relationship between maternal adverse childhood experiences and infant development: A systematic review. Medicine, 98(10) doi: 10.1097/ MD.0000000000014644

5. Centers for Disease Control and Prevention. (2020). Prevention Strategies. Washington, DC: U.S. Department of Health and Human Services, Children's Bureau. Retrieved from https://www.cdc.gov/violenceprevention/childabuseandneglect/ acestudy/prevention.html 
PART II

PARENTING THEORY 


\title{
1600S: AUTOCRATIC PARENTING
}

\author{
Diana Lang
}

\section{Autocratic Parenting and Thomas Hobbes}

Thomas Hobbes, 1588-1679, contributed to the era of autocratic parenting due to his views regarding human motivation, Psychological Egoism, and the social contract. ${ }^{1}$ According to Hobbes, humans are extremely self-interested and born with original sin.

Hence, adults had to use control and discipline because children were born "evil" and had to be saved. Further, as a result of adults' own self-interests, Hobbes believed that absolute authority was a necessity in politics, in dealing with others, and in the home. ${ }^{2}$

During this era, many believed that children learned obedience to God via their parents' use of harsh discipline and strict parenting. Children were typically viewed as being "willful" and were used as household servants.

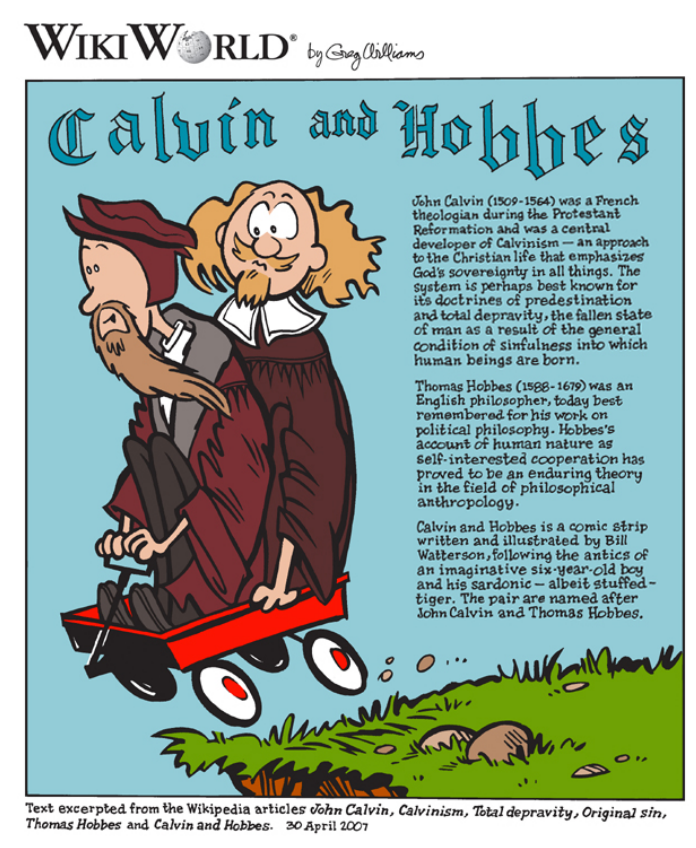

Figure 1. Calvin and Hobbes comic. (Image Source: Greg Williams, CC BY)

1. Friend, C. (n.d.). Social contract theory. In Internet Encyclopedia of Philosophy. https://www.iep.utm.edu/soc-cont/\#SH2a 2. Hobbes, T. (1651). Leviathan, or the matter, forme, and power of a commonwealth ecclesiastical and civil. Project Gutenberg. http://www.gutenberg.org/files/3207/3207-h/3207-h.htm 


\section{Key Takeaways}

- Babies were born with original sin and were very egocentric.

- Parents were to direct children away from their evil tendencies.

- Similar to the current authoritarian approach.

- Recommended that rigid and strict rules be used to shape children into well-behaved, successful adults. 


\title{
EARLY 1800S: ROUSSEAU
}

\author{
Diana Lang
}

\section{Jacques Rousseau and Childlike Innocence}

During the eighteenth century, Jean-Jacques Rousseau's views started to change parenting practices. Rousseau contended that children were inherently innocent (not sinful, as Hobbes believed), weak, and easily tempted. He believed that humans were born pure until one's interactions with the environment caused negative effects on one's development. ${ }^{1}$ Rousseau also believed that children needed protection from child labor and negative influences within civilization.

Rousseau's work is credited as being the first developmental account of childhood via his emphasis on maturation and stages of development: ${ }^{2}$

- Childhood (0 to 12 years): children are guided by simple impulses and simply react to their surroundings.

- Pre-Adolescence (12 to 16 years): children begin to develop reason and are able to comprehend more abstract ideas.

- Puberty and Adulthood (16 years and onward): children develop into adults that can navigate society and its moral issues.

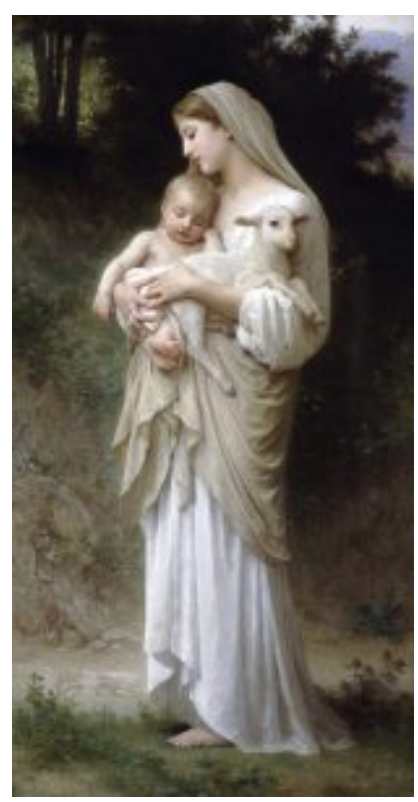

Figure 1. Photo of a painting by Bouguereau: "L’Innocence"

These stages elicited guidelines outlining "developmentally-appropriate" practices in parenting and education. Rousseau's work also emphasized the importance of play and teaching within the early years of childhood education: ${ }^{3}$

"When the child flies a kite he is training eye and hand to accuracy; when he whips a top, he is increasing his strength by using it, but without learning anything. I have sometimes asked why children are not given the same games of skill as men; tennis, mall, billiards, archery, football, and musical instruments. I was told that some of these are beyond their strength, that the child's senses are not sufficiently developed for others. These do not strike me as valid reasons; a child is not as tall as a

1. Friend, C. (n.d.). Social contract theory. In Internet Encyclopedia of Philosophy. https://www.iep.utm.edu/soc-cont/\#SH2c

2. Rousseau, J. (1762). Emile, or On Education. (B.Foxley, Trans.). J.M. Dent \& Sons. http://www.gutenberg.org/files/5427/ 5427-h/5427-h.htm

3. Rousseau, J. (1762). Emile, or On Education. (B. Foxley, Trans.). J.M. Dent \& Sons. http://www.gutenberg.org/files/5427/ $\underline{5427-h / 5427-h . h t m}$ 
man, but he wears the same sort of coat; I do not want him to play with our cues at a billiard-table three feet high; I do not want him knocking about among our games, nor carrying one of our racquets in his little hand; but let him play in a room whose windows have been protected; at first let him only use soft balls, let his first racquets be of wood, then of parchment, and lastly of gut, according to his progress."

\section{Key Takeaways}

- Children were born innocent and exposure to certain circumstances resulted in them acting negatively.

- Parents were to shelter children from negative circumstances and interactions.

- Children mature over time throughout three stages-childhood, pre-adolescence, puberty, and adulthood.

- Maturation and development worked alongside each other. 


\section{LATE 1900S: STANLEY HALL}

\section{Diana Lang}

\section{Stanley Hall and Pedagogy}

Hall was one of the first scientific psychologists who gained notoriety as an educational expert; his work was often geared toward parents and educators in addition to psychologists. ${ }^{1}$

Hall presented public lectures to educators on the psychology underlying childhood and how to "best" teach children (otherwise known as "pedagogy"). This work made significant contributions to the study of, and improvements within, parenting and educational practices.

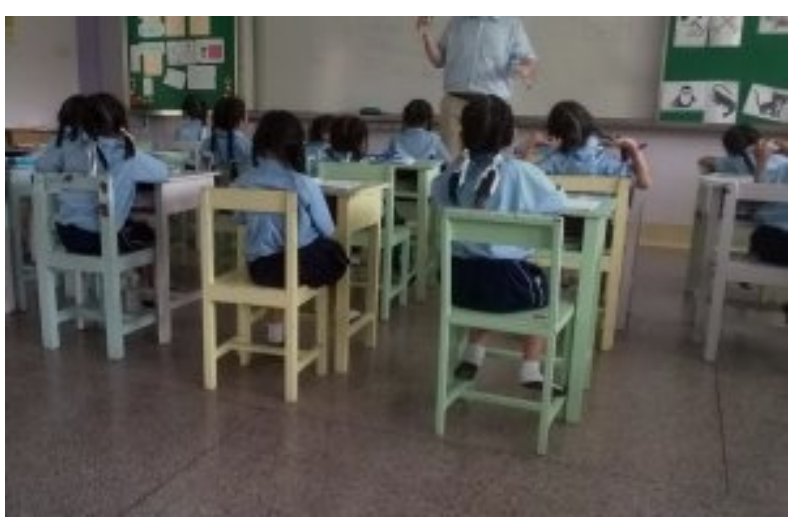

Figure 1. Children in a classroom environment.

Hall believed that a child's nature should guide educational practices so children could become healthy, productive members of society. Overall, Hall's in-person presentations started the movement for the U.S. to integrate psychological and scientific studies within educational endeavors. $^{2}$

\section{Key Takeaways}

- One of the first psychologists to be known as an educational expert.

- Developed "pedagogy" (how to "best" teach for optimal learning).

- A child's nature should guide educational practices in order to become a healthy, productive member of society.

1. Ross, D. (1972). G. Stanley Hall: The psychologist as prophet. University of Chicago Press.

2. Young, J. L. (2016). G. Stanley Hall, child study, and the American public. The Journal of Genetic Psychology, 177(6): 195-208. https://doi.org/10.1080/00221325.2016.1240000 


\section{LATE 1900S: MONTESSORI}

\section{Diana Lang}

\section{Maria Montessori: The Montessori Method}

Maria Montessori scientifically observed and measured the behaviors of young children which resulted in her development of The Montessori

Method-an educational teaching method and philosophy. According to Montessori, a child's mind is quickly developing within the first six years of life ("the absorbent mind") whereby a child takes in as much as possible from one's environment. ${ }^{1}$

Key hallmarks of The Montessori Method include self-directed, hands-on experiential learning, collaborative play, and freedom of movement and activity within a safe, multi-sensory environment. Trained teachers maximize these hallmarks by offering developmentally-appropriate activities that promote individualized learning to optimize children's physical, cognitive, social, and emotional development.

Children work at their own pace and engage in free choice activities within clear, firm, reasonable, and developmentally-appropriate boundaries established by trained teachers. Montessori's research deduced that these practices stimulate deeper learning experiences, independent thinking, problemsolving, creativity, confidence, and lifelong enthusiasm for learning.

1. Montessori, M. (1917). The Montessori elementary manual (A. Livingston, Trans.). Frederick A. Stokes Company. http://www.gutenberg.org/files/42869/42869-h/42869-h.htm 


\section{Key Takeaways}

- The "absorbent mind"-children are capable of taking in the maximum learning from their environment during the first six years of life.

- The Montessori Method emphasizes self-directed, hands-on, experiential learning, collaborative play, and freedom of movement in a safe and multi-sensory environment.

- Teachers offer developmentally-appropriate activities and foster individualized learning. 


\section{S: WATSON}

\section{Lumen Learning; Wikimedia contributors; and Diana Lang}

\section{Watson: Behaviorism}

John B. Watson was an influential American psychologist whose most famous work occurred during the early 20th century at Johns Hopkins University. Watson conducted research on animal behavior, child-rearing, and advertising. Along with this research, he conducted the controversial "Little Albert" study. ${ }^{1}$

Watson believed that an objective analysis of the mind was impossible; therefore, he preferred to focus directly on observable behavior and attempted to modify it. Watson was a major proponent in shifting the focus of psychology from the mind to behavior, and this approach of observing and controlling behavior came to be known as behaviorism. A major object of study by behaviorists was learned behavior and its interaction with the inborn qualities of the organism.

Behaviorism commonly used animals in experiments under the assumption that what was learned using animal models could, to some degree, be applied to human behavior. This famous quote from Watson explains his contentions: ${ }^{2}$

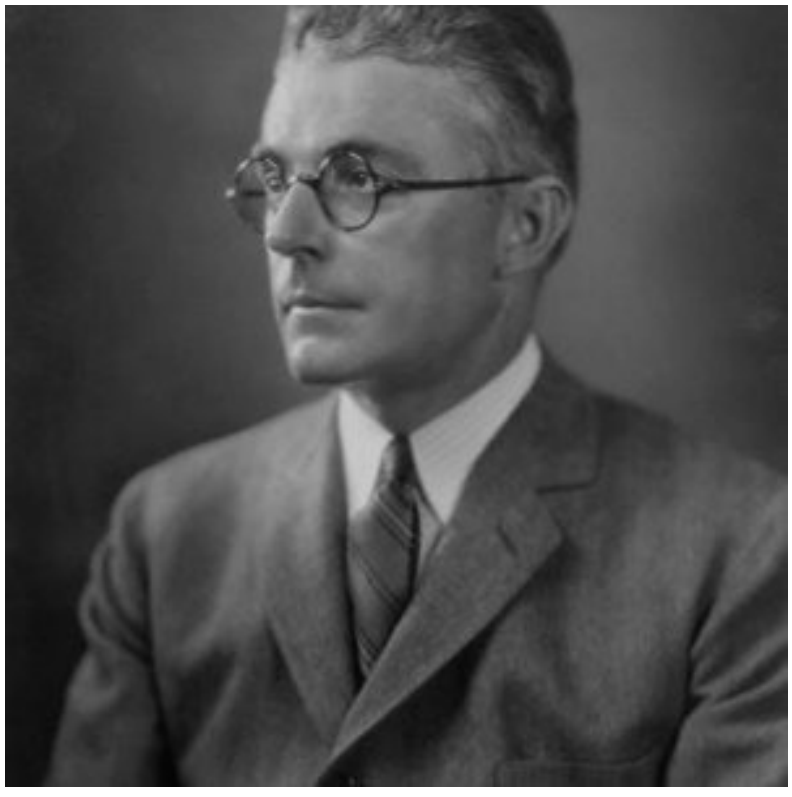

Figure 1. A photograph of John Watson

"Give me a dozen healthy infants, well-formed, and my own specified world to bring them up in and I'll guarantee to take any one at random and train him to become any type of specialist I might select doctor, lawyer, artist, merchant-chief and, yes, even beggar-man and thief, regardless of his talents, penchants, tendencies, abilities, vocations, and race of his ancestors. I am going beyond my facts and I admit it, but so have the advocates of the contrary and they have been doing it for many thousands of years."

Watson believed that children should be treated as young adults. In his book, he warned against the

1. This chapter is an adaptation of The History of Psychology Continued by Lumen Learning, and is used under a CC BY 4.0 license. 2. Watson, J. B. (1930). Behaviorism (Revised edition). University of Chicago Press. 
inevitable dangers of a mother providing too much love and affection. Watson's slogan was 'not more babies but better brought up babies'. Watson argued for the nurture side of the nature-nurture debate and contended that everything is built into a child through their interactions with their environment.

Thus, according to Watson, parents and caregivers hold complete responsibility for their children's actions since they choose the environment into which their child is reared. ${ }^{3}$ Based on the results from his "Little Albert" study, Watson concluded that caregivers can shape a child's behavior and development simply by taking control of all stimulus-response associations.

\section{The Little Albert Experiment (1920)}

The goal of the Little Albert Experiment was to show how the principles of classical conditioning could be applied to a 9-month-old boy. Watson and his assistant conditioned "Little Albert" to fear a white rat by clanging an iron rod when a white rat was shown to Albert. ${ }^{4}$

First, they presented a white rat to the boy and observed that he was not afraid of it. Second, they showed him a white rat and then clanged an iron rod. "Little Albert" responded by crying. This second presentation was repeated several times. Finally, the researchers introduced the white rat by itself and the boy showed fear.

Later, in an attempt to see if the fear transferred to other objects, Watson presented Albert with a rabbit, a dog, and a fur coat. "Little Albert" cried at the sight of all of them. ${ }^{5}$

\section{Video Example}

Watch this video of the Little Albert study to get an overview of how the study was carried out.

This study demonstrated how emotions could become conditioned responses. Analyses of Watson's film footage of Albert have caused some to conclude that "Little Albert" may have had cognitive or

3. Watson, J. B. (1928). Psychological Care of Infant and Child. New York: W.W. Norton Company, Inc.

4. This section is an adaptation of Little Albert Experiment (1920) on Wikipedia and is used under a CC BY SA 3.0 license.

5. Watson, J. B., \& Rayner, R. (1921). Studies in infant psychology. The Scientific Monthly, 13(6): 493-515. 
developmental delays. ${ }^{6}$ An ethical problem with the study was that Watson never reversed this conditioned response in Little Albert. ${ }^{7}$

\section{Watson Today}

Watson's advice to treat children with respect, but with relative emotional detachment, has been strongly criticized. However, behaviorism is still evident today and is largely responsible for establishing psychology as a scientific discipline through its objective methods and experimentation. It is currently used in behavioral and cognitive-behavioral therapies, in classroom settings, and in child-rearing.

\section{Key Takeaways}

- Objective analysis of the mind was impossible, therefore Watson coined "behaviorism" where the focus of psychology is to observe and control behavior.

- Individuals can be trained to behave in certain ways as a result of their environment and the types of stimuli applied.

- The Little Albert experiment-emotional responses can be conditioned in humans.

\section{(ㅇ) (1) (2)}

1920s: Watson by Lumen Learning; Wikimedia contributors; and Diana Lang is licensed under a Creative Commons AttributionShareAlike 4.0 International License, except where otherwise noted. 


\section{S: VYGOTSKY}

Ana R. Leon; Jennfier Paris; Antoinette Ricardo; Dawn Rymond; and Diana Lang

\section{Vygotsky: Sociocultural Theory}

Lev Vygotsky believed that a person has both a set of abilities and a set of potential abilities that can be reached if given the proper guidance from others. ${ }^{1}$

His Sociocultural Theory emphasizes the importance of culture and interaction in the development of cognitive abilities. Vygotsky concentrated more on children's immediate social and cultural environment and their interactions with adults and peers. He saw a child as more of an apprentice, learning through a social environment with others who had more experience and were sensitive to the child's needs and abilities.

Vygotsky theorized that through guided participation with a teacher or a more capable person, also known as scaffolding, a child can learn

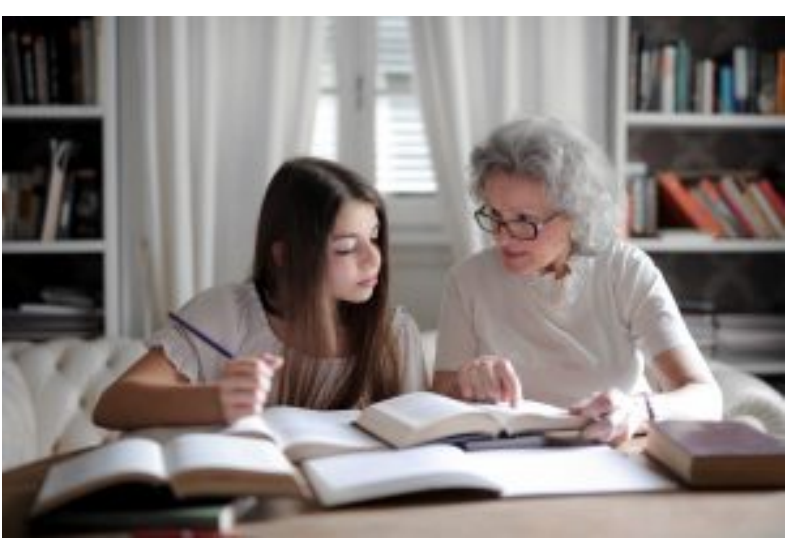

Figure 1. An adolescent working with a tutor through guided participation. (Photo Credit: Andrea Piacquadio, Pexels License) cognitive skills within a certain range known as the zone of proximal development. According to Vygotsky, development occurs first through children's immediate social interactions and then moves to the individual level as they began to internalize their learning.

1. This chapter is an adaptation of Child Growth and Development by Paris, Ricardo, and Rymond, and is used under a CC BY 4.0 license. 


\section{Lev Vygotsky's Zone of Proximal Development}

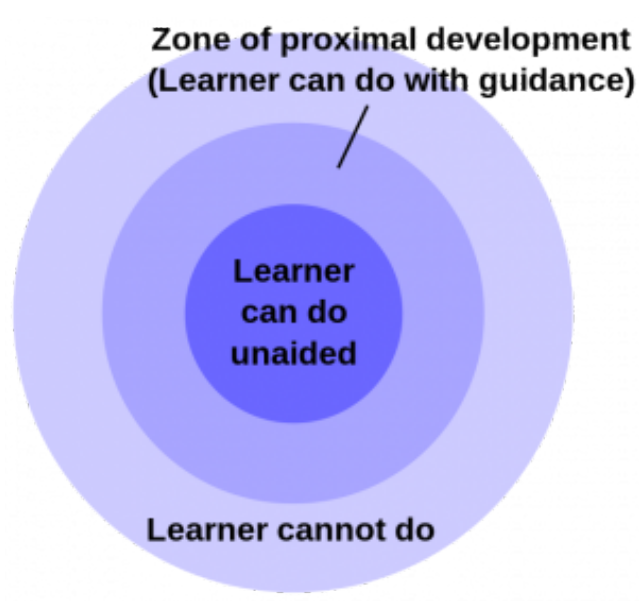

Figure 2. A simple visualization of the zone of proximal development.
Have you ever taught children how to perform a task? Maybe it was brushing their teeth or tying their shoestrings.

Chances are you spoke to them and described what you were doing while you demonstrated the skill and let them work along with you throughout the process. You provided them assistance when they seemed to need it, but once they knew what to do, you stood back and let them perform the task alone. This is an example of scaffolding. ${ }^{2}$

Examples of scaffolding, the temporary support that parents, peers or teachers give a child to perform a task, can be seen throughout the world in an unlimited number of situations. Vygotsky's theory contends that instead of assessing what people are doing, people should be understood in terms of what they are capable of doing with the proper guidance. This approach to teaching has also been adopted by educators.

\section{Video Example}

An example of the zone of proximal development can be seen in how to tie your shoes. 
The zone of proximal development (ZPD) is the distance between a child's potential to learn and the actual learning that takes place. Vygotsky hypothesized that a "quality teacher" first identifies a child's ZPD and then helps the child learn beyond their ZPD. ${ }^{3}$

After this, the teacher (or any person with more advanced skills) gradually withdraws support until the child can perform the task without assistance. At this point, the child has reached a new developmental level and can begin progressing further in their studies.

Of course, this learning and teaching can occur with people of

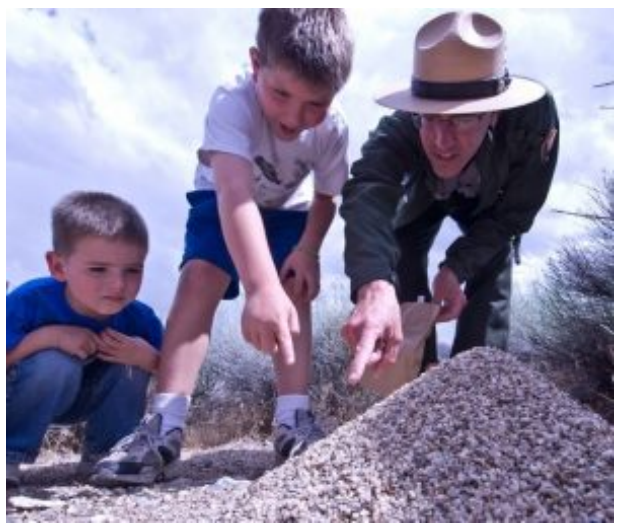

Figure 3. A park ranger teaching children. all ages and skill levels.

\section{Key Takeaways}

- Culture and interactions are key to the development of cognitive abilities.

- Scaffolding-a process of teaching by explaining a process, demonstrating the process, and performing the process.

- Zone of proximal development-the distance between a person's potential to learn and their actual learning. 


\title{
1930S: FREUD
}

\author{
Saylor Academy and Diana Lang
}

\section{Freud and Psychodynamic Theories of Personality: The Role of the Unconscious}

One of the most important psychological approaches to understanding personality is based on the theorizing of the Austrian physician and psychologist Sigmund Freud (1856-1939), who founded what is known today as the psychodynamic approach to understanding personality. ${ }^{1}$ Many people know about Freud because his work has had a longstanding impact on our everyday thinking about psychology, and the psychodynamic approach is one of the most important approaches to psychological therapy. ${ }^{2}$ Freud is probably the best known psychologist, in part because of his impressive observation and analyses of personality (there are 24 volumes of his writings). As is true of all theories, many of Freud's ingenious ideas have turned out to be at least partially incorrect, but yet other aspects of his theories are still influencing psychology.

Freud used the observations that he and French neurologist Jean-Martin Charcot (1825-1893) made to develop his theory

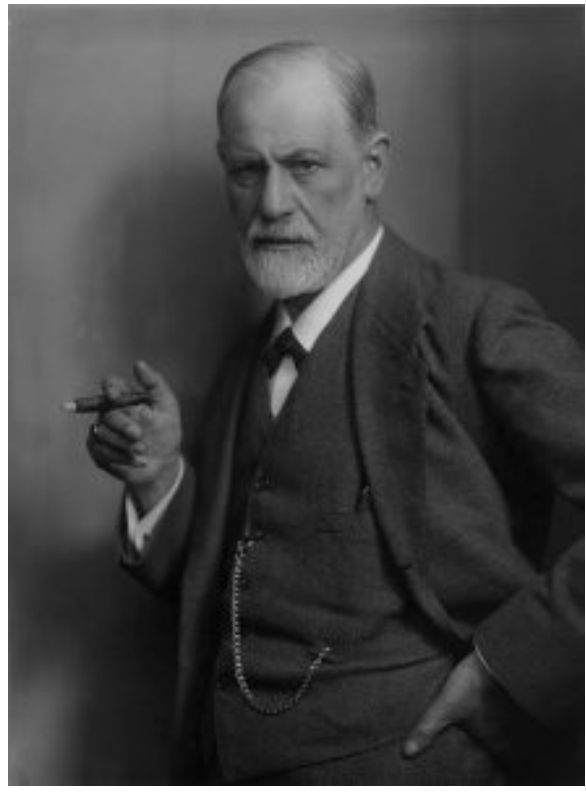

Figure 1. A photograph of Sigmund Freud. regarding the sources of personality and behavior, and his insights are central to the fundamental themes of psychology. In terms of free will, Freud did not believe that we are able to control our own behaviors. Rather, he believed that all behaviors are predetermined by motivations that lie outside our awareness, in the unconscious. These forces show themselves in our dreams, in neurotic symptoms such as obsessions, while we are under hypnosis, and in Freudian "slips of the tongue" in which people reveal their unconscious desires in language. Freud argued that we rarely understand why we do what we do, although we can make up explanations for our behaviors after the fact. For Freud the mind was like an iceberg - many

1. This chapter is an adaptation of The Origins of Personality by Saylor Academy and [Author removed at request of publisher] and is used under a CC BY NC SA license.

2. Roudinesco, E. (2003). Why psychoanalysis? New York, NY: Columbia University Press.

3. Taylor, E. (2009). The mystery of personality: A history of psychodynamic theories. Springer Science. 
motivations of the unconscious being much larger, but out of sight, in comparison to the consciousness of which we are aware.

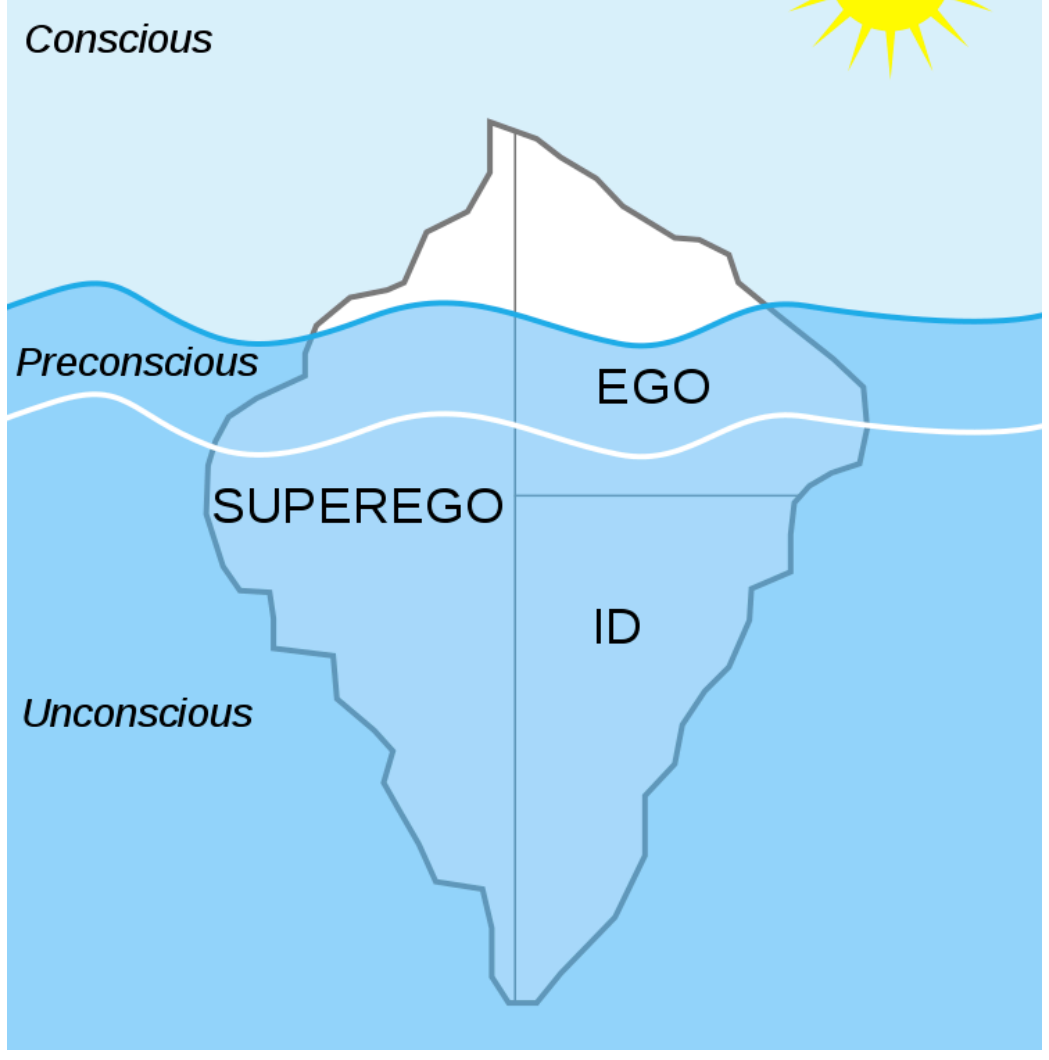

Figure 2. The mind as an iceberg. Note how the Ego is largely visible above the water in the image, while the superego and id are submerged at varying depths.

\section{Id, Ego, and Superego}

Freud proposed that the mind is divided into three components: the id, ego, and superego, and that the interactions and conflicts among the components create a personality. ${ }^{4}$ According to Freudian theory, the id is the component of personality that forms the basis of our most primitive impulses. The id is entirely unconscious, and it drives our most important motivations, including the sexual drive (libido) and the aggressive or destructive drive (Thanatos). According to Freud, the id is driven by the pleasure principle-the desire for immediate gratification of our sexual and aggressive urges. The id is why we smoke cigarettes, drink alcohol, view pornography, tell mean jokes about 
people, and engage in other fun or harmful behaviors, often at the cost of doing more productive activities.

The function of the ego is based on the reality principle - the idea that we must delay gratification of our basic motivations until the appropriate time with the appropriate outlet. The ego is the largely conscious controller or decision-maker of personality. The ego serves as the intermediary between the desires of the id and the constraints of society contained in the superego (Figure 2. "Ego, Id, and Superego in Interaction"). We may wish to scream, yell, or hit, and yet our ego normally tells us to wait, reflect, and choose a more appropriate response.

In stark contrast to the id, the superego represents our sense of morality and doing what is "right". The superego tells us all the things that we shouldn't do, or the duties and obligations of society. The superego strives for perfection, and when we fail to live up to its demands we feel guilty.

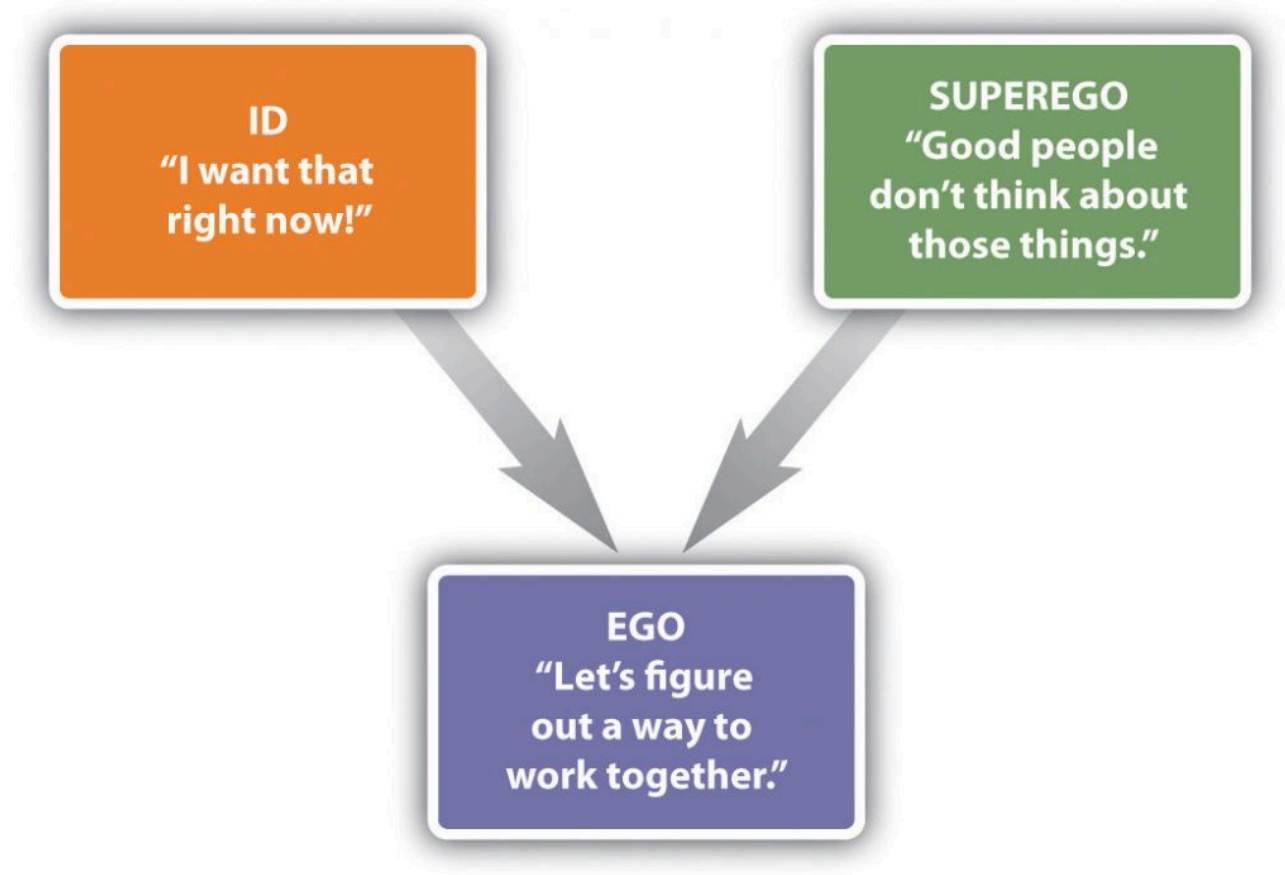

Figure 3. The ego, id, and superego interact to help an individual solve and work through problems.

Freud believed that psychological disorders, particularly the experience of anxiety, occur when there is conflict or imbalance among the motivations of the id, ego, and superego. When the ego finds that the id is pressing too hard for immediate pleasure, it attempts to correct or compensate for this problem, often through the use of defense mechanisms-unconscious psychological strategies used to cope with anxiety and to maintain a positive self-image. Freud believed that defense mechanisms were essential for effective coping with everyday life, but that any of them could be overused (See Table 1. “The Major Freudian Defense Mechanisms”). 
Table 1. The Major Freudian Defense Mechanisms

\begin{tabular}{|c|c|c|}
\hline $\begin{array}{l}\text { Defense } \\
\text { mechanism }\end{array}$ & Definition & Possible behavioral example \\
\hline Displacement & $\begin{array}{l}\text { Diverting threatening impulses away from } \\
\text { the source of the anxiety and toward a } \\
\text { more acceptable source }\end{array}$ & $\begin{array}{l}\text { A student who is angry at her professor for a } \\
\text { low grade lashes out at her roommate, who is a } \\
\text { safer target of her anger. }\end{array}$ \\
\hline Projection & $\begin{array}{l}\text { Disguising threatening impulses by } \\
\text { attributing them to others }\end{array}$ & $\begin{array}{l}\text { A man with powerful unconscious sexual } \\
\text { desires for women claims that women use him } \\
\text { as a sex object. }\end{array}$ \\
\hline Rationalization & $\begin{array}{l}\text { Generating self-justifying explanations } \\
\text { for our negative behaviors }\end{array}$ & $\begin{array}{l}\text { A drama student convinces herself that getting } \\
\text { the part in the play wasn't that important after } \\
\text { all. }\end{array}$ \\
\hline $\begin{array}{l}\text { Reaction } \\
\text { formation }\end{array}$ & $\begin{array}{l}\text { Making unacceptable motivations appear } \\
\text { as their exact opposite }\end{array}$ & $\begin{array}{l}\text { Jane is sexually attracted to friend Jake, but she } \\
\text { claims in public that she intensely dislikes him. }\end{array}$ \\
\hline Regression & $\begin{array}{l}\text { Retreating to an earlier, more childlike, } \\
\text { and safer stage of development }\end{array}$ & $\begin{array}{l}\text { A college student who is worried about an } \\
\text { important test begins to suck on his finger. }\end{array}$ \\
\hline $\begin{array}{l}\text { Repression (or } \\
\text { denial) }\end{array}$ & $\begin{array}{l}\text { Pushing anxiety-arousing thoughts into } \\
\text { the unconscious }\end{array}$ & $\begin{array}{l}\text { A person who witnesses his parents having sex } \\
\text { is later unable to remember anything about the } \\
\text { event. }\end{array}$ \\
\hline Sublimation & $\begin{array}{l}\text { Channeling unacceptable sexual or } \\
\text { aggressive desires into acceptable } \\
\text { activities }\end{array}$ & $\begin{array}{l}\text { A person participates in sports to sublimate } \\
\text { aggressive drives. A person creates music or art } \\
\text { to sublimate sexual drives. }\end{array}$ \\
\hline
\end{tabular}

The most controversial, and least scientifically valid, part of Freudian theory is its explanations of personality development. Freud argued that personality is developed through a series of psychosexual stages, each focusing on pleasure from a different part of the body (See Table 2. "Freud's Stages of Psychosexual Development”). Freud believed that sexuality begins in infancy and that the appropriate resolution of each stage has implications for later personality development.

Table 2. Freud's Stages of Psychosexual Development

\begin{tabular}{|c|c|c|}
\hline Stage & $\begin{array}{l}\text { Approximate } \\
\text { ages }\end{array}$ & Description \\
\hline Oral & $\begin{array}{l}\text { Birth to } 18 \\
\text { months }\end{array}$ & Pleasure comes from the mouth in the form of sucking, biting, and chewing. \\
\hline Anal & $\begin{array}{l}18 \text { months to } 3 \\
\text { years }\end{array}$ & $\begin{array}{l}\text { Pleasure comes from bowel and bladder elimination and the constraints of toilet } \\
\text { training. }\end{array}$ \\
\hline Phallic & $\begin{array}{l}3 \text { years to } 6 \\
\text { years }\end{array}$ & $\begin{array}{l}\text { Pleasure comes from the genitals, and the conflict is with sexual desires for the } \\
\text { opposite-sex parent. }\end{array}$ \\
\hline Latency & $\begin{array}{l}6 \text { years to } \\
\text { puberty }\end{array}$ & Sexual feelings are less important. \\
\hline Genital & $\begin{array}{l}\text { Puberty and } \\
\text { older }\end{array}$ & If prior stages have been properly reached, mature sexual orientation develops. \\
\hline
\end{tabular}


In the first of Freud's proposed stages of psychosexual development, which begins at birth and lasts until about 18 months of age, the focus is on the mouth. During this oral stage, the infant obtains sexual pleasure by sucking and drinking. Infants who receive either too little or too much gratification become fixated or "locked" in the oral stage, and are likely to regress to these points of fixation under stress, even as adults.

According to Freud, a child who receives too little oral gratification (e.g., who was underfed or neglected) will become orally dependent as an adult and be likely to manipulate others to fulfill his or her needs rather than becoming independent. On the other hand, the child who was overfed or overly gratified will resist growing up and try to return to the prior state of dependency by acting helpless, demanding satisfaction from others, and acting in a needy way.

The anal stage, lasting from about 18 months to 3 years of age is when children first experience psychological conflict. During this stage, children desire to experience pleasure through bowel

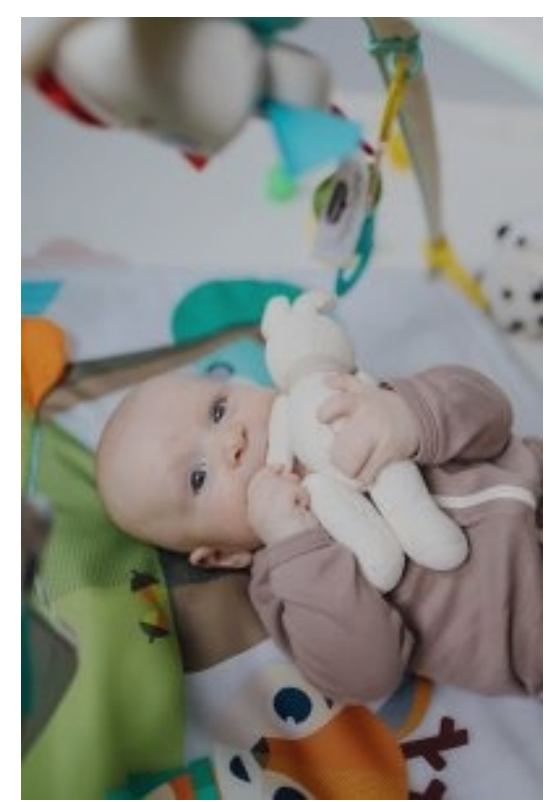

Figure 4. An infant chewing on their toy, exhibiting the "oral stage." (Photo Credit: Polina Tankilevitch, $\underline{\text { Pexels License) }}$ movements, but they are also being toilet trained to delay this gratification. Freud believed that if this toilet training was either too harsh or too lenient, children would become fixated in the anal stage and become likely to regress to this stage under stress as adults. If the child received too little anal gratification (i.e., if the parents had been very harsh about toilet training), the adult personality would be anal retentive-stingy, and compulsively seeking order and tidiness. On the other hand, if the parents had been too lenient, the anal expulsive personality would be the result, characterized by a lack of self-control and a tendency toward messiness and carelessness.

The phallic stage, which lasts from age 3 to age 6, is when the penis (for boys) and clitoris (for girls) become the primary erogenous zone for sexual pleasure. During this stage, Freud believed that children develop a powerful but unconscious attraction for the opposite-sex parent, as well as a desire to eliminate the same-sex parent as a rival. Freud based his theory of sexual development in boys (the "Oedipus complex") on the Greek mythological character Oedipus, who unknowingly killed his father and married his mother, and then gouged his own eyes out when he learned what he had done. Freud argued that boys will normally eventually abandon their love of the mother, and instead identify with the father, also taking on the father's personality characteristics, but that boys who do not successfully resolve the Oedipus complex will experience psychological problems later in life. Although it was not as important in Freud's theorizing, in girls the phallic stage is often termed the "Electra complex," after the Greek character who avenged her father's murder by killing her mother. Freud believed that girls frequently experienced penis envy, the sense of deprivation supposedly experienced by girls because they do not have a penis. Scholars have heavily criticized 
this concept in the decades since Freud's work and it is no longer taken seriously in the psychological community. ${ }^{5}$

The latency stage is a period of relative calm that lasts from about 6 years to 12 years of age. During this time, Freud believed that sexual impulses were repressed, leading boys and girls to have little or no interest in members of the opposite sex.

The fifth and last stage, the genital stage, begins about 12 years of age and lasts into adulthood. According to Freud, sexual impulses return during this time frame, and if development has proceeded normally to this point, the child is able to move into the development of mature romantic relationships. But if earlier problems have not been appropriately resolved, difficulties with establishing intimate love attachments are likely.

\section{Key Takeaways}

- Stages of sexual and emotional development: oral, anal, phallic, latency, and genital.

- Human personality contains the id, ego, and superego.

- Individuals have unconscious drives and should be allowed to follow their own instincts.

- A more relaxed approach to child-rearing for improved well-being.

\section{(우)(1) (2)}

1930s: Freud by Saylor Academy and Diana Lang is licensed under a Creative Commons Attribution-NonCommercial-ShareAlike 4.0 International License, except where otherwise noted. 


\section{S: SPOCK}

Wikimedia contributors and Diana Lang

\section{Benjamin Spock: A Child-Centered Approach}

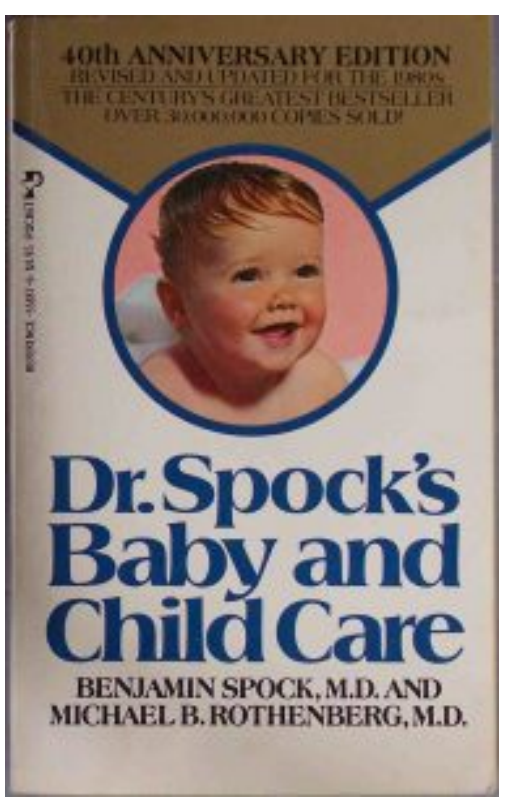

Figure 1. An example of one of Dr. Spock's published books on child care. (Image source:

Flickr, CC by 2.0)
Benjamin Spock was the first American pediatrician to study psychoanalysis in an attempt to understand children's needs and family dynamics. ${ }^{1}$ His ideas about childcare significantly changed overall attitudes toward the rearing of infants and children via his book, The Common Sense Book of Baby and Child Care (1946), one of the best selling volumes in history. The book's premises to parents are that "you know more than you think you do," and if you "feel like comforting the child, do it." 2 He encouraged parents to be more flexible and affectionate with their children and to treat them as individuals.

Spock's first edition advised mothers to indulge their own impulses and as well as their children's, assuring them on the basis of the latest scientific studies that it was safe to do so. In the process, the book changed child-rearing advice from the previous generation and authorized mothers to express their "natural" feelings toward their children. However, his theories were criticized by colleagues for relying too heavily on anecdotal evidence rather than academic research. ${ }^{3}$ Spock recommended spontaneity, warmth, and a fair amount of fun for parents and children.

1. This chapter is an adaptation of Benjamin Spock and The Common Sense Book of Baby and Child Care by Wikimedia Foundation contributors and is used under a CC BY SA license.

2. Spock, B. (1946). The Common Sense Book of Baby and Child Care. Duell, Sloan, and Pearce.

3. Maier, T. (1998). Doctor Spock: An American life. Harcourt Brace. 
In subsequent editions of his book, Spock also included fathers in the contexts of childcare and child-rearing, acknowledged gender roles, and addressed divorce and single parenting. ${ }^{4}$

Overall, Spock's advice encouraged caregivers to help children fit into the current needs of society and become contributing members of that society. He highly advocated for caregivers to instill values of cooperativeness and congeniality and help their child be likable. Spock was one of the most notable American authors of child-rearing advice during the twentieth century due to publications in contemporary, mainstream magazines.

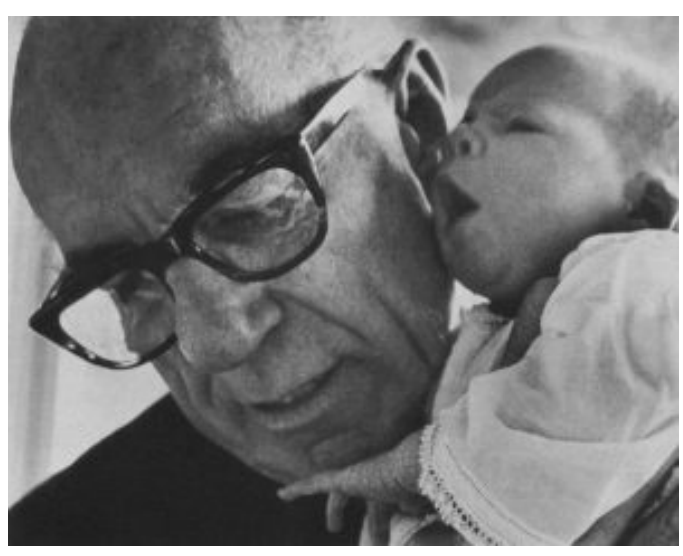

Figure 2. A photograph of Dr. Spock holding an infant

\section{Key Takeaways}

- Parents should be adaptable, loving and encourage individuality within each child.

- Parents should have balanced relationships with their children composed of spontaneity, warmth, and fun.

- Parents should help children become contributing members of society by teaching cooperativeness and congeniality.

- The first American pediatrician to study psychoanalysis to understand children's needs and family dynamics. 


\section{Further Reading}

Spock, B., \& Morgan, M. (1989). Spock on Spock: A memoir of growing up with the century. Pantheon.

Bloom, L. (1972). Doctor Spock: Biography of a conservative radical. Bobbs-Merrill.

Mitford, J. (1969). The trial of Dr. Spock, the Rev. William Sloane Coffin, Jr., Michael Ferber, Mitchell Goodman, and Marcus Raskin. Knopf.

Watson, J. B. (1928). Psychological care of infant and child. Norton.

Zuckerman, M. (1993). Doctor Spock: The confidence man. In Almost chosen people: Oblique biographies in the American grain. University of California Press.

\section{(ㅇ) (1) (2)}

1940s: Spock by Wikimedia contributors and Diana Lang is licensed under a Creative Commons Attribution-ShareAlike 4.0 International License, except where otherwise noted. 


\section{S: SPITZ}

Wikimedia contributors and Diana Lang

\section{René Spitz: The Effects of Emotional Deprivation}

René Spitz, a psychoanalyst, performed research in the 1930s and '40s on the effects of maternal deprivation and hospitalism in infants who were institutionalized for long periods and deprived of substitute maternal care. His studies focused on infants who had experienced abrupt, long-term separation from their primary caregiver, such as when the primary caregiver was sent to prison. Spitz was one of the first to directly observe infants. ${ }^{1}$

Spitz adopted the term anaclitic depression to describe the child's reaction of grief, anger, and apathy to partial emotional deprivation ${ }^{2}$ (the loss of a loved object) and proposed that when the loved object is returned to the child within three to five months, recovery is prompt, but after five months, a child will show symptoms of increasingly serious deterioration. He called this reaction to total deprivation hospitalism. ${ }^{34}$

\section{Video Example}

Watch this silent video to see actual footage of the research conducted by Spitz.

1. Spitz, R. (1950). Relevance of direct infant observation. Psychoanalytic Study of the Child, 5(1), 66-73.

2. Spitz, R. (1946). Anaclitic depression. Psychoanalytic Study of the Child, 2(1), 313-342.

3. Spitz, R. (1945). Hospitalism: An inquiry into the genesis of psychiatric conditions in early childhood. Psychoanalytic Study of the Child, 1(1), 53-74.

4. Hospitalism. (n.d.). International Dictionary of Psychoanalysis. https://www.encyclopedia.com/psychology/dictionariesthesauruses-pictures-and-press-releases/hospitalism. 
Spitz studied children who were evacuated and orphaned as a result of World War II to assess their reactions to separation, including the ability to cope by forming relationships with other children.

Results demonstrated that these children experienced stunted development related to height, weight, motor functioning, emotions, relations, and affective expressions. Many forms of these overall developmental deteriorations were thought to be irreversible and some led to child deaths.

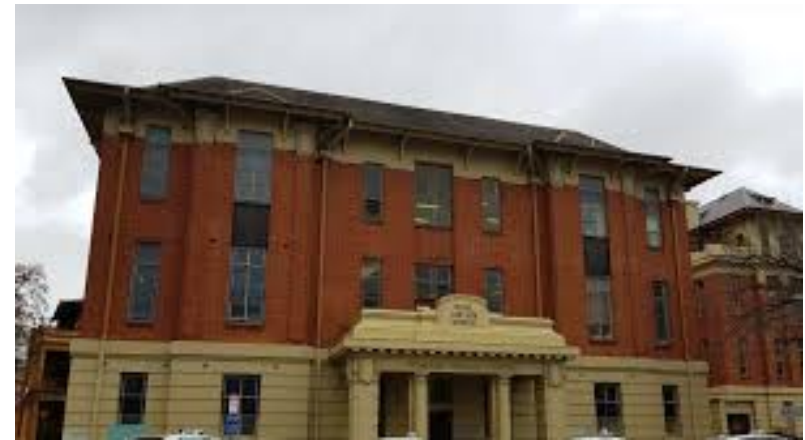

Figure 1. Old Royal Adelaide Hospital (Photo Source: Wikimedia, CC BY SA)

Spitz defined these "total affective deficiencies" as hospitalism and concluded that children who have at least six months of satisfactory relations with their mother could improve once the child was reunited with the mother; Spitz defined the latter as anaclitic depression and partial deficiency.

Most of this research was not published until after the war and only gradually contributed to the understanding of young children's reactions to loss. ${ }^{5}$ Ultimately, these studies of young infants being separated from their maternal caregiver led to recommendations that children need responsive, nurturing caregivers for their overall well-being.

\section{Key Takeaways}

- Infants without warm, nurturing, supportive care and affection will develop anaclitic depression.

- When this type of care and affection are returned to infants within three to five months, the infant will most likely recover.

- When this type of care is denied to infants for more than five months, the infant's anaclitic depression will continually worsen.

- Anaclitic depression can stunt development in height, weight, motor function, emotions, relations, and affective expressions.

- Hospitalism-a child's reaction to total deprivation. 


\section{Further Reading}

Ainsworth, M. D. (1962). The effects of maternal deprivation: a review of findings and controversy in the context of research strategy. In M.D. Ainsworth \& R.G. Andry (Eds.), Deprivation of maternal care (pp. 97-165). World Health Organization.

Spitz, R. A. (1946). Hospitalism: a follow-up report. Psychoanalytic Study of the Child, 2(1), 113-118.

\section{(ㅇ) (1) (2)}

1940s: Spitz by Wikimedia contributors and Diana Lang is licensed under a Creative Commons Attribution-ShareAlike 4.0 International License, except where otherwise noted. 


\title{
1940S: SKINNER
}

\author{
OpenStax and Diana Lang
}

\section{B.F. Skinner: Operant Conditioning}

Psychologist B.F. Skinner saw that classical conditioning is limited to existing behaviors that are reflexively elicited, and doesn't account for new behaviors such as riding a bike. ${ }^{1}$ He proposed a theory about how such behaviors come about. Skinner believed that behavior is motivated by the consequences we receive for the behavior: reinforcements and punishments. His idea that learning is the result of consequences is based on the law of effect, which was first proposed by psychologist Edward Thorndike. According to the law of effect, behaviors that are followed by consequences that are satisfying to the organism are more likely to be repeated, and behaviors that are followed by unpleasant consequences are less likely to be repeated. ${ }^{2}$ Essentially, if an organism does something that brings about a desired result, the organism is more likely to do it again. If an organism does something that does not bring about the desired result, the organism is less likely to do it again. An example of the law of effect is employment. One of the reasons (and often the main reason) we show up for work is because we get paid to do so. If we stop getting paid, we will likely stop showing up-even if we love our job.

Table 1. Classical and Operant Conditioning Compared

\begin{tabular}{|c|c|c|}
\hline & Classical Conditioning & Operant Conditioning \\
\hline $\begin{array}{l}\text { Conditioning } \\
\text { approach }\end{array}$ & $\begin{array}{l}\text { An unconditioned stimulus (such as food) is paired } \\
\text { with a neutral stimulus (such as a bell). The neutral } \\
\text { stimulus eventually becomes the conditioned } \\
\text { stimulus, which brings about the conditioned } \\
\text { response (salivation). }\end{array}$ & $\begin{array}{l}\text { The target behavior is followed by } \\
\text { reinforcement or punishment to either } \\
\text { strengthen or weaken it so that the } \\
\text { learner is more likely to exhibit the } \\
\text { desired behavior in the future. }\end{array}$ \\
\hline $\begin{array}{l}\text { Stimulus } \\
\text { timing }\end{array}$ & $\begin{array}{l}\text { The stimulus occurs immediately before the } \\
\text { response. }\end{array}$ & $\begin{array}{l}\text { The stimulus (either reinforcement or } \\
\text { punishment) occurs soon after the } \\
\text { response. }\end{array}$ \\
\hline
\end{tabular}

Working with Thorndike's law of effect as his foundation, Skinner began conducting scientific experiments on animals (mainly rats and pigeons) to determine how organisms learn through operant conditioning. ${ }^{3}$ He placed these animals inside an operant conditioning chamber, which has

1. This chapter was adapted from OpenStax Psychology, and is used under a CC BY 4.0 license. Download for free at http://cnx.org/contents/4abf04bf-93a0-45c3-9cbc-2cefd46e68cc@12.2.

2. Thorndike, E. L. (1911). Animal intelligence: Experimental studies. Macmillan Company.

3. Skinner, B. F. (1938). Behavior of organisms. Appleton-Century-Crofts. 
come to be known as a "Skinner box" (See Figure 1.). A Skinner box contains a lever (for rats) or disk (for pigeons) that the animal can press or peck for a food reward via the dispenser. Speakers and lights can be associated with certain behaviors. A recorder counts the number of responses made by the animal.

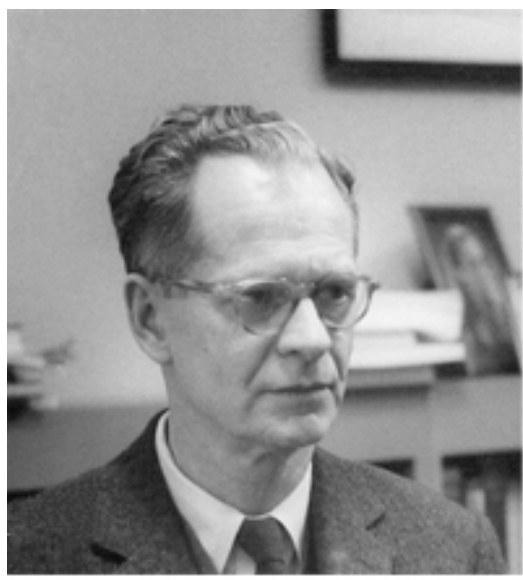

(a)

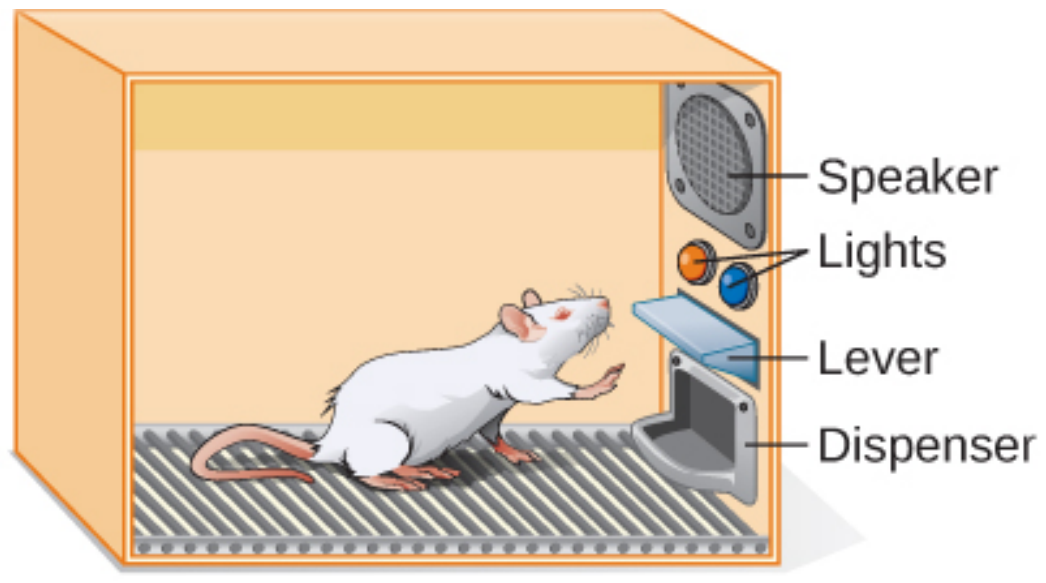

(b)

Figure 1. (a) B. F. Skinner developed operant conditioning for systematic study of how behaviors are strengthened or weakened according to their consequences. (b) In a Skinner box, a rat presses a lever in an operant conditioning chamber to receive a food reward.

\section{Video Example}

Watch this brief video clip to learn more about operant conditioning: Skinner is interviewed, and operant conditioning of pigeons is demonstrated.

In discussing operant conditioning, we use several everyday words-positive, negative, reinforcement, and punishment-in a specialized manner. In operant conditioning, positive and negative do not mean good and bad. Instead, positive means you are adding something, and negative means you are taking something away. Reinforcement means you are increasing a behavior, and punishment means you are decreasing a behavior. Reinforcement can be positive or negative, and punishment can also be positive or negative. All reinforcers (positive or negative) increase the likelihood of a behavioral response. All punishers (positive or negative) decrease the likelihood of a behavioral response. Now let us combine these four terms: positive reinforcement, negative reinforcement, positive punishment, and negative punishment (Table 2.). 
Table 2. Positive and Negative Reinforcement and Punishment

\begin{tabular}{|c|c|c|}
\hline & Reinforcement & Punishment \\
\hline Positive & $\begin{array}{l}\text { Something is added to increase the likelihood of a } \\
\text { behavior. }\end{array}$ & $\begin{array}{l}\text { Something is added to decrease the likelihood of a } \\
\text { behavior. }\end{array}$ \\
\hline Negative & $\begin{array}{l}\text { Something is removed to increase the likelihood } \\
\text { of a behavior. }\end{array}$ & $\begin{array}{l}\text { Something is removed to decrease the likelihood } \\
\text { of a behavior. }\end{array}$ \\
\hline
\end{tabular}

\section{Reinforcement}

The most effective way to teach a person or animal a new behavior is with positive reinforcement. In positive reinforcement, a desirable stimulus is added to increase a behavior.

For example, let's say you tell your five-year-old son, Jerome, that if he cleans his room, he will get a toy. Jerome quickly cleans his room because he wants a new art set. Some people might say, "Why should I reward my child for doing what is expected?" However, we are constantly and consistently rewarded in our lives. Our paychecks are rewards, as are high grades or acceptance into our preferred schools. Being praised for doing a good job or for passing a driver's test are also rewards. Positive reinforcement as a learning tool is extremely effective. It has been found that one of the most effective ways to increase achievement in school districts with below-average reading scores was to pay the children to read.

An example of this can be seen in Dallas, where second-grade students in Dallas were paid $\$ 2$ each time they read a book and passed a short quiz about the book. The result was a significant increase in reading comprehension. ${ }^{4}$ What do you think about this program? If Skinner were alive today, he would probably think this was a great idea. He was a strong proponent of using operant conditioning principles to influence students' behavior at school. In fact, in addition to the Skinner box, he also invented what he called a teaching machine that was designed to reward small steps in learning - an early forerunner of computer-assisted learning. ${ }^{5}$ His teaching machine tested students' knowledge as they worked through various school subjects. If students answered questions correctly, they received immediate positive reinforcement and could continue; if they answered incorrectly, they did not receive any reinforcement. The idea was that students would spend additional time studying the material to increase their chance of being reinforced the next time.

In negative reinforcement, an undesirable stimulus is removed to increase a behavior. For example, car manufacturers use the principles of negative reinforcement in their seatbelt systems, which go "beep, beep, beep" until you fasten your seatbelt. The annoying sound stops when you exhibit the

\footnotetext{
4. Fryer, R. G. Jr. (2010). Financial incentive and student achievement: Evidence from randomized trials. National Bureau of Economic Research. Working Paper No. 15898. DOI 10.3386/w15898
}

5. Skinner, B. F. (1961). Teaching machines. Scientific American, 205(3), 90-112. https://doi.org/10.2307/1926170. 
desired behavior, increasing the likelihood that you will buckle up in the future. Negative reinforcement is also used frequently in horse training. Riders apply pressure-by pulling the reins or squeezing their legs-and then remove the pressure when the horse performs the desired behavior, such as turning or speeding up. The pressure is the negative stimulus that the horse wants to remove.

\section{Punishment}

Many people confuse negative reinforcement with punishment in operant conditioning, but they are two very different concepts. Remember that reinforcement, even when it is negative, always increases a behavior. In contrast, punishment always decreases a behavior. In positive punishment, you add an undesirable stimulus to decrease a behavior. An example of positive punishment is reprimanding a student to get the student to stop texting in class. In this case, a stimulus (the reprimand) is added in order to decrease the behavior (texting in class). In negative punishment, you remove a pleasant stimulus to decrease a behavior, such as something the child enjoys (e.g., a toy or a scheduled outing). Time-outs are a very common form of negative punishment - they momentarily take away children's access to something they enjoy.

Punishment, especially when it is immediate, is one way to decrease undesirable behavior. For example, imagine your four-year-old son, Brandon, runs into a busy street to get his ball. You give him a time-out (positive punishment) and tell him never to go into the street again. Chances are he will not repeat this behavior. While strategies like time-outs are common today, in the past children were often subject to physical punishment, such as spanking. It's important to be aware of some of the drawbacks of using physical punishment on children. Within the context of parenting, it is important to note that the term "punishment" doesn't mean that the consequence should be harmful.

In fact, experts caution that punishments like spanking can cause more harm than good. ${ }^{6}$ First, punishment may teach fear. Brandon may become fearful of the street, but he also may become fearful of the person who delivered the punishment-you, his parent. Similarly, children who are punished by teachers may start to fear the teacher and try to avoid school. ${ }^{7}$ Consequently, most schools in the United States have banned corporal punishment. Second, punishment may cause children to become more aggressive and prone to antisocial behavior and delinquency. ${ }^{8}$ They see their parents resort to spanking when they become angry and frustrated, so, in turn, they may act

6. Murphy, R. (2017). What is 'negative punishment'? Definition and real-world examples. https://www.care.com/c/stories/11980/ what-is-negative-punishment-definition-and-real-world-examples/.

7. Gerschoff, E. T. (2013). Spanking and child development: We know enough now to stop hitting our children. Child Development Perspectives, 7(3), 133-137. https://doi.org/10.1111/cdep.12038

8. Gershoff, E. T. (2002). Corporal punishment by parents and associated child behaviors and experiences: A meta-analytic and theoretical review. Psychological Bulletin, 128(4), 539-579. https://doi.org/10.1037/0033-2909.128.4.539 
out this same behavior when they become angry and frustrated. For example, because you spank Brenda when you are angry with her for her misbehavior, she might start hitting her friends when they will not share their toys.

While positive punishment can be effective in some cases, Skinner suggested that the use of punishment should be weighed against the possible negative effects. Today's psychologists and parenting experts favor reinforcement over punishment-they recommend that you catch your child doing something good and reward her for it.

\section{Shaping}

In his operant conditioning experiments, Skinner often used an approach called shaping. Instead of rewarding only the target behavior, in shaping, we reward successive approximations of a target behavior. For instance, parents can break a task into smaller more "attainable" steps. These smaller steps should be in sequence of completing the entire desired task. As children start a step, or show improvements on a step, they should be praised and rewarded. As children master each step, they should again be praised and rewarded and then encouraged to the next step. This process of successive approximations is followed until a child masters the entire task. This takes time, but it is a proven method of shaping a child's behavior via rewarding and praising ongoing improvements.

Why is shaping needed? Remember that in order for reinforcement to work, the organism must first display the behavior. Shaping is needed because it is extremely unlikely that an organism will display anything but the simplest of behaviors spontaneously. In shaping, behaviors are broken down into many small, achievable steps. The specific steps used in the process are the following:

1. Reinforce any response that resembles the desired behavior.

2. Then reinforce the response that more closely resembles the desired behavior. You will no longer reinforce the previously reinforced response.

3. Next, begin to reinforce the response that even more closely resembles the desired behavior.

4. Continue to reinforce closer and closer approximations of the desired behavior.

5. Finally, only reinforce the desired behavior.

Shaping is often used to teach a complex behavior or chain of behaviors. Skinner used shaping to teach pigeons not only relatively simple behaviors such as pecking a disk in a Skinner box, but also many unusual and entertaining behaviors, such as turning in circles, walking in figure eights, and even playing ping pong; this technique is commonly used by animal trainers today. An important part of shaping is stimulus discrimination. Recall Pavlov's dogs-he trained them to respond to the tone of a bell, and not to similar tones or sounds. This discrimination is also important in operant conditioning and in shaping behavior. 


\section{Video Example}

Here is a brief video of Skinner's pigeons playing ping pong.

It is easy to see how shaping is effective in teaching behaviors to animals, but how does shaping work with humans? Let us consider parents whose goal is to have their child learn to clean his room. They use shaping to help him master steps toward the goal. Instead of performing the entire task, they set up these steps and reinforce each one. First, he cleans up one toy. Second, he cleans up five toys. Third, he chooses whether to pick up ten toys or put his books and clothes away. Fourth, he cleans up everything except two toys. Finally, he cleans his entire room.

\section{Primary and Secondary Reinforcers}

Rewards such as stickers, praise, money, toys, and more can be used to reinforce learning. Let us go back to Skinner's rats again. How did the rats learn to press the lever in the Skinner box? They were rewarded with food each time they pressed the lever. For animals, food would be an obvious reinforcer.

What would be a good reinforcer for humans? For your daughter Sydney, it was the promise of a toy if she cleaned her room. How about Joaquin, the soccer player? If you gave Joaquin a piece of candy every time he made a goal, you would be using a primary reinforcer. Primary reinforcers are reinforcers that have innate reinforcing qualities. These kinds of reinforcers are not learned. Water, food, sleep, shelter, sex, and touch, among others, are primary reinforcers. Pleasure is also a primary reinforcer. Organisms do not lose their drive for these things. For most people, jumping in a cool lake on a very hot day would be reinforcing and the cool lake would be innately reinforcing-the water would cool the person off (a physical need), as well as provide pleasure.

A secondary reinforcer has no inherent value and only has reinforcing qualities when linked with a primary reinforcer. Praise, linked to affection, is one example of a secondary reinforcer, such as when you called out "Great shot!" every time Joaquin made a goal. Another example, money, is only worth something when you can use it to buy other things-either things that satisfy basic needs (food, water, shelter-all primary reinforcers) or other secondary reinforcers. If you were on a remote island in the middle of the Pacific Ocean and you had stacks of money, the money would not be useful if you could not spend it. What about the stickers on the behavior chart? They also are secondary reinforcers.

Sometimes, instead of stickers on a sticker chart, a token is used. Tokens, which are also secondary 
reinforcers, can then be traded in for rewards and prizes. Entire behavior management systems, known as token economies, are built around the use of these kinds of token reinforcers. Token economies have been found to be very effective at modifying behavior in a variety of settings such as schools, prisons, and mental hospitals. 


\section{Everyday Connection: Behavior Modification in Children}

Parents and teachers often use behavior modification to change a child's behavior. Behavior modification uses the principles of operant conditioning to accomplish behavior change so that undesirable behaviors are switched out for more socially acceptable ones. Some teachers and parents create a sticker chart, in which several behaviors are listed. Sticker charts are a form of token economies, as described in the text. Each time children perform the desired behavior, they get a sticker, and after a certain number of stickers, they get a prize, or reinforcer. The goal is to increase acceptable behaviors and decrease misbehavior. Remember, it is better to reinforce desired behaviors than to use punishment. In the classroom, the teacher can reinforce a wide range of behaviors, from students raising their hands, to walking quietly in the hall, to turning in their homework. At home, parents might create a behavior chart that rewards children for things such as putting away toys, brushing their teeth, and helping with dinner. In order for behavior modification to be effective, the reinforcement must be connected with the behavior, the reinforcement must matter to the child, and the process must be performed consistently over time.

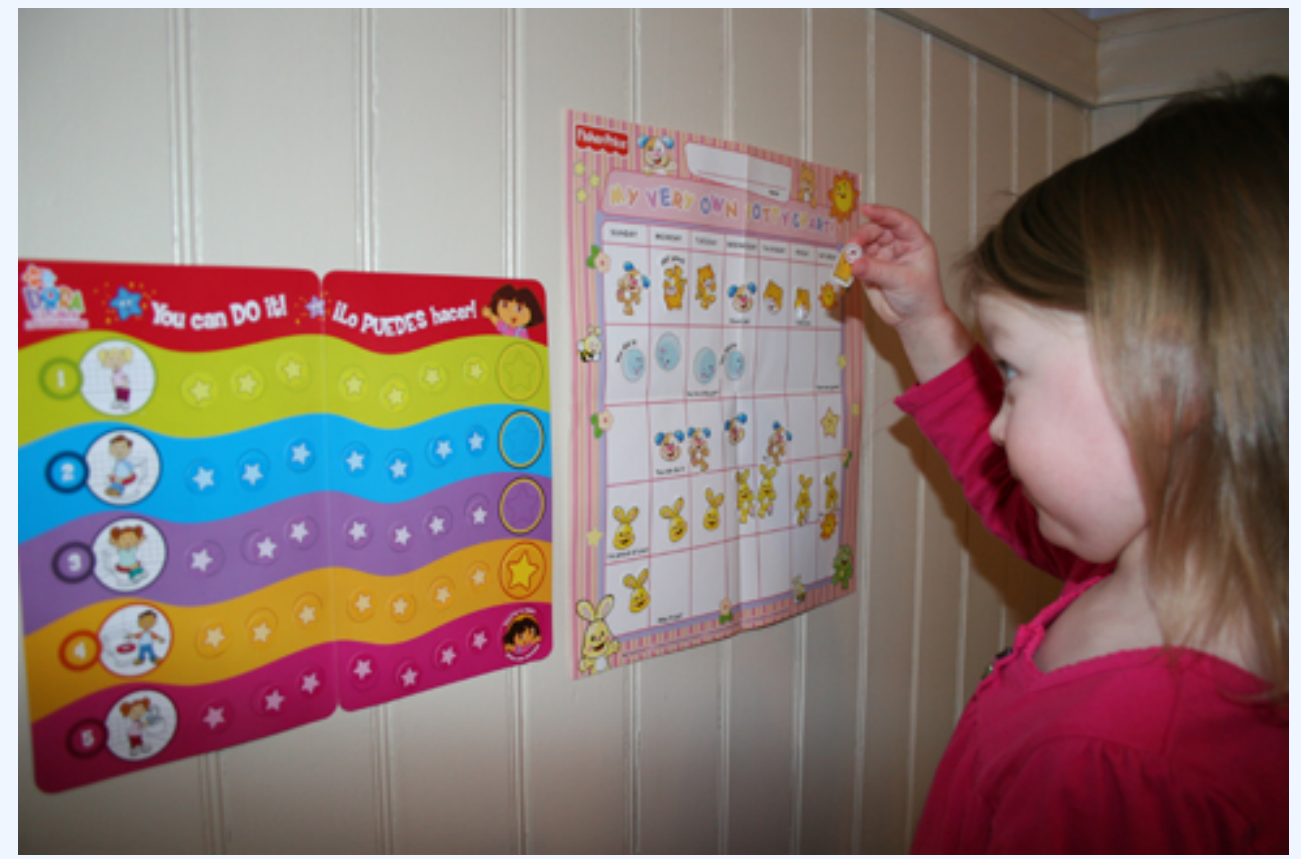

Sticker charts are a form of positive reinforcement and a tool for behavior modification. Once this little girl earns a certain number of stickers for demonstrating a desired behavior, she will be rewarded with a trip to the ice cream parlor. (credit: Abigail Batchelder)

Time-out is another popular technique used in behavior modification with children. When a child demonstrates an undesirable behavior, she is removed from the desirable activity at hand. For example, say that Sophia and her brother Mario are playing with building blocks. Sophia throws some 
blocks at her brother, so you give her a warning that she will go to time-out if she does it again. A few minutes later, she throws more blocks at Mario. You remove Sophia from the room for a few minutes. When she comes back, she doesn't throw blocks.

There are several important points to consider if you plan to implement time-out as a behavior modification technique. First, make sure the child is being removed from a desirable activity and placed in a less desirable location. If the activity is something undesirable for the child, this technique will backfire because it is more enjoyable for the child to be removed from the activity. Second, the length of the time-out is important. The general rule of thumb is one minute for each year of the child's age. Sophia is five; therefore, she sits in time-out for five minutes. Setting a timer helps children know how long they have to sit in time-out. Third, using this method should be dependent upon the child's cognitive and social development, not merely the child's chronological age. Finally, as a caregiver, keep several guidelines in mind over the course of a time-out: remain calm when directing your child to time-out; ignore your child during time-out (because caregiver attention may reinforce misbehavior), and give the child a hug or a kind word when the time-out is over.

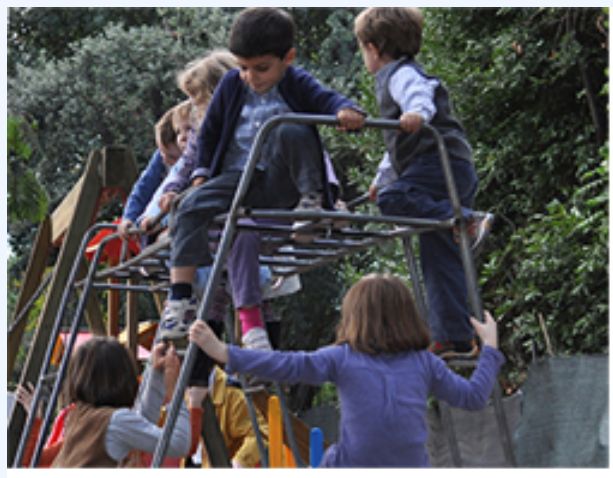

(a)

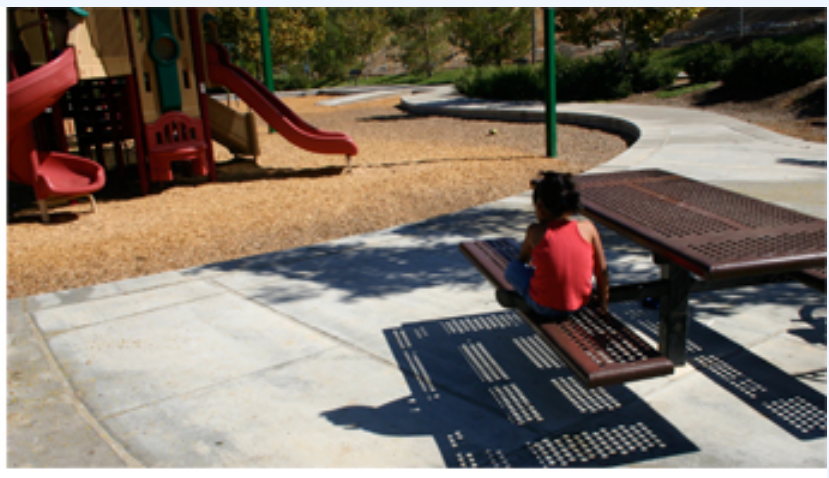

(b)

Time-out is a popular form of negative punishment used by caregivers. When a child misbehaves, the child is removed from a desirable activity in an effort to decrease the unwanted behavior. For example, (a) a child might be playing on the playground with friends and push another child; (b) the child who misbehaved would then be removed from the activity for a short period of time. (credit a: modification of work by Simone Ramella; credit b: modification of work by "JefferyTurner"/Flickr)

\section{Reinforcement Schedules}

Remember, the best way to teach a person or animal a behavior is to use positive reinforcement. For example, Skinner used positive reinforcement to teach rats to press a lever in a Skinner box. At first, the rat might randomly hit the lever while exploring the box, and out would come a pellet of food. After eating the pellet, what do you think the hungry rat did next? It hit the lever again and received another pellet of food. Each time the rat hit the lever, a pellet of food came out. When an organism 
receives a reinforcer each time it displays a behavior, it is called continuous reinforcement. This reinforcement schedule is the quickest way to teach someone a behavior, and it is especially effective in training a new behavior. Let's look at a dog learning to sit. Each time the dog sits, you give the dog a treat. Timing is important here: you will be most successful if you present the reinforcer immediately after the dog sits so that the dog can make an association between the target behavior (sitting) and the reinforcement (getting a treat).

\section{Video Example}

Watch this video clip of veterinarian Dr. Sophia Yin shaping a dog's behavior using the steps outlined above.

\section{Key Takeaways}

- Behavior is motivated by the consequences of that behavior.

- Behaviors with satisfying consequences are often repeated, while behaviors with unpleasant consequences are often avoided.

- Conditioning can be done through positive reinforcement, negative reinforcement, positive punishment, and negative punishment.

- Reinforcement increases a behavior; punishment decreases a behavior.

- Shaping is slowly reinforcing behaviors that are more and more similar to the ideal goal behavior.

\section{() (1)}

1940s: Skinner by OpenStax and Diana Lang is licensed under a Creative Commons Attribution 4.0 International License, except where otherwise noted. 


\title{
1950S: HARLOW, BOWLBY, AND AINSWORTH
}

\author{
Lumen Learning and Diana Lang
}

\section{Harlow and Bowlby: Attachment}

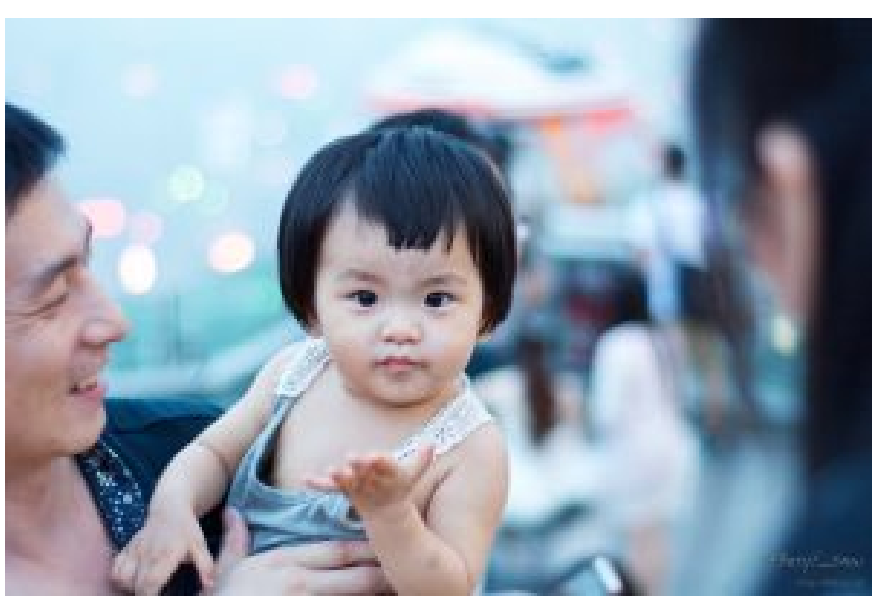

Figure 1. A child comfortably rests in their parent's arms. (Photo Credit: pxhere, $\underline{\text { CC0 1.0) }}$
Psychosocial development occurs as children form relationships, interact with others, and understand and manage their feelings. In social and emotional development, forming healthy attachments is very important and is the major social milestone of infancy. ${ }^{1}$ Attachment is a long-standing connection or bond with others. Developmental psychologists are interested in how infants reach this milestone. They ask questions such questions as: How do parent and infant attachment bonds form? How does neglect affect these bonds? What accounts for children's attachment differences?

Researchers Harry Harlow, John Bowlby, and Mary Ainsworth conducted studies designed to answer these questions. In the 1950s, Harlow conducted a series of experiments on monkeys. He separated newborn monkeys from their mothers. Each monkey was presented with two surrogate mothers. One surrogate monkey was made out of wire mesh, and she could dispense milk. The other monkey was softer and made from cloth, but did not dispense milk. The findings showed that the monkeys preferred the soft, cuddly cloth monkey, even though she did not provide any nourishment. The baby monkeys spent their time clinging to the cloth monkey and only went to the wire monkey when they needed to be fed. Prior to this study, the medical and scientific communities generally thought that babies become attached to the people who provide their nourishment. However, Harlow concluded that there was more to the mother-child bond than nourishment. ${ }^{2}$ Feelings of comfort and security are the critical components of maternal-infant bonding, which leads to healthy psychosocial development. 


\section{Video Example}

Harlow's studies of monkeys were performed before modern ethics guidelines were in place, and today his experiments are widely considered to be unethical and even cruel. Watch this video to see footage of Harlow's monkey studies.

Building on the work of Harlow and others, John Bowlby developed the concept of attachment theory. He defined attachment as the affectional bond or tie that infants form with their mother. ${ }^{3}$ An infant must form this bond with a primary caregiver in order to have normal social and emotional development. In addition, Bowlby proposed that this attachment bond is very powerful and continues throughout life. He used the concept of a secure base to define a healthy attachment between parent and child. ${ }^{4}$ A secure base is a parental presence that gives the child a sense of safety as he explores his surroundings. Bowlby said that two things are needed for a healthy attachment: the caregiver must be responsive to the child's physical, social, and emotional needs, and the caregiver and child must engage in mutually enjoyable interactions (See Figure 1.). ${ }^{5}$ 


\section{Mary Ainsworth}

While Bowlby believed that attachment was an allor-nothing process, Mary Ainsworth's research showed otherwise. ${ }^{6}$ Mary identified the existence of what she calls "attachment behaviors," which are examples of behaviors demonstrated by insecure children in hopes of establishing or re-establishing an attachment to a presently absent caregiver. 'Since this behavior occurs uniformly in children, it is a compelling argument for the existence of "innate" or instinctual behaviors in human beings.?

Ainsworth wanted to know if children differ in the ways they bond, and if so, why. To find the answers to these questions, she used the Strange Situation

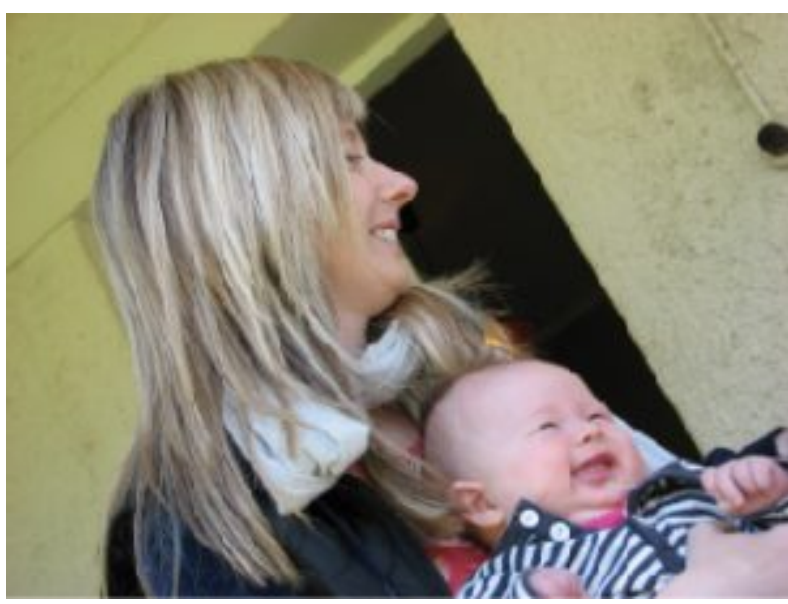

Figure 2. Mutually enjoyable interactions promote the mother-infant bond. (Image Credit: Peter Shanks) procedure to study attachment between mothers and their infants in 1970. In the Strange Situation, the mother (or primary caregiver) and the infant (age 12-18 months) are placed in a room together. There are toys in the room, and the caregiver and child spend some time alone in the room. After the child has had time to explore one's surroundings, a stranger enters the room. The primary caregiver then leaves the baby with the stranger. After a few minutes, the caregiver returns to comfort the child.

6. Ainsworth, M. D. S., \& Bell, S. M. (1970). Attachment, exploration, and separation: Illustrated by the behavior of one-year-olds in a strange situation. Child Development,41(1), 49-67.

7. Psychologist World. (2019). Attachment theory. https://www.psychologistworld.com/developmental/attachment-theory 


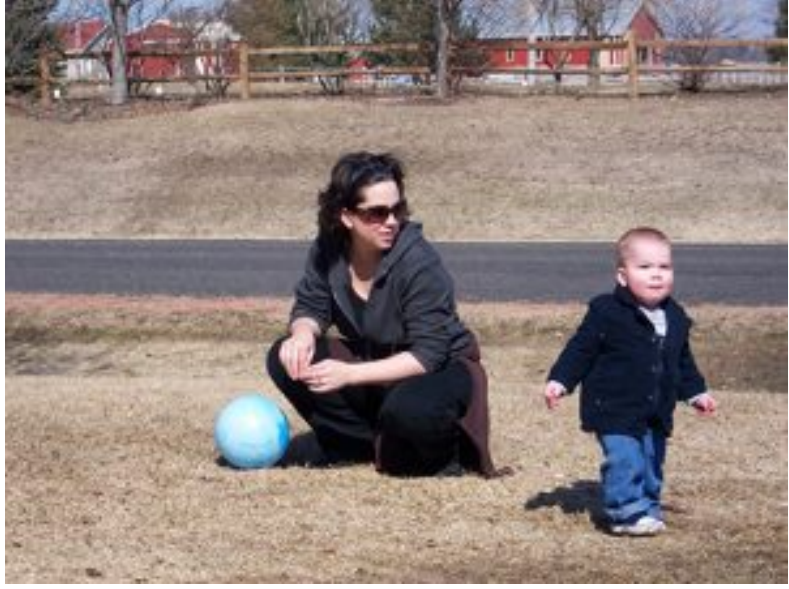

Figure 3. In secure attachment, the parent provides a secure base for the toddler, allowing him to securely explore his environment. (Image Credit: Kerry Ceszyk)
Based on how the infants/toddlers responded to the separation and reunion, Ainsworth identified three types of parent-child attachments: secure, avoidant, and resistant. ${ }^{8}$ A fourth style, known as disorganized attachment, was later described. ${ }^{9}$ The most common type of attachment-also considered the healthiest-is called secure attachment (See Figure 2.). In this type of attachment, the toddler prefers their parent over a stranger. The attachment figure is used by the child as a secure base to explore their environment and is sought out in times of stress. Securely attached children were distressed when their caregivers left the room in the Strange Situation experiment, but when their caregivers returned, the securely attached children were happy to see them. Securely attached children have caregivers who are sensitive and responsive to their needs.

With avoidant attachment (sometimes called insecure or anxious-avoidant), the child is unresponsive to the parent, does not use the parent as a secure base, and does not care if the parent leaves. The toddler reacts to the parent the same way she reacts to a stranger. When the parent does return, the child is slow to show a positive reaction. Ainsworth theorized that these children were most likely to have a caregiver who was insensitive and inattentive to their needs. ${ }^{10}$

In cases of resistant attachment (also called ambivalent or anxious-ambivalent/resistant), children tend to show clingy behavior, but then reject the attachment figure's attempts to interact with them. ${ }^{11}$ These children do not explore the toys in the room, as they are too fearful. During separation in the Strange Situation, they became extremely disturbed and angry with the parent. When the parent returns, the children are upset and difficult to comfort. Resistant attachment is the result of the caregivers' inconsistent level of response to their child.

Finally, children with disorganized attachment behave oddly in the Strange Situation. They freeze,

8. Ainsworth, M. D. S., \& Bell, S. M. (1970). Attachment, exploration, and separation: Illustrated by the behavior of one-year-olds in a strange situation. Child Development, 41(1), 49-67.

9. Main, M., \& Solomon, J. (1990). Procedures for identifying infants as disorganized/disoriented during the Ainsworth Strange Situation. In M. T. Greenberg, D. Cicchetti, \& E. M. Cummings (Eds.), Attachment in the preschool years: Theory, research, and intervention (pp. 121-160). University of Chicago Press.

10. Ainsworth, M. D. S., Blehar, M. C., Waters, E., \& Wall, S. (1978). Patterns of attachment: A psychological study of the Strange Situation. Erlbaum.

11. Ainsworth, M. D. S., \& Bell, S. M. (1970). Attachment, exploration, and separation: Illustrated by the behavior of one-year-olds in a strange situation. Child Development, 41(1), 49-67. 
run around the room in an erratic manner, or try to run away when the caregiver returns. ${ }^{12}$ This type of attachment is seen most often in children who have been abused. Research has shown that abuse disrupts a child's ability to regulate their emotions.

\section{Video Example}

Watch this video to view a clip of the Strange Situation. Try to identify which type of attachment baby Lisa exhibits.

While Ainsworth's research has found support in subsequent studies, it has also met criticism. Some researchers have pointed out that a child's temperament may have a strong influence on attachment, and others have noted that attachment varies from culture to culture, a factor not accounted for in Ainsworth's research. ${ }^{13} 1415$

12. Main, M., \& Solomon, J. (1990). Procedures for identifying infants as disorganized/disoriented during the Ainsworth Strange Situation. In M. T. Greenberg, D. Cicchetti, \& E. M. Cummings (Eds.), Attachment in the preschool years: Theory, research, and intervention (pp. 121-160). University of Chicago Press.

13. Gervai, J. (2009). Environmental and genetic influences on early attachment. Child and Adolescent Psychiatry and Mental Health, 3(1), 25. https://doi.org/10.1186/1753-2000-3-25

14. Harris, J. R. (2009). Attachment theory underestimates the child. Behavioral and Brain Sciences, 32(1), 30. https://doi.org/ $10.1017 /$ S0140525X09000119

15. Van Ijzendoorn, M. H., \& Sagi-Schwartz, A. (2008). Cross-cultural patterns of attachment: Universal and contextual dimensions. In J. Cassidy \& P. R. Shaver (Eds.), Handbook of attachment: Theory, research and clinical applications (pp. 880-905). Guilford Press. 


\section{Key Takeaways}

- Harlow: Contact comfort research concerning wire and cloth monkeys.

- Bowlby: Human attachment theory derived from Harlow's research.

- Attachment: The connection formed between two individuals over time.

- Secure base: A primary caregiver a child views as "home base" who provides the child with security to actively explore one's environment.

- Ainsworth: Strange Situation research which led to identifying types of attachment: secure, avoidant, disorganized, and resistant attachment. 


\section{S: PIAGET}

Dawn Rymond; Antoinette Ricardo; Jennfier Paris; Lumen Learning; and Diana Lang

\section{Piaget: Cognitive Development Theory}

Jean Piaget studied how children and youth gradually become able to think logically and scientifically, resulting in his Cognitive Development Theory. Cognition refers to thinking and memory processes, and cognitive development refers to long-term changes in these processes. He was one of the first to recognize and map out the ways in which children's thought differs from that of adults. His interest in this area began when he was asked to test the IQ of children and began to notice that there was a pattern in their wrong answers. ${ }^{1}$

Piaget believed that children's intellectual skills change over time based on biological predispositions and their own individual interactions with the world. He was very critical of teacher-directed instruction, believing that teachers or caregivers who take control of the child's learning place the child into a passive role. ${ }^{2}$ According to Piaget, children of differing ages interpret the world differently; therefore, he divided this learning into four stages. His stages assumed a sequence of thinking patterns with these key features:

1. They always happen in the same order.

2. No stage is ever skipped.

3. Each stage is a significant transformation from the stage before it.

4. Each later stage builds upon and incorporates the earlier stages.

\section{Sensorimotor Stage}

Piaget described intelligence in infancy as sensorimotor, or based on direct, physical contact via the use of their senses. Infants taste, feel, pound, push, hear, and move in order to experience the world.

1. This chapter is an adaptation of Child Growth and Development by Paris, Ricardo, \& Rymond, and Child Development by Lumen Learning, used under a CC BY 4.0 license.

2. Crain, W. (2005). Theories of development concepts and applications (5th ed.). Pearson Education, Inc. 


\section{Video Example}

Watch this video for an example of a child who has not mastered object permanence.

\section{Preoperational Stage}

Piaget's stage that coincides with early childhood is the preoperational stage. The word operational means logical, so these children were thought to be illogical. However, they learn to use language and to think of the world symbolically.

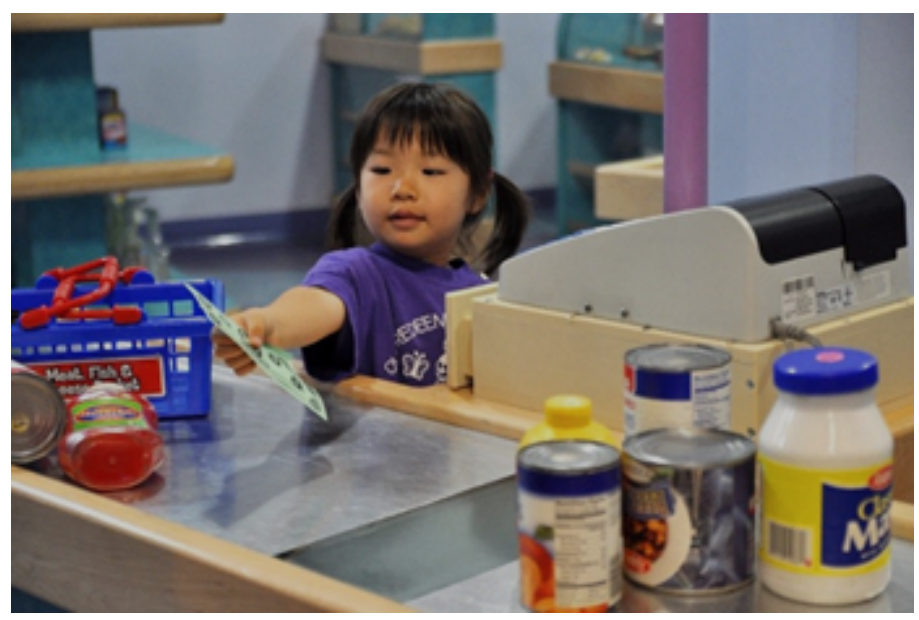

Figure 1. A child pretending to buy items at a toy grocery store. (Photo Credit: Ermalfaro, CC BY SA 4.0.)

\section{Pretend Play}

Pretending is a favorite activity during the preoperational stage. A toy has qualities beyond the way it was designed to function and can now be used to stand for a character or object unlike anything for which it was originally intended. A teddy bear, for example, can be a baby or the queen of a faraway land! 


\section{Video Example}

Watch this Preoperational Stage example video. Note that children in the Preoperational Stage exhibit symbolic play, egocentrism, lack of understanding conservation tasks, and inability to understand reversibility.

\section{Egocentrism}

Egocentrism in early childhood refers to the tendency of young children to think that everyone sees things in the same way as them. This trait is particularly common in the preoperational stage.

\section{Concrete Operational Stage}

This stage takes place from around 7 years old to 11 years of age and is characterized by the development of organized and rational thinking. The child is now mature enough to use logical thought or operations (e.g., rules) but can only apply logic to physical or "concrete" objects and events (hence the name "concrete operational"). Children gain the abilities of conservation (number, area, volume, orientation) and understand that when concrete objects change in appearance, they still contain the same volume, area, number, and orientation and can return to their original state (reversibility). ${ }^{3}$

Their rules of thinking still seem very basic by adult standards and usually operate unconsciously, but they allow children to solve problems more systematically than before, and therefore to be

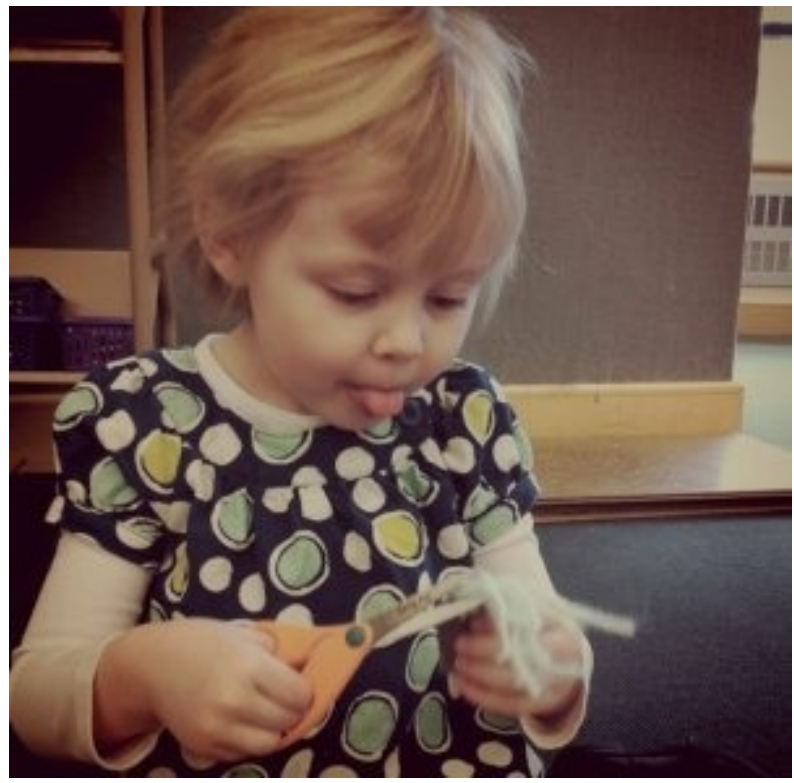

Figure 2. A child with scissors (Photo Source: Flickr, CC BY 2.0.) successful with many academic tasks. For example, a child may unconsciously follow the rule: "If nothing is added or taken away, then the amount of something stays the same." This simple principle

3. Lally, M., \& Vlentine-French, S. (2017). Lifespan development:

A psychological perspective. College of Lake County Foundation. http://dept.clcillinois.edu/psy/LifespanDevelopment.pdf. 
helps children to understand certain arithmetic tasks, such as adding or subtracting zero from a number.

\section{Video Examples}

Watch this video for an example of a child who has not mastered concrete operations. Note that this child does not understand conservation or reversibility.

For more information, watch this video about Concrete Operations.

\section{Formal Operational Stage}

During this stage, adolescents are able to understand abstract principles. They are no longer limited by what can be directly seen or heard and are able to contemplate constructs such as beauty, love, freedom, and morality. Adolescents demonstrate hypothetical-deductive reasoning, which is developing hypotheses based on what might logically occur. They are able to think about all the possibilities in a situation beforehand, and then test them systematically because they are able to engage in scientific thinking.

\section{Video Example}

Watch this informational video about the Formal Operations Stage with a focus on Child Psychology for more information. 
Table 1. Jean Piaget's Theory of Cognitive Development

Name of Stage

Sensorimotor Stage

Preoperational Stage

Concrete Operational Stage

Formal Operational

Stage

\section{Description of Stage}

During the sensorimotor stage, children rely on the use of the senses and motor skills. From birth until about 2 years, the infant learns by tasting, smelling, touching, hearing, and moving objects around. This is a hands-on type of knowledge.

In the preoperational stage, children from ages 2 to 7 years become able to think about the world using symbols. A symbol is something that stands for something else. The use of language, whether it is in the form of words or gestures, facilitates knowing and communicating about the world. This is the hallmark of preoperational learning and it typically occurs in early childhood. However, these children are preoperational or pre-logical. They still do not understand how the physical world operates. They may, for instance, fear that they will go down the drain if they sit at the front of the bathtub, even though they are too big.

Children in the concrete operational stage, ages 7 to 11 years, develop the ability to think logically about the physical world. Middle childhood is a time of understanding concepts such as size, distance, and constancy of matter, and cause and effect relationships. A child knows that a scrambled egg is still an egg and that 8 ounces of water are still 8 ounces no matter what shape of glass contains it.

During the formal operational stage children, at about 12 years of age, acquire the ability to think logically about concrete and abstract events. The teenager who has reached this stage is able to consider possibilities and to contemplate ideas about situations that have never been directly encountered. More abstract understanding of religious ideas, morals, or ethics, and abstract principles such as freedom and dignity can be considered.

\section{Criticisms of Piaget's Theory}

Critics have discovered a considerable variation in what children are able to do at various ages in different parts of the world and in different cultures. Further, many contend that Piaget may have underestimated what children are capable of given the right circumstances. ${ }^{4}$ For instance, he believed that learning peaked around the age of 12 years, designated by his last stage-formal operational stage.

4. Lumen Learning. (n.d.). Lecture transcript: Developmental theories. https://courses.lumenlearning.com/lifespandevelopment2/ chapter/lesson-2-lecture-transcript/. 


\section{Key Takeaways}

- Children develop cognitively through stages-sensorimotor, preoperational, concrete operational, and formal operational.

- Each stage must be mastered before moving on to the next stage.

- Children's intellectual skills change based on their direct experiences with the environment. 


\section{S: ERIKSON}

Jennfier Paris; Antoinette Ricardo; Dawn Rymond; Lumen Learning; and Diana Lang

\section{Erik Erikson's Psychosocial Theory}

Erik Erikson suggested that our relationships and society's expectations motivate much of our behavior in his theory of psychosocial development. Unlike Freud, Erikson believed that we are not driven by unconscious urges. He is considered the father of developmental psychology because his model gives us a guideline for the entire life span and suggests certain primary psychological and social concerns throughout life. ${ }^{1}$

Erikson expanded on Freud's theory by emphasizing the importance of culture in parenting practices and motivations. He also added three stages of social and emotional domains regarding adult development. He believed that we are aware of what motivates us throughout life and that the ego has greater importance in guiding our actions than the id does. ${ }^{2}$ We make conscious choices in life and these choices focus on meeting certain social and cultural needs rather than purely biological ones. Humans are motivated, for instance, by the need to feel that the world is a trustworthy place, that we are capable individuals, that we can make a contribution to society, and that we have lived a meaningful life. These are all psychosocial issues.

1. This chapter is an adaptation of Child Growth and Development by Paris, Ricardo, and Rymond, used under a CC BY 4.0 license. 2. Erikson, E. (1959). Identity and the life cycle. International Universities Press. 
Erikson divided the lifespan into eight stages. In each stage, we have a major psychosocial task to accomplish or crisis to overcome. Successful completion of each developmental task results in a sense of competence and a healthy personality. Failure to master these tasks leads to feelings of inadequacy. Erikson believed that our personality continues to take shape throughout our lifespan as we face these challenges in living. ${ }^{3}$

These eight stages form a foundation for discussions on emotional and social development during the life span. However, these stages or crises can occur more than once and can occur at different ages. ${ }^{4}$ For instance, a person may struggle with a lack of trust beyond infancy under certain circumstances.

Erikson's theory has been criticized for focusing so

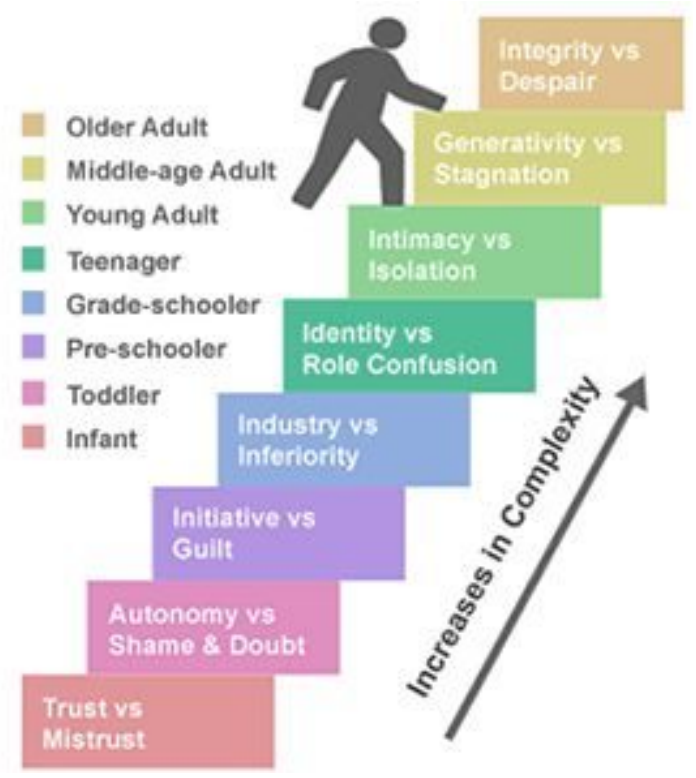

Figure 1. Erikson's Lifespan Stages (Image Source: Brianne Thompson) heavily on stages and assuming that the completion of one stage is a prerequisite for the next development crisis. ${ }^{5}$ His theory also focuses on the social expectations that are found in some cultures, but not in others. For instance, the idea that adolescence is a time of searching for identity might translate well in the middle-class culture of the United States, but not as well in cultures where the transition into adulthood coincides with puberty through rites of passage and where adult roles offer fewer choices. Here is a brief overview of the eight stages ${ }^{6}$ :

3. Erikson, E. (1959). Identity and the life cycle. International Universities Press.

4. Erikson, E. (1968). Identity: Youth and crisis. W.W. Norton \& Company.

5. Marcia, J. E. (1980). Identity in adolescence. In J. Adelson, (Ed.), Handbook of adolescent psychology (pp. 159-187). John Wiley \& Sons.

6. Erikson's Eight Stages is adapted from Lumen Learning's 8 Stages of Psychosocial Development, used under a CC BY SA license. 
Table 1. Erik Erikson's Psychosocial Theory

Name of Stage and Age

Trust vs. mistrust (0-1 year)

Autonomy vs. shame and doubt (1-2 years)

Initiative vs. guilt (3-5 years)

Industry vs. inferiority (6-11 years)

Identity vs. role confusion (adolescence)

Intimacy vs. isolation (young adulthood)

Generativity vs. stagnation (middle adulthood)

Integrity vs. Despair (late adulthood)

\section{Description of Stage}

The infant must have basic needs met in a consistent way in order to feel that the world is a trustworthy place.

Mobile toddlers have newfound freedom that they like to exercise and by being allowed to do so, they learn some basic independence.

Preschoolers like to initiate activities and emphasize doing things "all by myself."

School-aged children focus on accomplishments and begin making comparisons between themselves and their classmates.

Teenagers try to gain a sense of identity as they experiment with various roles, beliefs, and ideas.

In our 20s and 30s, we make some of our first long-term commitments in intimate relationships.

In the 40s through the early 60s we focus on being productive at work and home and are motivated by wanting to feel that we've made a contribution to society.

We look back on our lives and hope to like what we see - that we have lived well and have a sense of integrity because we lived according to our beliefs.

\section{Trust vs. Mistrust}

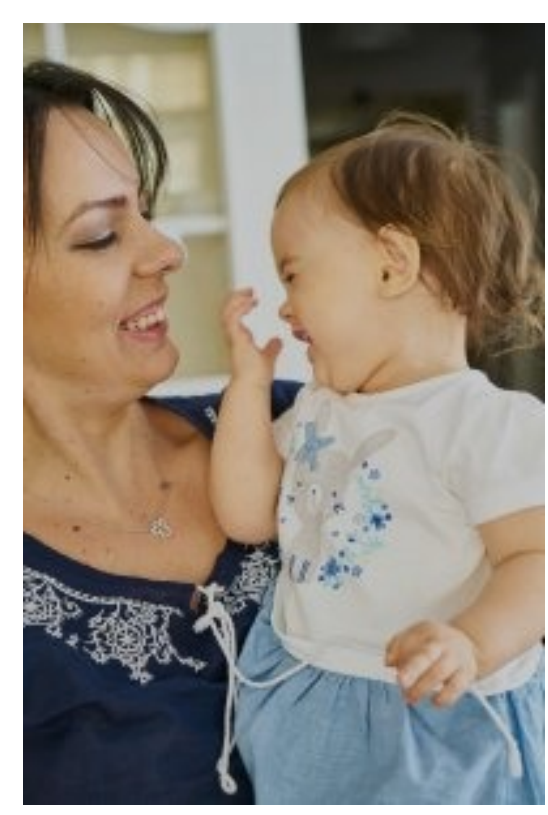

Figure 2. An infant grimacing in laughter. (Photo Source: Engin Akyurt on Pixabay)
From birth to 12 months of age, infants must learn that adults can be trusted. This occurs when adults meet a child's basic needs for survival. Infants are dependent upon their caregivers, so caregivers who are consistently and appropriately responsive and sensitive to their infant's needs help their baby to develop a sense of trust; their baby will see the world as a safe, predictable place. Unresponsive or inconsistent caregivers who do not meet their baby's needs can elicit feelings of anxiety, fear, and mistrust; their baby may see the world as unpredictable and unsafe. If infants are treated cruelly or their needs are not met appropriately, they will likely grow up with a sense of mistrust for people in the world.

\section{Autonomy vs. Shame/Doubt}

As toddlers (ages 1-3 years) begin to explore their world, they learn that they can control their actions and act on their environment to get results. They begin to show clear preferences for certain

elements of the environment, such as food, toys, and clothing. A toddler's main task is to resolve the 
issue of autonomy vs. shame and doubt by working to establish independence. This is the "me do it" stage. For example, we might observe a budding sense of autonomy in a 2-year-old child who wants to choose her clothes and dress herself. Although her outfits might not be appropriate for the situation, her input in such basic decisions has an effect on her sense of independence. If denied the opportunity to act on her environment (within developmentally-appropriate measures), she may begin to doubt her abilities, which could lead to low self-esteem and feelings of shame.

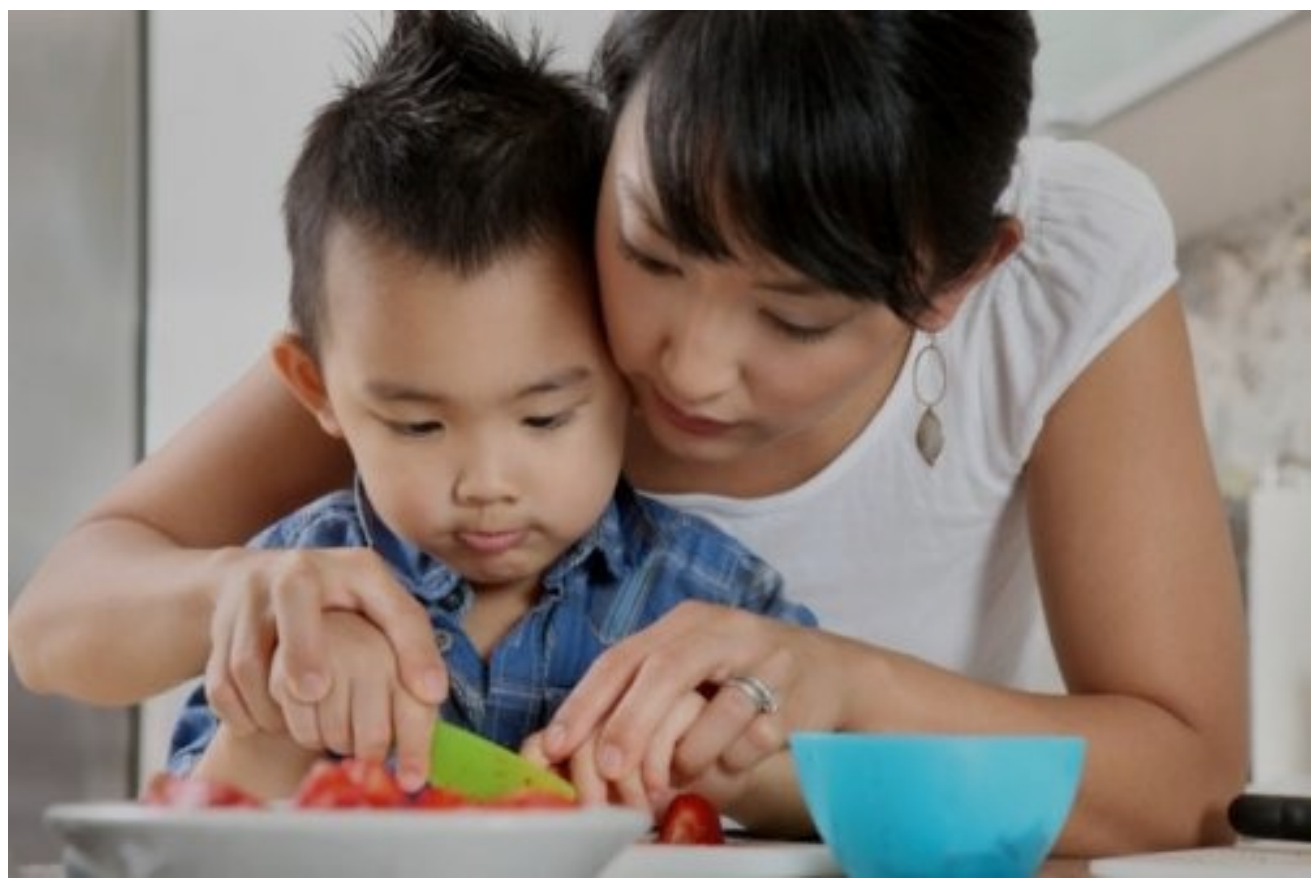

Figure 3. A mother helps her son cut his food.

\section{Initiative vs. Guilt}

Once children reach the preschool stage (ages 3-6 years), they are typically capable of initiating activities and asserting control over their world through social interactions and play. According to Erikson, preschool children must resolve the task of initiative vs. guilt. By learning to plan and achieve goals while interacting with others, preschool children can master this task. Initiative, a sense of ambition and responsibility, occurs when parents allow a child to explore within limits and then support the child's choice. These children tend to develop self-confidence and feel a sense of purpose. Those who are unsuccessful at this stage-with their initiative stifled by over-controlling caregivers-may develop feelings of guilt.

\section{Industry vs. Inferiority}

During the elementary school stage (ages 6-12 years), children face the task of industry vs. inferiority. Many children begin to compare themselves to their peers to see how they measure up. They either develop a sense of pride and accomplishment in their schoolwork, sports, social 
activities, and family life, or they feel inferior and inadequate because they feel that they don't measure up. If children do not learn to get along with others or have negative experiences at home or with peers, an inferiority complex might develop into adolescence and adulthood.

\section{Identity vs. Role Confusion}

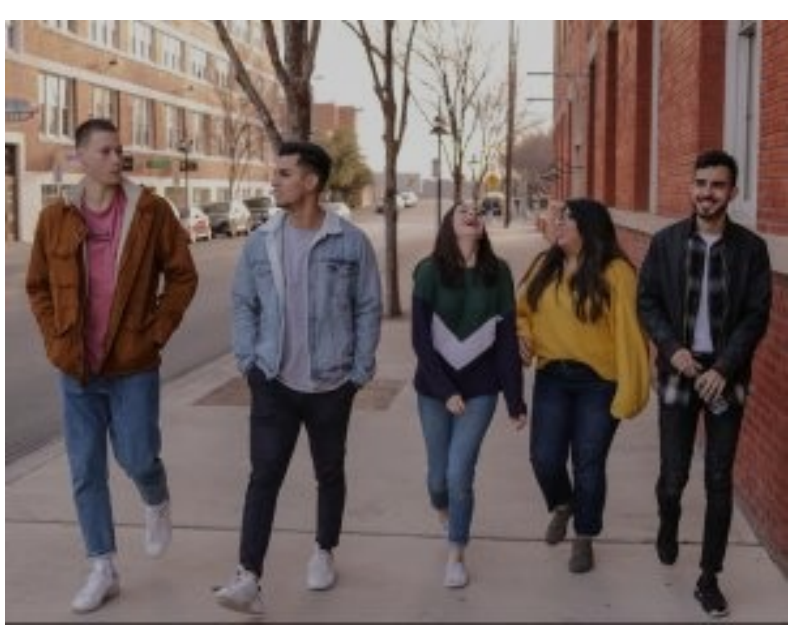

Figure 4. High school cliques may be a movie cliche, but adolescent relationships do influence identity. (Photo Source: Eliott Reyna on Unsplash)
In adolescence (ages 12-18 years), children face the task of identity vs. role confusion. According to Erikson, an adolescent's main task is developing a sense of self. Adolescents struggle with questions such as "Who am I?" and "What do I want to do with my life?" Along the way, most adolescents try on many different "selves" or identities to see which ones fit; they explore various roles and ideas, set goals, and attempt to discover their "adult" selves.

Adolescents who are successful at this stage have a strong sense of identity and are able to remain true to their beliefs and values in the face of problems and other people's perspectives. When adolescents are apathetic, do not make a conscious search for identity, or are pressured to conform to their caregivers' ideas for the future, they may develop a weak sense of self and experience role confusion. They may be unsure of their identity and confused about the future. Teenagers who have difficulty adopting a positive role may struggle to "find" themselves as adults.

\section{Intimacy vs. Isolation}

People in early adulthood (20s through early 40s) are concerned with intimacy vs. isolation. After we have developed a sense of self in adolescence, many of us are ready to share our life with others. However, if the previous developmental stages have not been successfully resolved, young adults may have trouble creating and maintaining healthy relationships with others. Erikson said that we must have a strong sense of self before we can form strong, successful intimate relationships. Adults who do not develop a positive self-concept in adolescence may experience feelings of loneliness and emotional isolation.

\section{Generativity vs. Stagnation}

When people reach their 40s, they enter the time known as middle adulthood, which extends to the mid-60s. The social task of middle adulthood is generativity vs. stagnation. Generativity involves 
finding your "life's work" and fostering the development of others through activities such as volunteering, mentoring, and rearing children. During this stage, middle-aged adults begin contributing to the next generation, often through childbirth and caring for others; they also engage in meaningful and productive work which positively benefits society. Those who do not master this task may experience stagnation and feel as though they are not leaving a mark on the world in a meaningful way; they may have little connection with others and little interest in productivity and self-improvement.

\section{Integrity vs. Despair}

From the mid-60s to the end of life, we are in a period of development known as late adulthood. Erikson's task at this stage is called integrity vs. despair. He said that people in late adulthood reflect on their lives and feel either a sense of satisfaction or a sense of failure. People who feel proud of their accomplishments feel a sense of integrity, and they look back on their lives with few regrets. However, people who are not successful at this stage may feel as if their life has been wasted. They focus on what

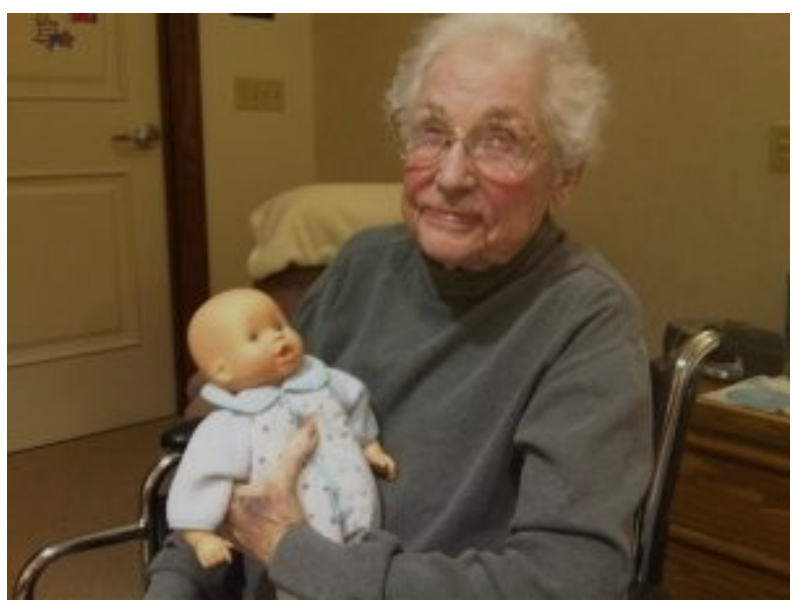

Figure 5. An elderly person holding a baby doll may be reflecting on an earlier stage in their life. "would have," "should have," and "could have" been. They may face the end of their lives with feelings of bitterness, depression, and despair. 


\section{Key Takeaways}

Erikson was a student of Freud but focused on conscious thought.

- His stages of psychosocial development address the entire lifespan and suggest a primary psychosocial crisis in some cultures that adults can use to understand how to support children's social and emotional development.

- Certain cultures may need to resolve the stages in different ways based upon their cultural and survival needs.

- During each of Erikson's eight development stages, two conflicting ideas must be resolved successfully in order for a person to become a confident, contributing member of society. Failure to master these tasks leads to feelings of inadequacy.

- The stages include: trust vs. mistrust, autonomy vs. shame and doubt, initiative vs. guilt, industry vs. inferiority, identity vs. role confusion, intimacy vs. isolation, generativity vs. stagnation, and integrity vs. despair.

\section{(ㅇ) (1) (2)}

1960s: Erikson by Jennfier Paris; Antoinette Ricardo; Dawn Rymond; Lumen Learning; and Diana Lang is licensed under a Creative Commons Attribution-ShareAlike 4.0 International License, except where otherwise noted. 


\section{S: BANDURA}

Mark E. Bouton and Diana Lang

\section{Bandura's Social Learning Theory and Observational Learning}

Observational learning is a component of Albert Bandura's Social Learning Theory, which asserts that individuals can learn new responses via observation of key others' behaviors. ${ }^{1}$ Observational learning does not necessarily require reinforcement, but instead hinges on the presence of others, referred to as social models. Social models typically possess a higher status or authority compared to the observer, examples of which include parents, teachers, or police officers. ${ }^{2}$

Bandura theorized that the observational learning process consists of four parts. The first is attention-one must pay attention to what one is observing in order to learn. The second part is retention. To learn, one must be able to retain the observed behavior into one's memory. The third part of observational learning, initiation, acknowledges that the learner must be able to execute, or initiate the learned behavior. Lastly, the observer must possess the motivation to engage in observational learning.

1. Bandura, A. (1977). Social learning theory. Prentice Hall.

2. This chapter is an adaptation of CONDITIONING AND LEARNING by Mark E. Bouton, used under a CC BY NC SA 4.0 license. 


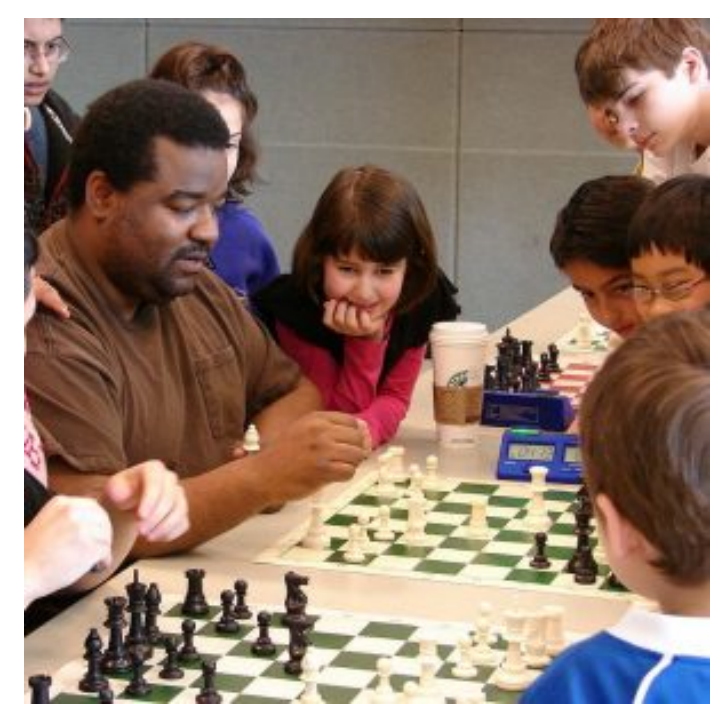

Figure 1. Children observe a social model (an experienced chess player) to learn the rules of the game. (Photo Source: David R. Tribble, $\underline{\text { CC BY-SA 3.0.) }}$
Imagine a child walking up to a group of children playing a game on the playground. The game looks fun, but it is new and unfamiliar. Rather than joining the game immediately, the child opts to sit back and watch the other children play a round or two. While observing the others, the child takes note of the ways in which they behave while playing the game. By watching the behavior of the other kids, the child can figure out the rules of the game and even some strategies for performing well at the game. This is called observational learning.

In the example here, the child must want to learn how to play the game in order to properly engage in observational learning. The children who already know how to play the game could be thought of as being authorities - and are therefore social models-even though they are the same age as the observer.

By observing how the social models behave, an individual is able to learn how to act in a certain situation. Other examples of observational learning might include a child learning to place her napkin in her lap by watching her parents at the dinner table, or a child learning how to use a pair of scissors after watching another child successfully use a pair of scissors.

\section{The Bobo Doll Experiment}

Researchers have conducted countless experiments designed to explore observational learning, the most famous of which is Albert Bandura's "Bobo

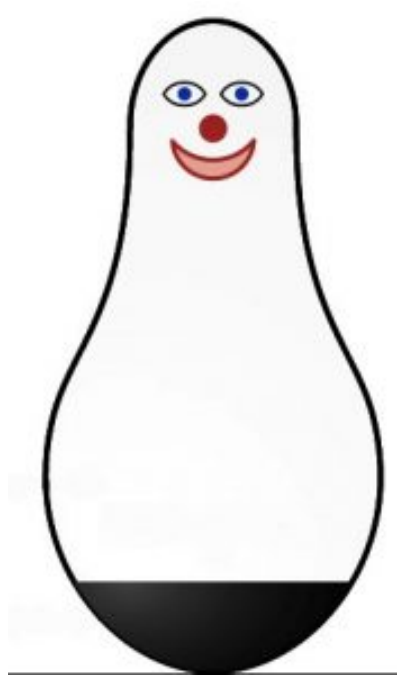

Figure 2. Bobo doll diagram (Image Source: Sémhur, CC BY SA 3.0) 
doll experiment." In this experiment, Bandura had children individually observe an adult social model interact with a clown doll ("Bobo"). ${ }^{3}$

For one group of children, the adult interacted aggressively with Bobo: punching it, kicking it, throwing it, and even hitting it in the face with a toy mallet. Another group of children watched the adult interact with other toys, displaying no aggression toward Bobo. In both instances, the adult left and the children were allowed to interact with Bobo on their own.

Bandura found that children exposed to the aggressive social model were significantly more likely to behave aggressively toward Bobo, hitting and kicking him, compared to those exposed to the nonaggressive model. The researchers concluded that the children in the aggressive group used their observations of the adult social model's behavior to determine that aggressive behavior toward Bobo was acceptable.

\section{Video Example}

Watch this video about the Bobo doll experiment to learn more.

While reinforcement was not required to elicit the children's behavior in Bandura's first experiment, it is important to acknowledge that consequences do play a role within observational learning. A future adaptation of this study demonstrated that children in the aggression group showed less aggressive behavior if they witnessed the adult model receive punishment for aggressing against Bobo. ${ }^{4}$ Bandura referred to this process as vicarious reinforcement, as the children did not experience the reinforcement or punishment directly, yet were still influenced by observing it.

3. Bandura, A., Ross, D., \& Ross, S. A. (1961). Transmission of aggression through the imitation of aggressive models. Journal of Abnormal and Social Psychology, 63(3), 575-582.

4. Bandura, A., Ross, D., \& Ross, S. (1963). Imitation of film-mediated aggressive models. Journal of Abnormal and Social Psychology, 66(1), 3-11. 


\section{Key Takeaways}

- Individuals learn through observing others.

- Bobo doll experiment-children were more aggressive toward the Bobo doll if they witnessed models being aggressive.

\section{Further Reading}

Rescorla, R. A. (1988). Pavlovian conditioning: It's not what you think it is. American Psychologist, 43(1), 151-160.

Bouton, M. E. (2007). Learning and behavior: A contemporary synthesis. Sinauer Associates.

Bouton, M. E. (2009). Learning theory. In B. J. Sadock, V. A. Sadock, \& P. Ruiz (Eds.), Kaplan \& Sadock's comprehensive textbook of psychiatry (9th ed., pp. 647-658). Lippincott Williams \& Wilkins.

Domjan, M. (2010). The principles of learning and behavior (6th ed.). Wadsworth.

\section{(c) (1) (2) (2)}

1960s: Bandura by Mark E. Bouton and Diana Lang is licensed under a Creative Commons Attribution-NonCommercial-ShareAlike 4.0 International License, except where otherwise noted. 


\section{S: DREIKURS}

New World Encyclopedia; Wikimedia contributors; and Diana Lang

\section{Rudolf Dreikurs}

Rudolf Dreikurs was an American psychiatrist and educator who developed Alfred Adler's system of individual psychology into a pragmatic method for understanding the purposes of misbehavior in children and stimulating cooperative behavior without punishment or reward. His primary focus was on pre-adolescents, and he reasoned that their problematic behavior resulted from feelings of lack of significance in their social group. He described four "mistaken goals" that such children would resort to, and outlined the most effective ways that teachers and parents could respond. ${ }^{1}$

He saw the family as the first social setting in which education takes place, with the school environment as an extension of the family. Thus, his techniques for preventing misbehavior and encouraging appropriate behavior could be applied equally in both settings. Dreikurs' work continues through the training centers he and his colleagues established to train counselors in addressing the social problems of youth.

\section{Individual Psychology}

Dreikurs was often credited with "elaborating, building, and working out in a clear, systematic and logical form, the basic ideas of Individual Psychology." While most agree that his greatest contribution was in the application and practice of individual psychology, some felt he also contributed to the creation of the original theory. He is most well-known for his simplification and application of Adler's principles for use by parents and educators. In 1964, he and Vicki Soltz wrote Children: The Challenge, and in 1968, he and Loren Grey wrote A Parent's Guide to Child Discipline.

1. This chapter is an adaptation of Rudolf Dreikurs by contributors to the the Wikimedia Foundation and New World Encyclopedia, and is used under a CC BY SA 3.0 license.

2. Adler University. (n.d.). Rudolf Dreikurs. https://www.adler.edu/page/community-engagement/center-for-adlerian-practiceand-scholarship/history/rudolf-dreikurs. 
Adler and Dreikurs firmly believed that encouragement was essential to the improvement of behavior and human relationships. Their basic assumption was that human behavior is not predetermined by genetics, or merely the result of outside forces beyond one's control. They argued that behavior is a result of a search for significance within a social setting. Dreikurs said "anticipation influences outcome-the fear of making a mistake leads to mistakes. Anyone who can alter the expectations of people can change their behavior." ${ }^{3}$ Accordingly, encouragement and positive support have a direct correlation with improved behavior in others.

Adlerian Parent Education aims to give children the skills to meet life challenges in a constructive, positive way and the courage to circumvent the many pitfalls and dangers that confront children in society. It supports parents by providing them with tools to ease and handle the stress of being a parent and to raise children with courage and compassion.

Dreikurs believed that all behavior has a purpose. He constructed

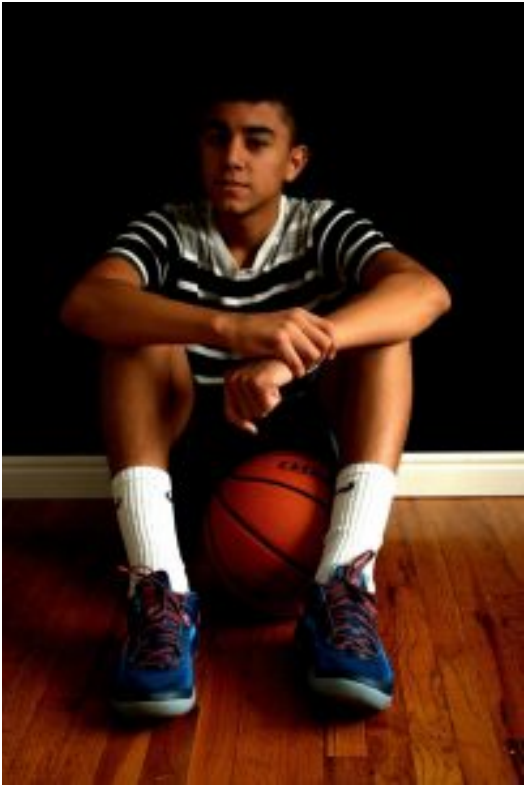

Figure 1. Sports is often seen as a method of building social competence in children and adolescents. (Photo Source: Deeann Arant, CC0 1.0) what is often considered the most effective tool in helping to understand children's behavior: The Four Goals of Misbehavior and the techniques of effectively revealing these to a misbehaving child. The development of the system of natural and logical consequences and the application of these techniques may well be Dreikurs' finest contribution to the betterment of human society. 


\section{The Roots of Misbehavior}

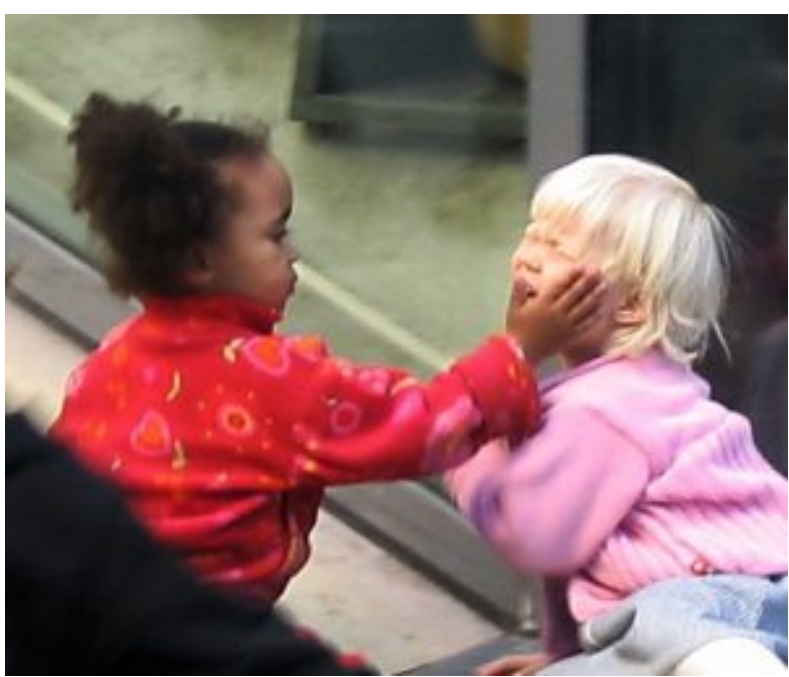

Figure 2. Children squabbling in a public environment may be dealing with internal conflicts they don't yet understand. (Photo Source: Itneill, CC by 2.0 )
Dreikurs suggested that human misbehavior is the result of not having one's basic needs of belonging to, and contributing to, a social group met. The child then resorts to one of four mistaken goals: attention, power, revenge, or avoidance of failure.

Dreikurs' main theory dealt with the misbehavior of pre-adolescents. He reasoned that these students will "act out" based on these four, principled "mistaken goals." ${ }^{4}$ The first reason for their misbehavior is that they desire attention. If they do not receive the attention they crave through their actions (good or bad, e.g., doing well on a paper or throwing a tantrum), they move onto seeking power (e.g., they may refuse to complete a paper). If their power struggle is thwarted, they seek revenge. If even revenge does not achieve the desired response,

they begin to feel inadequate.

His books list many ways to combat these behaviors. The first step is for teachers to identify the mistaken goal while also noting their own response to the misbehavior, and observe the students' reactions. Second, a teacher should confront the mistaken goal by providing an explanation of it along with a discussion of the faulty logic involved. By doing so, students are given an opportunity to examine and change their behavior. Third, Dreikurs emphasized the importance of avoiding power struggles with students. One way is simply by withdrawing as an authority figure; teachers can also redirect students' ambitions for power by having them participate in making decisions or giving directions. This is called "democratic teaching."

Dreikurs also recommended taking positive steps against revenge-seeking behavior. The teacher is instructed to set up situations where the students can exhibit talents and strengths and ultimately experience acceptance. Lastly, teachers should encourage students who display inadequacy by offering these students encouragement and support for even minimal efforts. ${ }^{6}$ His overall goal was 
that students would learn to cooperate reasonably, without being penalized or rewarded, because they would feel that they are valuable contributors to the classroom.

\section{Logical and Natural Consequences}

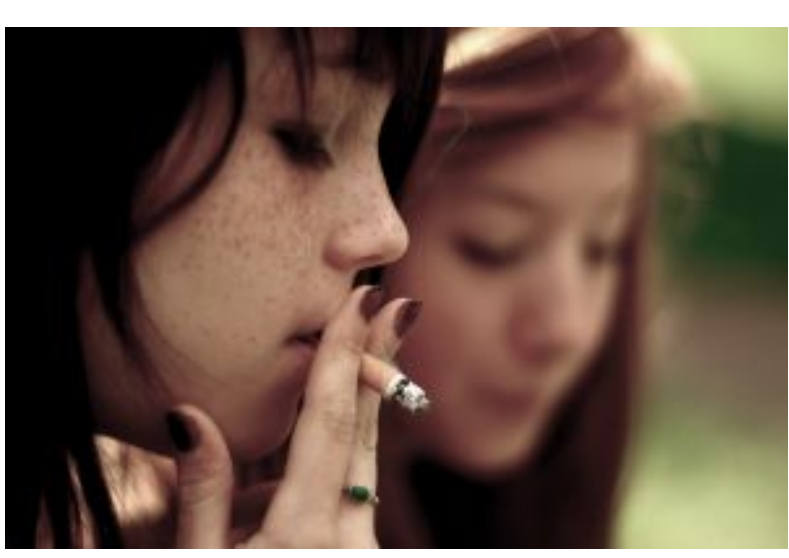

Figure 3. A teenage girl smoking. (Photo Source: Valentin Ottone, $\underline{C C \text { by } 2.0 \text { ) }}$
Dreikurs described two types of consequences: logical and natural. Logical consequences refer to "reasonable results that follow behavior either desirable or non-desirable." They typically require students to make right of what they have done wrong. For example, if students do not complete their work during class, they are required to do it for homework. In a democratic classroom, the students would know in advance the consequences of their misbehavior because as part of the classroom they helped formulate the consequences.

Natural consequences differ from logical consequences in that the results following the behavior occur naturally. For example, if a student tips his chair backward and falls, leaving him hurt or embarrassed, this would be a natural consequence, because the hurt and embarrassment alone is a sufficient consequence for his misbehavior.

Dreikurs did not consider punishment an effective method of discipline. He viewed punishment as an action taken by the teacher as an act of revenge to show the students who is in charge. He believed that punishment was humiliating and offensive to students.

Dreikurs believed in prevention, and his main focus was on constructive behavior rather than coercive discipline. He recommended that teachers have a democratic classroom and teaching style to help students gain a sense of belonging which is the genuine goal. In this manner, students would have a social interest: a condition in which students would realize themselves that it is to their advantage to contribute to the welfare of a group. Therefore, to understand children, they must be observed in a social setting and in relationship to others, to discover the reasons for their behavior. 


\section{Key Takeaways}

- Children who do not feel the basic need of belonging to a social group turn to attention, power, revenge, and avoidance of failure.

- Misbehavior can be modified without punishment through implementing natural and logical consequences.

- Dreikurs focused on pre-adolescents' reasons for their problematic behaviors and how teachers and parents can respond to it.

- Humans have a basic need for unconditional positive regard and acceptance.

\section{(ㅇ) (1) (2)}

1960s: Dreikurs by New World Encyclopedia; Wikimedia contributors; and Diana Lang is licensed under a Creative Commons Attribution-ShareAlike 4.0 International License, except where otherwise noted. 


\section{S: BRONFENBRENNER}

New World Encyclopedia; Wikimedia contributors; Jaime Ballard; Elizabeth Wieling; Catherine Solheim; and Diana Lang

\section{Bioecological Systems Theory}

Urie Bronfenbrenner was one of the first psychologists to adopt a holistic perspective on human development via his Bioecological Systems Theory, which had a widespread influence on the way psychologists and other social scientists approach the study of human beings and their environments. ${ }^{1}$

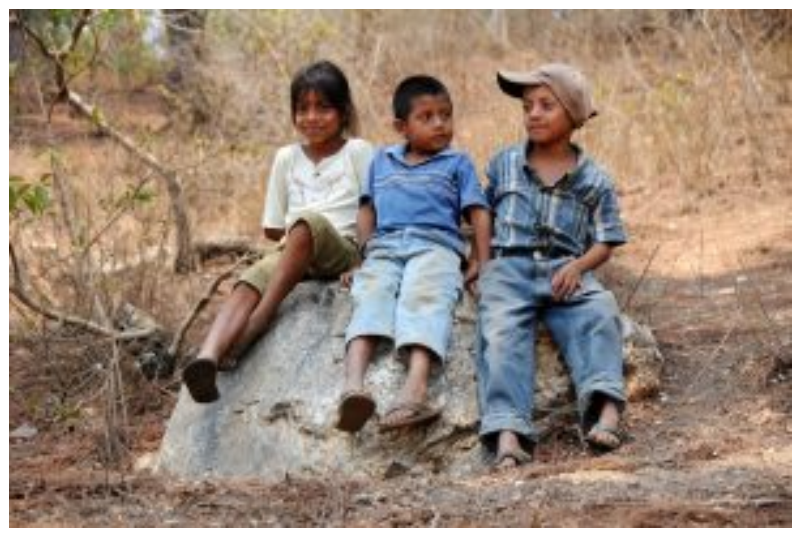

Bronfenbrenner emphasized the importance of the social environments in which children are raised, and saw the breakdown of the family as the leading cause of the ever-growing rates of alienation, apathy, rebellion, delinquency, and violence among American youth. His work led to new directions in research and the design of programs and policies affecting the well-being of children and families.

Figure 1. Children lounging on a rock. (Photo Source: Maj Heath Allen)

1. This chapter is an adaptation of Urie Bronfenbrenner at the New World Encyclopedia, by contributors to Wikimedia, used under a CC BY SA 3.0 license. 
Bronfenbrenner's primary theoretical contribution was his Bioecological Systems Theory, in which he identified four types of nested systems. ${ }^{2}$

Bronfenbrenner recognized that is it necessary to understand how not only the family or school influences human development, but how broader influences do as well.

The four systems are:

- Microsystem: Immediate environments such as family, school, peer group, neighborhood, and childcare environments.

- Mesosystem: A system comprised of connections between immediate environments (i.e., a child's home and school).

- Exosystem: External environmental settings which only indirectly affect development, such as parent's workplace.

- Macrosystem: The larger cultural context (Eastern vs. Western culture, national economy, political culture, subculture).

Later a fifth system was added:

- Chronosystem: The patterning of environmental events and transitions over the course of life.

Each system contains roles, norms, and rules that can powerfully shape development (See Table 1.). For example, in order to understand the issues a learner is having with math, we can't simply look at that individual and what challenges they face directly with the subject. We have to look at the interactions that occur between the teacher and the child. Perhaps the teacher needs to make modifications as well. The teacher may be responding to regulations made by the school, such as new expectations for students in math or constraints on time that interferes with the teacher's ability to instruct. These new demands may be a response to national efforts to promote math and science deemed important by political leaders in response to relations with other countries at a particular time in history. 
Table 1. Urie Bronfenbrenner's Ecological Systems Model

\begin{abstract}
Name of System

\section{Description of System}

Microsystems impact a child directly. These are the people with whom the child interacts

Microsystems such as parents, peers, and teachers. The relationship between individuals and those around them need to be considered. For example, to appreciate what is going on with a student in math, the relationship between the student and teacher should be known.
\end{abstract}

Mesosystems Mesosystems are interactions between environments closely surrounding the individual. The relationship between parents and schools, for example, will indirectly affect the child.

Larger institutions such as the mass media or the healthcare system are referred to as the

Exosystem ecosystem. These have an impact on families, peers, and schools that operate under policies and regulations found in these institutions.

Macrosystems We find cultural values and beliefs at the level of macrosystems. These larger ideals and expectations inform institutions that will ultimately impact the individual.

All of this happens in a historical context referred to as the chronosystem. Cultural values Chronosystem change over time, as do the policies of educational institutions or governments in certain political climates. Development occurs at a point in time.

According to the Bioecological theory, if the relationships in the immediate microsystem break down, the child will not have the tools to explore other parts of his environment. Children looking for the affirmations that should be present in the child/parent (or child/other important adult) relationship look for attention in inappropriate places. These deficiencies tend to show themselves in adolescence as anti-social behavior, lack of self-discipline, and inability to provide self-direction. ${ }^{3}$

The major assumptions of The (Bio)Ecology of Human Development, have had widespread influence on the way psychologists and other social scientists approach the study of human beings and their environments. ${ }^{4}$ It has been said that before Bronfenbrenner, child psychologists studied the child, sociologists examined the family, anthropologists the society, economists the economic framework of the times, and political scientists the political structure.

As a result of Bronfenbrenner's groundbreaking work in human ecology, these environments, from the family to economic and political structures, have come to be viewed as part of the life course from childhood through adulthood. The "bioecological" approach to human development broke down barriers among the social sciences and built bridges between the disciplines that have allowed findings to emerge about which key elements in the larger social structure, and across societies, are vital for optimal human development.

3. Addison, J. T. (1992). Urie Bronfenbrenner. Human Ecology, 20(2), 16-20.

4. Bronfenbrenner, U. (1981). The ecology of human development: Experiments by nature and design. Harvard University Press. 


\title{
Application of the Theory: Head Start
}

Bronfenbrenner played an active role in the design of developmental programs, including being one of the founders of Head Start, the federal child development program. In 1965, his ideas and ability to translate them into operational research models and effective social policies spurred the creation of Head Start. One of the most successful and longest-running programs for stopping the cycle of poverty in the United States, Head Start has provided comprehensive education, health, nutrition, and parent involvement services to low-income children and their families.

\section{Later Years}

The following quote from Bronfenbrenner's obituary highlights the ways his work impacted the world:

\begin{abstract}
"[Bronfenbrenner] spent many of his later years warning that the process that makes human beings human is breaking down as disruptive trends in American society produce ever more chaos in the lives of America's children. 'The hectic pace of modern life poses a threat to our children second only to poverty and unemployment,' he said. 'We are depriving millions of children-and thereby our country - of their birthright... virtues, such as honesty, responsibility, integrity, and compassion."' 5
\end{abstract}

\section{The Human Ecology Framework}

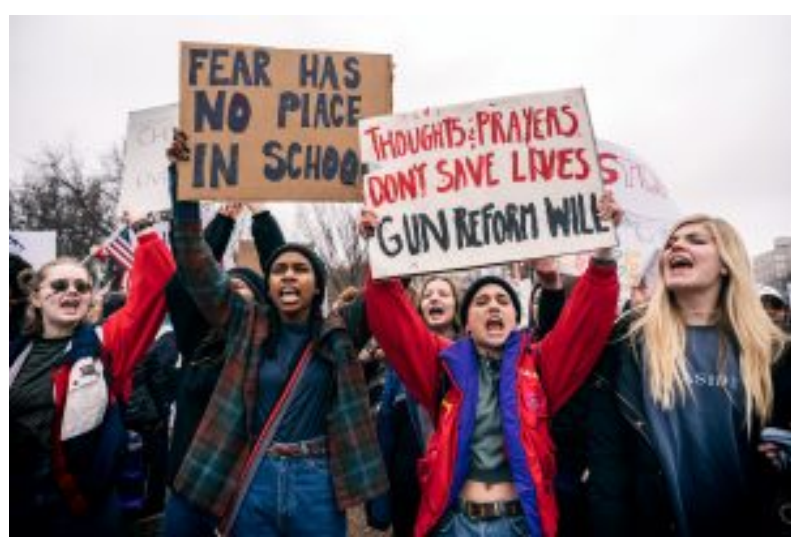

Figure 3. Protests for gun reform in the United States. (Photo Source: Lorie Shaull on Flickr, CC by SA 2.0)
The human ecology framework assumes that families interact within multiple environments that mutually influence each other. These environments include the biophysical (personal variables), the microsystem (the systems in immediate surroundings, such as family, neighborhood, church, work, or school), the mesosystem (the ways in which these immediate systems connect, such as the relationships between family and work), the exosystem (the larger social system, such as the stress of another family member's job), and the 
macrosystem (the cultural values and the larger social system, such as immigration policy that influences admission and social system access). ${ }^{6}$

In the context of a refugee family, the family might be influenced by their biophysical (e.g., whether or not members were injured as they fled the persecution), their microsystem (e.g., parental conflict while fleeing), their mesosystem (e.g., teachers and school personnel who are struggling with their own trauma from fleeing conflict and thus their ability to provide robust services is impaired), their exosystem (e.g., local leaders who do not consult with women living in shelters regarding their resources needs and don't provide feminine hygiene products or children's toys), and countless other environments. ${ }^{7}$ The family may have access to and be able to directly influence their mesosystem and at the same time feel powerless to make changes in the exosystem. Each of these environments will contribute to their coping.

With its focus on interaction within multiple environments, the human ecology framework is an incredibly useful lens to employ cross-cultural contexts such as when considering immigrant families. For example, a researcher could ask, "How do Hmong immigrant families manage financial resources in their new environment in the United States?" and "How did Hmong families manage their financial resources while still living in Laos?" The assumptions and central concepts of human ecology theory would apply equally in either culture. The needs, values, and environment would be sensitively identified within each culture. ${ }^{8}$

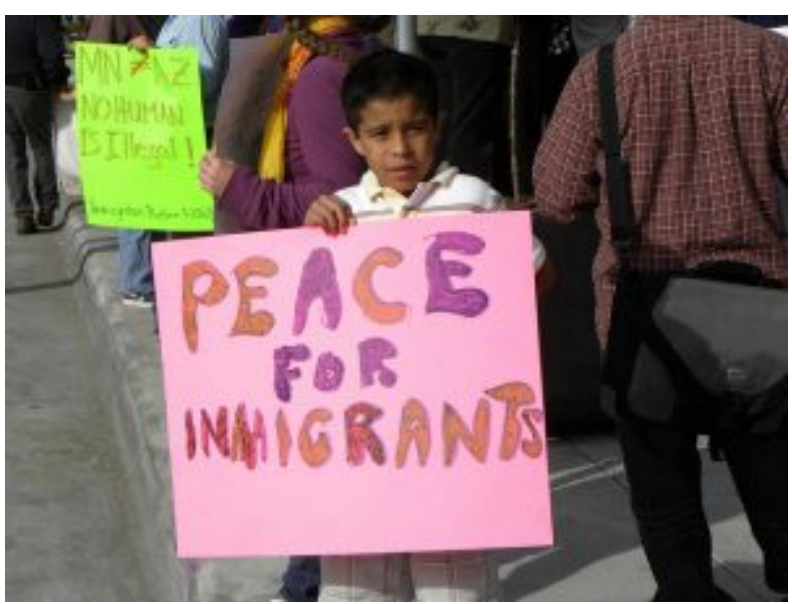

Figure 4. Protesting for immigrants. (Photo Source: Minneapolis protest against Arizona immigrant law SB 1070, CC BY 2.0.)

Additionally, human ecology theory assumes that families are intentional in their decision-making and that they work toward biological sustenance, economic maintenance, and psychosocial function. As patterns in the social environment are more and more threatening to the family's quality of life in these three areas, the system will be more and more likely to seek change, possibly by a move to a new country.

The family system has certain needs, including physical needs for resources and interpersonal needs

6. Human Ecology Framework is an adaptation of Family Theories: A New Direction for Research with Resettled Populations by Jaime Ballard, Elizabeth Wieling, and Catherine Solheim, used under a CC BY 4.0 license.

7. Hoffman, M. A., \& Kruczek, T. (2011). A bioecological model of mass trauma: Individual, community, and societal effects. The Counseling Psychologist, 39(8), 1087-1127. https://doi.org/10.1177/0011000010397932.

8. Solheim, C. A., \& Yang, P. N. D. (2010). Understanding generational differences in financial literacy in Hmong immigrant families. Family and Consumer Sciences Research Journal 38(4), 435-454. 
for relationships. If their current situation is not meeting these needs, the family system will engage in management to meet these needs within their value system.

\section{Key Takeaways}

- Bioecological Systems Theory - the study of how individual development can be shaped by one's interactions with the various systems and how an individual can impact the nested systems.

- Five nested systems: Microsystem, Mesosystem, Exosystem, Macrosystem, and Chronosystem.

- Each system contains roles, norms, and rules that can impact human development.

- Head Start educates and provides services to parents and children to address multiple systems and domains of development.

\section{(ㅇ) (1) (2)}

1970s: Bronfenbrenner by New World Encyclopedia; Wikimedia contributors; Jaime Ballard; Elizabeth Wieling; Catherine Solheim; and Diana Lang is licensed under a Creative Commons Attribution-ShareAlike 4.0 International License, except where otherwise noted. 


\title{
1980S: GALINSKY
}

\author{
Marissa L. Diener and Diana Lang
}

\section{Galinsky’s Six Stages of Parenthood}

Ellen Galinsky, a researcher who studies changing family dynamics, was one of the first scholars to emphasize the development of parents themselves, how they respond to their children's development, and how they grow as parents. ${ }^{1}$ Parenthood is an experience that transforms one's identity as one takes on new roles. Children's growth and development force parents to change their roles. They must develop new skills and abilities in response to children's development. Galinsky identified six stages of parenthood that focus on different tasks and goals (See Table 1.). ${ }^{2}$

Table 1. Galinsky's Stages of Parenthood

\begin{tabular}{|c|c|c|}
\hline Stage & Age of Child & Main Tasks and Goals \\
\hline $\begin{array}{l}\text { Stage 1: The } \\
\text { Image-Making Stage }\end{array}$ & $\begin{array}{l}\text { Planning for a child; } \\
\text { Pregnancy }\end{array}$ & $\begin{array}{l}\text { Prospective parents consider what it means to be a parent } \\
\text { and plan for changes to accommodate a child. }\end{array}$ \\
\hline $\begin{array}{l}\text { Stage 2: The Nurturing } \\
\text { Stage }\end{array}$ & Infancy & $\begin{array}{l}\text { Parents develop an attachment relationship with the child } \\
\text { and adapt to the new baby. }\end{array}$ \\
\hline $\begin{array}{l}\text { Stage 3: The Authority } \\
\text { Stage }\end{array}$ & $\begin{array}{l}\text { Toddler and } \\
\text { pre-school }\end{array}$ & $\begin{array}{l}\text { Parents create rules and figure out how to effectively guide } \\
\text { their child's behavior. }\end{array}$ \\
\hline $\begin{array}{l}\text { Stage 4: The } \\
\text { Interpretive Stage }\end{array}$ & Middle childhood & $\begin{array}{l}\text { Parents help their children interpret their experiences } \\
\text { within the social world beyond the family. }\end{array}$ \\
\hline $\begin{array}{l}\text { Stage 5: The } \\
\text { Interdependent Stage }\end{array}$ & Adolescence & $\begin{array}{l}\text { Parents renegotiate their relationship with their children to } \\
\text { allow for shared power in decision-making. }\end{array}$ \\
\hline $\begin{array}{l}\text { Stage 6: The Departure } \\
\text { Stage }\end{array}$ & Early adulthood & $\begin{array}{l}\text { Parents evaluate their successes and failures as parents as } \\
\text { their children become independent. }\end{array}$ \\
\hline
\end{tabular}

According to Galinsky, all people have the innate desire to learn. There are seven essential life skills that we learn including focus and self control, perspective taking (understanding how others think),

1. Galinsky, E. (1987). The six stages of parenthood. Perseus Books.

2. This chapter is an adaptation of The Developing Parent by Marissa L. Diener and is used under a CC BY NC SA license. 
communicating, making connections (creatively), critical thinking, taking on challenges, and selfdirected, engaged learning.

\section{Video Example}

The video below showcases how we learn these seven essential life skills and why they are important in the 21 st century.

The Seven Essential Life Skills.

\section{The Image-Making Stage}

Prospective parents enter the image-making stage when they (a) think about and form images about their roles as parents, (b) contemplate what will emerge as a result of parenthood, and (c) prepare for changes associated adding an infant to their family. Future parents develop ideas about what it will be like to be a parent and what type of parent they want to be. Individuals may evaluate their relationships with their own parents as a model for their upcoming roles as parents. 


\section{The Nurturing Stage}

The second stage, the nurturing stage, occurs at the birth of the baby. A parent's main goal during this stage is to develop an attachment relationship with their baby. Parents must adapt their romantic relationships, their relationships with their other children, and their relationships with their own parents to include the new infant. Some parents feel attached to their baby immediately, but for other parents, this occurs more gradually. Parents may have imagined their infant in specific ways, but they now have to reconcile those images with their actual baby. In incorporating their relationship with their child into their other relationships, parents often have to reshape their conceptions of themselves and their identity. Parenting responsibilities are the most demanding during infancy because infants are completely dependent on caregiving.

\section{The Authority Stage}

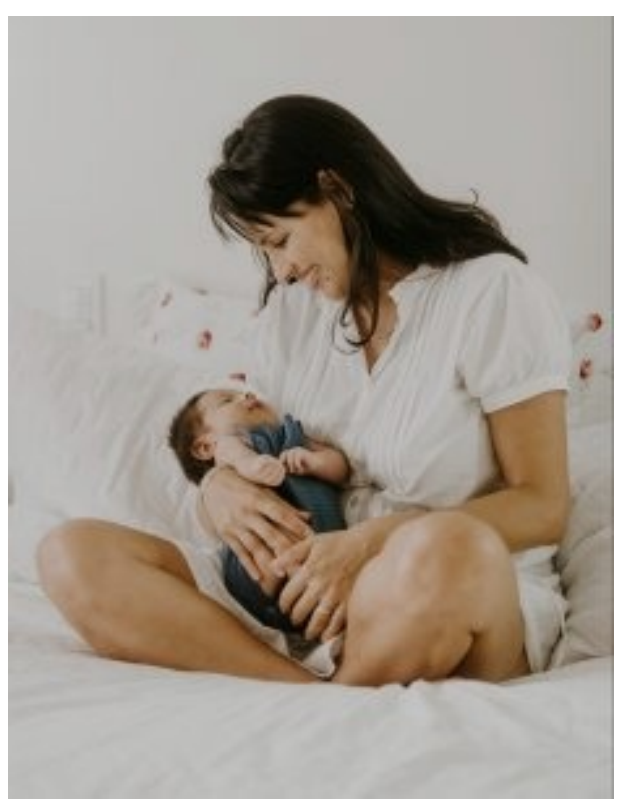

Figure 1. A parent holding her infant child. (Photo Credit: Jonathan Borba, Pexels License)

The authority stage occurs when children are 2 years old until about 4 or 5 years old. In this stage, parents make decisions about how much authority to exert over their children's behavior. Parents must establish rules to guide their child's behavior and development. They have to decide how strictly they should enforce rules and what to do when rules are broken. 


\section{The Interpretive Stage}

The interpretive stage occurs when children enter school (preschool or kindergarten) and lasts until the beginning of adolescence. Parents interpret their children's experiences as they are increasingly exposed to the world outside of the family. Parents answer their children's questions, provide explanations, and determine what behaviors and values to teach. They decide what experiences to provide their children in terms of schooling, neighborhood, and extracurricular activities. By this time, parents have experience in the parenting role and often reflect on their strengths and weaknesses as parents, review their images of parenthood, and determine how realistic they have been. Parents have to negotiate how involved to be with their children, when to step in, and when to encourage children to make choices independently.

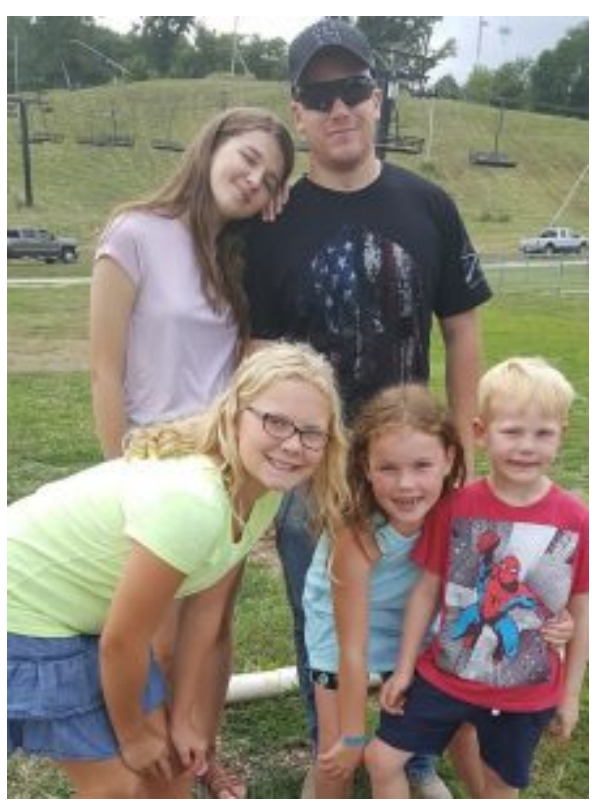

Figure 2. A family with children of various ages.

\section{The Interdependent Stage}

Parents of teenagers are in the interdependent stage. They must redefine their authority and renegotiate their relationship with their adolescent as the children increasingly make decisions independent of parental control and authority. On the other hand, parents do not permit their adolescent children to have complete autonomy over their decision-making and behavior, and thus adolescents and parents must adapt their relationship to allow for greater negotiation and discussion about rules and limits.

\section{The Departure Stage}

During the departure stage of parenting, parents evaluate their entire parenting experience. They prepare for their child's departure, redefine their identity as the parent of an adult child, and assess their parenting accomplishments and failures. This stage forms a transition to a new era in parents' lives. This stage usually spans a long time period from when the oldest child moves away (and often returns) until the youngest child leaves. The parenting role must be redefined as a less central role in a parent's identity.

Despite the interest in the development of parents, little research has examined developmental changes in parents' experiences and behaviors over time. Thus, it is not clear whether these theoretical stages are generalizable to parents of different races, ages, cultures, and religions, nor do we have empirical data on the factors that influence individual differences in these stages. On a practical note, how-to books and websites geared toward parental development should be evaluated with caution, as not all advice provided is supported by research. 


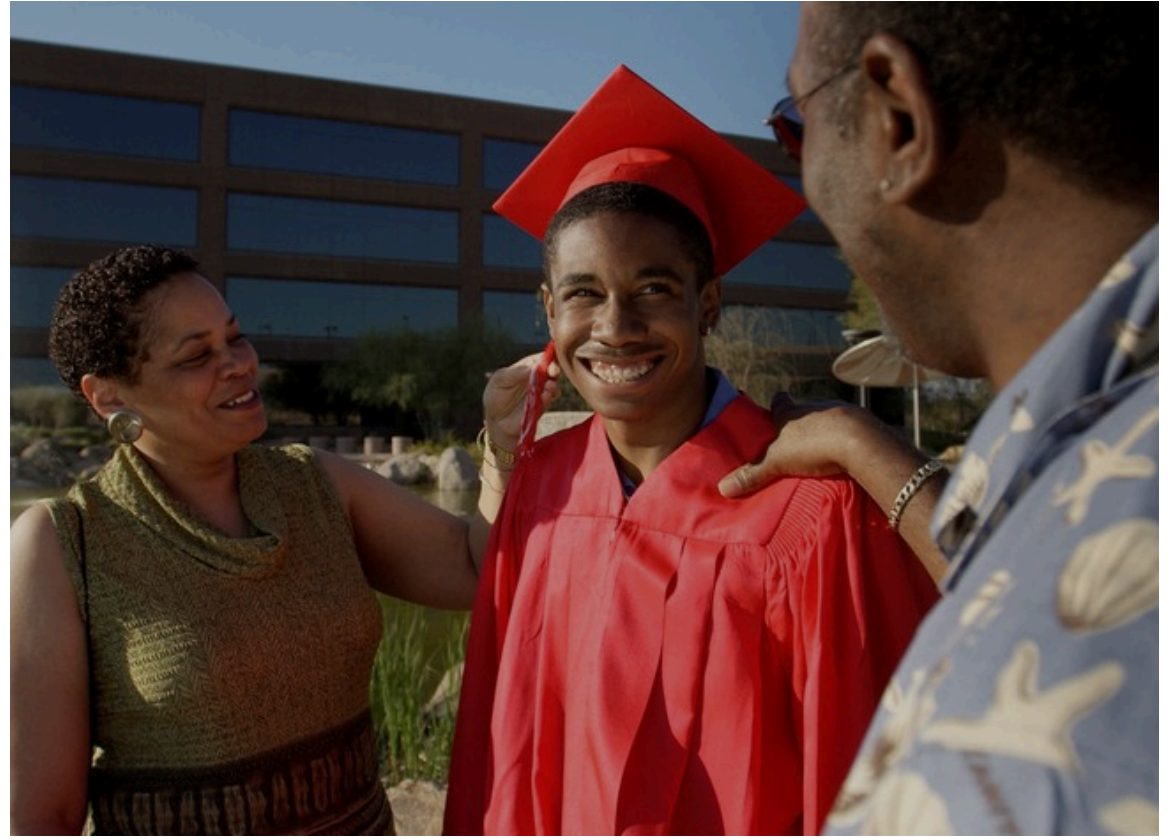

Figure 3. When a child achieves a new level of independence and leaves the home it marks another turning point in the identity of a parent. (Photo Source: State Farm, licensed CC BY 2.0)

\section{Key Takeaways}

- Parents' roles pass through stages as children develop.

- Parenthood stages-image-making, nurturing, authority, interpretive, interdependent, and departure.

\section{(1) (1) $\circledast(0$}

1980s: Galinsky by Marissa L. Diener and Diana Lang is licensed under a Creative Commons Attribution-NonCommercial-ShareAlike 4.0 International License, except where otherwise noted. 
PART III

FAMILY THEORIES 


\section{THE DOUBLE ABC-X MODEL OF FAMILY STRESS}

Jaime Ballard; Elizabeth Wieling; Catherine Solheim; and Diana Lang

\section{The Double ABC-X Stress Model}

\section{ABC-X Model of Family Crisis}

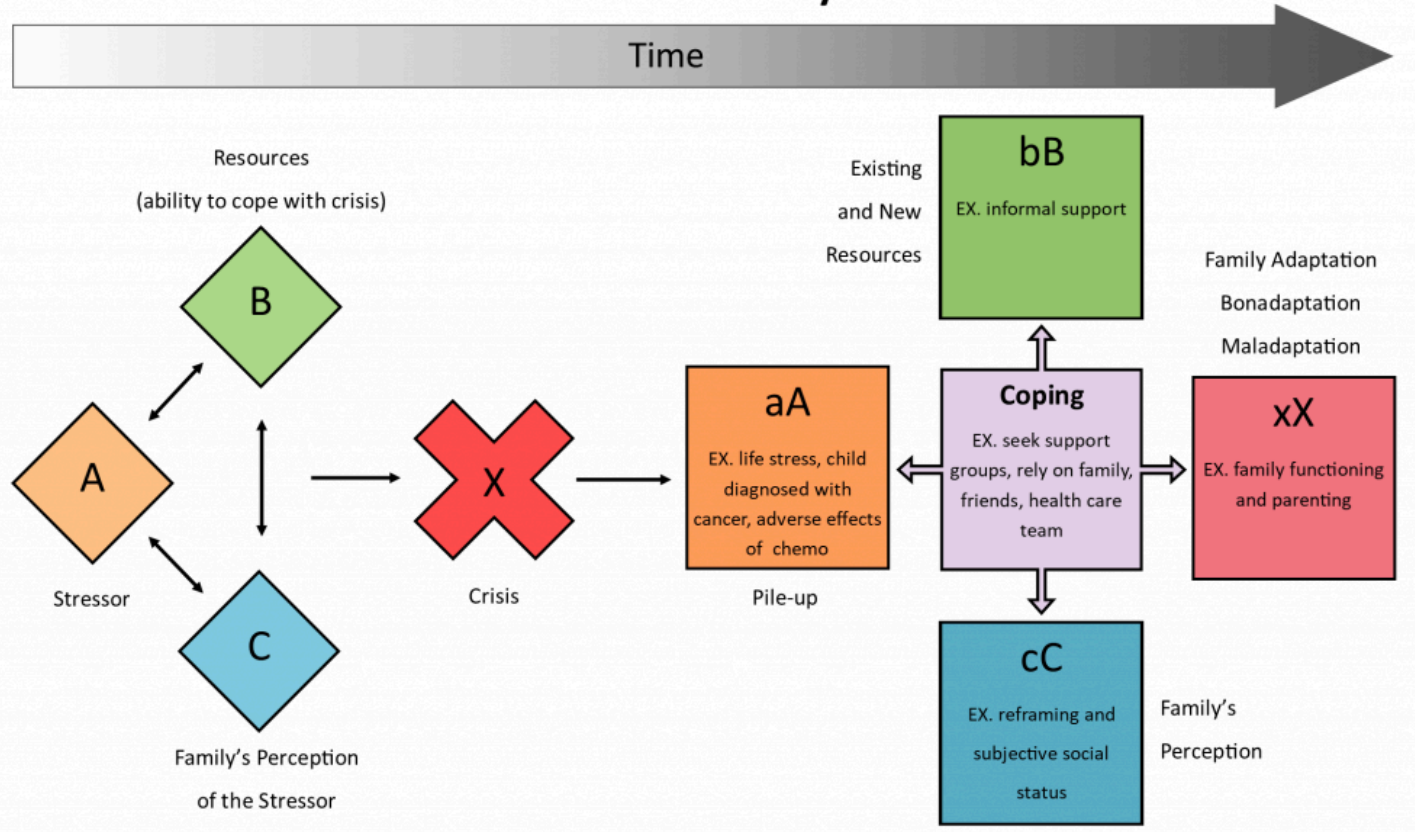

Figure 1. The image above is an adaptation of the ABC-X model by McCubbin, H. I., \& Patterson, J. M. (1983). The family stress process: The Double ABCX Model of family adjustment and adaptation. In H. I. McCubbin, M. Sussman, \& J. M. Patterson (Eds.), Social stress and the family: Advances and developments in family stress theory and research (pp. 7-37). Haworth.

The Double $\mathrm{ABC}-\mathrm{X}$ model describes the impact of crises on a family. It states that the combination of stressors (A), the family's resources (B), and the family's definition of the event (C) will produce the family's experience of a crisis $(\mathrm{X}) .{ }^{12}$

1. McCubbin, H. I., \& Patterson, J. M. (1983). The family stress process: The Double ABCX Model of family adjustment and adaptation. In H. I. McCubbin, M. Sussman, \& J. M. Patterson (Eds.), Social stress and the family: Advances and developments in family stress theory and research (pp. 7-37). Haworth.

2. The Double ABCX Stress Model section is an adaptation of Family Theories: A New Direction for Research with Resettled Populations by Jaime Ballard, Elizabeth Wieling, and Catherine Solheim, used under a CC BY NC license. 


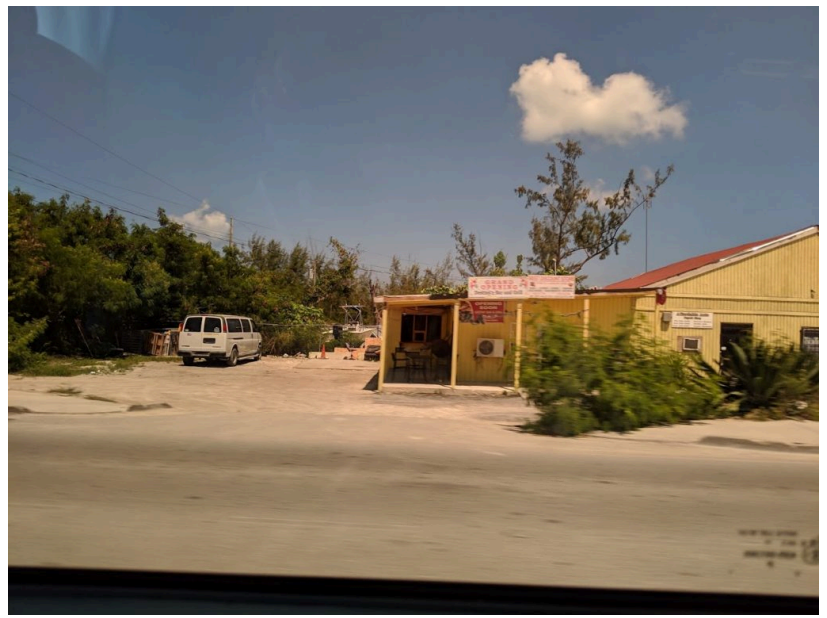

Figure 2. An impoverished home along a roadside.
The family's multiple environments influence each component of the model, consistent with the human ecology framework. The Double ABC-X suggests that there are multiple paths of recovery following a crisis, and these paths will be determined by the family's resources and coping processes, both personal and external.

This model is relevant to families that come from another country (e.g., those who self-identify as immigrant or refugee) and live in a new country, as many families experience significant transitions in the process of resettlement. Whether or not this transition, or the events that precipitate it, are interpreted as crises will depend on the family's other stressors, such as employment, housing, healthcare, and family conflict; family meaning-making,(cultural and family values), and resources (socioeconomic, family support, community).

\section{Key Takeaway}

- The Double ABC-X Model describes how a crisis affects a family using environmental and biological perspectives.

\section{(ㅇ) (1) (\$)}

The Double ABC-X Model of Family Stress by Jaime Ballard; Elizabeth Wieling; Catherine Solheim; and Diana Lang is licensed under a Creative Commons Attribution-NonCommercial 4.0 International License, except where otherwise noted. 


\title{
FAMILY SYSTEMS THEORY
}

\author{
Diana Lang
}

The Family Systems Theory assumes that a family is understood best by examining the family as one whole system. This one system is a complex, deeply-connected changing collection of parts, subsystems and family members, where each member has a known purpose or function. ${ }^{1}$

Other key concepts within the Family Systems Theory include:

- boundaries (e.g., who is a member of the system),

- equilibrium (e.g., during stressors or crises, the system attempts to return to its original state wherein members are functional and comfortable), and

- bidirectional (e.g., a change with one member will impact at least one other member, and hence impact the whole system).

Based on this theory, individuals experiencing a crisis or problem are best-served by assessments that include other members of the system as opposed to examining only one family member. ${ }^{2}$

This theory also assumes that families can examine their own processes and set deliberate goals. Change can occur when a family system acknowledges that a particular family pattern is dysfunctional and identifies new processes that support the family's goals. Resettlement is one example of a large change that a family system may choose or be forced to make.

1. Hammond, R., Cheney, P., \& Pearsey, R. (2015). Sociology of the Family Textbook. Rocky Ridge Press. http://freesociologybooks.com/.

2. Bowen, M. (1978). Family therapy in clinical practice. Jason Aronson. 


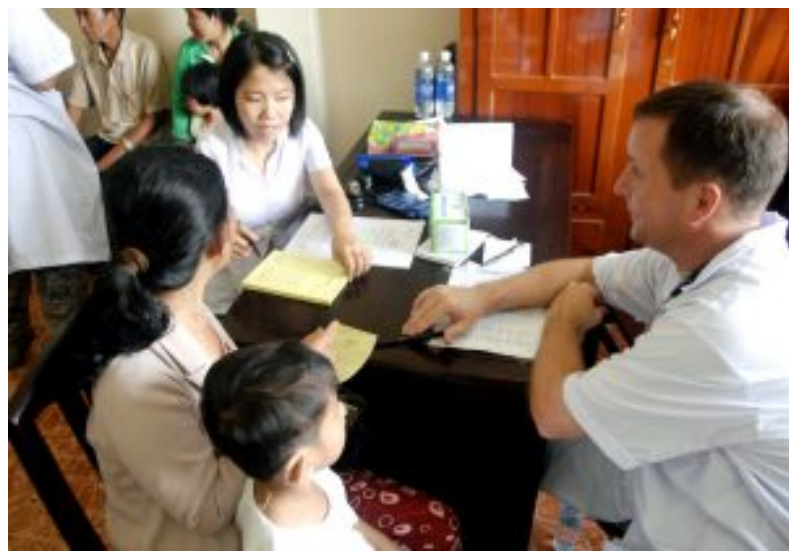

Figure 1. Doctors ask patients medical questions during a visit to a family practice clinic in Vietnam. (Photo Source: U.S. Air Force photo/Capt. Timothy Lundberg)

system level. ${ }^{4}$
In order to assess patterns of adjustment in families that have resettled into a new country, we must examine the structure of the family unit and the processes that occur within that family system.

For example, one study collected data from parents and their children who immigrated to the United States from Vietnam and Cambodia to assess the role of family processes in disagreements over cultural values. The researchers found that cultural clashes were linked to parent-child conflict, which in turn was linked to reduced parent-child bonding, both of which increase adolescent behavioral problems. ${ }^{3}$ This demonstrates one family pattern related to resettlement that is best understood at the family

\section{Key Takeaways}

- A family is a whole, complex, single system; each member's behaviors can impact another member.

- Key concepts-boundaries, equilibrium, bidirectional, patterns, roles, and functions.

3. Choi, Y., He, M., \& Harachi, T. W. (2008). Intergenerational cultural dissonance, family conflict, parent-child bonding, and youth antisocial behaviors among Vietnamese and Cambodian immigrant families. Journal of Youth and Adolescence, 37(1), 85-96.

4. This text is taken from Family Theories: A New Direction for Research with Resettled Populations by Jaime Ballard, Elizabeth Wieling, Lekie Dwanyen, and Catherine Solheim, used under a CC BY NC 4.0 license. 


\title{
SYSTEMIC FAMILY DEVELOPMENT THEORY
}

\author{
Diana Lang
}

The Systemic Family Development Theory asserts that families are (a) complex, (b) extremely diverse related to the types, numbers, and timing of transitions and stressors, and (c) multigenerational systems. It also assumes that

families share common processes through their development, but the processes must take into account intergenerational influences and variations within and between all families. No two families are alike. ${ }^{1}$

Many studies have shown that patterns of family interactions are similar within families across generations. ${ }^{2}$ Intergenerational transmissions of conflict, trauma, communication styles, parenting practices, etc., continue to be examined.

The following genogram (a pictorial display of

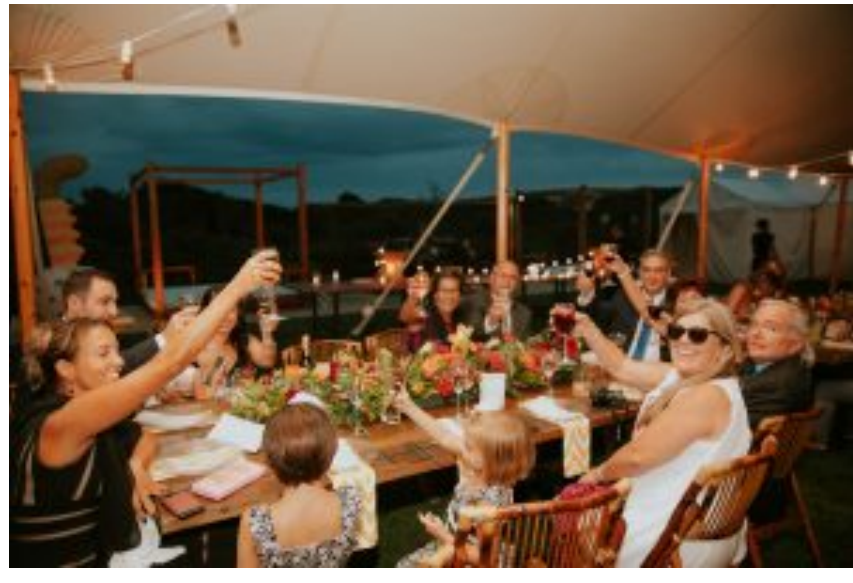

Figure 1. Extended family members of multiple generations celebrating at an event. (Photo Source: Lee Hnetinka, Pexels License) family relationships and medical history) shows relationship patterns across generations within a family.

1. Laszloffy, T. A. (2002). Rethinking family development theory: Teaching with the Systemic Family Development (SFD) Model. Family Relations, 51(3), 206-214.

2. Kovan, N. M., Chung, A. L., \& Sroufe, L. (2009). The intergenerational continuity of observed early parenting: A prospective, longitudinal study. Developmental Psychology, 45(5), 1205-1213.

3. Conger, R. D., Belsky, J., \& Capaldi, D. M. (2009). The intergenerational transmission of parenting: Closing comments for the special section. Developmental Psychology, 45(5), 1276-1283. 


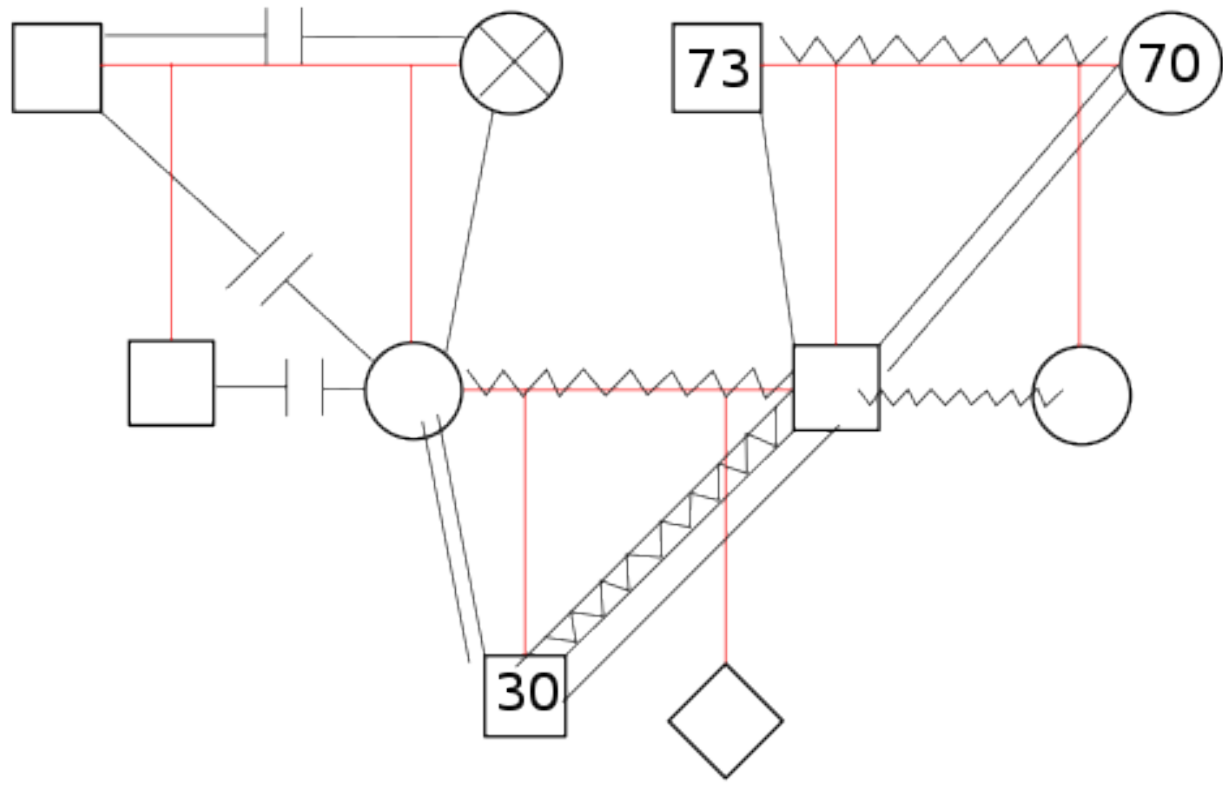

Figure 2. A genogram, a family tree that displays connections and relationships with more detail (Image Source: Wikimedia Commons, CC BY SA)

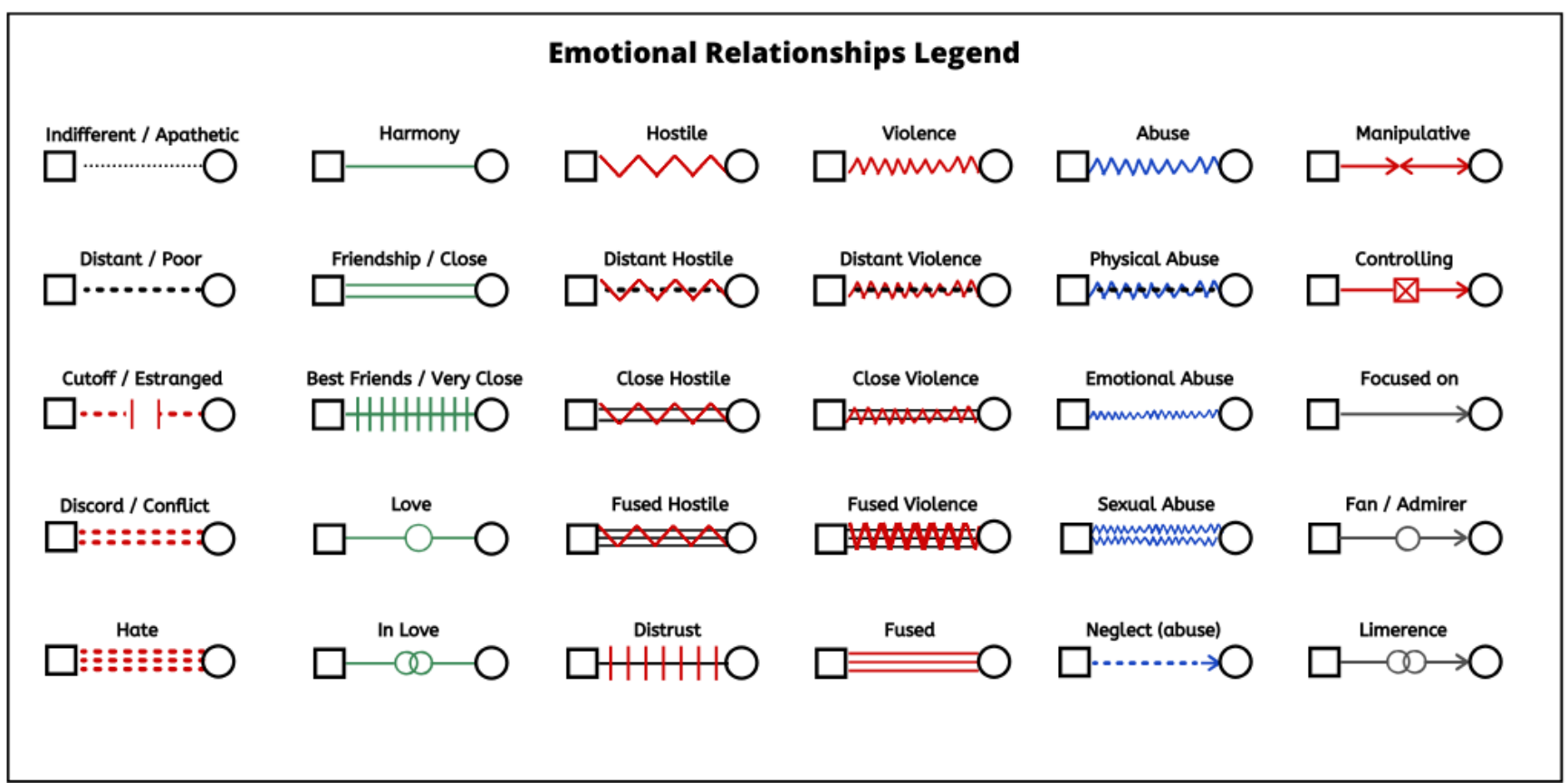

Figure 3. This legend explains what different kinds of connectors in a genogram represent. 


\section{Key Takeaways}

- Families are complex, diverse, and multigenerational.

- Families share common processes through their development, but there are intergenerational influences and variations between the number and types of crises, transitions, and stressors.

- Family interactions are typically similar across generations (intergenerational). 


\section{FAMILY DEVELOPMENT THEORY}

\section{Diana Lang}

\section{Duvall's Family Development Theory}

According to Duvall's Family Development Theory (1988), families move through stages in a particular order across time after members successfully master tasks for each stage. ${ }^{1}$

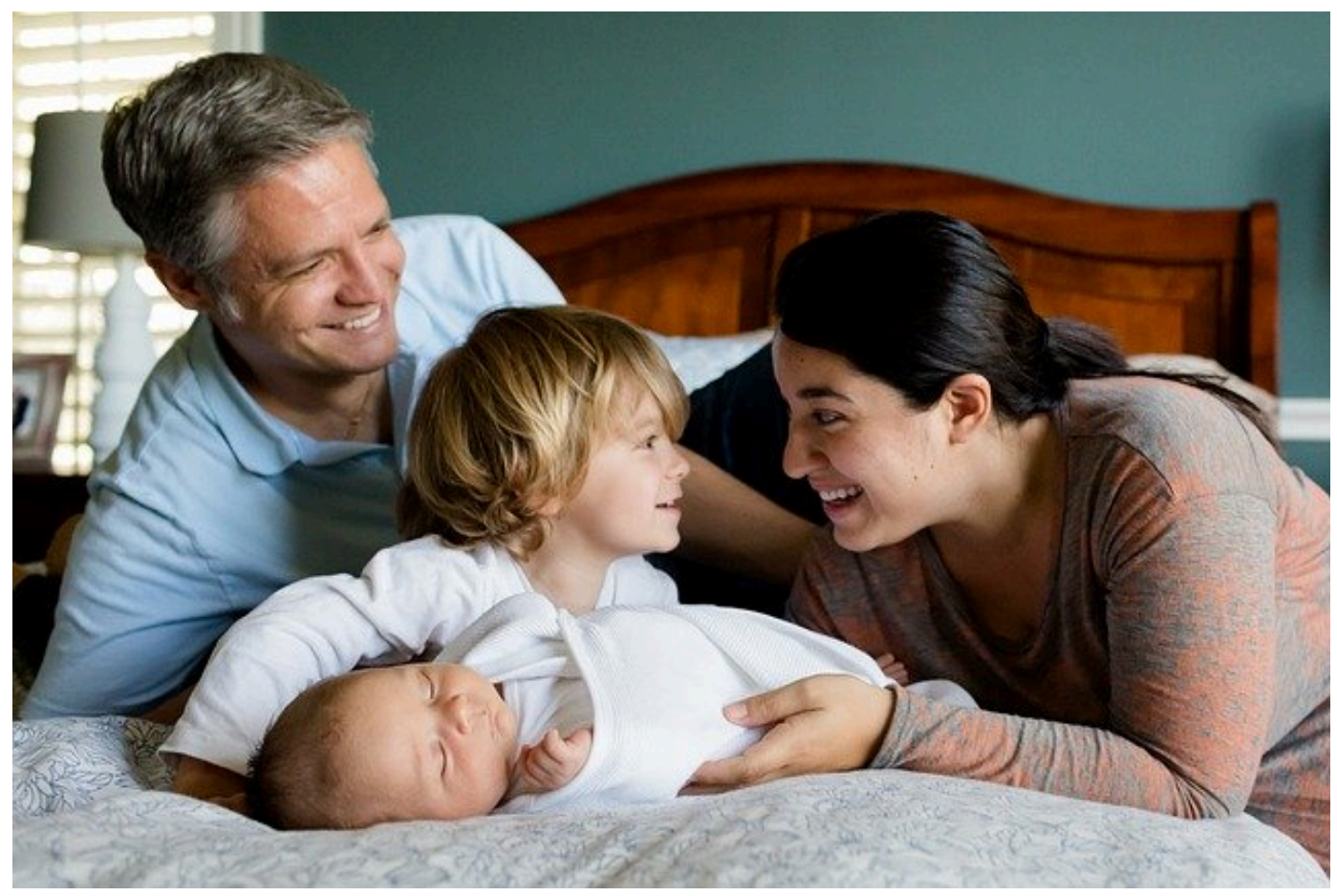

Figure 1. A set of parents smile at their toddler and new baby. (Photo Source: Pixabay)

This theory was different from other theories during this time because:
"(a) its family life cycle dimension that provides a basis for study of families over time; (b) its emphasis on the developmental tasks of individual family members and of families at every stage of their development; (c) its built-in recognition of family stress at critical periods in development; and (d) its recognition ever since 1947 of the need for services, supports, and programs for families throughout their family life cycles."2 
It is important to note that this theory is based on the traditional, nuclear, intact family, which is evidenced by the following stages: ${ }^{3}$

Table 1. Stages and tasks of family development

STAGE

\section{Married couple without children}

Childbearing families with the oldest child between birth and 30 months.

Families with preschool children.

Families with school-age children.

Families with adolescents.

Launching families (first to last child is leaving home).

Middle-age families ("empty/spacious nest" to retirement).

Aging families (retirement to death of both spouses).

\section{TASKS}

Navigating how to live together.

Adjusting relationships with families-of-origin and social networks to include a partner.

Preparing and adjusting the family system to accommodate children.

Developing roles as parents.

Redefining roles with extended families.

Socializing, educating and guiding children.

Assessing and adjusting parenting roles as children age and more children join the family.

Providing guidance to children while collaborating with outside resources (e.g., school, extracurricular activities).

Adjusting parent-child relationships with adolescents to provide more independence with safe limits.

Tending to parents' midlife relationship and career issues.

Navigating adult-to-adult relationships with children.

Resolving midlife issues.

Caring for aging family members.

Adjusting to being a couple without children living at home. Caring for aging family members.

Learning new roles related to retirement, becoming grandparents, losing a partner, and health-related changes.

3. Laszloffy, T. A. (2004). Rethinking family development theory: Teaching with the Systematic Family Development (SFD)

Model. Family Relations, 51(3), 206-214. 


\section{Key Takeaways}

- Duvall's theory is based on the traditional, nuclear, intact family.

- Families will move through each stage in order across time.

- A family will move from one stage to the next after all members successfully master the tasks within a stage. 
PART IV

PARENTING STYLES 


\title{
BAUMRIND'S PARENTING STYLES
}

\author{
Joel A Muraco; Wendy Ruiz; Rebecca Laff; Ross Thompson; and Diana Lang
}

\section{Diana Baumrind's Parenting Styles}

The parenting style used to rear a child will likely impact that child's future success in romantic, peer and parenting relationships. Diana Baumrind, a clinical and developmental psychologist, coined the following parenting styles: authoritative, authoritarian, and permissive/indulgent, Later, Maccoby and Martin added the uninvolved/neglectful style. ${ }^{1}$

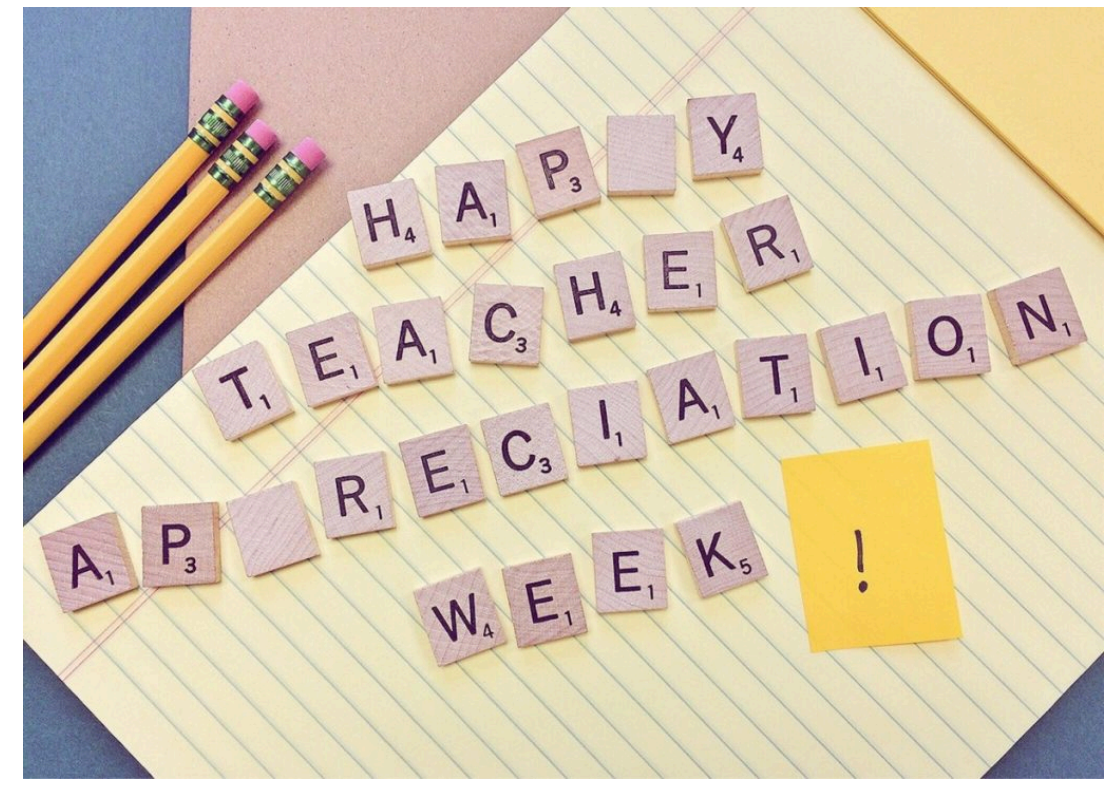

Figure 1. Like effective teaching, effective parenting requires a mix of authoritative and considerate responses to a child's needs. This balance can lead to more appreciative child behavior.

It is beneficial to evaluate the support and demandingness of a caregiver in order to determine which style is being used and how to effectively use it. Support refers to the amount of affection, acceptance, and warmth a parent provides to a child. Demandingness refers to the degree a parent controls a child's behavior.

1. Baumrind's Parenting Styles is an adaptation of Child, Family, and Community (Chapter 6: A Closer Look at Parenting) by Laff \& Ruiz (2019), licensed CC BY 4.0 and Social and Personality Development in Childhood by Ross Thompson, licensed CC BY NC $\underline{\text { SA. }}$ 


\section{Authoritative Parenting}

In general, children tend to develop greater competence and self-confidence when parents have high-but reasonable and consistent- expectations for children's behavior, communicate well with them, are warm and responsive, and use reasoning rather than coercion to guide children's behaviors. This kind of parenting style has been described as authoritative. ${ }^{2}$ Parents who use this style are supportive and show interest in their kids' activities but are not overbearing and allow children to make constructive mistakes. This "tender teacher" approach deemed the most optimal parenting style to use in western cultures. Children whose parents use the authoritative style are generally happy, capable, and successful. ${ }^{3}$

\section{Authoritarian Parenting}

Parents using the authoritarian ("rigid ruler") approach are low in support and high in demandingness. These parents expect and demand obedience because they are "in charge" and they do not provide any explanations for their orders. ${ }^{4}$ Parents also provide well-ordered and structured environments with clearly stated rules.

Many would conclude that this is the parenting style used by Harry Potter's harsh aunt and uncle, and Cinderella's vindictive stepmother. Children reared in environments using the authoritarian approach are more likely to be obedient and proficient, but score lower in happiness, social competence, and self-esteem.

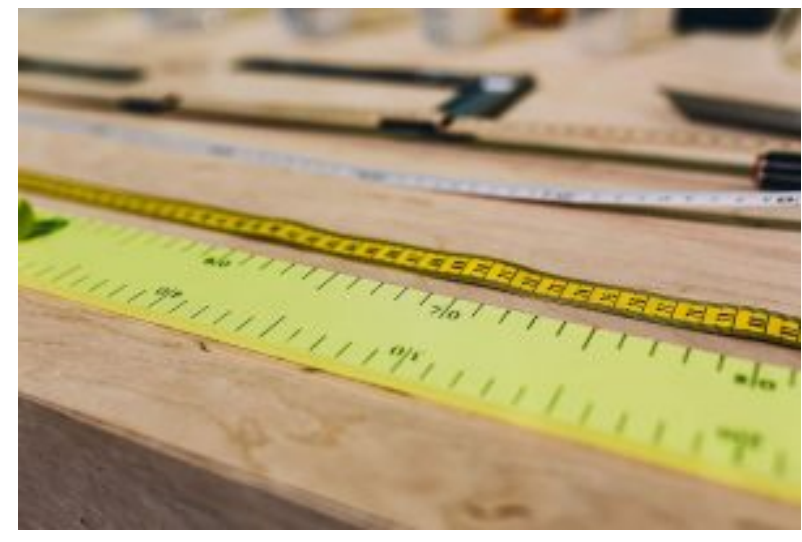

Figure 2. Authoritarian parenting called "rigid ruler" in part because wooden rulers were often used for capital punishment in the 20th century.

\section{Permissive Parenting}

Parents who are high in support and low in demandingness are likely using the permissive-also

2. Baumrind, D. (2013). Authoritative parenting revisited: History and current status. In R. E. Larzelere, A. Sheffield, \& A. W. Harrist (Eds.), Authoritative parenting: Synthesizing nurturance and discipline for optimal child development. Washington, DC: American Psychological Association.

3. Maccoby, E. E. (1992). The role of parents in the socialization of children: An historical overview. Developmental Psychology, 28(6), 1006-1017.

4. Baumrind, D. (1991). Parenting styles and adolescent development. In J. Brooks-Gunn, R. M. Lerner, \& A. C. Petersen (Eds.), The encyclopedia on adolescence (pp. 746-758). New York: Garland Publishing. 
called the indulgent-style. Their children tend to rank low in happiness and self-regulation, and are more likely to have problems with authority. Parents using this approach are lenient, do not expect their children to adhere to boundaries or rules, and avoid confrontation. ${ }^{5}$

\section{Uninvolved Parenting}

Children reared by parents who are low in both support and demandingness tend to rank lowest across all life domains, lack self-control, have low self-esteem, and are less competent than their peers. Parents using the uninvolved (or sometimes referred to as indifferent or neglectful) approach are neglectful or rejecting of their children and do not provide most, if any, necessary parenting responsibilities.

\section{Video Example}

Watch this video about Baumrind's parenting styles.

\section{Parenting Styles and Outcomes for Children}

Parenting style has been found to predict child well-being in the domains of social competence, academic performance, psychosocial development, and problem behavior. Research in the United States, based on parent interviews, child reports, and parent observations consistently finds:

- Children and adolescents whose parents use the authoritative style typically rate themselves and are rated by objective measures as more socially and instrumentally competent than those whose parents do not use the authoritative style. ${ }^{6} 8$

- Children and adolescents whose parents are uninvolved typically perform most poorly in all domains.

5. Baumrind, D. (1991). Parenting styles and adolescent development. In J. Brooks-Gunn, R. M. Lerner, \& A. C. Petersen (Eds.), The Encyclopedia on Adolescence (pp. 746-758). New York: Garland Publishing.

6. Baumrind, D. (1991). The influence of parenting style on adolescent competence and substance use. Journal of Early Adolescence, 11(1), 56-95.

7. Weiss, L. H., \& Schwarz, J. C. (1996). The relationship between parenting types and older adolescents' personality, academic achievement, adjustment, and substance use. Child Development, 67(5), 2101-2114. EJ 539840.

8. Miller, N. B., Cowan, P. A., Cowan, C. P., \& Hetherington, E. M. (1993). Externalizing in preschoolers and early adolescents: A cross-study replication of a family model. Developmental Psychology, 29(1), 3-18. EJ 461700. 
In general, parental responsiveness tends to predict social competence and psychosocial functioning, while parental demandingness is typically associated with instrumental competence and behavioral control (e.g., academic performance and deviance). These findings indicate:

- Children and adolescents reared in households using the authoritarian style (high in demandingness, but low in responsiveness) tend to perform moderately well in school and be uninvolved in problem behavior, but tend to have poorer social skills, lower self-esteem, and higher levels of depression when compared to their peers who are reared in households using the authoritative approach.

- Children and adolescents reared in homes using the indulgent style (high in responsiveness, low in demandingness) tend to be more involved in problem behavior and perform less well in school, but they have been shown to have higher self-esteem, better social skills, and lower levels of depression when compared to their peers who are not reared using the indulgent style. ${ }^{9}$

Table 1. Four parenting styles. Other, less advantageous parenting styles include authoritarian (in contrast to authoritative), permissive, and uninvolved.

\begin{tabular}{lll}
\hline & \multicolumn{1}{c}{ Support (Low) } & \multicolumn{1}{c}{ Support (High) } \\
Demand (Low) & Uninvolved & Permissive \\
Demand (High & Authoritarian & Authoritative \\
\hline
\end{tabular}

In reviewing the literature on parenting styles, it is apparent that using the authoritative parenting style is associated with both instrumental and social competence and lower levels of problem behavior at all developmental stages for youth in the United States. The benefits of using the authoritative parenting style and the detrimental effects of the uninvolved parenting style are evident as early as the preschool years and continue throughout adolescence and into early adulthood.

\section{Support for Baumrind's Authoritative Parenting}

Support for the benefits of authoritative parenting has been found in countries as diverse as the

9. Darling, N. (1999). Parenting style and its correlates. ERIC digest. Retrieved from https://www.ericdigests.org/1999-4/ parenting.htm 
Czech Republic, ${ }^{10}$ India, ${ }^{11}$ China, ${ }^{12}$ Israel, ${ }^{13}$ and Palestine. ${ }^{14}$ In fact, authoritative parenting appears to be superior in Western, individualistic societies-so much so that some people have argued that there is no longer a need to study it. ${ }^{15}$

Other researchers are less certain about authoritative parenting and point to differences in cultural values and beliefs. For example, while many children reared in European-American cultures fare poorly with too much strictness (authoritarian parenting), children reared in Chinese cultures often perform well, especially academically. The reason for this likely stems from Chinese culture viewing strictness in parenting as related to training, which is not central to American parenting beliefs. ${ }^{16}$

As children mature, parent-child relationships should naturally adapt to accommodate developmental changes. Parent-child relationships that do not adapt to a child's abilities can lead to high parent-child conflict and ultimately a reduced parent-child relationship quality. ${ }^{17}$

\section{Key Takeaways}

\section{(๑)(1) ( ()}

10. Dmitrieva, J., Chen, C., Greenberger, E., \& Gil-Rivas, V. (2004). Family relationships and adolescent psychosocial outcomes: Converging findings from Eastern and Western cultures. Journal of Research on Adolescence, 14, 425-447.

11. Carson, D., Chowdhurry, A., Perry, C., \& Pati, C. (1999). Family characteristics and adolescent competence in India: Investigation of youth in southern Orissa. Journal of Youth and Adolescence, 28, 211-233.

12. Pilgrim, C., Luo, Q., Urberg, K.A., \& Fang, X. (1999). Influence of peers, parents, and individual characteristics on adolescent drug use in two cultures. Merril-Palmer Quarterly, 45, 85-107.

13. Mayseless, O., Scharf, M., \& Sholt, M. (2003). From authoritative parenting practices to an authoritarian context: Exploring the person-environment fit. Journal of Research on Adolescence, 17, 23-50.

14. Punamaki, R., Qouta, S., \& Sarraj, E. (1997). Models of traumatic experiences and children's psychological adjustment: The roles of perceived parenting and the children's own resources and activity. Child Development, 68, 718-728.

15. Steinberg, L. (2001). We know some things: Adolescent-parent relationships in retrospect and prospect. Journal of Research on Adolescence, 11, 1-19.

16. Chao, R. K. (1994). Beyond parental control and authoritarian parenting style: Understanding Chinese parenting through the cultural notion of training. Child Development, 65, 1111-1119.

17. Support for Baumrind's Authoritative Parenting is taken from The Family by Joel A Muraco, licensed CC BY NC SA. 
Baumrind's Parenting Styles by Joel A Muraco; Wendy Ruiz; Rebecca Laff; Ross Thompson; and Diana Lang is licensed under a Creative Commons Attribution-NonCommercial-ShareAlike 4.0 International License, except where otherwise noted. 


\section{ADDITIONAL PARENTING STYLES}

\section{Diana Lang}

Researchers have identified additional parenting approaches that are not applicable to Baumrind's styles, definitions, or outcomes. Below is an overview of three of these approaches-overindulgent parenting, helicopter parenting, and traditional parenting.

\section{Overindulgent Parenting}

Overindulgent parenting is providing children with too much of what "looks good, too soon, too long." Oftentimes, it appears that parents implement these strategies to fulfill their own unmet needs or feelings of neglect from their own childhood.

Examples include giving children an overabundance of:

- things or experiences that are not developmentally appropriate for the child,

- family resources that appear to meet the child's needs but do not,

- anything that actively harms or prevents a child from developing and achieving one's full potential, and

- freedom with minimal boundaries and limits that are developmentally-inappropriate for the child. $^{2}$

\section{Risks of Overindulgence}

To learn 12 risks of overindulging a child, visit the Overindulgence website's Resources for Parents page.

1. Clarke, J. I., Dawson, C., \& Bredehoft, D. (N.D.). Definition of childhood overindulgence. http://www.overindulgence.org/howmuch-is-too-much/what-is-overindulgence.html.

2. Clarke, J. I., Dawson, C., \& Bredehoft, D. (N.D.). Raising likeable, responsible, respectful children in an age of overindulgence. http://overindulgence.org/. 


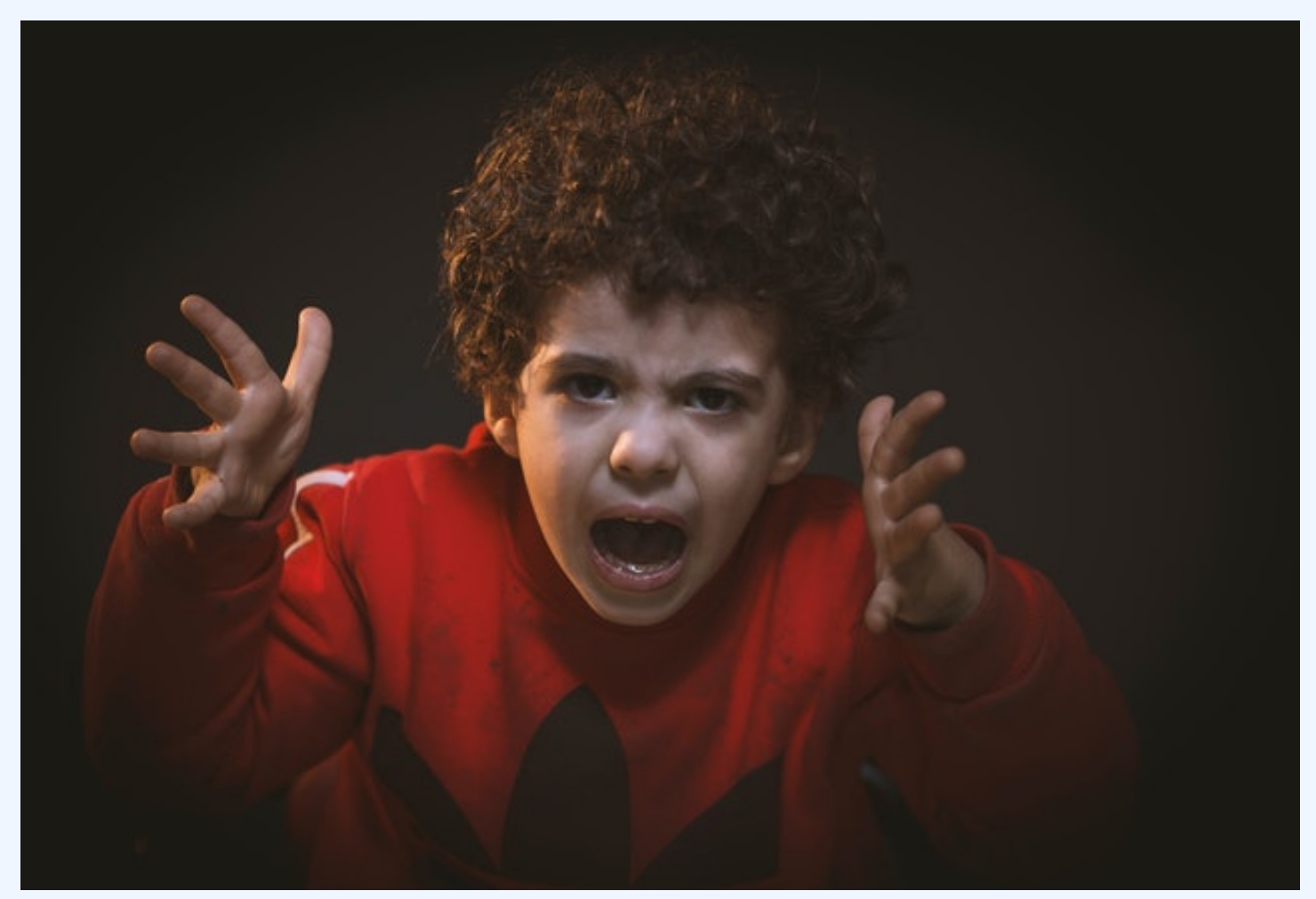

Figure 1. An overindulged child might become prone to outbursts or tantrums when faced with limitations (Photo Source: Mohamed Abdelgaffar on Pexels)

Many negative outcomes have been linked to overindulgent parenting, which include, but are not limited to, children who exhibit:

1. extreme self-centeredness,

2. excessive degrees of a sense of entitlement,

3. poor decision-making and coping skills, and

4. stifled developmental growth as a result of not experiencing or learning "necessary" life lessons. 


\section{Video Example}

Learn more in this short video about overindulgent parenting.

\section{Helicopter Parenting}

Helicopter parenting is characterized by caregivers who are extremely overinvolved in their child's life due to the belief that they can protect their child's physical and/or emotional well-being. Caregivers using this approach appear overbearing and overprotective due to the close attention they pay to all of their child's problems and successes. Parents "hover overhead" by constantly overseeing or being excessively interested in every aspect of their child's life. Some contend that cell phones are "the world's longest umbilical cord" which is contributing to this phenomenon. ${ }^{3}$ 


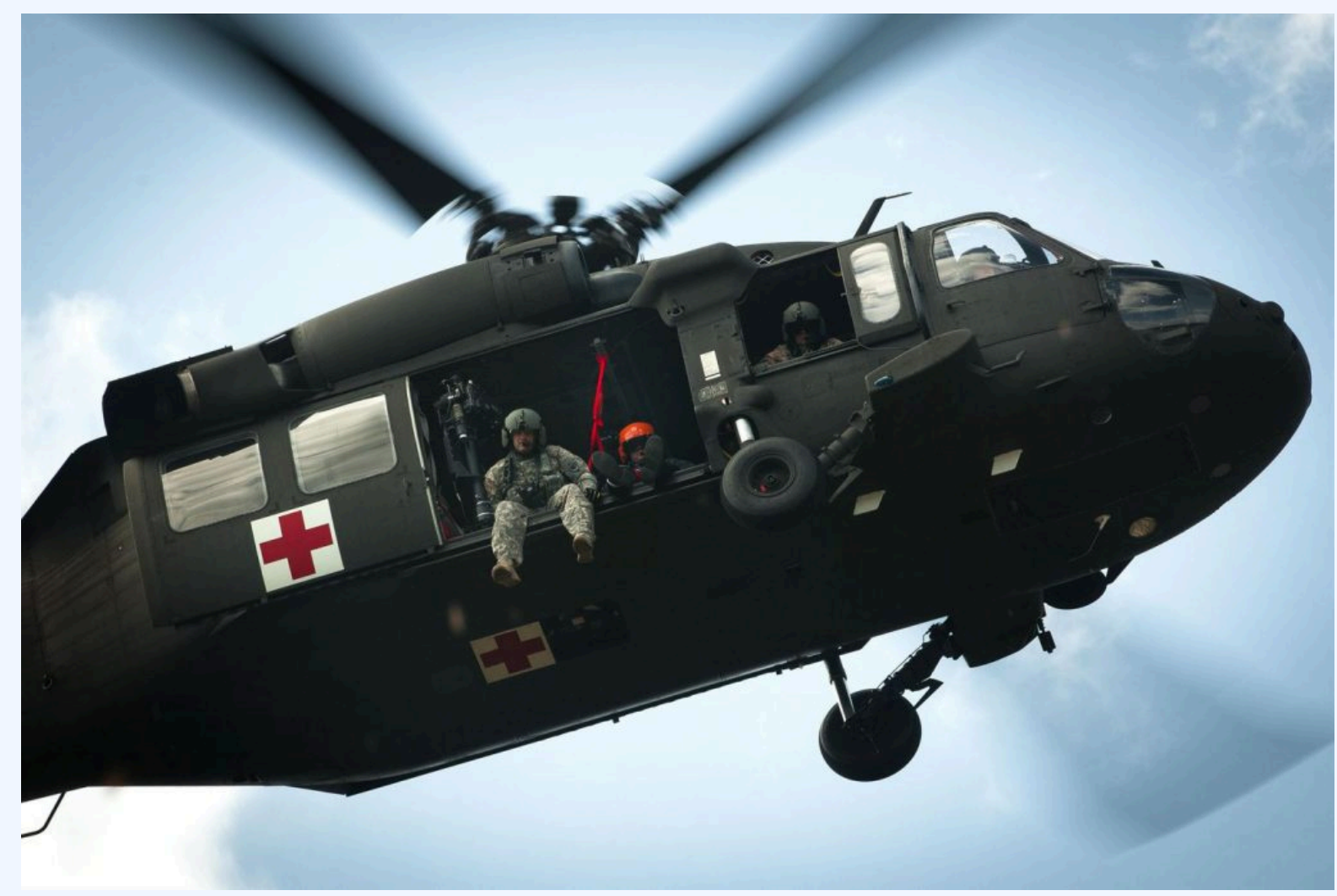

Figure 2. Helicopter parents don't literally ride in helicopters, but their hovering, overwatch mentality is similar. (Photo Source: Army Staff Sgt. Roberto Di Giovine)

Many negative outcomes have been linked to helicopter parenting, which may include, but are not limited to, children and adults who exhibit:

1. stifled developmental growth as a result of not experiencing or learning "necessary" life lessons,

2. long-term mental health problems,

3. rebellious behaviors in adolescence, ${ }^{4}$ and

4. a lack of independence coupled with poor decision-making, motivational, and coping skills. ${ }^{5}$

4. Wallace, M., Weybright, E., Rohner, B., \& Crawford, J. (2015). Over-involved parenting and competition in youth development programs. Washington State University Extension. http://pubs.cahnrs.wsu.edu/publications/pubs/fs $179 \mathrm{e} /$.

5. Helicopter Parenting by Diana Lang is an adaptation of Helicopter Parent by Wikimedia Foundation contributors, licensed CC BY SA. 


\section{Traditional Parenting Style}

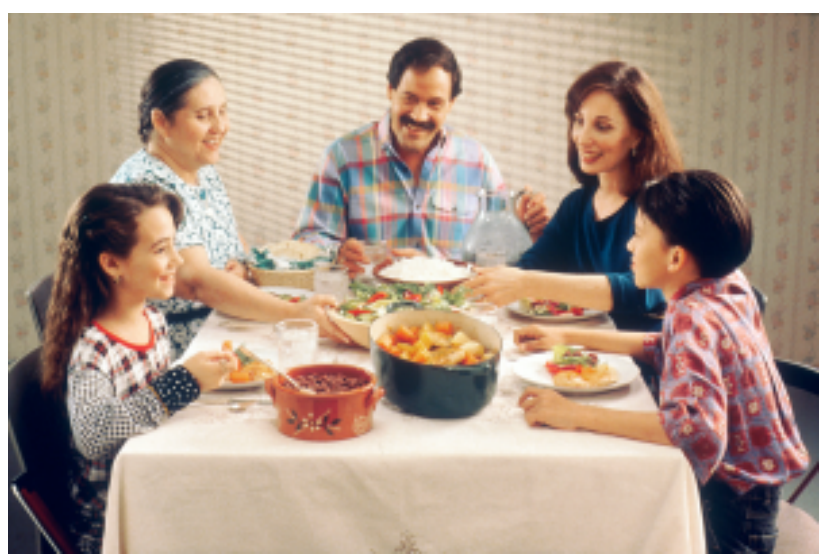

Figure 3. A family eating a large meal. (Photo Source: National Cancer Institute)
The traditional parenting style is more commonly used in families with non-Western cultural values. Parents using this approach expect their children to respect and obey authority (e.g., parents, elders, etc.) and comply with their cultural beliefs and values without questions. Parents using this approach are high in demandingness, warmth, and responsiveness, similar to the authoritative approach, however, they do not engage in democratic discussions. ${ }^{6}$ This style was created because many parenting styles in non-Western cultures do not meet the criteria for authoritarian (due to expressing warmth) or authoritative (due to

lack of communication).

For example, many families who self-identify as Asian Americans and Latino Americans engage in high demandingness and expect respect and obedience of their children. However, these caregivers also value closeness and love which is different from the authoritarian parenting style. Adolescents who grow up in families using traditional parenting style characteristics tend to show higher academic achievements and lower behavioral and psychological problems when compared to their peers who are reared by caregivers using the authoritarian approach. These positive outcomes may be related to the closeness and love shown to children, which is different from the "cold" or "distant" characteristics consistent with the authoritarian style. ${ }^{7}$ Additional, less-researched parenting styles are listed below.

6. Chao, R. K. (2001). Extending Research on the Consequences of Parenting Style for Chinese Americans and European Americans. Child Development, 72(6), 1832-1843. doi:10.1111/1467-8624.00381

7. Chao, R. K. (2001). Extending Research on the Consequences of Parenting Style for Chinese Americans and European Americans. Child Development, 72(6), 1832-1843. doi:10.1111/1467-8624.00381 
Table 1. Lemasters and Defrain Parenting Styles 8

\begin{tabular}{lll}
\hline Style & Description & Possible Outcomes \\
\hline Martyr & $\begin{array}{l}\text { Will do anything for the child; even tasks that the child should } \\
\text { do for himself or herself; may use all they do for the child to } \\
\text { guilt the child into compliance }\end{array}$ & $\begin{array}{l}\text { Child learns to be } \\
\text { dependent and } \\
\text { manipulative }\end{array}$ \\
\hline Pal & $\begin{array}{l}\text { Wants to be the child's friend; lets children do what they want } \\
\text { and focuses mostly on being entertaining and fun; sets few limits }\end{array}$ & $\begin{array}{l}\text { Child may have little } \\
\text { self-discipline and } \\
\text { may try to test limits } \\
\text { with others }\end{array}$ \\
\hline $\begin{array}{l}\text { Police officer/drill } \\
\text { sergeant }\end{array}$ & $\begin{array}{l}\text { Focuses primarily on making sure that the child is obedient and } \\
\text { that the parent has full control of the child; may scold or punish } \\
\text { child for not doing things right; struggles to allow child to grow } \\
\text { and learn to make decisions independently }\end{array}$ & $\begin{array}{l}\text { Child may have a lot } \\
\text { of resentment } \\
\text { toward parent that is } \\
\text { displaced on others }\end{array}$ \\
\hline Teacher-counselor & $\begin{array}{l}\text { Pays a lot of attention to expert advice on parenting and who } \\
\text { believes that as long as all of the steps are followed, the parent } \\
\text { can rear a perfect child }\end{array}$ & $\begin{array}{l}\text { Puts all responsibility } \\
\text { of outcomes on } \\
\text { parent }\end{array}$ \\
\hline \multirow{2}{*}{$\begin{array}{l}\text { Helps the child understand what needs to happen in certain } \\
\text { situations and encourages and advises the child about how to } \\
\text { manage these situations; does not intervene or do things for the } \\
\text { child; sets consistent and objective rules }\end{array}$} & $\begin{array}{l}\text { Child is supported } \\
\text { and guided while } \\
\text { they learn firsthand } \\
\text { how to handle } \\
\text { situations }\end{array}$ \\
\hline
\end{tabular}

\section{The Danish Way of Parenting}

- To learn about the Danish way of parenting, visit thedanishway.com.

- To learn about how the "Danish" way of parenting differs from the "American" way of parenting, read this article about Danish parenting styles. 


\section{Key Takeaways}

- Overindulgent parenting is when parents over-provide things which are typically not developmentally-appropriate for their child.

- This style of parenting can result in the child having poor decision-making and coping skills and being highly self-centered.

- Helicopter parenting is when parents are over-involved in their child's life, many times as a way to protect their child.

- This style can result in the child lacking independence, having poor decision-making and coping skills, etc.

- Traditional parenting is when parents expect their children to respect and obey authority, as well as comply with their cultural beliefs and values.

- This style of parenting can result in higher academic achievements and lower behavioral and psychological problems. 
PART V

CHILD-REARING STRATEGIES 


\section{CHILD-REARING AND GUIDANCE}

\section{Diana Lang}

Parents and caregivers have a responsibility to guide and promote positive socialization strategies for children in their care. These activities are known as discipline or guidance-two words that are often used interchangeably in parenting education. Discipline is defined as "ongoing teaching and nurturing that facilitates self-control, self-direction, competence, and care for others". ${ }^{1}$ It is recommended that caregivers utilize a comprehensive disciplinary approach for guiding children's behaviors.

Caregivers should proactively teach children how to regulate their own behaviors by using age- and developmentally-appropriate strategies that enhance:

- positive, supportive, and nurturing caregiverchild relationships,

- safety, permanency, and consistency,

- acceptable behavioral patterns by removing reinforcements to eliminate undesired behaviors and providing positive reinforcements to strengthen desired behaviors, and

- cognitive, socioemotional, and executive functioning skills.

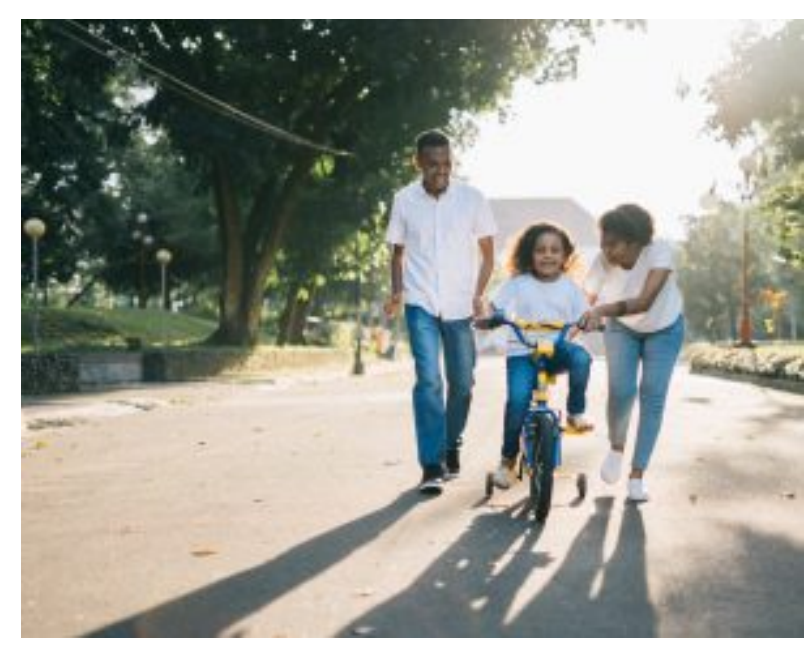

Figure 1. A family teaching a child to ride a bicycle with support. (Photo Source: Agung Pandit Wiguna, Pexel License)

For optimal outcomes, all of the above components must consistently function well in an individualized manner for each child, and within the context of youth, feeling loved, safe, and secure. Recommended child-rearing strategies are outlined in upcoming pages. 


\section{Examples}

Examples of caregivers' guidance by stage:

- Newborns: recognize and respond flexibly to infant's needs while providing generally structured daily routines.

- Infants and toddlers: use limitations, protection, and structure to create safe spaces for play and exploration.

- Early childhood: utilize creative and individualized strategies to guide children's desirable behavior patterns to become their "typical interactions".

- School-age: increase children's own responsibility for self-control via the integration of previouslydeveloped internalized rules of conduct.

- Adolescence: change strategies to foster more autonomy, self-regulation, and responsibility while guiding teens' safety and positive decision-making skills.

For more information about positive parenting strategies by ages and stages, visit the $\underline{C D C}$ website. 


\section{ACTIVE LISTENING}

\section{Diana Lang}

Active listening is a type of communication strategy between two or more people that consists of paying attention to what someone is saying and attempting to understand what is being said.

Clinical research studies demonstrate that active listening can be a catalyst in one's personal growth. For example, children are more likely to listen to themselves if someone else allows them to speak and successfully convey their message. ${ }^{1}$

Learning how to actively listen takes time, practice, and full commitment. Once achieved, it can build a strong foundation for positive communication resulting in a strong caregiver-child relationship by building trust throughout the lifespan. This strategy also tends to improve the quality of conversations by connecting with others on a deeper level, ${ }^{2}$ which can lead to more positive and healthy relationships. ${ }^{3}$

\section{How to use this method:}

- Caregivers should be on the child's level and listen in an attentive, nonjudgmental, non-interrupting manner.

- Listeners should pay close attention to possible hidden messages and meanings contained in the verbal communication and should note all non-verbal communication from the child. ${ }^{4}$

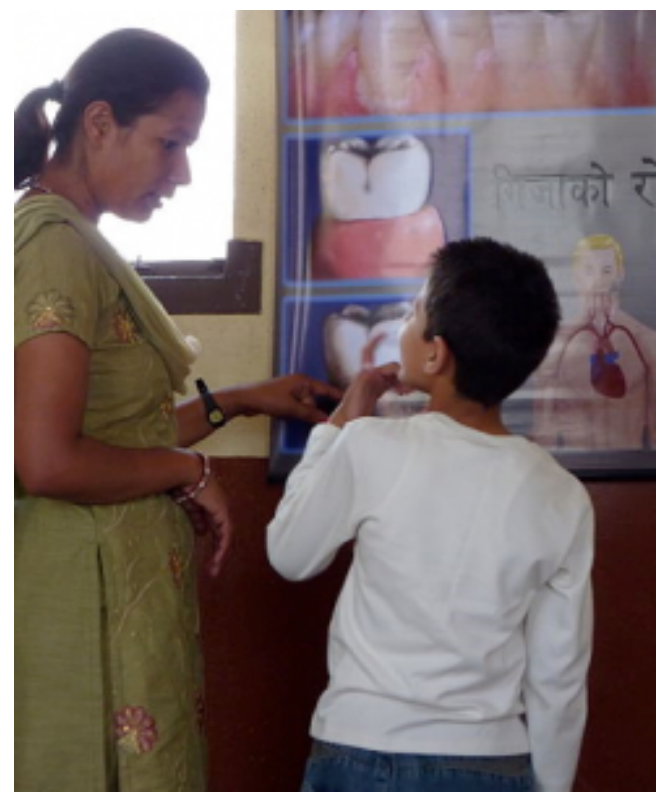

Figure 1. A doctor stops and listens to a child explain how they feel. (Image Source: Latrobebohs, CC by-SA 3.0)

- It is important to remember that you are not giving your opinion and thoughts regarding what the child relays to you; you are paraphrasing what the child said and expressing back to the child the emotions the child conveyed.

1. Rogers, C. R., \& Farson, R. E. (2015). Active listening. Martino Publishing. Retrieved from https://www.amazon.com/ActiveListening-Carl-R-Rogers/dp/1614278725.

2. Hoppe, M. H. (n.d.). Active listening: Improve your ability to listen and lead, first edition. Retrieved from https://www.oreilly.com/ library/view/active-listening-improve/9781882197941/xhtml/07_Chapter02.xhtml.

3. Rogers, C. R., \& Farson, R. E. (2015). Active listening. Martino Publishing. Retrieved from https://www.amazon.com/ActiveListening-Carl-R-Rogers/dp/1614278725.

4. Active Listening. (2002). In D. H. Yarn (Ed.), Dictionary of conflict resolution, Wiley. Wiley. Credo Reference: http://proxy.lib.iastate.edu/login?url=https://search.credoreference.com/content/entry/wileyconfres/active_listening/ $\underline{0}$ ?institutionId=1110. 


\section{Example}

The Center for Disease Control and Prevention's website provides useful information about active listening. ${ }^{5}$

\section{Key Takeaways}

- Active listening is paying attention and attempting to understand what someone else is saying.

- It is important to note hidden messages in verbal and non-verbal communications.

- It is important to refrain from giving opinions while paraphrasing what the other person is saying. 


\section{ANTICIPATORY STRUCTURE}

\section{Diana Lang}

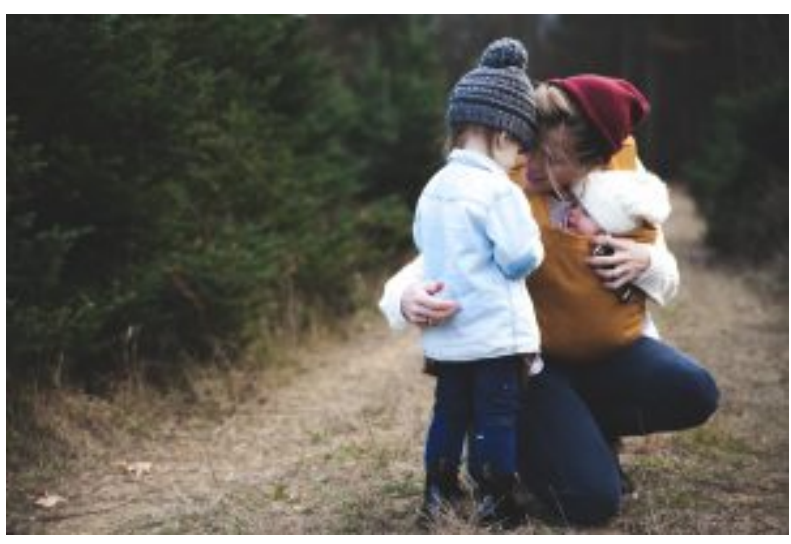

Figure 1. A parent talking to their child at their height can help remove stress from a situation. (Photo Source: Losh Willink, Pexels License)
Anticipatory structure is a strategy where caregivers share plans and provide forewarnings to children regarding upcoming transitions between activities. This can help establish routines and facilitate more smooth changes in routines. It also allows time for children to prepare for changes, which can heighten their cooperation when the change happens.

Anticipatory structure is most effective when caregivers provide multiple forewarnings before transitions, give reasoning for what the child is being asked to do, and use age-appropriate language that the child can understand. ${ }^{1}$ It is helpful for parents

to provide praise or compliments for their children as they follow each step and meet the end goal.

\section{Example}

- A parent tells their children that it is almost time to go to bed and they have ten minutes to finish playing and then they need to put their toys away. Later the parent reminds the children again and tells them that they have five minutes left to play and then they need to have all of their toys put away. After five minutes, the parent makes sure the children's toys are put away and asks them to get ready for bed by reminding them of their regular bedtime routine. 


\section{Key Takeaway}

- Anticipatory structure provides forewarnings to changes in activities and can help establish routines and cooperation. 


\section{CALM}

\section{Diana Lang}

The CALM method is a technique for parents to use to communicate with their children, whether that be talking through a conflict or just sharing about what happened that day. The goal of this method is to give children a voice and help them feel heard. The "best-practice" way to utilize this method would be to implement it every time your child wants to have a conversation one-on-one with you.

- Connect

- Affect

- Listen

- Mirroring

\section{How to use this method:}

CONNECT. The first step in the CALM method is connecting with the child. This means putting aside any and all distractions in order to give your full and undivided attention to what the child says to you.

AFFECT. The second step is affect, which is emotion. This means you want to share and show your emotions and feelings with your children and let them know that you have the same emotions as they do. Through this, they can see that you understand and empathize with what they are going through or telling you.

LISTEN. The third step is listening to the child by repeating what is said back to you or asking for

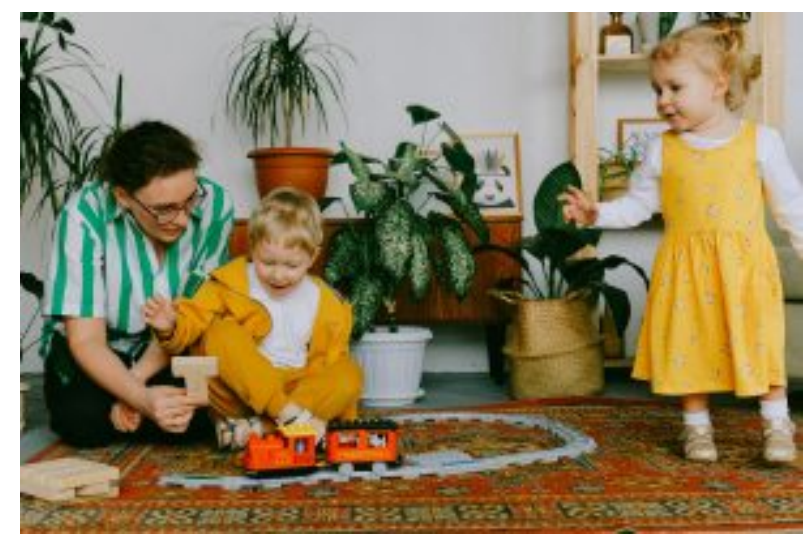

Figure 1. Parents often have to juggle giving attention to multiple children, which may lead to outbursts if one child feels neglected. In these cases, the CALM method may be of help. (Photo Source: Anna Shvets, Pexels License) clarifications to help the child feel listened to and heard.

MIRRORING. The fourth and final step is mirroring. This is when you (a) make sure you fully understand what the child is telling you, (b) clear up any questions or misunderstandings by 
paraphrasing (back to the child) what the child said, and (c) share in your child's thoughts and feelings. ${ }^{1}$

\section{Example and Video}

Your daughter, Deidre, came to you upset because she didn't win a contest at school.

First, you would connect by removing all of your distractions (putting away phone, stopping what you are doing), turning your attention to her, and making eye contact with her.

Next, you would show how her actions affected you by having an upset look on your face and tone in your voice to show you understand her emotions.

After this, you would listen to what she tells you and then clarify details to show Deidre you are invested

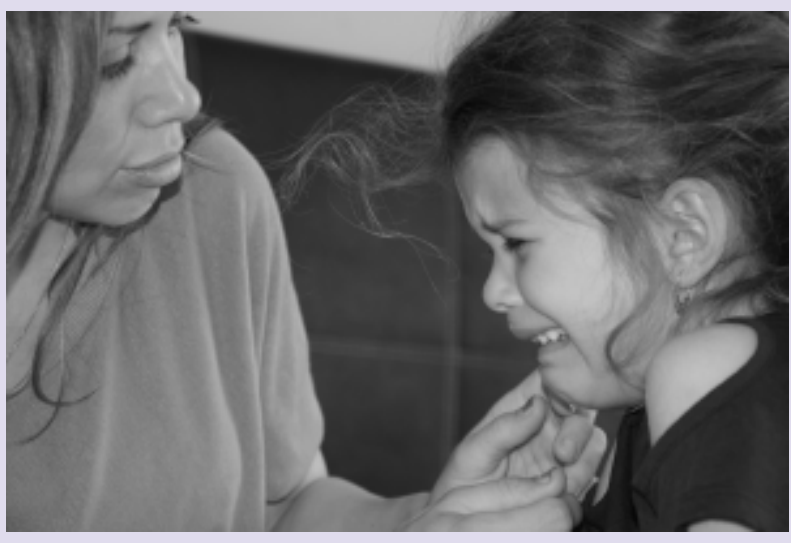

Figure 2. A parent comforts their crying child. (Photo Source: codewan, $\underline{\mathrm{CC} 0}$ in the conversation.

Lastly, you would mirror the interaction back to Deidre by paraphrasing what she told you to show you care about her thoughts and feelings.

By using this technique, children will be able to see and feel that you are listening, caring, and involved in what they are telling you. You want them to feel that they can come to you and trust you about anything going on in their life, big or small.

Watch this video (start at 27:00) for an overview of the technique.

1. tvoparents. (2012, April 26). Jennifer Kolari: The CALM Technique and Child Brain Development. [Video]. Youtube. https://www.youtube.com/watch?v=fppxgAnbED4 


\section{CONSTRUCTIVE CHOICES}

\section{Diana Lang}

Constructive choices are a child-rearing strategy where parents provide the child with options for the child when making decisions. This allows children to be involved in making choices in their everyday activities, while still maintaining choices that are positive and safe.

This strategy can help children learn how to make decisions, and it teaches and guides children about how to analyze their decision-making abilities so they can eventually make decisions on their own. ${ }^{1}$

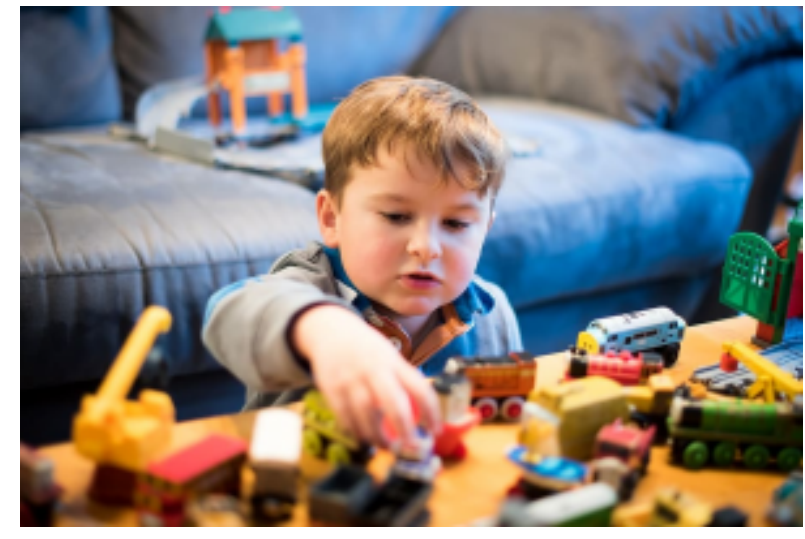

Figure 1. A child playing with toy vehicles. (Photo Source: Pxfuel, DMCA)

\section{How to use this method:}

- Limit the number of times you give a child a choice,

- Limit the number of choices you give a child (two to four choices work well),

- Provide developmentally-appropriate choices that keep the child safe and healthy,

- Support the child's decision, and

- Help children think about their choices and the reasoning behind making each decision.

\section{Example}

- A caregiver may give a child a choice to keep playing with their toys inside or to clean up the toys and go play outside.

1. National Academies of Sciences, Engineering, and Medicine; Division of Behavioral and Social Sciences and Education; Board on Children, Youth, and Families; Committee on Supporting the Parents of Young Children. (2016). Parenting knowledge, attitudes, and practices. Retrieved from https://www.ncbi.nlm.nih.gov/books/NBK402020/ 


\section{Key Takeaway}

- Caregivers provide specific options to help guide children's activities and decision-making abilities. 


\section{FOUR PLUSES AND A WISH}

\section{Diana Lang}

Four Pluses and a Wish is a parenting strategy aimed at creating cooperation and motivation for children to comply with parental requests. Along with leading to better behavior outcomes, it also works to foster healthy communication and is a good example of parental supportive speech. Four Pluses and a Wish involves the parent providing three pluses, which are positive actions toward their child, before making a request. This helps the child feel more respected by their parents and therefore more likely to comply with parental wishes and requests. There are four steps to follow for this strategy. ${ }^{1}$

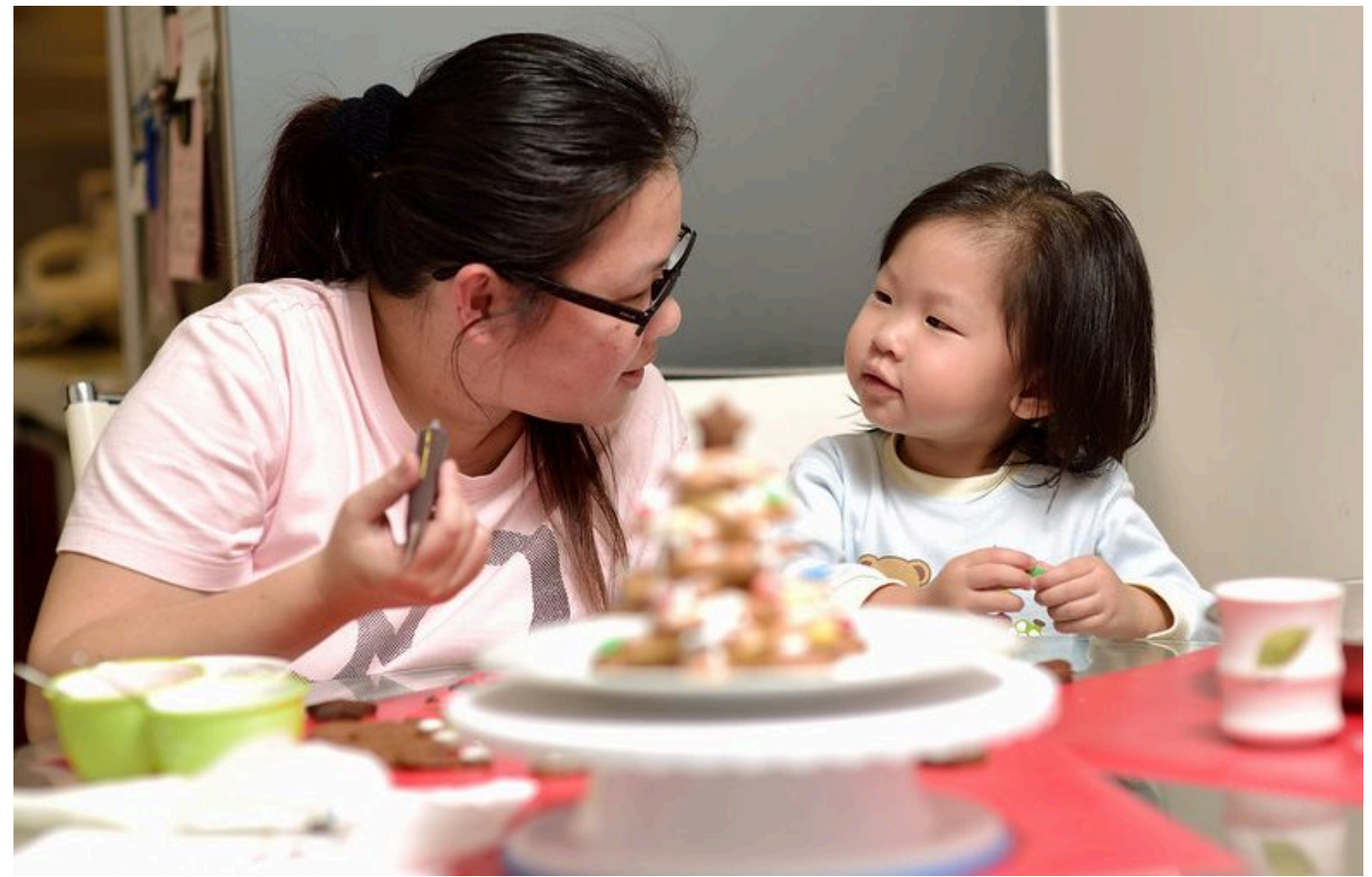

Figure 1. A parent works with their child to create a gingerbread dessert. (Photo Source: Alan Wat, CC by 2.0) 


\section{How to use this method:}

\section{Plus 1}

Smile: The parent approaches the child with a smile and a happy facial expression to show the child that nothing is wrong.

\section{Plus 2}

Relaxed body language: The parent displays a relaxed body and uses a friendly voice to communicate friendliness and acceptance toward the child.

\section{Plus 3}

Say the child's name: For children, hearing a parent say their name feels more personal, is affirming, and helps make them feel included and respected in the communication.

\section{Plus 4}

Compliment the child: Make a positive comment on something the child is doing, wearing, etc., to make the child feel appreciated.

\section{The Wish}

Make the request: After providing four pluses for the child, the parent can then make a request (the wish). ${ }^{2}$ 


\section{Example}

Luke is playing with blocks and his mother comes into the room.

Luke's mother: "Luke, it's almost time for dinner, please clean up your toys and wash your hands."

Luke: "I don't want to clean up yet. I want to keep playing."

Luke's mother smiles at Luke and with relaxed body language, kneels to his level. "Luke, that is a great car you built with your blocks, you did a good job building it. Could you put it away for a while and come wash your hands for dinner, please?”

Luke smiled and complied with his mother's request.

\section{Key Takeaways}

- Three positive actions are made towards the child before making a request.

- This method promotes cooperation and compliance with requests. 


\section{GROUNDING}

\section{Diana Lang}

Grounding is a technique in which caregivers teach children that there are consequences to their actions by taking away certain privileges or freedoms. This is especially beneficial to start using at around 12 years of age, when many children are starting to gain new freedoms and may push the limits.

The goals of grounding are to provide the child with appropriate limits and boundaries and teach the child that there are consequences to behaving in certain ways, such as pushing these limits or crossing these boundaries. If a child chooses to behave in contrast to the limits or boundaries set by a caregiver, grounding can be the logical consequence for the child's behavior. ${ }^{1}$

\section{How to use this method:}

- Start early: From as early on as preschool, a caregiver can begin to set boundaries and family rules for the child and should explain to the child that not following these will lead to consequences.

- Choose specific activities to take away that are desirable to the child: When grounding, choose a tangible activity, privilege, or freedom to take away from the child such as toys, television time, or playing with friends. The activity, privilege, or freedom must be something the child enjoys or this method will be ineffective.

- Do not give in to guilt: Even though a caregiver

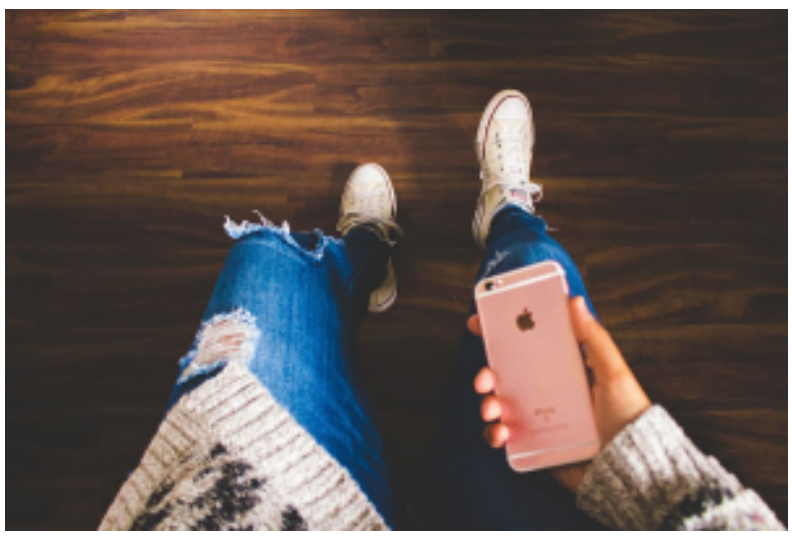

Figure 1. Cell phones are a common item removed when grounding a child. (Image Source: pxfuel, $\underline{\mathrm{CC} 01.0}$ may feel bad and want to give the privileges back to the child early, the child must learn that poor decisions lead to negative consequences; a child will not learn the lessons that grounding aims to teach if a caregiver does not follow through with the entire process.

- Consistency is key: Caregivers must consistently follow through with all consequences in order for grounding, or any other guidance technique, strategy, or method, to be beneficial and

1. Brooks, R., \& Goldstein, S. (2001). Raising Resilient Children: Fostering Strength, Hope, and Optimism in Your Child. New York: McGraw-Hill. 
successful in their child's life. ${ }^{2}$

\section{Example}

- Lucy's parents have established the rule that Lucy can only be out with friends until 11 p.m. on weeknights.

- One night, Lucy did not follow this rule and came back home at 1 a.m.

- As a consequence, Lucy's primary caregiver decides to not allow Lucy to go out with her friends in the evening for the next week and take her cell phone away from her for three days.

\section{Key Takeaways}

- Grounding is when caregivers take away certain privileges or freedoms from a child as a consequence for undesirable behaviors.

- The goal is to provide limits and boundaries to teach children that there are consequences when boundaries are crossed.

- The removed privilege or freedom MUST be desirable to the child or it will not be effective in changing the behavior.

- Once caregivers state the consequences, they must follow through with the consequence or the child's behavior will likely remain the same.

2. Zolten, K., \& Long, N. (2006). Modified Grounding. Retrieved from https://extension.tennessee.edu/centerforparenting/ TipSheets/Modified\%20Grounding.pdf 


\section{I-MESSAGES}

\section{Diana Lang}

I-messages are effective communication techniques to use when talking with another person. The goals of I-messages are to keep interactions positive, and avoid blame, guilt, judgment, and shame. Imessages express your own feelings, while "you" messages place assumptions or judgments onto the person with whom you are speaking. A "you" message would sound like, "You need to pay more attention!" or "You shouldn't be acting like that."1

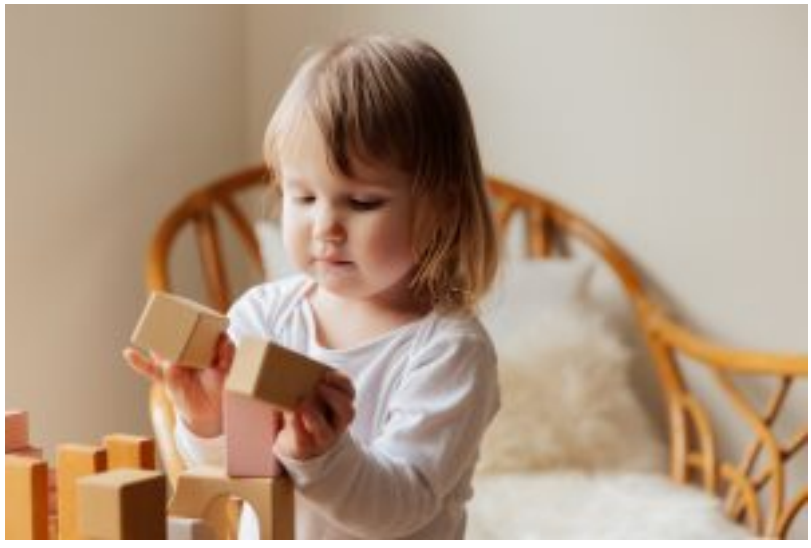

Figure 1. A child playing with blocks (Photo Source: Tatiana Syrikova, Pexels License)
Here is an example of turning a "you" message into an I-message. The "you" message might be something like, "You always disobey our rules and do whatever you want!" However, turning it into an I-message might sound more like this, "I feel angry when you disobey the rules we've laid out for you because I feel disrespected. I like it when you obey the rules, guidelines, and boundaries we have in this family because it makes me feel like you care about me, yourself, and the whole family."

\section{How to use this method:}

- "I feel

- When

- Because

- I like "3

This outline expresses how you feel about a given situation, action, or behavior by explaining what you feel, why you feel that way, and what you would like the desired behavior to be.

1. Eastman, K. L., Corona, R. A., \& Schuster, M. (2006, October). Talking Parents, Healthy Teens: A Worksite-based Program for Parents to Promote Adolescent Sexual Health. Retrieved from https://www.cdc.gov/pcd/issues/2006/oct/06_0012.htm

2. American Academy of Pediatrics. (2015, November 21). Components of Good Communication. Retrieved April 11, 2020, from https://www.healthychildren.org/English/family-life/family-dynamics/communication-discipline/Pages/Components-ofGood-Communication.aspx

3. Heath, P. (2013). Parent-child relations: Context, research, and application (3rd Ed.). Pearson. 


\section{Example}

- "I feel worried and anxious when it is one hour past the time you were to be home and I have not heard from you because I fear something bad has happened. I like it when you keep in touch with me if you might be late. I need you to contact me if you will be late."

\section{Key Takeaway}

- I-messages start with the word "I," express your own feelings to keep communication positive, and help avoid blame and judgment onto the other person. 


\title{
INDUCTION
}

\author{
Diana Lang
}

Induction can be used to help youth develop empathy, ${ }^{1}$ guide their behaviors, take ownership of their actions, learn acceptable behaviors, and understand how their actions may impact themselves (self-centered induction) and others (other-oriented induction). ${ }^{2}$

\section{How to use this method:}

When you have a child's full attention:

- Explain how one's actions can affect themselves and others (positively and negatively).

- Use a child's actions as an example to discuss and recommend expectations for acceptable behavior.

- Model desired behaviors for a child to imitate.

- Use others' actions as examples to discuss and assess how behaviors can impact others' feelings.

- Encourage, discuss, and reward desired behaviors.

- Explain and discourage undesirable actions.

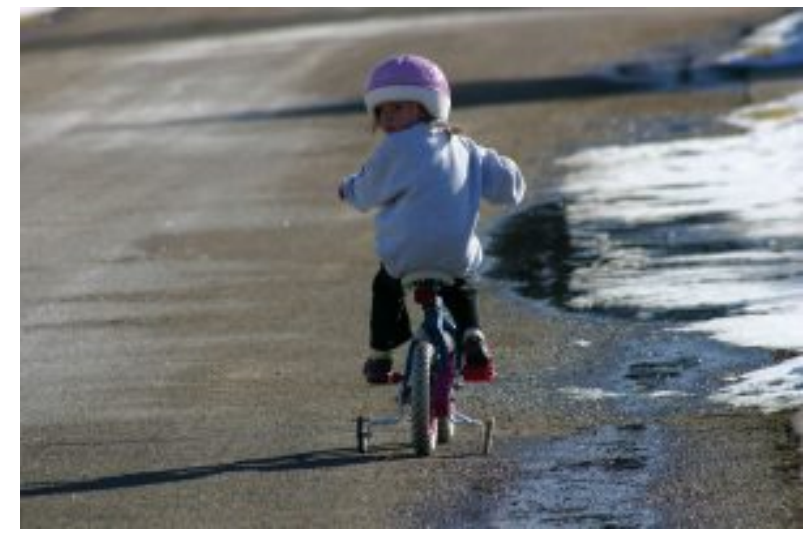

Figure 1. Riding a bicycle in the road can be dangerous, but explaining that to a child requires patience and understanding. (Photo Source: Pixabay, Pixabay License)

- Be consistent and proactive by communicating expectations, discussing outcomes, and identifying feelings related to behaviors on an ongoing basis.

Children reared in an environment that uses this approach tend to have higher moral reasoning, internalized standards for behaviors, prosocial skills, and resistance to external influences when compared to their peers who have not been exposed to this technique ${ }^{3}$.

1. Krevans, J., \& Gibbs, J. (1996). Parents' Use of Inductive Discipline: Relations to Children's Empathy and Prosocial Behavior. Child Development, 67(6), 3263-3277. doi:10.2307/1131778.

2. Heath, P. (2013). Parent-child relations: Context, research, and application (3rd Ed.). Pearson.

3. Bannon R.S. (2011). Inductive Parenting. In: Goldstein S., Naglieri J. A. (eds). Encyclopedia of Child Behavior and Development. Springer, Boston, MA. 


\section{Example}

- If a child is taking a sibling's toys, a caregiver can explain, "When you take your brother's toys, it causes him to feel sad and that you do not like him. How might you feel if your friend took your bike out of our yard without asking you?”

\section{Key Takeaway}

- Induction is used to help children understand how their behaviors affect themselves and others, take ownership of their actions, and guide them to engage in acceptable behaviors. 


\title{
NATURAL AND LOGICAL CONSEQUENCES
}

\author{
Diana Lang
}

For definitions and examples of natural and logical consequences see the Dreikurs chapter.

Caregivers can use both natural and logical consequences for children to learn better behaviors. Both natural and logical consequences encourage children to take responsibility for their actions and behaviors, but in different ways. ${ }^{1}$

Natural consequences allow children to learn from the natural outcomes of a situation ${ }^{2}$ and logical consequences allow the parent to set the consequences of a child's undesired actions or behaviors. $^{3}$

Logical consequences work best when consequences

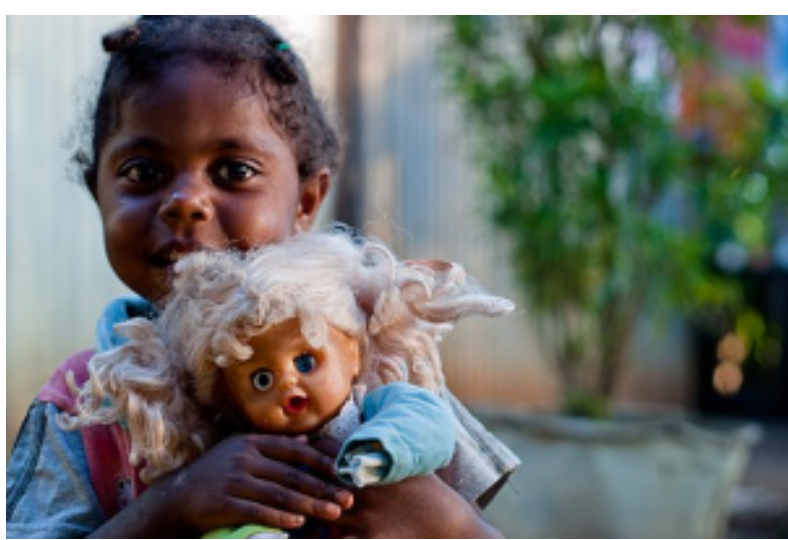

Figure 1. A young girl plays with a toy doll. (Photo Source: Graham Crumb/Imagicity.com, CC BY-SA 3.0) are immediate and consistent. It is also important to talk with the child about the behavior and to discuss what alternative behaviors would be better to use. ${ }^{4}$

1. Matthews, D. (2017). Logical consequences: Helping kids learn from their mistakes. Retrieved from http://www.psychologytoday.com/intl/blog/beyond-intelligence/201710/logical-consequences-helping-kids-learn-their$\underline{\text { mistakes }}$

2. Morin, A. (2019). How to make natural consequences an effective discipline tool. Retrieved from https://www.verywellfamily.com/ natural-consequences-as-a-discipline-strategy-1094849

3. Allen, R. A., \& Boelter, L. A. (2016). Using natural and logical consequences. Retrieved from https://extension.umn.edu/ encouragingrespectful-behavior/using-natural-and-logical-consequences

4. Wise, R. W. R. (2019). How to use natural and logical consequences to improve children's behavior. Retrieved from https://www.educationandbehavior.com/examples-of-logical-consequences-in-parenting/ 


\section{Examples}

- Natural consequence: Sophie leaves her favorite hair styling doll outside overnight. It rains on Sophie's doll and ruins its hair. Now Sophie's doll is ruined and she is no longer able to style the doll's hair.

- Logical consequence: Juan hits a baseball into his neighbor's yard and breaks the neighbor's window. Juan's parents require Juan to apologize to the neighbor and to complete chores around their own home in order to pay for the neighbor's broken window.

\section{Key Takeaways}

- Natural consequences are when a child learns from and experiences the natural outcomes of situations.

- Logical consequences are when parents set the consequences of a child's behaviors.

- This works best when the consequences are immediate and consistent. 


\section{NO-LOSE METHOD}

\section{Diana Lang}

This is a democratic approach that results in caregivers and children resolving conflict in a manner in which all parties are satisfied with the solution.

\section{How to use this method:}

- Define: All parties communicate their perspectives of the "problem".

- Brainstorm Solutions: All parties list all possible solutions to resolve the issue.

- Assess Solutions: All parties decide and discuss how they feel about all of the solutions.

- Best Solution: All parties decide upon and agree to implement the best solution.

- Plan in Action: All parties put the best solution into practice.

- Follow-Up: Adult(s) proactively discuss the problem and solution with the child(ren) to revisit the situation ${ }^{1}$. 


\section{Example}

- Define: The "problem" is that siblings are fighting over a book.

- Brainstorm Solutions: The children can take turns reading the book; each child can read a different book; both children can read with each other at the same time with that book; a parent can remove the book so both children need to find different books.

- Assess Solutions: Both children want to read the book together.

- Best Solution: The children and parent agree that

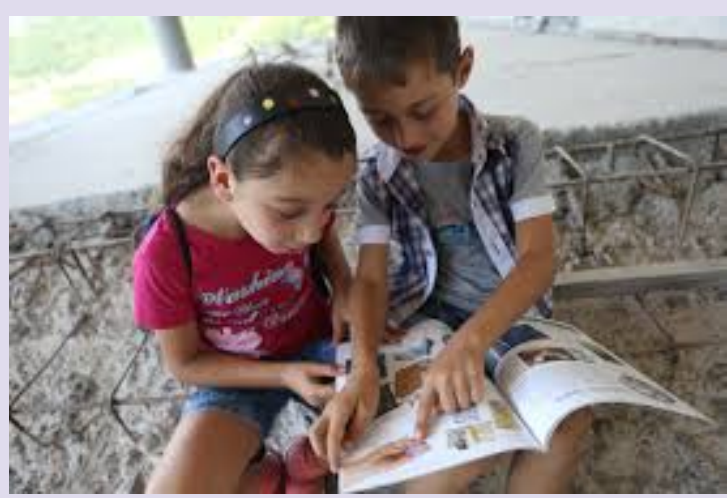

Figure 1. Siblings. (Photo Source: AnukEvo, CCby-SA 4.0) the children will read the book together as long as the children do not fight. If they fight while reading the book, the parent will remove the book and both children will need to take a break.

- Plan in Action: The children read the book together and do not fight.

- Follow-Up: Later that same day, the parent asks if they both enjoyed reading that book together. Both children agreed it was an enjoyable time. The parent praised them for not fighting and for solving the issue.

\section{Key Takeaways}

- This method is used to resolve conflict where every party involved discusses their perspective on the problem and possible solutions.

- A solution that satisfies all parties is decided and agreed upon. 


\title{
PROBLEM OWNERSHIP
}

\author{
Diana Lang
}

Problem ownership is an important tool to utilize when caregivers are communicating with children because it can help avoid blaming and arguing. This is when caregivers take time to reflect on an issue and think, "Whose problem is this? Who is actually upset about this?" Sometimes we may think the child is the one with the problem when actually we are the ones getting upset. In reality, the child is just fine - we are the ones that have a problem. This is when a caregiver should own the problem.

If a caregiver owns the problem, it is a perfect opportunity to utilize effective communication strategies such as I-Messages to express one's thoughts and feelings regarding the problem.

If, however, the child owns the problem, caregivers can use this as a chance to practice adult-child interaction techniques such as active listening and the CALM method to connect with the child concerning the problem.

Problem ownership helps caregivers determine which problems they need to figure out themselves, and which problems they should allow their children to figure out. This provides a learning experience to gain responsibility for one's actions that can be utilized in other relationships as well. ${ }^{1}$

1. Taylor, M. (n.d.). Problem Ownership - key to solving your family/inter-personal dilemmas. Retrieved from https://www.lubish.com/problemownership.html

2. Heath, P. (2013). Parent-child relations: Context, research, and application (3rd Ed.). Pearson. 


\section{Example}

Third-grader tells his dad, "Caleb is not my friend anymore!"

Dad: (active listening) "So, I hear that you are upset. What happened?"

Third-grader: "Caleb knocked down our entire snow fort during recess today! It took us three entire recesses to build it!”

(Dad feels sad for his son and wants to advocate for his son. Dad contemplates calling the teacher or Caleb's parents. After reflecting, Dad asks himself, "Whose problem is this? It's my son who is upset. I need to help him navigate this and let him know he can talk to me about these types of issues." Dad decides to ask open-ended questions and use active listening to learn more about the entire situation.)

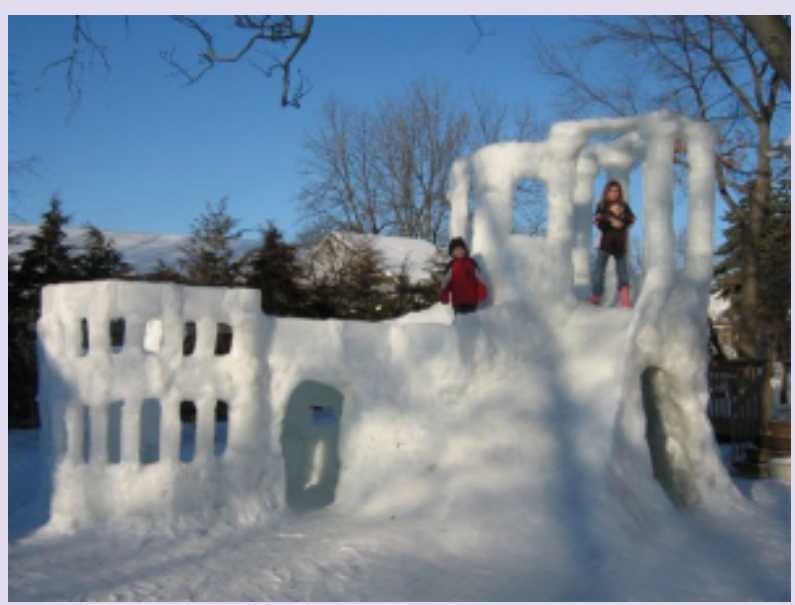

Figure 1. An elaborate snow fort. (Photo Source: brothersforever)

Dad: Why don't you tell me what happened.

Third-grader: Well... (child has the opportunity to retell the incident and decide for himself, with his dad's nurturing and understanding support, what to do about the problem).

This type of interaction allows a parent to provide support while assisting the child with ways to resolve or work through a problem.

\section{Key Takeaways}

- Problem ownership is when an issue is reflected upon and analyzed to determine who is upset and who owns the problem in a situation.

- A solution can be determined based on who owns the problem. 


\section{POSITIVE LANGUAGE}

\section{Diana Lang}

The manner in which parents communicate with their child can largely determine the child's own communication methods and language development and can affect the child's vocabulary and speaking skills over time. Using positive language can greatly support and encourage the child as they get older. ${ }^{1}$

\section{How to use this method:}

- Respond quickly and kindly to a child's needs.

- Provide a listening ear or advice even at inconvenient times.

- Be responsive and consistent.

- Use positive and encouraging words when speaking with a child.

- Set a good example of how to talk to other people in public as well as at home by using manners and respect, such as saying "please," "thank you," and "I'm

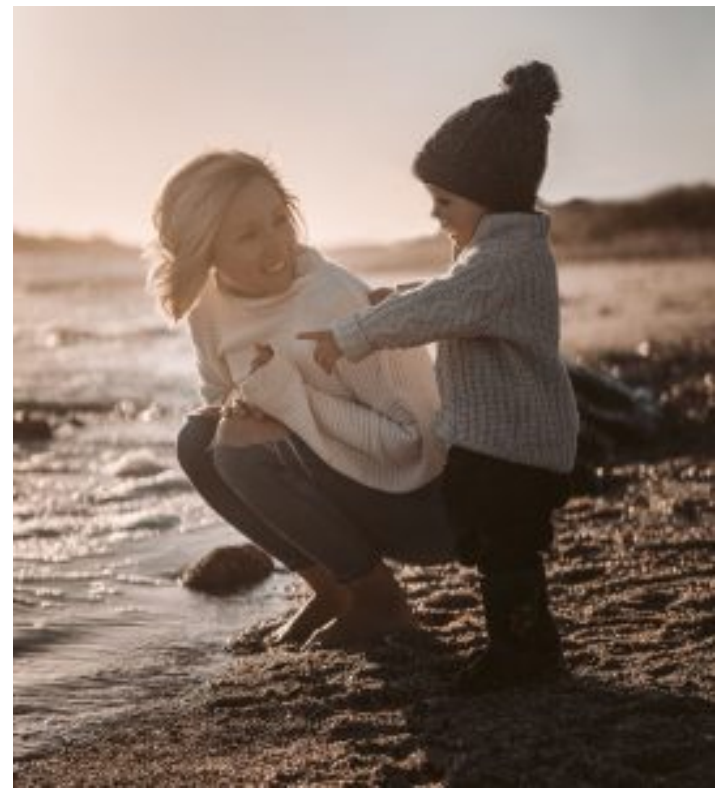

Figure 1. Communicating on a child's level can remove stress from an otherwise concerning situation. (Photo Source: Taryn Elliott, Pexels License) sorry."

- Avoid sarcasm or ill-willed teasing.

- Use positive, communicative forms of guidance and avoid any form of violent discipline such as spanking.

- Spend time alone with each child, even at a young age. Quality time coupled with open communication encourages the child to feel safe and comfortable with their parents and creates a reliable relationship. ${ }^{2}$

1. Feldman, H. M., (2019). The Importance of Language-Learning Environments to Child Language Outcomes. Pediatrics, 144(4). doi:10.1542/peds.2019-2157

2. American Academy of Pediatrics. (2019). Showing Love for Your Child - Tips From the American Academy of Pediatrics. Retrieved from https://www.aap.org/en-us/about-the-aap/aap-press-room/news-features-and-safety-tips/Pages/Showing-Love-forYour-Child-Tips-From-the-American-Academy-of-Pediatrics.aspx. 


\section{Examples}

- Peter and Dan's mother always says, "Thank you for picking up your toys" after they put away the toys in their playroom.

- Kaila returns home from school and says that she has had a bad day at school. Kaila's dad asks her what had made it a bad day and listens to Kaila explain what had happened.

\section{Key Takeaway}

- Using phrases such as, "I’m sorry," “please," "thank you”, and "I love you” often for children of all ages are recommended! 


\section{REDIRECTING}

Diana Lang and Jack Maass

\section{Redirection: Verbal and Physical}

Verbal and physical redirection help promote desirable behaviors by directing children's attention to a different activity, toy, or behavior. These strategies help teach appropriate behavior, prevent injuries, reduce punishments, remove children from situations, and promote learning and exploration. The goal is to provide children with easy-to-understand alternative actions (verbally and/or physically) instead of using threats, punishments, or telling children what not to do.

\section{How to Use Verbal and Physical Redirection}

1. Maintain eye contact and come down to the child's level. Let children know that the act they are performing is unacceptable by using a firm, nurturing voice.

2. Explain why the behavior is unacceptable in a clear, consistent, developmentally appropriate manner. This will help children associate these words with the undesirable action.

3. Encourage children to practice the desired outcome immediately. For example, instead of telling children not to stand on chairs, verbally explain that they need to sit down while gently touching them to help them sit down carefully.

4. Use physical and verbal redirection to foster children's curiosity. For instance, encourage them to participate in desired acts that they will undoubtedly want to join.

5. Provide positive reinforcement and praise for completing the act in a desirable manner.

Verbal redirection is effective without physical redirection, but physical redirection is not effective without verbal redirection. As in most forms of child rearing, communication is a pivotal component of effective parenting strategies. Physical redirection tends to be more effective with younger children because they are still developing their language comprehension. As children develop additional cognitive and language skills, physical redirection should be used less frequently and verbal redirection should be used more often. An extremely important part of effective physical redirection is adding a gentle, nurturing touch simultaneously with the verbal redirection. 


\section{Examples}

Correct and incorrect examples of redirection are shown below.

\section{VERBAL REDIRECTION}

\section{Incorrect}

1. "Stop running in the kitchen, you'll split your head open!"

2. "I like your jacket, but don't leave it laying on the ground."

3. "Stop standing on the chair, you are going to get hurt!"

\section{Correct}

1. "The kitchen is not a place to run, walk when you are in here, please."

2. "I like your jacket, please hang it up after you take it off."

3. "We do not stand on chairs. Let's go outside and play in your tree house."

\section{PHYSICAL REDIRECTION (WITH VERBAL REDIRECTION)}

\section{Incorrect}

4. Grab the child's arm to make him stop running.

5. Throw the child's jacket at her after she leaves it laying on the chair.

6. "Stop standing on the chair, you are going to get hurt!"

\section{Correct}

4. "The kitchen is not a place to run, please walk when you are in here," while gently touching the child's arm to slow him down to a walking pace.

5. "I like your jacket, please hang it up when you take it off." Gently touch the child's arm to guide her to the jacket and then to the coat hook.

6. "We do not stand on chairs, we sit on them," while gently and immediately, touching the child's leg and arm to help her get to a seated position. 


\section{Key Takeaways}

- Verbal redirection should always include explanations of the correct action that a child can understand while using a gentle, nurturing voice.

- Avoid using threats and telling children what not to do.

- Physical redirection should always be used in combination with verbal redirection.

- Consistent language is key for effective redirection so children associate the same words with undesirable actions.

- It is important to use the same steps and words if children repeat the same behavior. Consistency is key when reinforcing positive behaviors and deterring negative behaviors. 


\section{REWARD-ORIENTED PARENTING AND POSITIVE REINFORCEMENT}

Diana Lang

There are many ways to increase the likelihood of children exhibiting desirable behaviors by using positive reinforcements and rewards. ${ }^{1}$ To learn how to effectively reinforce behaviors, please re-visit the Skinner chapter.

Parents or teachers may wish to reinforce children for:

- Listening attentively;

- Using appropriate manners (e.g., saying “please," “you are welcome," and "thank you”);

- Moving and talking in a manner appropriate for the environment (e.g., using "library voices;" "walking feet");

- Playing nicely;

- Completing tasks without reminders; and

- Calling or texting if they will be late.

Examples of rewards and positive reinforcements include: ${ }^{2}$

- Complimenting a child's behavior (e.g., "I really like the way you put all of your clothes away in your room");

- Praising a child's actions (e.g., "I am proud of how hard you studied for your spelling quiz.");

- Giving additional privileges;

- Clapping or cheering;

- Thanking them for behaving a certain way (e.g., "Thank you very much for asking such a detailed question;" "I really appreciate you using your inside voice while we were at the museum.");

- Making sure they overhear you telling someone else about their positive behavior;

- Smiling at them; and

- Giving tangible rewards (e.g., stickers, incentives).

1. Craighead, W. E., Kazdin, A. E., \& Mahoney, M. J., (1981). Behavior modification: principles, issues, and applications. 2 nd ed. Boston, Mass.: Houghton Mifflin.

2. Centers for Disease Control and Prevention. (2019). How to use rewards. Retrieved from https://www.cdc.gov/parents/ essentials/consequences/rewards.html 
In order for these methods to be effective, rewards or incentives must:

- be important or valuable to the child,

- occur immediately after the desired behavior, and

- consistently be implemented.

To learn how to create a reward program, visit the CDC's website for information.

\section{Examples}

Here is a common example of (unintentionally and positively) rewarding inappropriate behavior: An aunt provides candy to her nephew every time he throws a tantrum in the store because he wants candy at the checkout lane.

The aunt reinforces the poor behavior (e.g., a tantrum) by providing reinforcers (e.g., candy and attention) every time he throws a tantrum at the grocery store.

Here is an example of positively rewarding the same child to stop the tantrums: Now that this child throws a tantrum with his parents when they go to the grocery store, his parents provide their son with candy only when he does not throw a tantrum in the store.

His parents reinforce the appropriate behavior (e.g., not

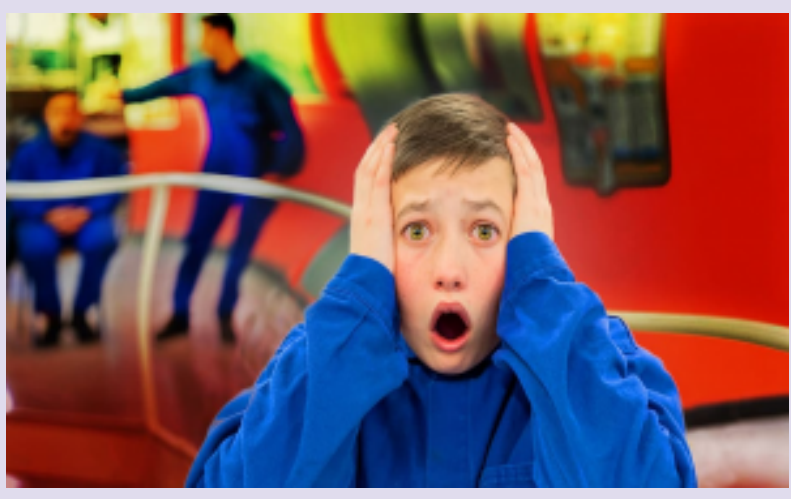

Figure 1. A child panicking in public. (Photo Source:pxfuel, DMCA) throwing a tantrum) by providing reinforcers (e.g., candy and attention) every time they go to the grocery store and he refrains from throwing a tantrum. 


\section{STRUCTURE (WITH FLEXIBILITY): ROUTINES, RULES, DIRECTIONS}

Diana Lang

Children (and most people of all ages) thrive in flexibly-structured environments. For children, the sense of knowing what to expect typically elicits feelings of safety and security. Caregivers can help children reduce feelings of chaos by providing flexible, but consistent:

- Routines,

- Rules, and

- Concrete, explicit directions with easy-to-understand expectations.

\section{Rules and Routines}

In order to maintain consistent routines (e.g., bedtimes, traditions) and rules (e.g., not eating food in certain areas of the house, curfews, wearing a helmet while riding a bicycle) it is important to facilitate and adhere to them as much as possible. Expectations should be developmentally-appropriate and communicated in a manner that can be easily understood. $^{1}$

For instance, perhaps family meals are at 6:30 p.m. because this is the time that everyone gets home from work and school activities. This expectation and all moderations should be communicated with all members on a daily basis but also remain flexible.

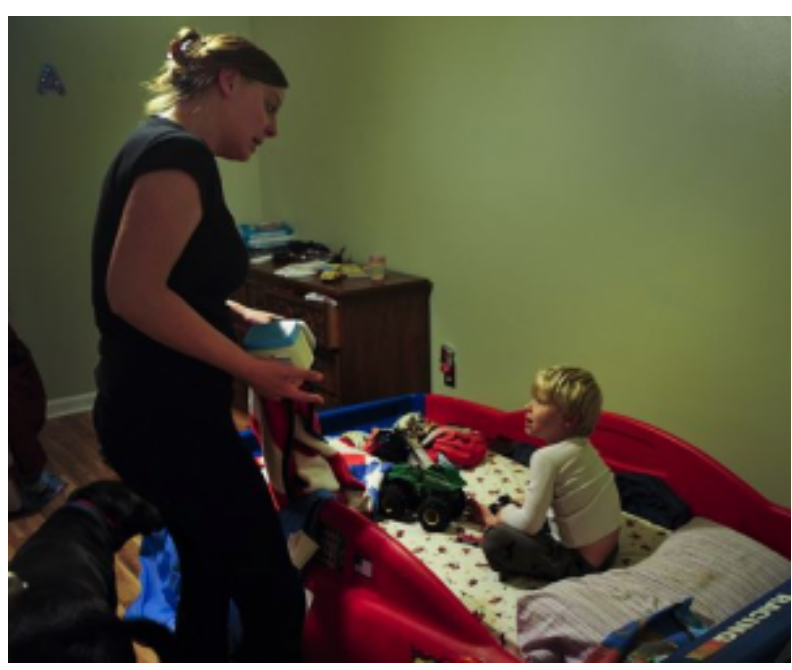

Figure 1. Setting routines is particularly important at bedtime. (Photo Source: Staff Sgt. Russ Scalf) Exceptions that may change a family mealtime might include attending a school-related activity or having a large family gathering every Sunday at 1:30 p.m. 


\section{Video Example}

Watch this YouTube video about creating structure.

\section{Directions}

Specific, warm, concrete, understandable directions and expectations can improve behaviors, prevent dangerous circumstances, reduce caregivers' frustrations, and foster children's learning of appropriate behaviors. It is most effective to tell children exactly what behaviors you desire.

\section{Examples}

- "Please use your walking feet while we are in the library," is more detailed than saying, "Stop that!"

- Another example is, "We must hold hands in the parking lot to avoid getting hit by a car," instead of "Hey, come back here!" as the child runs through the parking lot.

- Visit this website from the CDC to learn how to give good directions.

- Watch this YouTube video to learn how to provide quality directions.

\section{Consistency, Consistency, Consistency with Warmth}

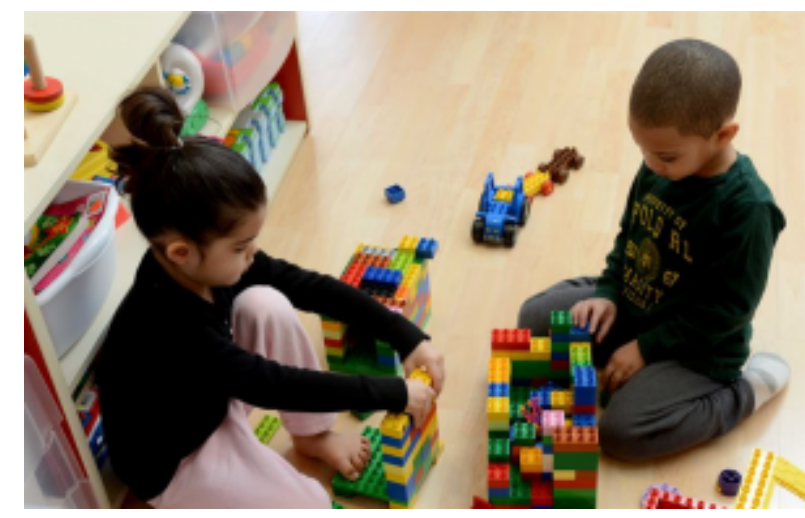

Figure 2. Children playing together comfortably. (Image Source: Caitlin Guinazu)
Research shows that children's abilities to anticipate change, use appropriate behaviors, and develop independence are fostered by warm, safe, stable, nurturing, caring, compassionate caregiving on a consistent basis! This means that routines, rules, 
directions, expectations, and consequences should be responded to or applied every time in a nurturing, warm, consistent manner. ${ }^{2} 3$

\section{Key Takeaways}

- Providing a warm, close, nurturing, and openly-communicative environment with consistent routines, directions, and rules with reasonable flexibility are key for eliciting feelings of predictability and security. ${ }^{4}$

- It is not too late to learn, teach, and reinforce these skills for caregivers and youth. However, it may take time and practice to elicit changes.

2. Centers for Disease Control and Prevention. (2019). Building structure. Retrieved from https://www.cdc.gov/parents/ essentials/structure/building.html

3. Gillespie, L. (2015). Rocking and Rolling - It takes two: The role of co-regulation in building self-regulation skills. Young Children 70(3). 94-96. https://www.naeyc.org/resources/pubs/yc/jul2015/rocking-rolling

4. American Psychological Association. (2014). Resilience booster: Parent tip tool. Retrieved from https://www.apa.org/topics/parenting/ resilience-tip-tool 


\section{TAKING AWAY PRIVILEGES}

\section{Diana Lang}

Taking away privileges can be used both at home and in the classroom as a way to discipline children. Within the classroom, teachers may take away privileges, such as the ability to participate in extracurricular activities (e.g., sports, music) if students are not performing well academically. At-home caregivers may take away privileges such as allowances, technology, toys, or time with friends when the child does not follow the rules. $^{1}$

Both within the classroom and at home, setting and communicating standards are extremely important parts of this child-rearing strategy.

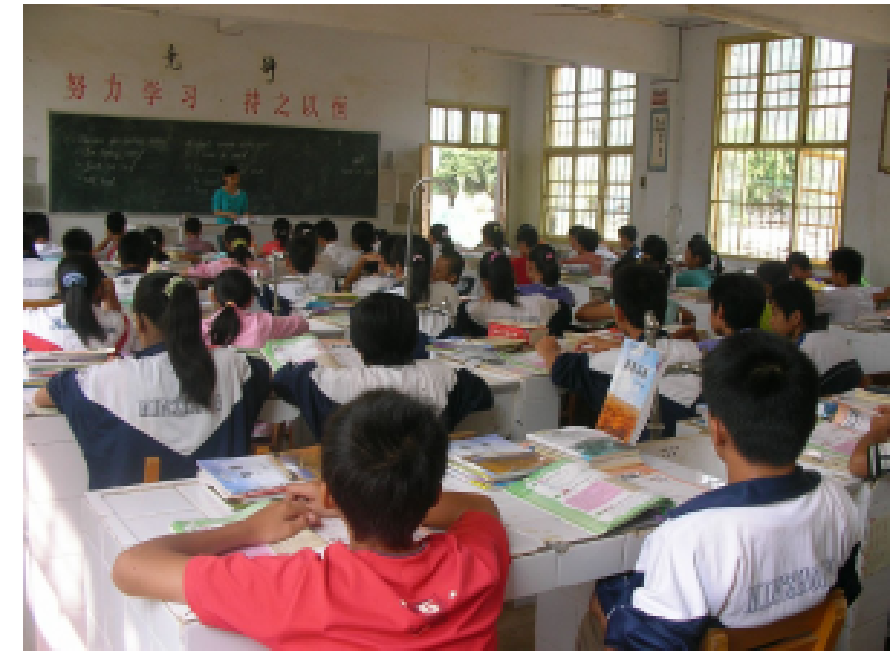

Figure 1. Children learning in a classroom. (Photo Source: $\underline{\operatorname{Rex} P e}, \underline{C C ~ B Y ~ 2.0)}$ When standards are set and communicated with the children, it allows children to know what is expected of them and when they do not meet these expectations then consequences, such as taking away privileges will happen. ${ }^{2}$

\section{Example}

- A child does not do their homework, so their caregiver takes away the child's cell phone until they have done their homework.

1. American Academy of Pediatrics. (n.d.). Discipline. Retrieved from https://www.aap.org/en-us/about-the-aap/aap-pressroom/aap-press-room-media-center/Pages/Discipline.aspx

2. Centers for Disease Control and Prevention. (2019). Building blocks. Retrieved from https://www.cdc.gov/parents/essentials/ structure/building.html 


\section{Key Takeaways}

- Taking away privileges can be an effective discipline method used both within the classroom and at home.

- Communication of standards that are set are an important aspect of this strategy. 


\section{TIME-INS AND TIME-OUTS}

\section{Diana Lang}

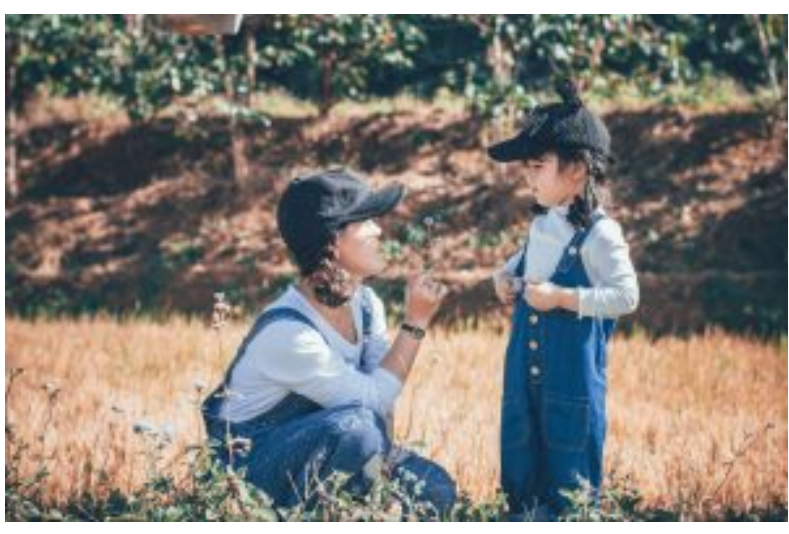

Figure 1. A parent talking to their child. (Photo Source: piqsels, $\underline{\mathrm{CC} 0}$ )
Time-ins are a positive child guidance strategy in which the caregiver stays with the child until they are both calm and can communicate about the issue at hand. When using a time-in the caregiver should stay with the child, and listen to the child and what they are feeling. Once the child has calmed down then the caregiver and child can discuss the child's behavior and what needs to be changed. Time-ins allow for children to not feel threatened and learn in a positive way. The caregiver and child are able to connect reducing power struggles since everyone's feelings and needs are considered. ${ }^{1}$

A more common and somewhat opposite approach is the use of time-outs. Time-outs are a less positive approach and can be less effective compared to time-ins. Time-outs are where a child is left to sit alone somewhere away from the caregiver for a set amount of time. To learn about time-outs, such as how and when to use them, visit the cdc's parent essentials site.

\section{Example}

Watch this video from the CDC to learn about using time-outs.

Both time-ins and time-outs are used to:

- stop undesirable behavior,

- help children learn better coping skills, and

- give parents and children a chance to calm down.

1. Siegel, D. J., \& Bryson, T. P. (2016). No-drama discipline: the whole-brain way to calm the chaos and nurture your child's developing mind. New York: Bantam Books. 


\section{Key Takeaways}

- Threats and punishments (e.g., time-outs) are often less effective than positive parenting strategies (e.g., time-ins) for changing behaviors.

- Not all children respond well to time-outs.

- Time-ins can reduce power struggles and calm brains. 
PART VI

\section{CHILD-REARING IN A VARIETY OF CONTEXTS}




\section{CHILD ABUSE, NEGLECT, AND FOSTER CARE}

Diana Lang and Wikimedia contributors

Child abuse takes many forms. Children can be physically or sexually assaulted, and they may also suffer from emotional abuse and neglect of many different forms. Whatever form it takes, child abuse is a serious problem.

It is especially difficult to know how much child abuse occurs. Infants obviously cannot talk, and toddlers and older children who are abused usually do not tell anyone about the abuse. They might not define it as abuse, they might be scared to tell a trusted adult, they might blame themselves for being abused, or they might not know with whom they could talk about their abuse. Whatever the reason, children usually remain silent, thus making it very difficult to know how much abuse takes place. Up-to-date statistics on the different types of child abuse in the United States can be found at the U.S. Children's Bureau website.

\section{Abuse}

Abuse can occur in multiple forms and across all family relationships. Breiding, Basile, Smith, Black, and Mahendra (2015) define the forms of abuse as:

- Physical abuse, the use of intentional physical force to cause harm. Scratching, pushing, shoving, throwing, grabbing, biting, choking, shaking, slapping, punching, and hitting are common forms of physical abuse;

- Sexual abuse, the act of forcing someone to participate in a sex act against the person's will. Such abuse is often referred to as sexual assault or rape.

- Psychological abuse, aggressive behavior that is intended to control someone else. Such abuse can include threats of physical or sexual abuse, manipulation, bullying, and stalking. ${ }^{1}$

Abuse between partners is referred to as intimate partner violence; however, such abuse can also occur between a parent and child (child abuse), adult children and their aging parents (elder abuse), and between siblings. ${ }^{2}$

1. Breiding, M. J., Basile, K. C., Smith, S. G., Black, M. C., \& Mahendra, R. (2015). Intimate Partner Violence Surveillance: Uniform Definitions and Recommended Data Elements. Center for Disease Control and Prevention, Version 2.0.

2. Breiding, M. J., Basile, K. C., Smith, S. G., Black, M. C., \& Mahendra, R. (2015). Intimate Partner Violence Surveillance: Uniform Definitions and Recommended Data Elements. Center for Disease Control and Prevention, Version 2.0. 
The most common form of child abuse is neglect. Child neglect is a deficit in meeting a child's basic needs, such as failure to provide adequate nutrition, supervision, health care, clothing, or housing, as well as other physical, emotional, social, educational, and safety needs. All societies have established necessary behaviors a caregiver must provide in order for a child to develop well within the domains of physical, social, and emotional development. Causes of neglect may result from caregivers experiencing problems associated with mental disorders, unplanned pregnancy, substance abuse, unemployment, over-employment, domestic violence, and, in special cases, poverty.

Child neglect depends on how a child and society perceives the caregivers' behaviors; it is not how parents or caregivers believe they are behaving toward their child. ${ }^{3}$ Caregiver's failure to provide for a child, when options are available, is different from failure to provide when options are not available. Poverty and lack of resources are often contributing factors that may prevent caregivers from meeting children's needs, when they otherwise would be able to meet those needs. ${ }^{4}$

There are various types of child neglect which include:

- Physical neglect is the failure to provide a child with basic necessities of life such as adequate food, shelter, and clothing.

- Medical neglect is the failure of caregivers to meet a child's basic health care needs. Examples include not brushing teeth on a daily basis, not bathing a child, and/or taking children to doctor visits when needed.

- Emotional neglect is the failure to provide emotional support such as emotional security and encouragement (love, nurturance, etc.).

- Educational and developmental neglect include the failure to provide children with experiences necessary for normative growth and development. These may include failing to ensure children receive adequate education or experiences that help foster normative, developmental standards.

- Depending on the laws and child protective policies in one's area, leaving a young child unsupervised may be considered neglect, especially if doing so places the child in danger.

3. Barnett, W. S., \& Belfield, C. R. (2006). Early childhood development and social mobility. The Future of Children. Princeton University. 16(2). 73-98. doi:10.1353/foc.2006.0011

4. This section is adapted in part from $\underline{\text { Child neglect }}$ by Wikimedia contributors, licensed CC BY SA. 
All types of abuse are complex issues, especially within families. There are many reasons people may become abusers, such as poverty, stress, and substance abuse are common characteristics shared by abusers, although abuse can happen in any family.

Children who experience any type of abuse may "act out" or respond in a variety of unhealthful ways. These may include acts of self-destruction, withdrawal, and aggression, and struggles with depression, anxiety, and academic performance. Researchers have found that abused children's brains may produce higher levels of stress hormones. These hormones can lead to decreased brain development, lower stress thresholds, suppressed

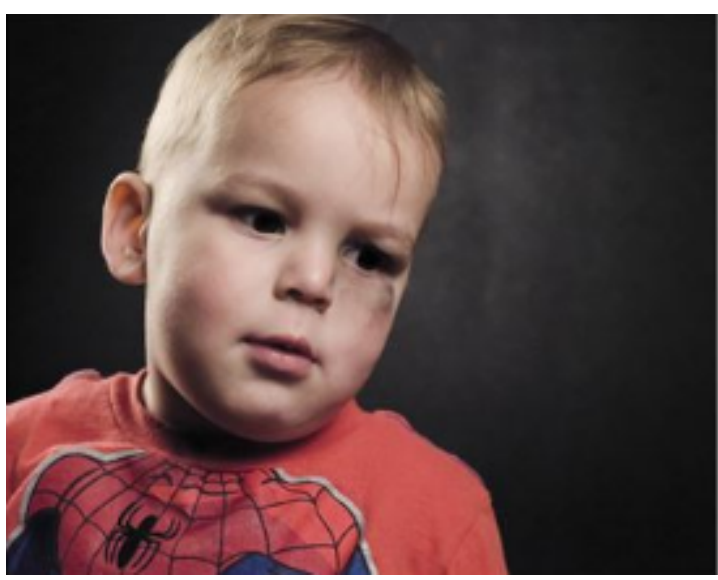

Figure 1. While physical abuse might be the easiest to see, neglect is much more common. (Photo Source: US Air Force) immune responses, and lifelong difficulties with learning and memory. ${ }^{5}$ Abused children are much more likely than children who are not abused to end up with various developmental, psychological, and behavioral problems throughout their life course. In particular, they are more likely to be aggressive, to use alcohol and other drugs, to be anxious and depressed, and to get divorced if they marry. 6

Children who experience abuse or neglect are at risk of developing lifelong social, emotional, and health problems, particularly if neglected before the age of two years. This is consistent with what we learned about ACEs. However, it is important to note that not all children who experience abuse and neglect will have the same outcomes. As we learned, there are many ways in which we can foster stable, permanent, safe, secure, nurturing, loving care for children who have been associated with reduced effects of ACEs.

It is extremely important to understand the ways in which child abuse and neglect can be prevented, such as those listed in this infographic from the CDC. For more information, visit cdc.gov/ violenceprevention/childabuseandneglect.

\section{Shaken Baby Syndrome}

Click here to learn more about shaken baby syndrome.

5. Middlebrooks, J. S., \& Audage, N. C. (2008). The Effects of Childhood Stress on Health Across the Lifespan. Centers for Disease Control and Prevention, National Center for Injury Prevention and Control. Atlanta, GA.

6. Laff, R., \& Ruiz, W. (2019). Child, Family, and Community. College of the Canyons. Open Textbook Library. https://open.umn.edu/opentextbooks/textbooks/child-family-and-community 


\section{Corporal Punishment}

Worldwide initiatives have recommended banning the use of corporal punishment with or in children of all ages. According to the Global Initiative to End all Corporal Punishment of Children, corporal punishment is defined as "any punishment in which physical force issued and intended to cause some degree of pain or discomfort, however light". ${ }^{7}$ Examples include shaking, kicking, forcing ingestion (e.g., soap, hot sauce), and "smacking," "slapping," or "spanking" with any object or a hand. Nonphysical forms of punishment (e.g., verbal and emotional abuse) include activities that are intended to cause shame to a person such as humiliation, threats, ridicules, etc.

Vast amounts of research have consistently demonstrated strong correlations between youth who experienced harsh punishment (e.g., spanking) by their parents and increased risks of:

- changes in brain physiology that show on MRI studies,

- mental health disorders such as depression or anxiety,

- elevated cortisol levels,

- cognitive problems,

- aggressive behaviors,

- unhealthy caregiver-child relationships,

- suicide attempts,

- moderate-to-heavy drinking,

- substance use disorders,

- misconduct, and

- adverse outcomes that extend into adulthood.

\section{Key Takeaways}

- Corporal punishment is not an effective method for teaching or changing performance.

- Corporal punishment has been linked to many negative outcomes.

- Caregivers should utilize methods other than corporal punishment to effectively and optimally guide children's behaviors and learning.

7. Wolraich, M. L., Aceves, J., Feldman, H. M., Hagan, J.F, Howard, B.J., Richtsmeier, A. J., Tolchin, D., \& Tolmas, H. C. (1998). Guidance for Effective Discipline. Pediatrics, 101(4) 723-728; DOI: https://doi.org/10.1542/peds.101.4.723. 


\section{Foster Care}

In the United States and in some other countries, another way to immediately protect children from further abuse is to remove them from their primary caregivers and place them into foster care or with family members. Foster care is a system in which a minor is placed into a group home (residential child care community, treatment center, etc.), or private home of a statecertified caregiver, referred to as a "foster parent," or with a family member approved by the state. The placement of the child is normally arranged through the government or a social service agency. The institution, group home, or foster parent is typically compensated for expenses unless the child is placed with a family member. ${ }^{8}$

In the United States, on any given day, there are more than 400,000 youth living in foster care (outof-home care) primarily due to abuse and/or neglect. And, more than 100,000 of these youth are waiting to be adopted from foster care. This means that these parents have lost permanent legal rights and custody of their children, leaving their children without any permanently legal caregivers (the government assumes this responsibility until someone adopts the children). The average age of youth waiting to be adopted from foster care is eight years old. Contrary to popular belief, it typically does not cost any money to adopt a child from foster care. For more information about becoming a foster parent or adopting from foster care, visit: www.adoptuskids.org. For additional statistics about adoption and foster care visit the Adoption and Foster Care Statistics website.

\section{(ㅇ) (1) (2)}

Child Abuse, Neglect, and Foster Care by Diana Lang and Wikimedia contributors is licensed under a Creative Commons AttributionShareAlike 4.0 International License, except where otherwise noted. 


\title{
ADOPTION
}

\author{
Diana Lang
}

Adoption of children is one of many ways in which families are formed. Adoption, the legal transfer of parental rights of a child to another person, can occur in many ways and elicit a wide variety of family types. In the United States, statistics for the total number of all types of adoptions are not compiled on a regular basis and statistics are not at all compiled for some adoption types. Adoption statistics and estimates are based on U.S. Census data and other sources. It is estimated that approximately $2-4 \%$ of all Americans are adopted. ${ }^{1}$

As we learned previously, more than 100,000 youth (with an average age of 8 years) are waiting to be adopted from foster care. But, a majority of individuals wish to adopt an infant. According to research, millions of American women have expressed a desire to adopt an infant ${ }^{2}$ and tens of thousands of families are waiting to adopt an infant.

However, it is also estimated that fewer than 20,000 babies are voluntarily placed for adoption each year in the United States. Certainly, there are thousands fewer infants placed for adoption than families waiting to adopt an infant. Research has shown that placing a baby for adoption can serve as a preventive option of child abuse and neglect for individuals who are not ready to parent, able to parent, or willing to parent. $^{3} 45$

Thus, it is a best-practice approach that individuals experiencing unplanned or unwanted pregnancies be provided the most accurate information concerning their options for parenting, adoption, the processes associated with all options, etc. ${ }^{6}$

1. Child Welfare Information Gateway. (2016). Trends in U.S. adoptions: 2008-12. Washington, DC: U.S. Department of Health and Human Services, Children's Bureau. Retrieved from https://www.childwelfare.gov/pubPDFs/adopted0812.pdf

2. Jones, J., \& Placek, P. (2017). Adoption by the numbers: A comprehensive report of U.S. adoption statistics. Retrieved from https://www.adoptioncouncil.org/publications/2017/02/adoption-by-the-numbers

3. Van IJzendoorn, M.H., \& Juffer, F. (2006). The Emanuel Miller Memorial Lecture 2006: Adoption as intervention. Metaanalytic evidence for massive catch-up and plasticity in physical, socio-emotional, and cognitive development. Journal of Child Psychology and Psychiatry, 47(12); 1228-1245 doi:10.1111/j.1469-7610.2006.01675.x

4. Van IJzendoorn, M.H., Juffer, F., \& Klein Poelhuis, C.W. (2005). Adoption and cognitive development: A meta-analytic comparison of adopted and non-adopted children's IQ and school performance. Psychological Bulletin, 131, $301-316$.

5. Van IJzendoorn, M.H., \& Juffer, F. (2005). Adoption is a successful natural intervention enhancing adopted children's IQ and school performance. Current Directions in Psychological Science, 14(6); 326 -330 https://doi.org/10.1111/ j.0963-7214.2005.00391.x

6. Gallagher, J.R., \& Rycraft, J.R. (2014). Evaluation of the Infant Adoption Awareness trainings: Transforming training knowledge to adoption practice. Adoption Quarterly, 17(4), 253-279. DOI: 10.1080/10926755.2014.891552 
In the U.S., it is common for birth parents to choose their baby's adoptive parents, and in some cases, adoptive and birth family members are able to maintain some contact with each other. It is important to note that infants who are voluntarily placed are typically taken home immediately from the birthing location by their adopting family. In conclusion, fewer children may end up in foster care if their parents were advised of their options for adoption and parenting. To learn how to educate parents about the option of placing their baby for adoption view this pdf, Adoption: Considering Your Options and Making a Plan [pdf]

\section{Family Types}

There are numerous adoptive family types. Below is a brief definition of each family type.

- Infant/newborn/domestic: A child who is born in a country and who is adopted shortly after birth (within the same country).

- Transnational/Intercountry/International: A child who is born in one country and is adopted by a family who lives in another country. Often, the child is orphaned. For statistics and information about intercountry adoptions visit this website.

- Kin: Children adopted by a relative such as an aunt, uncle, sister, brother, grandparent, or other relative.

- Foster care: Children who are no longer able to be cared for by their primary caregiver(s) who are adopted by another family member.

- Stepparent: Children adopted by one parent's spouse; the spouse agrees to take full responsibility for the child.

The following forms of adoption are a result of assisted reproductive technology (methods that utilize medical technology to achieve conception and birth). In most U.S. states, these forms require the legal transfer of parental rights to another parent(s).

- Embryo: Families can adopt an embryo produced from the sperm and egg of one couple. Clinics and agencies help match donating families and recipient/adopting families.

- Surrogacy: A surrogate mother carries a fertilized egg in utero. After the birth of the child, the intended parent(s) adopt(s) the child.

Below are some of the more commonly-used terms associated with adoption and the legal process.

- Adoption Triad: Birth parents, adoptive parents, and the adopted child(ren).

- Disrupted Adoption: An adoption agreement that ends before finalization.

- Dissolution of Adoption: An adoption that ends after finalization.

- Interstate Compact on the Placement of Children: A law that requires written notice and prior approval of the placement of a child for adoption or foster care from one state with a 
family in another state.

- Kinship care: The full-time nurturing of a child by someone related to the child by family ties or by prior relationship connection (fictive kin).

- Reunification: The returning of foster children to the custody of their parent(s) after placement outside the home.

- Relinquishment/Termination of Parental Rights: The legal step necessary for parents to voluntarily or involuntarily have their parental rights terminated to allow their child to be adopted by adoptive parents; sometimes referred to as a surrender or as making an adoption plan for one's child.

- Special Needs: Children with physical, behavioral, or mental impairments, children with siblings in need of adoption, and at-risk children.

Before and after the legal transfer of parental rights, families can decide how they may stay in contact after the child is no longer a legal member of the birth family. This decision is referred to as "levels of openness" or "degrees of contact."

\section{Levels of Openness/Degrees of Contact}

Non-identifying information: Information that allows the members of the adoption triad to know about each other, but without identifying information. First names, physical descriptions, occupation, education, personality characteristics, hobbies, interests, religious affiliation, and medical information are examples of non-identifying information.

Semi-open adoption: An adoption in which a child's birth parents and adoptive parents may exchange primarily non-identifying information. After the child is placed in the adoptive home, contact with the birth family may involve letters or pictures or other communications sent through the intermediary of the adoption agency or the attorney who assisted in the placement.

Closed adoption: An adoption that involves total confidentiality and sealed records; contact does not exist between any members of either family.

Identifying information: Information concerning birth parents which discloses their identities.

Open adoption: An adoption that involves some amount of initial and/or ongoing contact between birth and adoptive families, ranging from sending letters through the agency, to exchanging names, and/or scheduling visits.

\section{Terminology}

Using accurate adoption language can stop the spread of adoption-related misconceptions and educate others about adoption. For instance, the phrase "choosing to place your child for adoption" 
has a much more positive connotation than "giving up your baby." "Choosing to place your child for adoption" focuses on the fact that parents most likely considered options and chose the option they felt was best for the child. It is important to use appropriate terms so that accurate language may someday be the norm. Below is a list of "accurate adoption terminology."

Table: Adoption terminology, accurate and inaccurate language

\begin{tabular}{cc}
\hline Accurate Language & Inaccurate Language \\
\hline Birthparent, first parent & Real parent, natural parent \\
\hline My child & Adopted child \\
\hline Choosing an adoption plan & Giving away/giving up your child \\
\hline Finding a family to parent your child & Putting your child up for adoption \\
\hline Deciding to parent the child & Keeping your baby \\
\hline To parent & To keep \\
\hline Child in need of a family/parent & Adoptable child; Available child \\
\hline International or intercountry adoption & Foreign adoption \\
\hline Child who has special needs & Handicapped child, hard to place \\
\hline Child from another country & Foreign child \\
\hline Was adopted & Is adopted \\
\hline
\end{tabular}

\section{Key Takeaways}

- Adoption is a legal transfer of parental rights of a child

- There are many types of adoption and ways to build a family

- Families can negotiate how they wish to communicate after the adoption process is completed

- Using appropriate adoption terminology is very important 


\section{EXCEPTIONALITIES}

\section{Intellectual Disability and Giftedness}

The results of studies assessing the measurement of intelligence show that IQ is distributed in the population in the form of a Normal Distribution (or bell curve), which is the pattern of scores usually observed in a variable that clusters around its average. In a normal distribution, the bulk of the scores fall toward the middle, with many fewer scores falling at the extremes. The normal distribution of intelligence shows that on IQ tests, as well as on most other measures, the majority of people cluster around the average (in this case, where IQ =100), and fewer are either very smart or very dull (see Figure 5.13). Because the standard deviation of an IQ test is about 15, this means that about $2 \%$ of people score above an IQ of 130, often considered the threshold for giftedness, and about the same percentage score below an IQ of 70, often being considered the threshold for an intellectual disability.

Although Figure 5.13 presents a single distribution, the actual IQ distribution varies by sex such that the distribution for men is more spread out than is the distribution for women. These sex differences mean that about $20 \%$ more men than women fall in the extreme (very smart or very dull) ends of the distribution. ${ }^{1}$ Boys are about five times more likely to be diagnosed with the reading disability dyslexia than are girls, and are also more likely to be classified as having an intellectual disability. ${ }^{2}$ However, boys are also about 20\% more highly represented in the upper end of the IQ distribution.

1. Johnson, W., Carothers, A., \& Deary, I. J. (2009). A role for the X chromosome in sex differences in variability in general intelligence? Perspectives on Psychological Science, 4(6), 598-611.

2. Halpern, D. F. (1992). Sex differences in cognitive abilities (2nd ed.). Hillsdale, NJ: Lawrence Erlbaum Associates. 


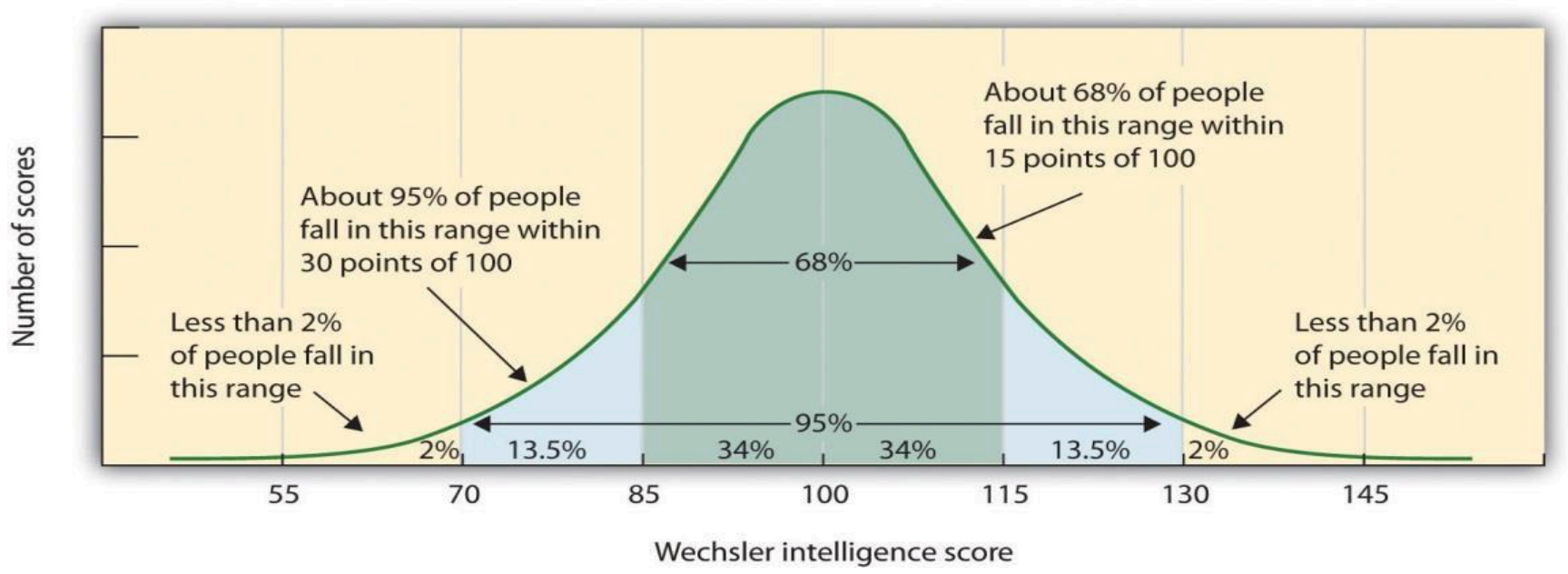

Figure 3. Distribution of IQ Scores in the General PopulationThe normal distribution of IQ scores in the general population shows that most people have about average intelligence, while very few have extremely high or extremely low intelligence.

One end of the distribution of intelligence scores is defined by people with very low IQ. Intellectual disability (or intellectual developmental disorder) is assessed based on cognitive capacity (IQ) and adaptive functioning. The severity of the disability is based on adaptive functioning, or how well the person handles everyday life tasks. About $1 \%$ of the United States population, most of them males, fulfill the criteria for intellectual developmental disorder, but some children who are given this diagnosis lose the classification as they get older and better learn to function in society. A particular vulnerability of people who have a low IQ is that they may be taken advantage of by others, and this is an important aspect of the definition of intellectual developmental disorder. ${ }^{3}$

One cause of intellectual developmental disorder is Down syndrome, a chromosomal disorder caused by the presence of all or part of an extra 21 st chromosome. The incidence of Down syndrome is estimated at approximately 1 per 700 births, and the prevalence increases as the mother's age increases. ${ }^{4}$ People with Down syndrome typically exhibit a distinctive pattern of physical features, including a flat nose, upwardly slanted eyes, a protruding tongue, and a short neck.

Fortunately, societal attitudes toward individuals with intellectual disabilities have changed over the past decades. We no longer use terms such as "retarded," "moron," "idiot," or "imbecile" to describe people with intellectual deficits, although these were the official psychological terms used to describe degrees of what was referred to as mental retardation in the past. Laws such as the Americans with

3. Greenspan, S., Loughlin, G., \& Black, R. S. (2001). Credulity and gullibility in people with developmental disorders: A framework for future research. In L. M. Glidden (Ed.), International review of research in mental retardation (Vol. 24, pp. 101-135). San Diego, CA: Academic Press.

4. Centers for Disease Control and Prevention. (2014). Birth defects. Retrieved from https://www.cdc.gov/ncbddd/birthdefects/ downsyndrome/data.html 
Disabilities Act (ADA) have made it illegal to discriminate on the basis of mental and physical disability, and there has been a trend to bring people with mental disabilities out of institutions and into our workplaces and schools.

Giftedness refers to children who have an IQ of 130 or higher. ${ }^{5}$ Having extremely high IQ is clearly less of a problem than having extremely low IQ, but there may also be challenges to being particularly smart. It is often assumed that schoolchildren who are labeled as "gifted" may have adjustment problems that make it more difficult for them to create social relationships. To study gifted children, Lewis Terman and his colleagues selected about 1,500 high school students who scored in the top 1\% on the Stanford-Binet and similar IQ tests (i.e., who had IQs of about 135 or higher), and tracked them for more than seven decades (the children became known as the "termites" and are still being studied today). ${ }^{6}$ This study found that these students were not unhealthy or poorly adjusted, but rather were above average in physical health and were taller and heavier than individuals in the general population. The students also had above-average social relationships and were less likely to divorce than the average person. ${ }^{7}$

Terman's study also found that many of these students went on to achieve high levels of education and entered prestigious professions, including medicine, law, and science. ${ }^{8}$ Of the sample, $7 \%$ earned doctoral degrees, $4 \%$ earned medical degrees, and 6\% earned law degrees. These numbers are all considerably higher than what would have been expected from a more general population. Another study of young adolescents who had even higher IQs found that these students ended up attending graduate school at a rate more than 50 times higher than that in the general population. ${ }^{9}$

As you might expect based on our discussion of intelligence, kids who are gifted have higher scores on general intelligence "g", but there are also different types of giftedness. Some children are particularly good at math or science, some at automobile repair or carpentry, some at music or art, some at sports or leadership, and so on. There is a lively debate among scholars about whether it is appropriate or beneficial to label some children as "gifted and talented" in school and to provide them with accelerated special classes and other programs that are not available to everyone. Although doing so may help the gifted kids, it also may isolate them from their peers and make such provisions unavailable to those who are not classified as "gifted." 10

5. Lally, M. J., \& Valentine-French, S. J. (2015). Introduction to Psychology [Adapted from Charles Stangor, Introduction to Psychology] Grayslake, IL: College of Lake County.

6. Terman, L. M., \& Oden, M. H. (1959). Genetic studies of genius: The gifted group at mid-life (Vol. 5). Stanford, CA: Stanford University Press.

7. Seagoe, M. V. (1975). Terman and the gifted. Los Altos, CA: William Kaufmann.

8. Terman, L. M., \& Oden, M. H. (1959). Genetic studies of genius: The gifted group at mid-life (Vol. 5). Stanford, CA: Stanford University Press.

9. Lubinski, D., \& Benbow, C. P. (2006). Study of mathematically precocious youth after 35 years: Uncovering antecedents for the development of math-science expertise. Perspectives on Psychological Science, 1(4), 316-345.

10. Colangelo, N., \& Assouline, S. (2009). Acceleration: Meeting the academic and social needs of students. In T. Balchin, B. 


\section{Children with Disabilities}

A Learning Disability (or LD) is a specific impairment of academic learning that interferes with a specific aspect of schoolwork and that reduces a student's academic performance significantly. An LD shows itself as a major discrepancy between a student's ability and some feature of achievement: The student may be delayed in reading, writing, listening, speaking, or doing mathematics, but not in all of these at once. A learning problem is not considered a learning disability if it stems from physical, sensory, or motor handicaps, or from generalized intellectual impairment. It is also not an LD if the learning problem really reflects the challenges of learning English as a second language. Genuine LDs are the learning problems left over after these other possibilities are accounted for or excluded. Typically, a student with an LD has not been helped by teachers' ordinary efforts to assist the student when he or she falls behind academically, though what counts as an "ordinary effort", of course, differs among teachers, schools, and students. Most importantly, though, an LD relates to a fairly specific area of academic learning. A student may be able to read and compute well enough, for example, but not be able to write. LDs are by far the most common form of special educational need, accounting for half of all students with special needs in the United States and anywhere from 5 to 20 percent of all students, depending on how the numbers are estimated. ${ }^{11} 12$ Students with LDs are so common, in fact, that most teachers regularly encounter at least one per class in any given school year, regardless of the grade level they teach.

These difficulties are identified in school because this is when children's academic abilities are being tested, compared, and measured. Consequently, once academic testing is no longer essential in that person's life (as when they are working rather than going to school) these disabilities may no longer be noticed or relevant, depending on the person's job and the extent of the disability.

Dyslexia is one of the most commonly diagnosed disabilities and involves having difficulty in the area of reading. This diagnosis is used for a number of reading difficulties. Common characteristics are difficulty with phonological processing, which includes the manipulation of sounds, spelling, and rapid visual/verbal processing. Additionally, the child may reverse letters, have difficulty reading from left to right, or may have problems associating letters with sounds. It appears to be rooted in neurological problems involving the parts of the brain active in recognizing letters, verbally responding, or being able to manipulate sounds. Recent studies have identified a number of genes

Hymer, \& D. J. Matthews (Eds.), The Routledge international companion to gifted education (pp. 194-202). New York, NY: Routledge.

11. United States Department of Education. (2005). 27th Annual Report to Congress on the implementation of the Individuals with Disabilities Education Act. Washington, D.C.: Author.

12. Ysseldyke, J. \& Bielinski, J. (2002). Effect of different methods of reporting and reclassification on trends in test scores for students with disabilities. Exceptional Children, 68(2), 189-201. 
that are linked to developing dyslexia. ${ }^{13}$ Treatment typically involves altering teaching methods to accommodate the person's particular problematic area.

\section{ADHD}

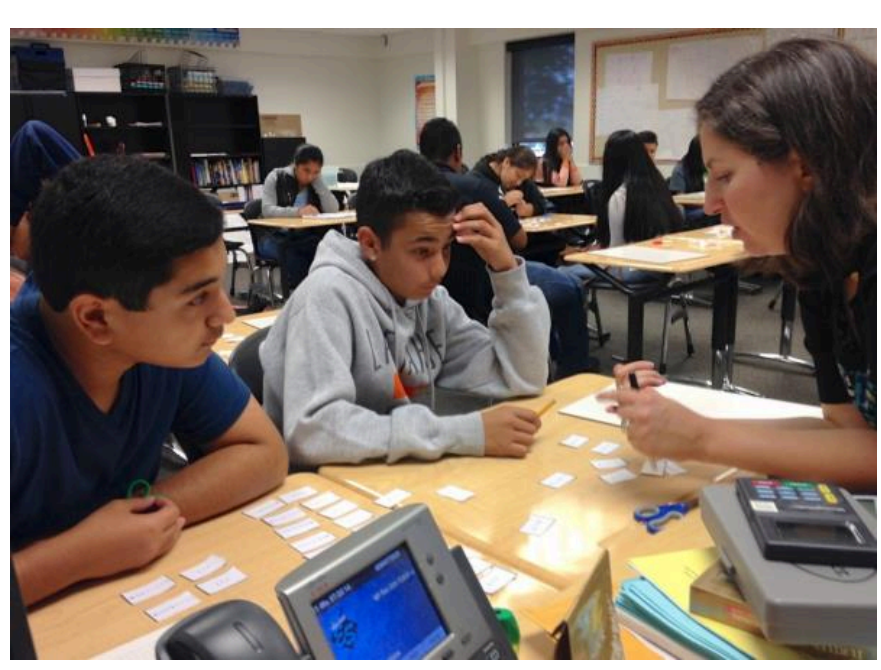

Figure 4. Some adolescents find it difficult to concentrate on complex tasks due to ADHD.
A child with Attention Deficit Hyperactivity

Disorder (ADHD) shows a constant pattern of inattention and/or hyperactive and impulsive behavior that interferes with normal functioning. ${ }^{14}$ Some of the signs of inattention include great difficulty with, and avoidance of, tasks that require sustained attention (such as conversations or reading), failure to follow instructions (often resulting in failure to complete schoolwork and other duties), disorganization (difficulty keeping things in order, poor time management, sloppy and messy work), lack of attention to detail, becoming easily distracted, and forgetfulness. Hyperactivity is characterized by excessive movement, and includes fidgeting or squirming, leaving one's seat in situations when remaining seated is expected, having trouble sitting still (e.g., in a restaurant), running about and climbing on things, blurting out responses before another person's question or statement has been completed, difficulty waiting for one's turn for something, and interrupting and intruding on others. Frequently, the hyperactive child comes across as noisy and boisterous. The child's behavior is hasty, impulsive, and seems to occur without much forethought; these characteristics may explain why adolescents and young adults diagnosed with ADHD receive more traffic tickets and have more automobile accidents than do others their age. ${ }^{15}$

13. National Institute of Neurological Disorders and Stroke. (2016). Dyslexia Information Page. Retrieved from https://www.ninds.nih.gov/Disorders/All-Disorders/Dyslexia-Information-Page

14. American Psychiatric Association. (2013). Diagnostic and statistical manual of mental disorders (5th ed.). Washington, DC: American Psychiatric Association.

15. Thompson, A., Molina, B. S. G., Pelham, W., \& Gnagy, E. M. (2007). Risky driving in adolescents and young adults with childhood ADHD. Journal of Pediatric Psychology, 32, 745-759. 


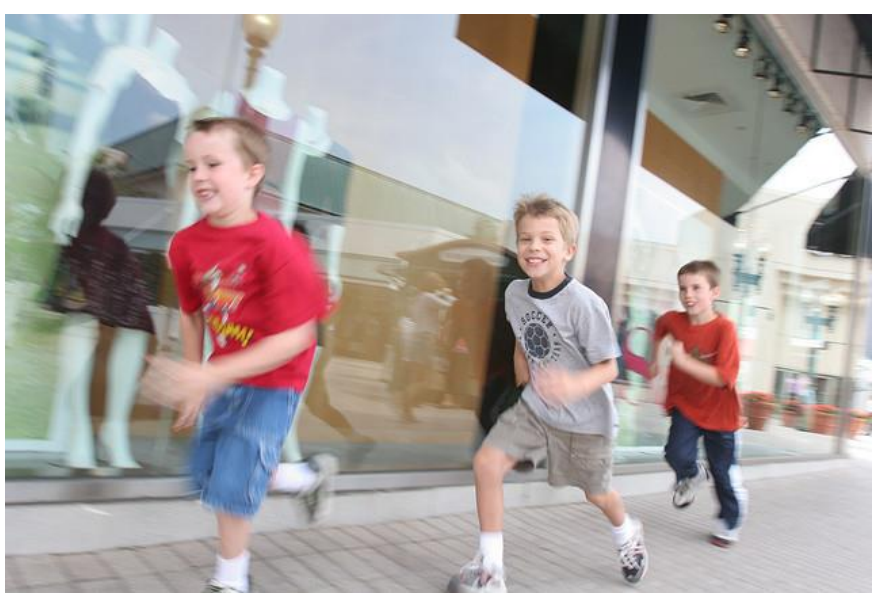

Figure 5. Children may be hyperactive or exceptionally quiet when exhibiting signs of ADHD. Symptoms tend to display differently in girls.
ADHD occurs in about $5 \%$ of children. ${ }^{16}$ On average, boys are 3 times more likely to have ADHD than are girls; however, such findings might reflect the greater propensity of boys to engage in aggressive and antisocial behavior and thus incur a greater likelihood of being referred to psychological clinics. ${ }^{17}$ Children with ADHD face severe academic and social challenges. Compared to their non-ADHD counterparts, children with ADHD have lower grades and standardized test scores and higher rates of expulsion, grade retention, and dropping out. ${ }^{18}$ They also are less well-liked and more often rejected by their peers. ${ }^{19}$

ADHD can persist into adolescence and adulthood. ${ }^{20}$ A recent study found that $29.3 \%$ of adults who had been diagnosed with ADHD decades earlier still showed symptoms. ${ }^{21}$ Somewhat troubling, this study also reported that nearly $81 \%$ of those whose ADHD persisted into adulthood had experienced at least one other comorbid disorder, compared to 47\% of those whose ADHD did not persist. Additional concerns when an adult has ADHD include Worse educational attainment, lower socioeconomic status, less likely to be employed, more likely to be divorced, and more likely to have non-alcohol-related substance abuse problems. ${ }^{22}$

\section{Causes of ADHD}

Family and twin studies indicate that genetics play a significant role in the development of ADHD.

16. American Psychiatric Association. (2013). Diagnostic and statistical manual of mental disorders (5th ed.). Washington, DC: American Psychiatric Association.

17. Barkley, R. A. (2006). Attention-deficit hyperactivity disorder: A handbook for diagnosis and treatment. New York, NY: Guilford Press.

18. Loe, I. M., \& Feldman, H. M. (2007). Academic and educational outcomes of children with ADHD. Journal of Pediatric Psychology, 32, 643-654.

19. Hoza, B., Mrug, S., Gerdes, A. C., Hinshaw, S. P., Bukowski, W. M., Gold, J. A., . . Arnold, L. E. (2005). What aspects of peer relationships are impaired in children with ADHD? Journal of Consulting and Clinical Psychology, 73, 411-423.

20. Barkley, R. A., Fischer, M., Smallish, L., \& Fletcher, K. (2002). The persistence of attention-deficit/hyperactivity disorder into young adulthood as a function of reporting source and definition of disorder. Journal of Abnormal Psychology, 111, 279-289.

21. Barbaresi, W. J., Colligan, R. C., Weaver, A. L., Voigt, R. G., Killian, J. M., \& Katusic, S. K. (2013). Mortality, ADHD, and psychosocial adversity in adults with childhood ADHD: A prospective study. Pediatrics, 131, 637-644.

22. Klein, R. G., Mannuzza, S., Olazagasti, M. A. R., Roizen, E., Hutchison, J. A., Lashua, E. C., \& Castellanos,F. X. (2012). Clinical and functional outcome of childhood attention-deficit/hyperactivity disorder 33 years later. Archives of General Psychiatry, 69, 1295-1303. 
Burt (2009), in a review of 26 studies, reported that the median rate of concordance for identical twins was .66, whereas the median concordance rate for fraternal twins was $.20 .{ }^{23}$ The specific genes involved in ADHD are thought to include at least two that are important in the regulation of the neurotransmitter dopamine, ${ }^{24}$ suggesting that dopamine may be important in ADHD. Indeed, medications used in the treatment of ADHD, such as methylphenidate (Ritalin) and amphetamine with dextroamphetamine (Adderall), have stimulant qualities and elevate dopamine activity. People with ADHD show less dopamine activity in key regions of the brain, especially those associated with motivation and reward, ${ }^{25}$ which provides support to the theory that dopamine deficits may be a vital factor in the development of this disorder. ${ }^{26}$

Brain imaging studies have shown that children with ADHD exhibit abnormalities in their frontal lobes, an area in which dopamine is in abundance. Compared to children without ADHD, those with ADHD appear to have smaller frontal lobe volume, and they show less frontal lobe activation when performing mental tasks. Recall that one of the functions of the frontal lobes is to inhibit our behavior. Thus, abnormalities in this region may go a long way toward explaining the hyperactive, uncontrolled behavior of ADHD.

Although some food additives have been shown to increase hyperactivity in non-ADHD children, the effect is rather small. ${ }^{27}$ Numerous studies, however, have shown a significant relationship between exposure to nicotine in cigarette smoke during the prenatal period and ADHD. ${ }^{28}$ Maternal smoking during pregnancy is associated with the development of more severe symptoms of the disorder. ${ }^{29}$

23. Burt, S. A. (2009). Rethinking environmental contributions to child and adolescent psychopathology: A meta-analysis of shared environmental influences. Psychological Bulletin, 135, 608-637.

24. Gizer, I. R., Ficks, C., \& Waldman, I. D. (2009). Candidate gene studies of ADHD: A meta-analytic review. Human Genetics, 126, 51-90.

25. Volkow N. D., Fowler J. S., Logan J., Alexoff D., Zhu W., Telang F., . . Apelskog-Torres K. (2009). Effects of modafinil on dopamine and dopamine transporters in the male human brain: clinical implications. Journal of the American Medical Association, 301, 1148-1154.

26. Swanson, J. M., Kinsbourne, M., Nigg, J., Lamphear, B., Stefanatos, G. A., Volkow, N., ...\& Wadhwa, P. D. (2007). Etiologic subtypes of attention-deficit/hyperactivity disorder: brain imaging, molecular genetic and environmental factors and the dopamine hypothesis. Neuropsychological Review, 17(1), 39-59.

27. McCann, D., Barrett, A., Cooper, A., Crumpler, D., Dalen, L., Grimshaw, K., ... Stevenson, J. (2007). Food additives and hyperactive behaviour in 3-year-old and 8/9-year-old children in the community: A randomised, double-blinded, placebocontrolled trial. The Lancet, 370(9598), 1560-1567.

28. Linnet, K. M., Dalsgaard, S., Obel, C., Wisborg, K., Henriksen, T. B., Rodriquez, A., .. Jarvelin, M. R.(2003). Maternal lifestyle factors in pregnancy risk of attention deficit hyperactivity disorder and associated behaviors: A review of current evidence. The American Journal of Psychiatry, 160, 1028-1040.

29. Thakur, G. A., Sengupta, S. M., Grizenko, N., Schmitz, N., Page, V., \& Joober, R. (2013). Maternal smoking during pregnancy and ADHD: A comprehensive clinical and neurocognitive characterization. Nicotine and Tobacco Research, 15, $149-157$. 


\section{Treatment for ADHD}

Recommended treatment for ADHD includes behavioral interventions, cognitive behavioral therapy, parent and teacher education, recreational programs, and lifestyle changes, such as getting more sleep. ${ }^{30}$ For some children medication is prescribed. For an overview of treatments options for a variety of ages, please visit this link to the the CDC website. Also visit this site to learn about evidence-based treatment options.

\section{Is the prevalence rate of ADHD increasing?}

Many people believe that the rates of ADHD have increased in recent years, and there is evidence to support this contention. ADHD may be over-diagnosed by doctors who are too quick to medicate children as a behavior treatment. There is also greater awareness of ADHD now than in the past. Nearly everyone has heard of ADHD, and most parents and teachers are aware of its key symptoms. Thus, parents may be quick to take their children to a doctor if they believe their child possesses these symptoms, or teachers may be more likely now than in the past to notice the symptoms and refer the child for evaluation. Further, the use of computers, video games, iPhones, and other electronic devices has become pervasive among children in the early 21 st century, and these devices could potentially shorten children's attention spans. Thus, what might seem like inattention to some parents and teachers could simply reflect exposure to too much technology.

\section{Legislation for Learning Disabilities}

Since the 1970s political and social attitudes have moved increasingly toward including people with disabilities into a wide variety of "regular" activities. In the United States, the shift is illustrated clearly in the Federal legislation that was enacted during this time. Three major laws were passed that guaranteed the rights of persons with disabilities, and of children and students with disabilities in particular. The third law has had the biggest impact on education.

\section{Rehabilitation Act of 1973, Section 504}

This law, the first of its kind, required that individuals with disabilities be accommodated in any program or activity that receives Federal funding. ${ }^{31}$ Although this law was not intended specifically for education, in practice it has protected students' rights in some extra-curricular activities (for older students) and in some child care or after-school care programs (for younger students). If those

30. Clay, R. A. (2013). Psychologists are using research-backed behavioral interventions that effectively treat children with ADHD. Monitor on Psychology, 44(2), 45-47.

31. Public Law 93-112, 87 Stat. 394 (Sept. 26, 1973). Rehabilitation Act of 1973. Washington, D.C.: United States Government Printing Office. 
programs receive Federal funding of any kind, the programs are not allowed to exclude children or youths with disabilities, and they have to find reasonable ways to accommodate the individuals' disabilities.

\section{Americans with Disabilities Act of 1990 (or ADA)}

This legislation also prohibited discrimination on the basis of disability, just as Section 504 of the Rehabilitation Act had done. ${ }^{32}$ Although the ADA also applies to all people (not just to students), its provisions are more specific and "stronger" than those of Section 504. In particular, ADA extends to all employment and jobs, not just those receiving Federal funding. It also specifically requires accommodations to be made in public facilities such as with buses, restrooms, and telephones. ADA legislation is therefore responsible for some of the "minor" renovations in schools that you may have noticed in recent years, like wheelchair-accessible doors, ramps, and restrooms, and public telephones with volume controls.

\section{Individuals with Disabilities Education Act (or IDEA)}

As its name implied this legislation was more focused on education than either Section 504 or ADA. It was first passed in 1975 and has been amended several times since, including most recently in 2004. ${ }^{33}$ In its current form, the law guarantees the following rights related to education for anyone with a disability from birth to age 21 . The first two influence schooling in general, but the last three affect the work of classroom teachers rather directly:

- Free, appropriate education: An individual or an individual's family should not have to pay for education simply because the individual has a disability, and the educational program should be truly educational; i.e., not merely care-taking or babysitting the person.

- Due process: In case of disagreements between an individual with a disability and the schools or other professionals, there must be procedures for resolving the disagreements that are fair and accessible to all parties, including the person himself or herself or the person's representative.

- Fair evaluation of performance in spite of disability: Tests or other evaluations should not assume test-taking skills that a person with a disability cannot reasonably be expected to have, such as holding a pencil, hearing or seeing questions, working quickly, or understanding and speaking orally. Evaluation procedures should be modified to allow for these differences. This provision of the law applies both to evaluations made by teachers and to school-wide or "highstakes" testing programs.

32. Public Law 101-336, 104 Stat. 327 (July 26, 1990). Americans with Disabilities Act of 1990. Washington, D.C.: United States Government Printing Office.

33. Public Law 108-446, 118 Stat. 2647 (December 3, 2004). Individuals with Disabilities Education Improvement Act. Washington, D.C.: United States Government Printing Office. 
- Education in the "least restrictive environment": Education for someone with a disability should provide as many educational opportunities and options for the person as possible, both in the short term and in the long term. In practice, this requirement has meant including students in regular classrooms and school activities as much as possible, though often not totally.

- An individualized educational program: Given that every disability is unique, instructional planning for a person with a disability should be unique or individualized as well. In practice, this provision has led to classroom teachers planning individualized programs jointly with other professionals (like reading specialists, psychologists, or medical personnel) as part of a team.

Evaluation and diagnosis can be the first step in helping provide children with disabilities the type of instruction and resources that will benefit them educationally, but diagnosis and labeling also have social implications. It is important to consider that children can be misdiagnosed and that once a child has received a diagnostic label, the child, teachers, and family members may tend to interpret actions of the child through that label. The label can also influence the child's self-concept. Consider, for example, a child who is misdiagnosed as learning disabled. That child may expect to have difficulties in school, lack confidence, and because of these expectations experience trouble. This self-fulfilling prophecy calls our attention to the power that labels can have whether or not they are accurately applied. It is also important to consider that children's difficulties can change over time; a child who has problems in school may improve later or may live under circumstances as an adult where the problem (such as a delay in math skills or reading skills) is no longer relevant. That person, however, will still have a label as learning disabled. It should be recognized that the distinction between abnormal and normal behavior is not always clear; some abnormal behavior in children is fairly common.

\section{Resources for Children who have Exceptionalities}

- The Office for Civil Rights provides this article on protecting children who have special needs.

- Information on the Individuals with Disabilities Education Act can be found in government $\underline{\text { websites }}$ and independent publications.

- Learn about children who are academically-gifted, by reading this article on academically gifted children and giftedness more generally.

- Parent resources are provided by the National Association for Gifted Children (NAGC).

- The NAGC also offers tip sheets for parents of gifted children.

- Download Gifted 101 [pdf]

- Children who have developmental variations: 1 in 6 children in the U.S. have one or more developmental disabilities or delays [pdf]

- The CDC has information about children who have birth defects, children diagnosed with Autism Spectrum Disorder, and children with Attention Deficit/Hyperactivity Disorder (ADHD). 
- For a more general overview of children's mental health, visit this children's mental health webpage from the CDC.

\section{Prevention and Interventions}

- Targeted Interventions Supporting Parents of Children with Special Needs, Parents Facing Special Adversities, and Parents Involved with Child Welfare Services; Click here for a link to the full book on interventions.

- Helping families that have special needs. 


\section{ADDITIONAL TOPICS THAT CAN IMPACT PARENTING, CHILD-REARING, FAMILIES, AND CHILD OUTCOMES}

There are many different family types (structures) and ways to navigate the complex processes that occur within families. Below are select resources to additional topics that may impact families and children across the world.

\section{Adoption and Foster Care}

For additional information concerning parenting within the contexts of adoption and foster care, read these articles on adoption and foster care.

\section{Family Structures and Associated Processes}

To learn more about divorce and separation, single parents, step-families, and LGBTQ+ families, read these articles on "types of families."

Divorce \& Separation

- https://pediatrics.aappublications.org/content/138/6/e20163020

- https://www.apa.org/topics/healthy-divorce

Single parents

- https://www.mayoclinic.org/healthy-lifestyle/childrens-health/in-depth/single-parent/ art-20046774

- https://www.apa.org/topics/single-parent

Step-families

- https://www.mayoclinic.org/healthy-lifestyle/childrens-health/in-depth/stepfamilies/ art-20047046

- https://www.apa.org/topics/stepfamily

LGBTQ+ families 
- LGBTQ-families-factsheet [pdf]

- https://www.hopkinsmedicine.org/diversity/resources/lgbtq-resources.html

\section{Grandparents Rearing Grandchildren}

- Here is another resource on the topic: Grandparents Raising Grandchildren [pdf]

- U.S. Census data on this topic can be found online: Grandparents and the opioid crisis.

\section{Racism}

- Information on the intersection between racism and health.

- Talking to kids about racism can be tough. For more information, visit this article with advice for talking about racism and this article for parents addressing racial bias.

\section{Gender Identity}

- Gender-Diverse \& Transgender Children - HealthyChildren.org

- Healthy Gender Development and Young Children

\section{Coping in a Pandemic}

The CDC also offers information on helping children cope during the pandemic.

\section{Poverty}

An infographic on the effect of poverty on infants and toddlers.

\section{Family Media Plan}

How to create a family media plan.

\section{The Importance of Family Meal Time}

- A video about family relationships.

- The importance of family dinners.

- The benefits of family dinners.

- How to have a healthy family table [pdf] 
180 | ADDITIONAL TOPICS THAT CAN IMPACT PARENTING, CHILD-REARING, FAMILIES, AND CHILD OUTCOMES

\section{Rituals}

To learn more, read this article about family rituals.

Community-based Partnerships

Young African American Boys Early Education Readiness Program

\section{HPV Vaccine Recommendations (for all genders through age 45 years)}

$\underline{\text { HPV vaccine recommendations. }}$

\section{Pornography, Sex Trafficking, and Human Trafficking}

- Safeguarding children from pornography.

- The Impact of Pornography on Children [pdf]

- 2018 Statistics from the National Human Trafficking Hotline [pdf]

- Human trafficking in Iowa.

- Recognizing the signs of human trafficking.

\section{Sextortion}

- Tips on Protecting Youth From Sextortion [pdf]

- $\underline{\text { A video about sextortion }}$

A comprehensive list of other topics can be found here. 
PART VII

DEVELOPMENTAL MILESTONES 


\section{DEVELOPMENTAL MILESTONES AND POSITIVE PARENTING TIPS}

\section{Infants ( $0-1$ year $)$}

Centers for Disease Control and Prevention. (2020). Developmental Milestones Checklist at 2 months [pdf]. Washington, DC: U.S. Department of Health and Human Services, Children's Bureau.

Centers for Disease Control and Prevention. (2020). Developmental Milestones Checklist at 4 months [pdf]. Washington, DC: U.S. Department of Health and Human Services, Children's Bureau.

Centers for Disease Control and Prevention. (2020). Developmental Milestones Checklist at 6 months [pdf]. Washington, DC: U.S. Department of Health and Human Services, Children's Bureau.

Centers for Disease Control and Prevention. (2020). Developmental Milestones Checklist at 9 months [pdf]. Washington, DC: U.S. Department of Health and Human Services, Children's Bureau.

Centers for Disease Control and Prevention. (2020). Developmental Milestones Checklist at 1 year [pdf]. Washington, DC: U.S. Department of Health and Human Services, Children's Bureau.

Centers for Disease Control and Prevention. (2020). Positive parenting tips for healthy child development infants (0-1 year of age) [pdf]. Washington, DC: U.S. Department of Health and Human Services, Children's Bureau.

\section{Toddlers (1-2 years)}

Centers for Disease Control and Prevention. (2020). Developmental Milestones Checklist at 18 months [pdf]. Washington, DC: U.S. Department of Health and Human Services, Children's Bureau.

Centers for Disease Control and Prevention. (2020). Positive parenting tips for healthy child development toddlers (1-2 year of age) [pdf]. Washington, DC: U.S. Department of Health and Human Services, Children's Bureau.

\section{Toddlers ( $2-3$ years)}

Centers for Disease Control and Prevention. (2020). Developmental Milestones Checklist at 2 years [pdf]. Washington, DC: U.S. Department of Health and Human Services, Children's Bureau. 
Centers for Disease Control and Prevention. (2020). Positive parenting tips for healthy child development toddlers (2-3 year of age) [pdf]. Washington, DC: U.S. Department of Health and Human Services, Children's Bureau.

\section{Preschoolers (3-5 years)}

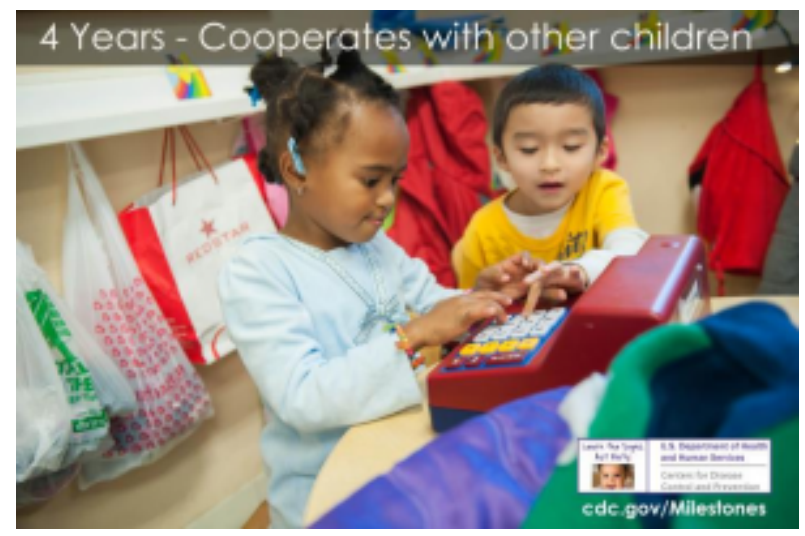

(Photo Credit: $\underline{\mathrm{CDC}}$

Centers for Disease Control and Prevention. (2020). Developmental Milestones Checklist at 3 years [pdf]. Washington, DC: U.S. Department of Health and Human Services, Children's Bureau.

Centers for Disease Control and Prevention. (2020). Developmental Milestones Checklist at 4 years [pdf]. Washington, DC: U.S. Department of Health and Human Services, Children's Bureau.

Centers for Disease Control and Prevention. (2020). Developmental Milestones Checklist at 5 years [pdf]. Washington, DC: U.S. Department of Health and Human Services, Children's Bureau.

Centers for Disease Control and Prevention. (2020). Positive parenting tips for healthy child development preschoolers (3-5 year of age) [pdf]. Washington, DC: U.S. Department of Health and Human Services, Children's Bureau.

\section{Video Examples}

Video examples of developmental milestones ( 2 months to 5 years) 


\section{Middle Childhood (6-8 years)}

Centers for Disease Control and Prevention. (2020). Positive parenting tips for healthy child development middle childhood (6-8 year of age) [pdf]. Washington, DC: U.S. Department of Health and Human Services, Children's Bureau.

\section{Middle Childhood (9-11 years)}

Centers for Disease Control and Prevention. (2020). Positive parenting tips for healthy child development middle childhood (9-1 1year of age) [pdf]. Washington, DC: U.S. Department of Health and Human Services, Children's Bureau.

\section{Young Teens (12-14 years)}

Centers for Disease Control and Prevention. (2020). Positive parenting tips for healthy child development young teens (12-1 4year of age) [pdf]. Washington, DC: U.S. Department of Health and Human Services, Children's Bureau.

\section{Teens $(15-17$ years)}

Centers for Disease Control and Prevention. (2020). Positive parenting tips for healthy child development teens (15-17 year of age) [pdf]. Washington, DC: U.S. Department of Health and Human Services, Children's Bureau. 


\section{PRENATAL DEVELOPMENT}

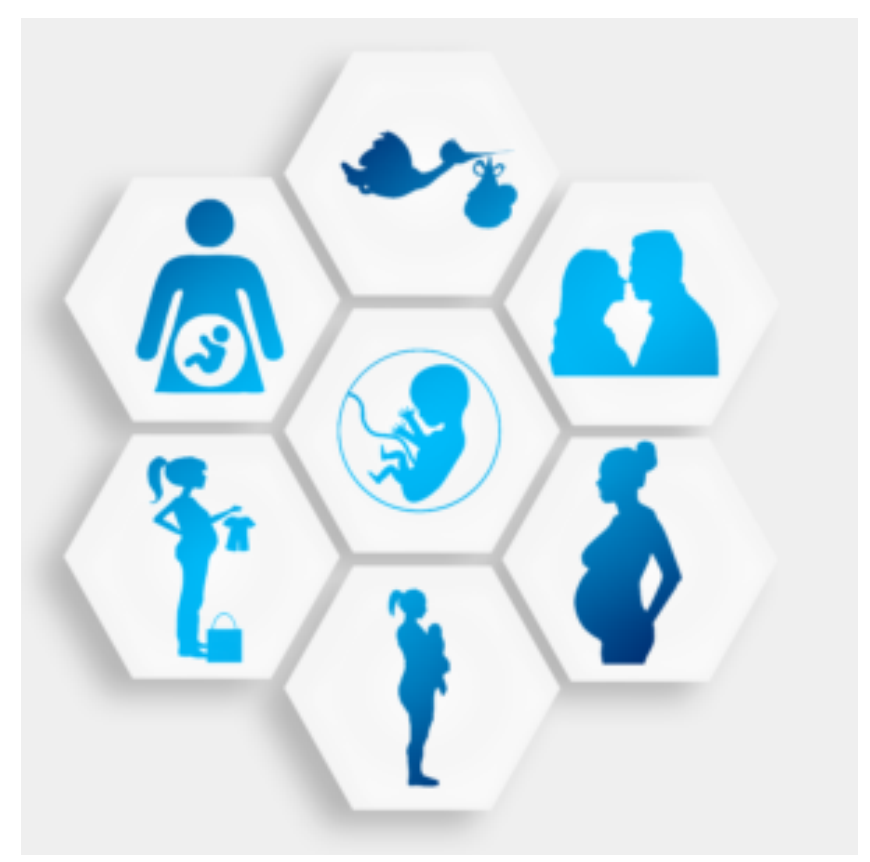

Figure 1. The stages of pregnancy

How did you come to be who you are? From beginning as a one-cell structure to your birth, your prenatal development occurred in an orderly and delicate sequence. There are three stages of prenatal development: germinal, embryonic, and fetal. Keep in mind that this is different than the three trimesters of pregnancy.

\section{Prenatal Development}

Let's take a look at some of the changes that take place during each of the three periods of prenatal development: the germinal period, the embryonic period, and the fetal period. 


\section{The Germinal Period (Weeks 1-2)}

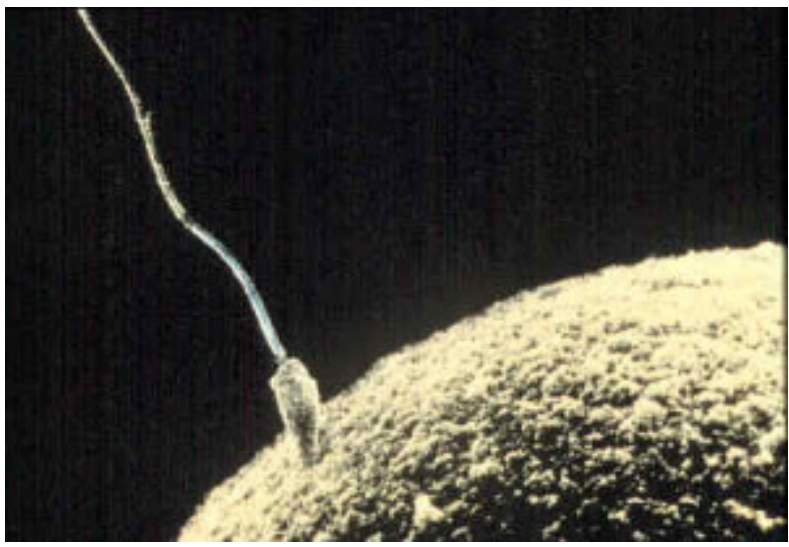

Figure 2. Sperm and Ovum at Conception
Conception occurs when a sperm fertilizes an egg and forms a zygote, which begins as a one-cell structure. The mother and father's DNA is passed on to the child at the moment of conception. The genetic makeup and sex of the baby are set at this point. The germinal period (about 14 days in length) lasts from conception to implantation of the zygote (fertilized egg) in the lining of the uterus.

During the first week after conception, the zygote divides and multiplies, going from a one-cell structure to two cells, then four cells, then eight cells, and so on. The process of cell division is called mitosis. After the fourth division, differentiation of the cells begins to occur as well. Differentiated cells become more specialized, forming different organs and body parts. After 5 days of mitosis, there are 100 cells, and after 9 months there are billions of cells. Mitosis is a fragile process, and fewer than one-half of all zygotes survive beyond the first two weeks. ${ }^{1}$

After the zygote divides for about 7-10 days and has 150 cells, it travels down the fallopian tubes and implants itself in the lining of the uterus. It's estimated that about 60 percent of natural conceptions fail to implant in the uterus. The rate is higher for in vitro conceptions. Once the zygote attaches to the uterus, the next stage begins. 


\section{The Embryonic Period (Weeks 3-8)}

The embryonic period begins once the zygote is implanted in the uterine wall. It lasts from the third through the eighth week after conception. Upon implantation, this multi-cellular organism is called an embryo. Now blood vessels grow, forming the placenta. The placenta is a structure connected to the uterus that provides nourishment and oxygen from the mother to the developing embryo via the umbilical cord.

During this period, cells continue to differentiate. Basic structures of the embryo start to develop into areas that will become the head, chest, and abdomen. During the embryonic stage, the heart begins to beat and organs form and begin to function. At 22 days after conception, the neural tube forms along the back of the embryo, developing into the spinal cord and brain.

Growth during prenatal development occurs in two major directions: from head to tail (cephalocaudal development) and from

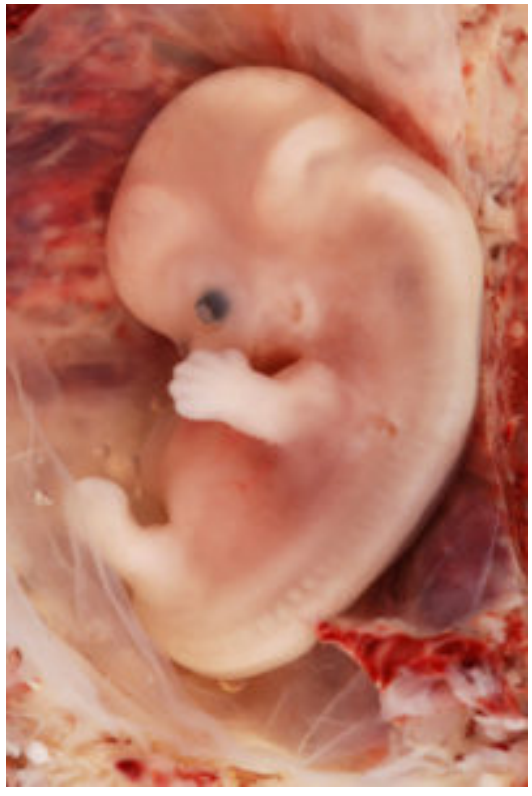

Figure 3. Human Embryo the midline outward (proximodistal development). This means that those structures nearest the head develop before those nearest the feet and those structures nearest the torso develop before those away from the center of the body (such as hands and fingers).

The head develops in the fourth week and the precursor to the heart begins to pulse. In the early stages of the embryonic period, gills and a tail are apparent. But by the end of this stage, they disappear and the organism takes on a more human appearance. The embryo is approximately 1 inch in length and weighs about 4 grams at the end of this period. The embryo can move and respond to touch at this time.

About 20 percent of organisms fail during the embryonic period, usually due to gross chromosomal abnormalities. As in the case of the germinal period, often the mother does not yet know that she is pregnant. It is during this stage that the major structures of the body are taking form making the embryonic period the time when the organism is most vulnerable to the greatest amount of damage if exposed to harmful substances. Potential mothers are not often aware of the risks they introduce to the developing child during this time. 


\section{The Fetal Period (Weeks 9-40)}

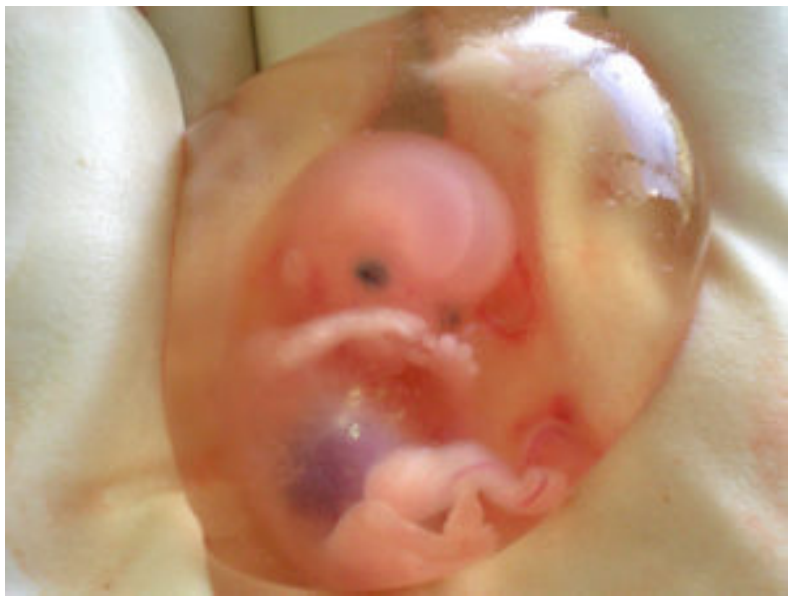

Figure 4. A fetus at 10 weeks of development.
When the organism is about nine weeks old, the embryo is called a fetus. At this stage, the fetus is about the size of a kidney bean and begins to take on the recognizable form of a human being as the "tail" begins to disappear.

From 9-12 weeks, the sex organs begin to differentiate. By the 12th week, the fetus has all its body parts including external genitalia. In the following weeks, the fetus will develop hair, nails, teeth and the excretory and digestive systems will continue to develop. At the end of the 12th week, the fetus is about 3 inches long and weighs about 28 grams.

At about 16 weeks, the fetus is approximately 4.5 inches long. Fingers and toes are fully developed, and fingerprints are visible. During the 4-6th months, the eyes become more sensitive to light and hearing develops. The respiratory system continues to develop. Reflexes such as sucking, swallowing, and hiccupping develop during the 5th month. Cycles of sleep and wakefulness are present at that time as well. Throughout the fetal stage, the brain continues to grow and develop, nearly doubling in size from weeks 16 to 28 . The majority of the neurons in the brain have developed by 24 weeks although they are still rudimentary and the glial or nurse cells that support neurons continue to grow. At 24 weeks the fetus can feel pain. ${ }^{2}$

The first chance of survival outside the womb, known as the age of viability is reached at about 22 to 26 weeks. ${ }^{3}$ By the time the fetus reaches the sixth month of development ( 24 weeks), it weighs up to 1.4 pounds. The hearing has developed, so the fetus can respond to sounds. The internal organs, such as the lungs, heart, stomach, and intestines, have formed enough that a fetus born prematurely at this point has a chance to survive outside of the mother's womb.

Between the 7th and 9th months, the fetus is primarily preparing for birth. It is exercising its muscles, its lungs begin to expand and contract. It is developing fat layers under the skin. The fetus gains about 5 pounds and 7 inches during this last trimester of pregnancy which includes a layer of fat gained during the 8 th month. This layer of fat serves as insulation and helps the baby regulate body temperature after birth.

2. Royal College of Obstetricians and Gynecologists. (1997). Fetal Awareness: Report of a Working Party. London: RCOG Press. 3. Moore, K. L., \& Persaud, T. V. (1998). Before we are born (5th ed.). Philadelphia, PA: Saunders. 
Around 36 weeks, the fetus is almost ready for birth. It weighs about 6 pounds and is about 18.5 inches long, and by week 37 all of the fetus's organ systems are developed enough that it could survive outside the uterus without many of the risks associated with premature birth. The fetus continues to gain weight and grow in length until approximately 40 weeks. By then, the fetus has very little room to move around and birth becomes imminent.

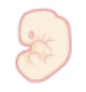

9 weeks Fetal stage begins

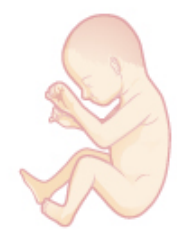

20 weeks Hearing begins

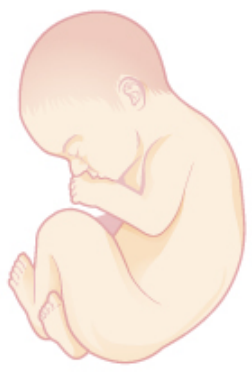

32 weeks Bones fully develop

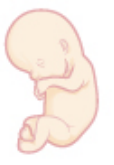

12 weeks Sex organs differentiate

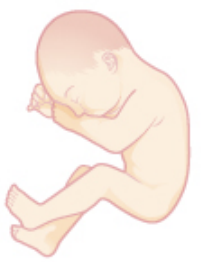

24 weeks Lungs begin to develop

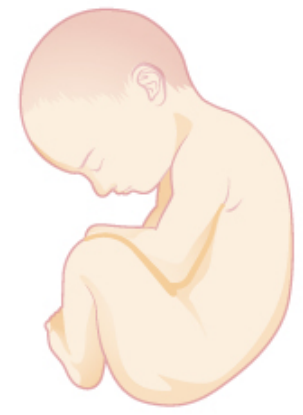

36 weeks Muscles fully develop

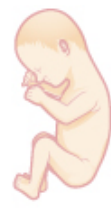

16 weeks Fingers and toes develop

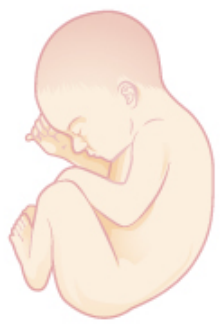

28 weeks Brain grows rapidly

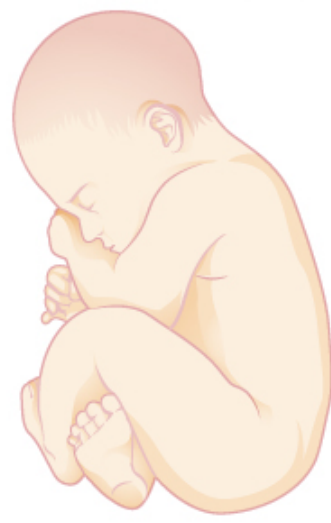

40 weeks Full-term development

Figure 5. During the fetal stage, the brain develops and the body adds size and weight until the fetus reaches full-term development. 


\section{Video Example}

This video on prenatal development explains many of the developmental milestones and changes that happen during each month of development for the embryo and fetus.

\section{Environmental Risks}

\section{Teratology}

Good prenatal care is essential. The developing embryo is most at risk for some of the most severe problems during the first three months of development. Unfortunately, this is a time at which most women are unaware that they are pregnant. It is estimated that $10 \%$ of all birth defects are caused by a prenatal exposure or teratogen. Teratogens are factors that can contribute to birth defects which include some maternal diseases, drugs, alcohol, and stress. These exposures can also include environmental and occupational exposures. Today, we know many of the factors that can jeopardize the health of the developing embryo and fetus. Some teratogen-caused birth defects are potentially preventable.

The study of factors that contribute to birth defects is called teratology. Teratogens are usually discovered after an increased prevalence of a particular birth defect. For example, in the early 1960's, a drug known as thalidomide was used to treat morning sickness. Exposure of the fetus during this early stage of development resulted in cases of phocomelia, a congenital malformation in which the hands and feet are attached to abbreviated arms and legs. 


\section{A Look at Some Teratogens}

\section{Alcohol}

One of the most commonly used teratogens is alcohol. Because half of all pregnancies in the United States are unplanned, it is recommended that women of childbearing age take great caution against drinking alcohol when not using birth control and when pregnant. ${ }^{4}$ Alcohol consumption, particularly during the second month of prenatal development, but at any point during pregnancy, may lead to neurocognitive and behavioral difficulties that can last a lifetime.

There is no acceptable safe limit for alcohol use during pregnancy, but binge drinking ( 5 or more drinks on a single occasion) or having 7 or more drinks during a single week places an embryo and fetus at particularly high risk. In extreme cases, alcohol consumption can lead to fetal death, but more frequently it can result in fetal alcohol spectrum disorders (FASD). This terminology is now used when looking at the effects of exposure and replaces the term fetal alcohol syndrome. It is preferred because it recognizes that symptoms occur on a spectrum

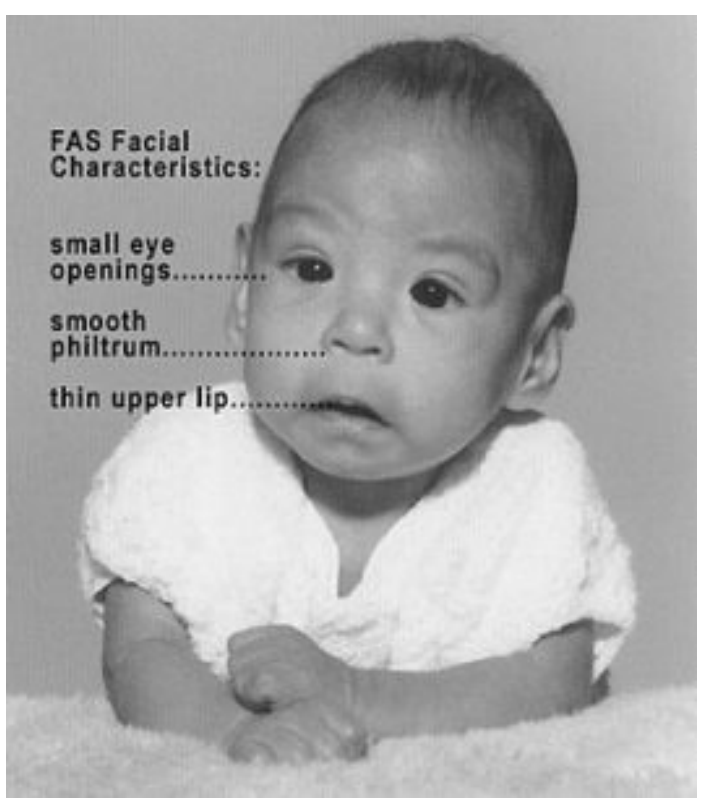

Figure 6. Some distinguishing characteristics of fetal alcohol spectrum disorders include more narrow eye openings, A smooth philtrum, meaning a smooth area between the upper lip and the nose, and a thin upper lip. and that all individuals do not have the same characteristics. Children with FASD share certain physical features such as flattened noses, small eye openings, small heads, intellectual developmental delays, and behavioral problems. Those with FASD are more at risk for lifelong problems such as criminal behavior, psychiatric problems, and unemployment. ${ }^{5}$

The terms alcohol-related neurological disorder (ARND) and alcohol-related birth defects (ARBD) have replaced the term Fetal Alcohol Effects to refer to those with less extreme symptoms of FASD. ARBD include kidney, bone and heart problems.

4. U.S. Department of Health \& Human Services. (2005). Advisory on alcohol use in pregnancy. Retrieved from: http://www.surgeongeneral.gov/pressreleases/sg02222005.html.

5. Centers for Disease Control and Prevention. (2006). FASDs: Secondary Conditions. Retrieved from https://www.cdc.gov/ ncbddd/fasd/secondary-conditions.html. 


\section{Video Example}

Several medical experts debunk common myths about the safety of drinking alcohol during pregnancy.

Uplugin.3playmedia.com/

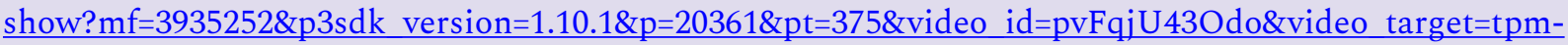
plugin-z36ohj31-pvFqiU43Odo

\section{Tobacco}

Smoking is also considered a teratogen because nicotine travels through the placenta to the fetus. When the pregnant woman smokes, the developing fetus experiences a reduction in blood oxygen levels. Tobacco use during pregnancy has been associated with low birth weight, placenta previa, birth defects, preterm delivery, fetal growth restriction, and sudden infant death syndrome. Smoking in the month before getting pregnant and throughout pregnancy increases the chances of these risks. Quitting smoking before getting pregnant is best. However, for women who are already pregnant, quitting as early as possible can still help protect against some health problems for the mother and baby. ${ }^{6}$

\section{Drugs}

Prescription, over-the-counter, or recreational drugs can have serious teratogenic effects. In general, if medication is required, the lowest dose possible should be used. Combination drug therapies and first trimester exposures should be avoided. Almost three percent of pregnant women use illicit drugs such as marijuana, cocaine, Ecstasy and other amphetamines, and heroin. These drugs can cause low birth-weight, withdrawal symptoms, birth defects, or learning or behavioral problems. Babies born with a heroin addiction need heroin just like an adult addict. The child will need to be gradually weaned from the heroin under medical supervision; otherwise, the child could have seizures and die. Visit this link for further information about opioid use during pregnancy.

\section{Environmental Chemicals}

Environmental chemicals can include exposure to a wide array of agents including pollution, organic mercury compounds, herbicides, and industrial solvents. Some environmental pollutants of major

6. Centers for Disease Control and Prevention. (2020). Birth Defects Research and Tracking. Retrieved from https://www.cdc.gov/ ncbddd/birthdefects/research.html 
concern include lead poisoning, which is connected with low birth weight and slowed neurological development. Children who live in older housing in which lead-based paints have been used have been known to eat peeling paint chips thus being exposed to lead. The chemicals in certain herbicides are also potentially damaging. Radiation is another environmental hazard that a pregnant woman must be aware of. If a woman is exposed to radiation, particularly during the first three months of pregnancy, the child may suffer some congenital deformities. There is also an increased risk of miscarriage and stillbirth. A pregnant woman's exposure to mercury can also lead to physical deformities and intellectual disabilities. ${ }^{7}$

\section{Sexually Transmitted Infections}

Sexually transmitted infections (STIs) can complicate pregnancy and may have serious effects on both the pregnant woman and the developing fetus. Most prenatal care today includes testing for STIs, and early detection is important. STIs, such as chlamydia, gonorrhea, syphilis, trichomoniasis, and bacterial vaginosis can all be treated and cured with antibiotics that are safe to take during pregnancy. STIs that are caused by viruses, like genital herpes, hepatitis B, or HIV cannot be cured. However, in some cases these infections can be treated with antiviral medications or other preventive measures that can be taken to reduce the risk of passing the infection to the baby. ${ }^{8}$

\section{Maternal Diseases}

Maternal illnesses increase the chance that a baby will be born with a birth defect or have a chronic health problem. Some of the diseases that are known to potentially have an adverse effect on the fetus include diabetes, cytomegalovirus, toxoplasmosis, rubella, varicella, hypothyroidism, and Strep B. If the pregnant woman contracts Rubella during the first three months of pregnancy, damage can occur in the eyes, ears, heart, or brain of the developing fetus. On a positive note, Rubella has been nearly eliminated in the industrial world due to the vaccine created in 1969. Diagnosing these diseases early and receiving appropriate medical care can help improve the outcomes. Routine prenatal care now includes screening for gestational diabetes and Strep B. ${ }^{9}$

\section{Maternal Stress}

Stress represents the effects of any factor able to threaten the homeostasis of an organism; these either real or perceived threats are referred to as the "stressors" and comprise a long list of

7. Dietrich, K. N. (1999). Environmental chemicals and child development. The Journal of Pediatrics. 134(1). DOI: https://doi.org/ 10.1016/S0022-3476(99)70363-X

8. Centers for Disease Control and Prevention. (2016). STDs during Pregnancy - CDC Fact Sheet. Retrieved from https://www.cdc.gov/std/pregnancy/stdfact-pregnancy.htm

9. Birth Defect Research for Children. (n.d.). Maternal Illness - Birth Defect Prevention for Expecting Parents. Retrieved from https://www.birthdefects.org/healthy-baby/maternal-illness/ 
potentially adverse factors, which can be emotional or physical. Because of a link in blood supply between a pregnant woman and her fetus, it has been found that stress can leave lasting effects on a developing fetus, even before birth. The best-studied outcomes of fetal exposure to maternal prenatal stress are preterm birth and low birth weight. Maternal prenatal stress is also considered responsible for a variety of changes in the child's brain, and a risk factor for conditions such as behavioral problems, learning disorders, high levels of anxiety, attention deficit hyperactivity disorder, autism, and schizophrenia. Furthermore, maternal prenatal stress has been associated with a higher risk for a variety of immune and metabolic changes in the child such as asthma, allergic disorders, cardiovascular diseases, hypertension, hyperlipidemia, diabetes, and obesity. ${ }^{10}$

\section{Factors influencing prenatal risks}

There are several considerations in determining the type and amount of damage that might result from exposure to a particular teratogen. ${ }^{11}$ These include:

- The timing of the exposure: Structures in the body are vulnerable to the most severe damage when they are forming. If a substance is introduced during a particular structure's critical period (time of development), the damage to that structure may be greater. For example, the ears and arms reach their critical periods at about 6 weeks after conception. If a pregnant woman exposes the embryo to certain substances during this period, the arms and ears may be malformed.

- The amount of exposure: Some substances are not harmful unless the amounts reach a certain level. The critical level depends in part on the size and metabolism of the mother.

- Genetics: Genetic make-up also plays a role in the impact a particular teratogen might have after the child is born. This is suggested by fraternal twin studies who are exposed to the same prenatal environment, yet do not experience the same teratogenic effects. The genetic make-up of the mother can also have an effect; some mothers may be more resistant to teratogenic effects than others.

- Biological sex: Males are more likely to experience damage due to teratogens than are females. It is believed that the $\mathrm{Y}$ chromosome, which contains fewer genes than the $\mathrm{X}$, may have an impact.

10. Douros, K., Moustaki, M., Tsabouri, S., Papadopoulou, A., Papadopoulos, M., Priftis, K. N. (2017). Prenatal Maternal Stress and the Risk of Asthma in Children. Frontiers in Pediatrics. Retrieved from https://www.frontiersin.org/article/10.3389/ fped.2017.00202

11. Berger, K. S. (2004). The developing person through the life span (6th ed.). New York: Worth. 


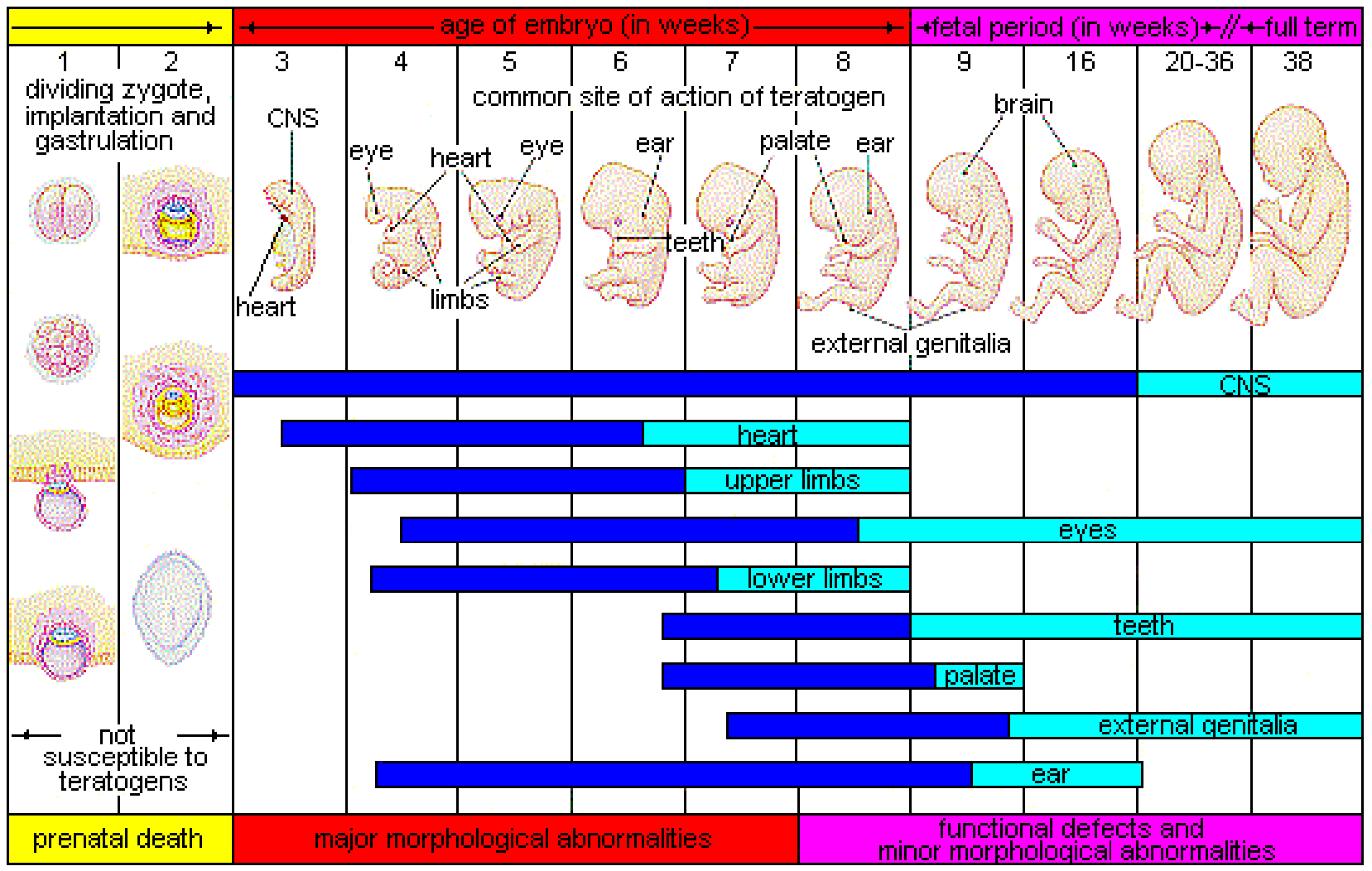

Figure 7. Critical Periods of Prenatal Development. This image summarizes the three developmental periods in prenatal development. The blue images indicate where major development is happening and the aqua indicate where refinement is happening. As shown, the majority of organs are particularly susceptible during the embryonic period. The central nervous system still continues to develop in major ways through the fetal period as well.

\section{Interactive Example}

Did you know that pregnant women can improve outcomes for themselves and their babies through a balanced diet and adequate exercise? Click through this interactive example to learn more about the importance of maternal health.

Visit this link for additional information on how to help prevent birth defects. 


\section{Complications of Pregnancy and Delivery}

There are a number of common side effects of pregnancy. Not everyone experiences all of these nor do women experience them to the same degree. And although they are considered "minor" these problems are potentially very uncomfortable. These side effects include nausea (particularly during the first 3-4 months of pregnancy as a result of higher levels of estrogen in the system), heartburn, gas, hemorrhoids, backache, leg cramps, insomnia, constipation, shortness of breath or varicose veins (as a result of carrying a heavy load on the abdomen). What is the cure? Delivery!

\section{Major Complications}

The following are some serious complications of pregnancy which can pose health risks to mother and child and that often require special care.

- Gestational diabetes is when a woman without diabetes develops high blood sugar levels during pregnancy.

- Hyperemesis gravidarum is the presence of severe and persistent vomiting, causing dehydration and weight loss. It is more severe than the more common morning sickness.

- Preeclampsia is gestational hypertension. Severe preeclampsia involves blood pressure over $160 / 110$ with additional signs. Eclampsia is seizures in a patient who is pre-eclamptic.

- Deep vein thrombosis is the formation of a blood clot in a deep vein, most commonly in the legs.

- A pregnant woman is more susceptible to infections. This increased risk is caused by an increased immune tolerance in pregnancy to prevent an immune reaction against the fetus.

- Peripartum cardiomyopathy is a decrease in heart function which occurs in the last month of pregnancy, or up to six months post-pregnancy.

\section{Maternal Mortality}

Maternal mortality is unacceptably high. About 830 women die from pregnancy or childbirthrelated complications around the world every day. It was estimated that in 2015, roughly 303,000 women died during and following pregnancy and childbirth. Almost all of these deaths occurred in 
low-resource settings, and most could have been prevented. The high number of maternal deaths in some areas of the world reflects inequities in access to health services and highlights the gap between rich and poor. Almost all maternal deaths (99\%) occur in developing countries. More than half of these deaths occur in sub-Saharan Africa and almost one third occur in South Asia.

Almost all maternal deaths can be prevented, as evidenced by the huge disparities found between the richest and poorest countries. The lifetime risk of maternal death in high-income countries is 1 in 3,300, compared to 1 in 41 in low-income. ${ }^{12}$

Even though maternal mortality in the United States is relatively rare today because of advanced in medical care, it is still an issue that needs to be addressed. The Centers for Disease Control and Prevention define a pregnancy-related death as the death of a woman while pregnant or within 1 year of the end of a pregnancy-regardless of the outcome, duration, or site of the pregnancy-from any cause related to or aggravated by the pregnancy or its management, but not from accidental or incidental causes. The reasons for the overall increase in pregnancy-related mortality are unclear. What do you think are some reasons for this surprising increase in the United States? What can be done to change this statistic?

\section{Video Example}

In the United States, black women are disproportionately more likely to die from complications related to pregnancy or childbirth than any other race; they are three or four times more likely than white women to die due to pregnancy-related death and are more likely to receive worse maternal care. ${ }^{13}$ Black women from higher income groups and with advanced education levels also have heightened risks-even tennis superstar Serena Williams had near-deadly complications during the birth of her daughter, Olympia. Why is this the case in our modern world? Watch this video to learn more:

Uplugin.3playmedia.com/show? mf=3935255\&p3sdk version=1.10.1\&p=20361\&pt=375\&video id=VYc-EqvDuA\&video target=tpm-plugin-ex4sdo7y-VYc-Eq-vDuA

12. World Health Organization. (February 2018). Maternal mortality. Retrieved from https://www.who.int/news-room/factsheets/detail/maternal-mortality

13. Black Women's Maternal Health: A Multifaceted Approach to Addressing Persistent and Dire Health Disparities (2018). National Partnership for Women and Families. Retrieved from http://www.nationalpartnership.org/our-work/health/reports/black-womensmaternal-health.html. 


\section{Miscarriage}

Spontaneous abortion, or miscarriage, is experienced in an estimated 20-40 percent of undiagnosed pregnancies and in another 10 percent of diagnosed pregnancies. Usually, the body aborts due to chromosomal abnormalities and this typically happens before the 12 th week of pregnancy. Cramping and bleeding result and normal periods return after several months. Some women are more likely to have repeated miscarriages due to chromosomal, amniotic, or hormonal problems; but miscarriage can also be a result of defective sperm. ${ }^{14}$

\section{(a) (1)}

Prenatal Development by Diana Lang is licensed under a Creative Commons Attribution 4.0 International License, except where otherwise noted.

14. Carrell, D. T., Wilcox, A. L., Lowry, L., Peterson, C. M., Jones, K. P., \& Erikson, L. (2003). Elevated sperm chromosome aneuploidy and apoptosis in patients with unexplained recurrent pregnancy loss. Obstetrics and Gynecology, 101(6), $1229-1235$. 


\title{
INFANCY AND TODDLERHOOD
}

\author{
Suzanne Valentine-French; Martha Lally; and Diana Lang
}

We will now turn our attention to the physical, cognitive, and socioemotional development during the first two years. ${ }^{1}$ Researchers have given this part of the lifespan more attention than any other period, perhaps because changes during this time are so dramatic and so noticeable. We have also assumed that what happens during these years provides a foundation for one's life to come. However, it has been argued that the significance of development during these years has been overstated. $^{2}$

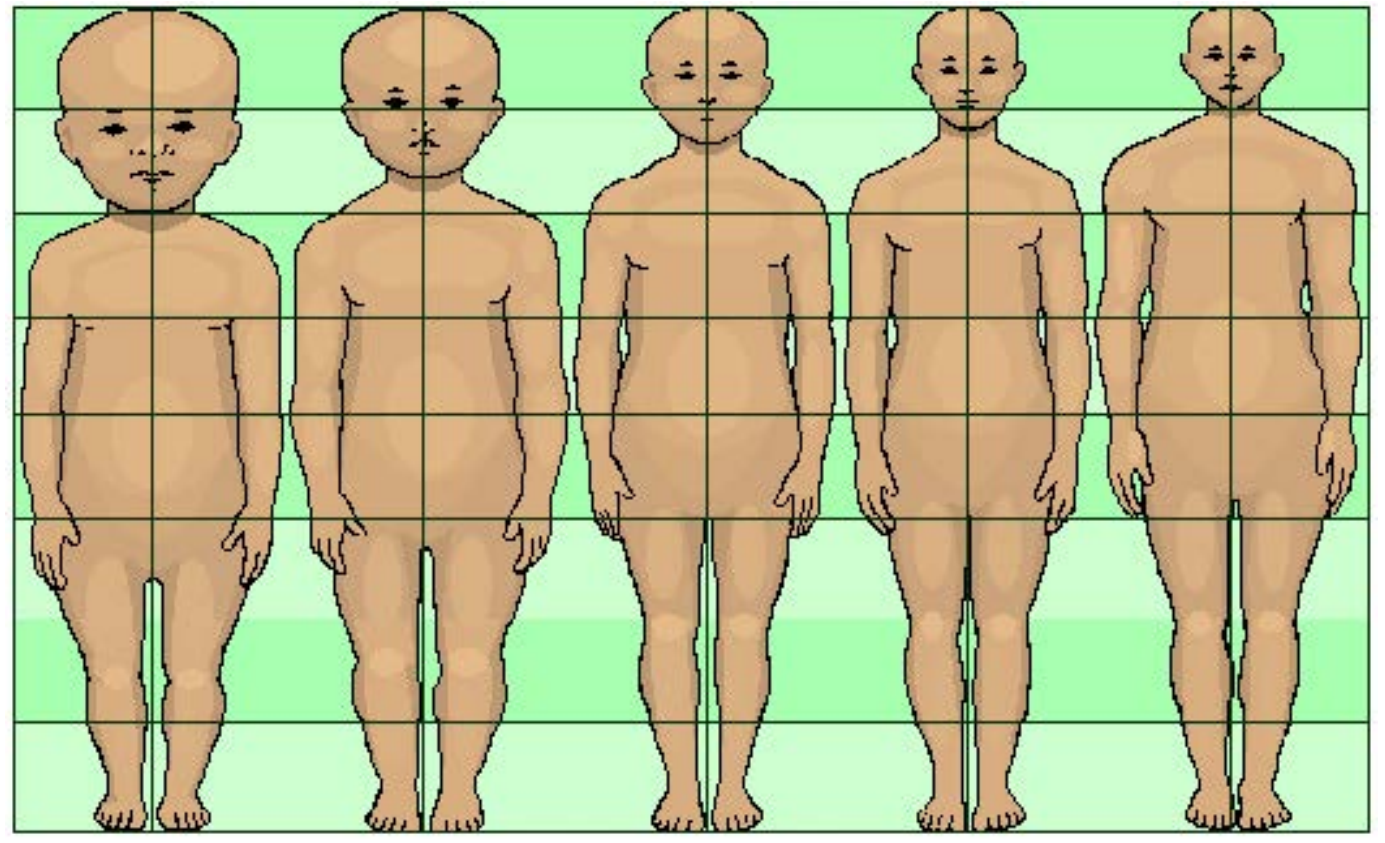

Figure 1. Changes in Proportions

\section{Physical Growth and Development}

The average newborn in the United States weighs about 7.5 pounds (between 5 and 10 pounds) and is about 20 inches in length. For the first few days of life, infants typically lose about 5 percent of their body weight as they eliminate waste and get used to feeding. This often goes unnoticed by most

1. This chapter is adapted from Lifespan Development by Martha Lally and Suzanne Valentine-French, licensed CC BY NC SA. https://courses.lumenlearning.com/suny-lifespandevelopment/

2. Bruer, J. T. (1999). The myth of the first three years: A new understanding of early brain development and lifelong learning. New York: Simon and Schuster. 
parents but can be cause for concern for those who have a smaller infant. This weight loss is temporary, however, and is followed by a rapid period of growth. By the time an infant is 4 months old, it usually doubles in weight and by one year has tripled the birth weight. By age 2, the weight has quadrupled, so we can expect that a 2-year-old should weigh between 20 and 40 pounds. The average length at one year is about 29.5 inches and at two years it is around 34.4 inches.

Body Proportions: Another dramatic physical change that takes place in the first several years of life is the change in body proportions. The head initially makes up about 50 percent of our entire length when we are developing in the womb. At birth, the head makes up about 25 percent of our length, and by age 25 it comprises about 20 percent our length.

\section{Infant Sleep}

A newborn typically sleeps approximately 16.5 hours per 24 -hour period. This is usually polyphasic sleep in that the infant is accumulating the 16.5 hours over several sleep periods throughout the day. ${ }^{3}$ The infant is averaging 15 hours per 24-hour period by one month, and 14 hours by 6 months. By the time children turn two, they are averaging closer to 10 hours per 24 hours.

Additionally, the average newborn will spend close to $50 \%$ of the sleep time in the Rapid Eye Movement (REM) phase, which decreases to $25 \%$ to $30 \%$ in childhood.

\section{Sudden Unexpected Infant Deaths (SUID)}

Each year in the United States, there are about 3,500 Sudden Unexpected Infant Deaths (SUID). These deaths occur among infants less than one year-old and have no immediately obvious cause. ${ }^{4}$ The three commonly reported types of SUID are:

- Sudden Infant Death Syndrome (SIDS): SIDS is identified when the death of a healthy infant occurs suddenly and unexpectedly, and medical and forensic investigation findings (including an autopsy) are inconclusive. SIDS is the leading cause of death in infants 1 to 12 months old, and approximately 1,500 infants died of SIDS in $2013 .{ }^{5}$ Because SIDS is diagnosed when no other cause of death can be determined, possible causes of SIDS are regularly researched. One leading hypothesis suggests that infants who die from SIDS have abnormalities in the area of the brainstem responsible for regulating breathing.

3. Salkind, N. J. (2005). Encyclopedia of human development. New York: Sage Publications.

4. Centers for Disease Control and Prevention. (2015). Sudden unexpected death and sudden infant death syndrome. Retrieved from http://www.cdc.gov/sids/data.htm

5. Centers for Disease Control and Prevention. (2015). Sudden unexpected death and sudden infant death syndrome. Retrieved from http://www.cdc.gov/sids/data.htm 
- Unknown Cause: The sudden death of an infant less than one year of age that cannot be explained because a thorough investigation was not conducted and cause of death could not be determined.

- Accidental Suffocation and Strangulation in Bed: Reasons for accidental suffocation include: Suffocation by soft bedding, another person rolling on top of or against the infant while sleeping, an infant being wedged between two objects such as a mattress and wall, and strangulation such as when an infant's head and neck become caught between crib railings.

As can be seen in the previous graph (Figure 3.6), the combined SUID death rate declined considerably following the release of the American Academy of Pediatrics safe sleep recommendations in 1992, which advocated that infants be placed for sleep on their backs (nonprone position). These recommendations were followed by a major Back to Sleep Campaign in 1994. However, accidental suffocation and strangulation in bed mortality rates remained unchanged until the late 1990s.

\section{Should infants be sharing the bed with parents?}

Colvin, Collie-Akers, Schunn, and Moon (2014) analyzed a total of 8207 deaths from 24 states during 2004-2012 that were contained in the National Center for the Review and Prevention of Child Deaths Case Reporting System, a database of death reports from state child death review teams. ${ }^{6}$ The results indicated that younger victims (0-3 months) were more likely to die by bed-sharing and sleeping in an adult bed/on a person. A higher percentage of older victims (4 months to 364 days) rolled into objects in the sleep environment and changed position from side/back to prone. Carpenter et al.

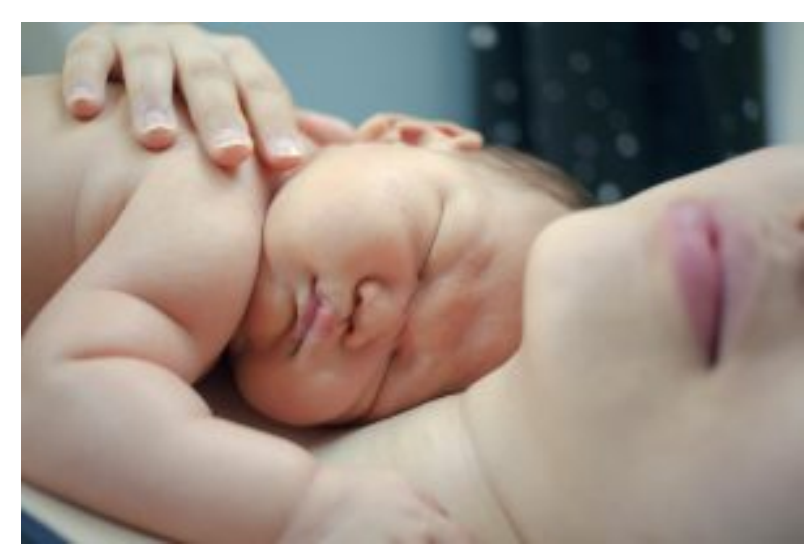

Figure 2. An infant holding onto their parent. (Photo Source: Pikrepo, DMCA) (2013) compared infants who died of SIDS with a matched control and found that infants younger than three months old who slept in bed with a parent were five times more likely to die of SIDS compared to babies who slept separately from the parents, but were still in the same room. ${ }^{7}$

They concluded that bed-sharing, even when the parents do not smoke or take alcohol or drugs, is

6. Colvin, J.D., Collie-Akers, V., Schunn, C., \& Moon, R.Y. (2014). Sleep environment risks for younger and older infants. Pediatrics Online. Retrieved from https://pediatrics.aappublications.org/content/134/2/e406

7. Carpenter, R., McGarvey, C., Mitchell, E. A., Tappin, D. M., Vennemann, M. M., Smuk, M., \& Carpenter, J. R. (2013). Bed sharing when parents do not smoke: Is there a risk of SIDS? An individual level analysis of five major case-control studies. BMJ Open. 
related to an increased risk of SIDS. However, when combined with parental smoking and maternal alcohol consumption and/or drug use, risks associated with bed-sharing greatly increased.

The two studies discussed above were based on American statistics. What about the rest of the world? Co-sleeping occurs in many cultures, primarily because of a more collectivist perspective that encourages a close parent-child bond and interdependent relationship. ${ }^{8}$ In countries where cosleeping is common, however, parents and infants typically sleep on floor mats and other hard surfaces which minimize the suffocation that can occur with bedding and mattresses. ${ }^{9}$

\section{Motor Development}

Motor development occurs in an orderly sequence as infants move from reflexive reactions (e.g., sucking and rooting) to more advanced motor functioning. As mentioned during the prenatal section, development occurs according to the Cephalocaudal (from head to tail) and Proximodistal (from the midline outward) principles. For instance, babies first learn to hold their heads up, then to sit with assistance, then to sit unassisted, followed later by crawling, pulling up, cruising, and then walking. As motor skills develop, there are certain developmental milestones that young children should achieve. For each milestone there is an average age, as well as a range of ages in which the milestone should be reached. An example of a developmental milestone is a baby holding up its head. Babies on average are able to hold up their head at 6 weeks old, and $90 \%$ of babies achieve this between 3 weeks and 4 months old. If a baby is not holding up his head by 4 months old, he is showing a delay. On average, most babies sit alone at 7 months old. Sitting involves both coordination and muscle strength, and $90 \%$ of babies achieve this milestone between 5 and 9 months old. If the child is displaying delays on several milestones, that is reason for concern, and the parent or caregiver should discuss this with the child's pediatrician. Some developmental delays can be identified and addressed through early intervention.

Motor Skills refer to our ability to move our bodies and manipulate objects. Fine motor skills focus on the muscles in our fingers, toes, and eyes, and enable coordination of small actions (e.g., grasping a toy, writing with a pencil, and using a spoon). Newborns cannot grasp objects voluntarily but do wave their arms toward objects of interest. At about 4 months of age, the infant is able to reach for an object, first with both arms and within a few weeks, with only one arm. At this age grasping an object involves the use of the fingers and palm, but no thumbs. This is known as the Palmer Grasp. The use of the thumb comes at about 9 months of age when the infant is able to grasp an object using the forefinger and thumb. Now the infant uses a Pincer Grasp, and this ability greatly enhances the ability to control and manipulate an object and infants take great delight in this newfound ability.

8. Morelli, G., Rogoff, B., Oppenheim, D., \& Goldsmith, D. (1992). Cultural variations in infants' sleeping arrangements: Questions of independence. Developmental Psychology, 28, 604-613.

9. Nelson, E. A., Schiefenhoevel, W., \& Haimerl, F. (2000). Child care practices in nonindustrialized societies. Pediatrics, $105,75$. 
They may spend hours picking up small objects from the floor and placing them in containers. By 9 months, an infant can also watch a moving object, reach for it as it approaches, and grab it.

Gross motor skills focus on large muscle groups that control our head, torso, arms and legs and involve larger movements (e.g., balancing, running, and jumping). These skills begin to develop first. Examples include moving to bring the chin up when lying on the stomach, moving the chest up, and rocking back and forth on hands and knees. But it also includes exploring an object with one's feet as many babies do as early as 8 weeks of age if seated in a carrier or other device that frees the hips. This may be easier than reaching for an object with the hands, which requires much more practice. ${ }^{10}$ Sometimes an infant will try to move toward an object while crawling and surprisingly move backward because of the greater amount of strength in the arms than in the legs.

\section{Sensory Capacities}

Current research techniques have demonstrated just how developed the newborn is with especially organized sensory and perceptual abilities.

Vision: The womb is a dark environment void of visual stimulation. Consequently, vision is the most poorly developed sense at birth and time is needed to build those neural pathways between the eye and the brain. Newborns typically cannot see further than 8 to 16 inches away from their faces, and their visual acuity is about 20/400, which means that an infant can see something at 20 feet that an adult with normal vision could see at 400 feet. Thus, the world probably looks blurry to young infants. Because of their poor visual acuity, they look longer at checkerboards with fewer large squares than with many small squares. Infants' thresholds for seeing a visual pattern are higher than adults'. Thus, toys for infants are sometimes manufactured with black and white patterns rather than pastel colors because the higher contrast between black and white makes the pattern more visible to the immature visual system. By about 6 months, infants' visual acuity improves and approximates adult 20/ 25 acuity.

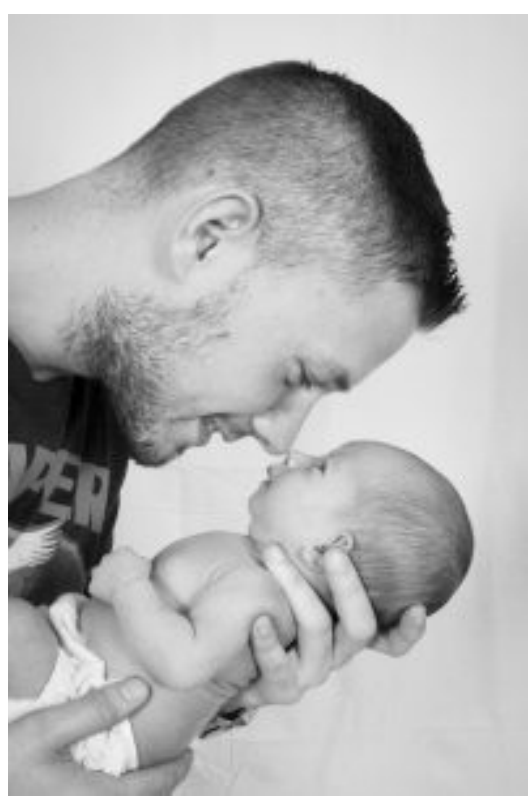

Figure 3. Carefully holding an infant. (Photo Source: Pikrepo, DMCA)

When viewing a person's face, newborns do not look at the eyes the way adults do; rather, they tend to look at the chin a less detailed part of the face. However, by 2 or 3 months, they will seek more detail when exploring an object visually and begin showing preferences for unusual images over familiar ones, for patterns over solids, for faces over patterns, and for three- 
dimensional objects over flat images. Newborns have difficulty distinguishing between colors, but within a few months they are able to discriminate between colors as well as adults. Sensitivity to binocular depth cues, which require inputs from both eyes, is evident by about 3 months and continues to develop during the first 6 months. By 6 months, the infant can perceive depth perception in pictures as well. ${ }^{11}$ Infants who have experience crawling and exploring will pay greater attention to visual cues of depth and modify their actions accordingly. ${ }^{12}$

\section{Hearing}

The infant's sense of hearing is very keen at birth, and the ability to hear is evidenced as soon as the 7 th month of prenatal development. In fact, an infant can distinguish between very similar sounds as early as one month after birth and can distinguish between a familiar and non-familiar voice even earlier. Infants are especially sensitive to the frequencies of sounds in human speech and prefer the exaggeration of infant-directed speech, which will be discussed later. Additionally, infants are innately ready to respond to the sounds of any language, but some of this ability will be lost by 7 or 8 months as the infant becomes familiar with the sounds of a particular language and less sensitive to sounds that are part of an unfamiliar language.

Newborns also prefer their mother's voices over another female when speaking the same material. ${ }^{13}$ Additionally, they will register in utero specific information heard from their mother's voice. DeCasper and Spence (1986) tested 16 infants (average age of hours) whose mothers had previously read to them prenatally. ${ }^{14}$ The mothers read several passages to their fetuses, including the first 28 paragraphs of the Cat in the Hat, beginning when they were 7 months pregnant. The fetuses had been exposed to the stories an average of 67 times or 3.5 hours. When the experimental infants were tested, the target stories (previously heard) were more reinforcing than the novel story as measured by their rate of sucking. However, for control infants, the target stories were not more reinforcing than the novel story indicating that the experimental infants had heard them before.

11. Sen, M. G., Yonas, A., \& Knill, D. C. (2001). Development of infants' sensitivity to surface contour information for spatial layout. Perception, 30, 167-176.

12. Berk, L. E. (2007). Development through the life span (4th ed.). Boston: Allyn and Bacon.

13. DeCasper, A. J., \& Fifer, W. P. (1980). Of human bonding: Newborns prefer their mother's voices. Science, $208,1174-1176$. 14. DeCasper, A. J., \& Spence, M. J. (1986). Prenatal maternal speech influences newborns' perception of speech sounds. Infant Behavior and Development, 9, 133-150. 


\section{Touch and Pain}

Immediately after birth, a newborn is sensitive to touch and temperature, and is also highly sensitive to pain, responding with crying and cardiovascular responses. ${ }^{15}$ Newborns who are circumcised, which is the surgical removal of the foreskin of the penis, without anesthesia experience pain as demonstrated by increased blood pressure, increased heart rate, decreased oxygen in the blood, and a surge of stress hormones. ${ }^{16}$ Research has demonstrated that infants who were circumcised without anesthesia experienced more pain and fear during routine childhood vaccines. Fortunately, many local pain

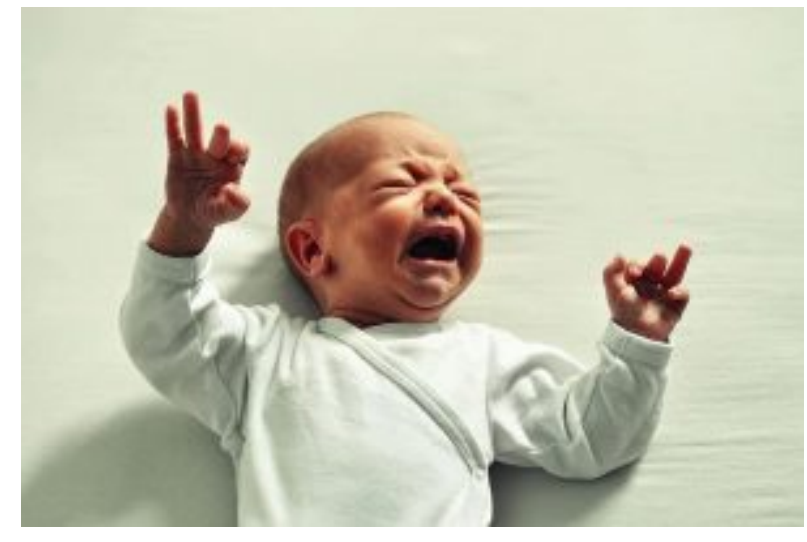

Figure 4. Infants are particularly sensitive to touch and pain. (Photo Source: Pikist, DMCA) killers are currently used during circumcision.

\section{Taste and Smell}

Studies of taste and smell demonstrate that babies respond with different facial expressions, suggesting that certain preferences are innate. Newborns can distinguish between sour, bitter, sweet, and salty flavors and show a preference for sweet flavors. Newborns also prefer the smell of their mothers. An infant only 6 days old is significantly more likely to turn toward its own mother's breast pad than to the breast pad of another baby's mother, ${ }^{17}$ and within hours of birth an infant also shows a preference for the face of its own mother. ${ }^{18} 19$

Infants seem to be born with the ability to perceive the world in an intermodal way; that is, through stimulation from more than one sensory modality. For example, infants who sucked on a pacifier with either a smooth or textured surface preferred to look at a corresponding (smooth or textured) visual model of the pacifier. By 4 months, infants can match lip movements with speech sounds and can match other audiovisual events. Although sensory development emphasizes the afferent processes used to take in information from the environment, these sensory processes can be affected

15. Balaban, M. T. \& Reisenauer, C. D. (2013). Sensory development. In N. J. Salkind (Ed.), Encyclopedia of human development (pp. 1144-1147). New, York: Sage Publications.

16. United States National Library of Medicine. (2016). Circumcision. Retrieved from https://medlineplus.gov/circumcision.html

17. Porter, R. H., Makin, J. W., Davis, L. M., Christensen, K. (1992). Responsiveness of infants to olfactory cues from lactating females. Infant Behavior and Development, 15, 85-93.

18. Bushnell, I. W. R. (2001) Mother's face recognition in newborn infants: Learning and Memory. Infant Child Development, 10, 67-94.

19. Bushnell, I. W. R., Sai, F., Mullin, J. T. (1989). Neonatal recognition of mother's face. British Journal of Developmental Psychology, 7, 3-15. 
by the infant's developing motor abilities. Reaching, crawling, and other actions allow the infant to see, touch, and organize his or her experiences in new ways.

\section{Nutrition}

Typically, breast milk is considered the ideal diet for newborns (exceptions would include if the milk contains teratogens such as HIV or due to a mother's consumption of alcohol or other drugs, etc.). Colostrum, the first breast milk produced during pregnancy and just after birth has been described as "liquid gold" (United States Department of Health and Human Services.) ${ }^{20}$ It is very rich in nutrients and antibodies. Breast milk changes by the third to fifth day after birth, becoming much thinner, but containing just the right amount of fat, sugar, water and proteins to support overall physical and neurological development. For most babies, breast milk is also easier to digest than formula. Formula-fed infants tend to experience more diarrhea and upset stomachs. The absence of antibodies in formula often results in a higher rate of ear infections and respiratory infections. Children who are breastfed tend to have lower rates of childhood leukemia, asthma, obesity, Type 1 and 2 diabetes, and a lower risk of SIDS. The USDHHS recommends that mothers breastfeed their infants until at least 6 months of age and that breast milk be used in the diet throughout the first year or two. ${ }^{21}$

Several recent studies have reported that it is not just babies that benefit from breastfeeding. Breastfeeding stimulates contractions in the uterus to help it regain its normal size, and women who breastfeed are more likely to space their pregnancies further apart. Mothers who breastfeed are at lower risk of developing breast cancer, ${ }^{22}$ especially among higher-risk racial and ethnic groups. ${ }^{23}$ Women who breastfeed have lower rates of ovarian cancer, ${ }^{24}$ reduced risk for developing Type 2 diabetes, ${ }^{25}$ and rheumatoid arthritis. ${ }^{26}$ In most studies these benefits have been seen in women who breastfeed longer than 6 months.

20. United States Department of Health and Human Services, Office of Women's Health (2011). Your guide to breastfeeding. Washington D.C.

21. United States Department of Health and Human Services, Office of Women's Health (2011). Your guide to breastfeeding. Washington D.C.

22. Islami, F., Liu, Y., Jemal, A., Zhou, J., Weiderpass, E., Colditz, G...Weiss, M. (2015). Breastfeeding and breast cancer risk by receptor status - a systematic review and meta-analysis. Annals of Oncology, 26, 2398-2407.

23. Redondo, C. M., Gago-Dominguez, M., Ponte, S. M., Castelo, M. E., Jiang, X., Garcia, A.A... Castelao, J. E. (2012). Breast feeding, parity and breast cancer subtypes in a Spanish cohort. PLoS One, 7(7): e40543 doi: 10.1371/journal.pone.00040543

24. Titus-Ernstoff, L., Rees, J. R., Terry, K. L., \& Cramer, D. W. (2010). Breast-feeding the last born child and risk of ovarian cancer. Cancer Causes Control, 21(2), 201-207. doi: 10.1007/s10552-009-9450-8

25. Gunderson, E. P., Hurston, S. R., Ning, X., Lo, J. C., Crites, Y., Walton, D... \& Quesenberry, C. P. Jr. (2015). Lactation and progression to type 2 diabetes mellitus after gestational diabetes mellitus: A prospective cohort study. American Journal of Medicine, 163, 889-898. Doi: 10.7326/m 15-0807.

26. Karlson, E.W., Mandl, L.A., Hankison, S. E., \& Grodstein, F. (2004). Do breast-feeding and other reproductive factors influence future risk of rheumatoid arthritis? Arthritis ef Rheumatism, 50 (11), 3458-3467. 
Mothers can certainly continue to provide breast milk to their babies by expressing and freezing the milk to be bottle fed at a later time or by being available to their infants at feeding time. Some workplaces support breastfeeding mothers by providing flexible schedules and welcoming infants, but many do not. In addition, not all women may be able to breastfeed. Women with HIV are routinely discouraged from breastfeeding as the infection may pass to the infant. Similarly, women who are taking certain medications or undergoing radiation treatment may be told not to breastfeed. ${ }^{27}$

\section{When to Introduce More Solid Foods}

Solid foods should not be introduced until the infant is ready. According to The Clemson University Cooperative Extension (2014), some things to look for include that the infant:

- can sit up without needing support

- can hold its head up without wobbling

- shows interest in foods others are eating

- is still hungry after being breastfed or formula-fed

- is able to move foods from the front to the back of the mouth

- is able to turn away when they have had enough ${ }^{28}$

For many infants who are 4 to 6 months of age, breast milk or formula can be supplemented with more solid foods. The first semi-solid foods that are introduced are iron-fortified infant cereals mixed with breast milk or formula. Typically rice, oatmeal, and barley cereals are offered as a number of infants are sensitive to more wheat-based cereals. Finger foods such as toast squares, cooked vegetable strips, or peeled soft fruit can be introduced by 10-12 months. New foods should be introduced one at a time, and the new food should be fed for a few days in a row to allow the baby time to adjust to the new food. This also allows parents time to assess if the child has a food allergy. Foods that have multiple ingredients should be avoided until parents have assessed how the child responds to each ingredient separately. Foods that are sticky (such as peanut butter or taffy), cut into large chunks (such as cheese and harder meats), and firm and round (such as hard candies, grapes, or cherry tomatoes) should be avoided as they are a choking hazard. Honey and Corn syrup should be avoided as these often contain botulism spores. In children under 12 months, this can lead to death. ${ }^{29}$

27. United States Department of Health and Human Services, Office of Women's Health (2011). Your guide to breast feeding. Washington D.C.

28. Clemson University Cooperative Extension. (2014). Introducing Solid Foods to Infants. Retrieved from http://www.clemson.edu/extension/hgic/food/nutrition/nutrition/life_stages/hgic4102.html

29. Clemson University Cooperative Extension. (2014). Introducing Solid Foods to Infants. Retrieved from http://www.clemson.edu/extension/hgic/food/nutrition/nutrition/life_stages/hgic4102.html 


\section{Cognitive Development: Piaget and the Sensorimotor Stage}

Piaget believed that we are continuously trying to maintain cognitive equilibrium, or a balance, in what we see and what we know. ${ }^{30}$ Children have much more of a challenge in maintaining this balance because they are constantly being confronted with new situations, new words, new objects, etc. All this new information needs to be organized, and a framework for organizing information is referred to as a schema. Children develop schemata through the processes of assimilation and accommodation.

When faced with something new, a child may demonstrate assimilation, which is fitting the new information into an existing schema, such as calling all animals with four legs "doggies" because he or she knows the word doggie. Instead of assimilating the information, the child may demonstrate.

Accommodation, which is expanding the framework of knowledge to accommodate the new situation and thus learning a new word to more accurately name the animal. For example, recognizing that a horse is different from a zebra means the child has accommodated, and now the child has both a zebra schema and a horse schema. Even as adults we continue to try and "make sense" of new situations by determining whether they fit into our old way of thinking (assimilation) or whether we need to modify our thoughts (accommodation).

According to the Piagetian perspective, infants learn about the world primarily through their senses and motor abilities. ${ }^{31}$ These basic motor and sensory abilities provide the foundation for the cognitive skills that will emerge during the subsequent stages of cognitive development. The first stage of cognitive development is referred to as the Sensorimotor Period.

\section{Development of Object Permanence}

A critical milestone during the sensorimotor period is the development of object permanence. Object permanence is the understanding that even if something is out of sight, it still exists. ${ }^{32}$ According to Piaget, young infants do not remember an object after it has been removed from sight. Piaget studied infants' reactions when a toy was first shown to an infant and then hidden under a blanket. Infants who had already developed object permanence would reach for the hidden toy, indicating that they knew it still existed, whereas infants who had not developed object permanence would appear confused. Piaget emphasizes this construct because it was an objective way for children to demonstrate that they can mentally represent their world. Children have typically

30. Piaget, J. (1954). The construction of reality in the child. New York: Basic Books.

31. Harris, Y. R. (2005). Cognitive Development. In N. J. Salkind (Ed.), Encyclopedia of human development (pp. 276-281). New, York: Sage Publications.

32. Bogartz, R. S., Shinskey, J. L., \& Schilling, T. (2000). Object permanence in five-and-a-half month old infants? Infancy, 403428. 
acquired this milestone by 8 months. Once toddlers have mastered object permanence, they enjoy games like hide and seek, and they realize that when someone leaves the room they will come back. Toddlers also point to pictures in books and look in appropriate places when you ask them to find objects.

In Piaget's view, around the same time children develop object permanence, they also begin to exhibit Stranger Anxiety, which is a fear of unfamiliar people. ${ }^{33}$ Babies may demonstrate this by crying and turning away from a stranger, by clinging to a caregiver, or by attempting to reach their arms toward familiar faces such as parents. Stranger anxiety results when a child is unable to assimilate the stranger into an existing schema; therefore, she can't predict what her experience with that stranger will be like, which results in a fear response.

\section{Critique of Piaget}

Piaget thought that children's ability to understand objects, such as learning that a rattle makes a noise when shaken, was a cognitive skill that develops slowly as a child matures and interacts with the environment. Today, developmental psychologists think Piaget was incorrect. Researchers have found that even very young children understand objects and how they work long before they have experience with those objects. ${ }^{34} 35$ For example, Piaget believed that infants did not fully master object permanence until substage 5 of the sensorimotor period. ${ }^{36}$

However, infants seem to be able to recognize that objects have permanence at much younger ages. Diamond (1985) found that infants show earlier knowledge if the waiting period is shorter. ${ }^{37}$ At age 6 months, they retrieved the hidden object if their wait for retrieving the object is no longer than 2 seconds, and at 7 months if the wait is no longer than 4 seconds. Even earlier, children as young as 3 months old demonstrated knowledge of the properties of objects that they had only viewed and did not have prior experience with them. In one study, 3-month-old infants were shown a truck rolling down a track and behind a screen. The box, which appeared solid but was actually hollow, was placed next to the track. The truck rolled past the box as would be expected. Then the box was placed on the track to block the path of the truck. When the truck was rolled down the track this time, it continued unimpeded. The infants spent significantly more time looking at this impossible event (Figure 3.16).

33. Crain, W. (2005). Theories of development concepts and applications (5th ed.). NJ: Pearson.

34. Baillargeon, R. (1987). Object permanence in $3 \frac{1}{2} 2$ and $4 \frac{1}{2} 2$ year-old infants. Developmental Psychology, 22, 655-664.

35. Baillargeon, R., Li, J., Gertner, Y, \& Wu, D. (2011). How do infants reason about physical events? In U. Goswami (Ed.), The Wiley-Blackwell handbook of childhood cognitive development. MA: John Wiley.

36. Thomas, R. M. (1979). Comparing theories of child development. Santa Barbara, CA: Wadsworth.

37. Diamond, A. (1985). Development of the ability to use recall to guide actions, as indicated by infants' performance on AB.

Child Development, 56, 868-883. 


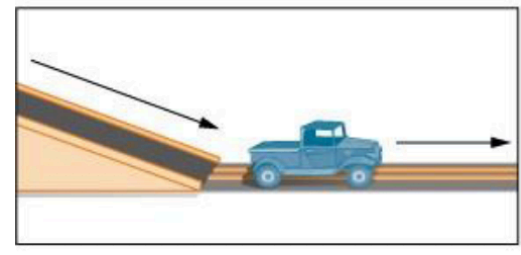

(a)

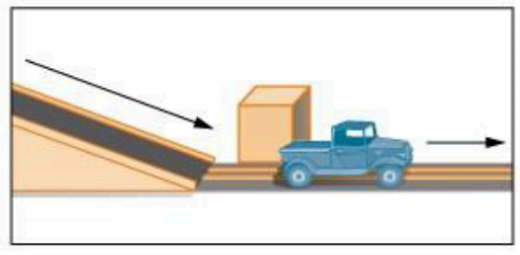

(b)

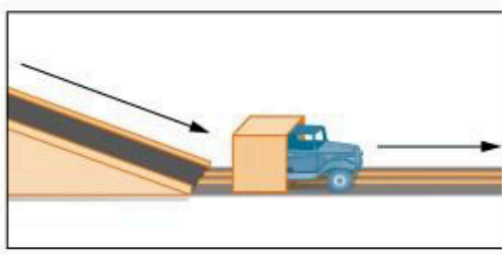

(c)

Figure 5. A truck moving down a track.

Baillargeon (1987) concluded that they knew solid objects cannot pass through each other. ${ }^{38}$ Baillargeon's findings suggest that very young children have an understanding of objects and how they work, which Piaget (1954) would have said is beyond their cognitive abilities due to their limited experiences in the world. ${ }^{39}$

\section{Language Development}

An important aspect of cognitive development is language acquisition. The order in which children learn language structures is consistent across children and cultures. ${ }^{40}$ Starting before birth, babies begin to develop language and communication skills. At birth, babies recognize their mother's voice and can discriminate between the language(s) spoken by their mothers and foreign languages, and they show preferences for faces that are moving in synchrony with audible language. ${ }^{4142}$

Do newborns communicate? Of course they do. They do not, however, communicate with the use of oral language. Instead, they communicate their thoughts and needs with body posture (being relaxed or still), gestures, cries, and facial expressions. A person who spends adequate time with an infant can learn which cries indicate pain and which ones indicate hunger, discomfort, or frustration.

\section{Intentional Vocalizations}

In terms of producing spoken language, babies begin to coo almost immediately. Cooing is a onesyllable combination of a consonant and a vowel sound (e.g., coo or ba). Interestingly, babies replicate sounds from their own languages. A baby whose parents speak French will coo in a different tone

38. Baillargeon, R. (1987). Object permanence in $3 \frac{1}{1} 2$ and $4 \frac{1}{2} 2$ year-old infants. Developmental Psychology, 22, 655-664.

39. Piaget, J. (1954). The construction of reality in the child. New York: Basic Books.

40. Hatch, E. M. (1983). Psycholinguistics: A second language perspective. Rowley, MA: Newbury House Publishers.

41. Blossom, M., \& Morgan, J. L. (2006). Does the face say what the mouth says? A study of infants' sensitivity to visual prosody. In 30th annual Boston University conference on language development, Somerville, MA.

42. Pickens, J., Field, T., Nawrocki, T., Martinez, A., Soutullo, D., \& Gonzalez, J. (1994). Full-term and preterm infants' perception of face-voice synchrony. Infant Behavior and Development, 17(4), 447-455. 
than a baby whose parents speak Spanish or Urdu. These gurgling, musical vocalizations can serve as a source of entertainment to an infant who has been laid down for a nap or seated in a carrier on a car ride. Cooing serves as practice for vocalization, as well as the infant hears the sound of his or her own voice and tries to repeat sounds that are entertaining. Infants also begin to learn the pace and pause of conversation as they alternate their vocalization with that of someone else and then take their turn again when the other person's vocalization has stopped.

At about four to six months of age, infants begin making even more elaborate vocalizations that include the sounds required for any language. Guttural sounds, clicks, consonants, and vowel sounds stand ready to equip the child with the ability to repeat whatever sounds are characteristic of the language heard. Eventually, these sounds will no longer be used as the infant grows more accustomed to a particular language.

At about 7 months, infants begin babbling, engaging in intentional vocalizations that lack specific meaning and comprise a consonant-vowel repeated sequence, such as ma-ma-ma or da-da-da. Children babble as practice in creating specific sounds, and by the time they are 1 year old, the babbling uses primarily the sounds of the language that they are learning. ${ }^{43}$ These vocalizations have a conversational tone that sounds meaningful even though it isn't. Babbling also helps children understand the social, communicative function of language. Children who are exposed to sign language babble in sign by making hand movements that represent real language. ${ }^{44}$

Children communicate information through gesturing long before they speak, and there is some evidence that gesture usage predicts subsequent language development. ${ }^{45}$ Babies who are deaf also use gestures to communicate wants, reactions, and feelings. Because gesturing seems to be easier than vocalization for some toddlers, sign language is sometimes taught to enhance one's ability to communicate by making use of the ease of gesturing. The rhythm and pattern of language is used when deaf babies sign just as it is when hearing babies babble.

Most infants shake their head "no" around 6-9 months, and they respond to verbal requests to do things like "wave bye-bye" or "blow a kiss" around 9-12 months. Children also use contextual information, particularly the cues that parents provide, to help them learn language. Children learn that people are usually referring to things that they are looking at when they are speaking, and that that the speaker's emotional expressions are related to the content of their speech. ${ }^{46}$

43. de Boysson-Bardies, B., Sagart, L., \& Durand, C. (1984). Discernible differences in the babbling of infants according to target language. Journal of Child Language, 11(1), 1-15.

44. Petitto, L. A., \& Marentette, P. F. (1991). Babbling in the manual mode: Evidence for the ontogeny of language. Science, 251(5000), 1493-1496.

45. Iverson, J. M., \& Goldin-Meadow, S. (2005). Gesture paves the way for language development. Psychological science, 16(5), 367-371.

46. Baldwin, D. A. (1993). Early referential understanding: Infants' ability to recognize referential acts for what they are. Developmental Psychology, 29(5), 832-843. 
Children begin using their first words at about 12 or 13 months of age and may use partial words to convey thoughts at even younger ages. These one word expressions are referred to as Holophrasic Speech. For example, the child may say "ju” for the word "juice" and use this sound when referring to a bottle. The listener must interpret the meaning of the holophrase, and when this is someone who has spent time with the child, interpretation is not too difficult. But, someone who has not been around the child will have trouble knowing what is meant. Imagine the parent who to a friend exclaims, "Ezra's talking all the time now!" The friend hears only "ju da ga" to which the parent explains means, "I want some milk when I go with Daddy."

The early utterances of children contain many errors, for instance, confusing /b/ and /d/, or /c/ and /z/. The words children create are often simplified, in part because they are not yet able to make the more complex sounds of the real language. ${ }^{47}$ Children may say "keekee" for kitty, "nana” for banana, and "vesketti" for spaghetti because it is easier. Often these early words are accompanied by gestures that may also be easier to produce than the words themselves. Children's pronunciations become increasingly accurate between 1 and 3 years, but some problems may persist until school age.

A child who learns that a word stands for an object may initially think that the word can be used for only that particular object, which is referred to as underextension. Only the family's Irish Setter is a "doggie", for example. More often, however, a child may think that a label applies to all objects that are similar to the original object, which is called overextension. For example, all animals become "doggies".

\section{First words and cultural influences}

First words if the child is using English tend to be nouns. The child labels objects such as cup, ball, or other items that they regularly interact with. In a verb-friendly language such as Chinese, however, children may learn more verbs. This may also be due to the different emphasis given to objects based on culture. Chinese children may be taught to notice action and relationships between objects, while children from the United States may be taught to name an object and its qualities (color, texture, size, etc.). These differences can be seen when comparing interpretations of art by older students from China and the United States.

By the time they become toddlers, children have a vocabulary of about 50-200 words and begin putting those words together in telegraphic speech, such as "baby bye-bye" or "doggie pretty". Words needed to convey messages are used, but the articles and other parts of speech necessary for grammatical correctness are not yet used. These expressions sound like a telegraph, or perhaps a better analogy today would be that they read like a text message. Telegraphic speech/text message

47. Dobrich, W., \& Scarborough, H. S. (1992). Phonological characteristics of words young children try to say. Journal of Child Language, 19(3), 597-616. 
speech occurs when unnecessary words are not used. "Give baby ball" is used rather than "Give the baby the ball."

\section{Infant-directed Speech}

Have you ever wondered why adults tend to use that sing-song type of intonation and exaggeration used when talking to children? This represents a universal tendency and is known as Infant-directed Speech. It involves exaggerating the vowel and consonant sounds, using a high-pitched voice, and delivering the phrase with great facial expression. ${ }^{48}$ Why is this done? Infants are frequently more attuned to the tone of voice of the person speaking than to the content of the words themselves and are aware of the target of speech. Werker, Pegg, and McLeod (1994) found that infants listened longer to a woman who was speaking to a baby than to a woman who was speaking to another adult. ${ }^{49}$ It may be in order to clearly articulate the sounds of a word so that the child can hear the sounds involved. It may also be because when this type of speech is used, the infant pays more attention to the speaker and this sets up a pattern of interaction in which the speaker and listener are in tune with one another.

48. Clark, E. V. (2009). What shapes children's language? Child-directed speech and the process of acquisition. In V. C. M. Gathercole (Ed.), Routes to language: Essays in honor of Melissa Bowerman. NY: Psychology Press.

49. Werker, J. F., Pegg, J. E., \& McLeod, P. J. (1994). A cross-language investigation of infant preference for infant-directed communication. Infant Behavior and Development, 17, 323-333. 


\section{Socioemotional Development: Infant Temperament}

Perhaps you have spent time with a number of infants. How were they alike? How did they differ? How do you compare with your siblings or other children you have known well. You may have noticed that some seemed to be in a better mood than others and that some were more sensitive to noise or more easily distracted than others. These differences may be attributed to temperament. Temperament is the innate characteristics of the infant, including mood, activity level, and emotional reactivity, noticeable soon after birth.

In a 1956 landmark study, Chess and Thomas (1996) evaluated 141 children's temperament based on parental interviews. ${ }^{50}$ Referred to as the New York Longitudinal Study, infants were assessed on 9 dimensions of temperament including: Activity level,

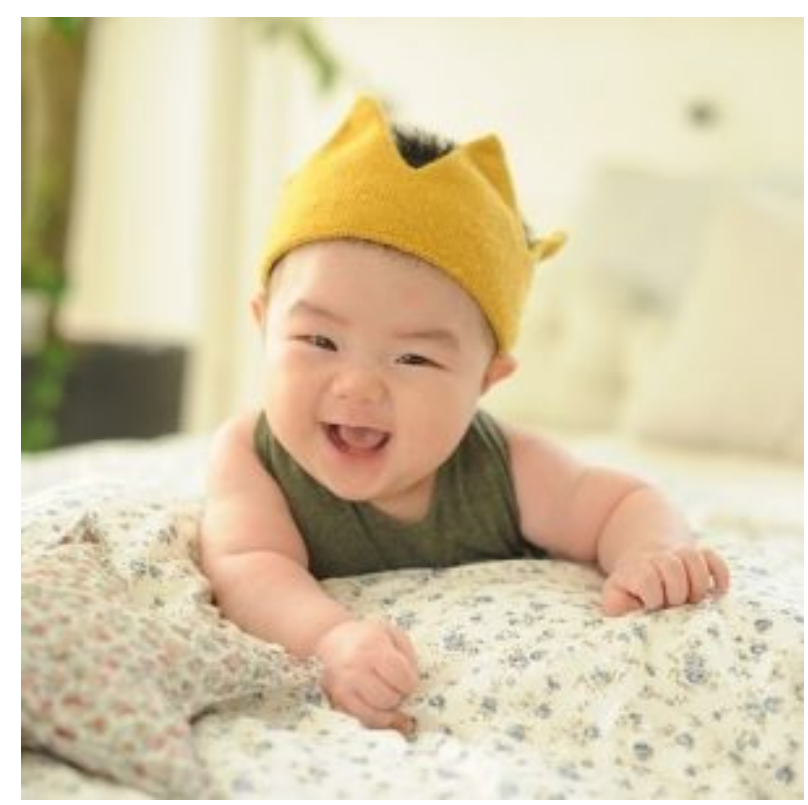

Figure 6. A happy infant. (Image Source: Noba Project, licensed $\underline{\text { CC } 0}$. rhythmicity (regularity of biological functions), approach/withdrawal (how children deal with new things), adaptability to situations, intensity of reactions, threshold of responsiveness (how intense a stimulus has to be for the child to react), quality of mood, distractibility, attention span, and persistence. Based on the infants' behavioral profiles, they were categorized into three general types of temperament:

- Easy Child (40\%) who is able to quickly adapt to routine and new situations, remains calm, is easy to soothe, and usually is in a positive mood.

- Difficult Child (10\%) who reacts negatively to new situations, has trouble adapting to routine, is usually negative in mood, and cries frequently.

- Slow-to-Warm-Up Child (15\%) has a low activity level, adjusts slowly to new situations and is often negative in mood.

The percentages listed above do not equal 100\% as some children were not able to be placed neatly into one of the categories. Think about how you might approach each type of child in order to improve your interactions with them. An easy child will not need much extra attention, while a slow to warm up child may need to be given advance warning if new people or situations are going to be introduced. A difficult child may need to be given extra time to burn off their energy. A caregiver's ability to work well and accurately read the child will enjoy a goodness-of-fit, meaning their styles 
match and communication and interaction can flow. Parents who recognize each child's temperament and accept it, will nurture more effective interactions with the child and encourage more adaptive functioning. For example, an adventurous child whose parents regularly take her outside on hikes would provide a good "fit" to her temperament. Remember that parenting and child-rearing is bidirectional; both caregivers and children influence each others behaviors. Revisit the Influences on Parenting section in Part I. Key Concepts to review this information.

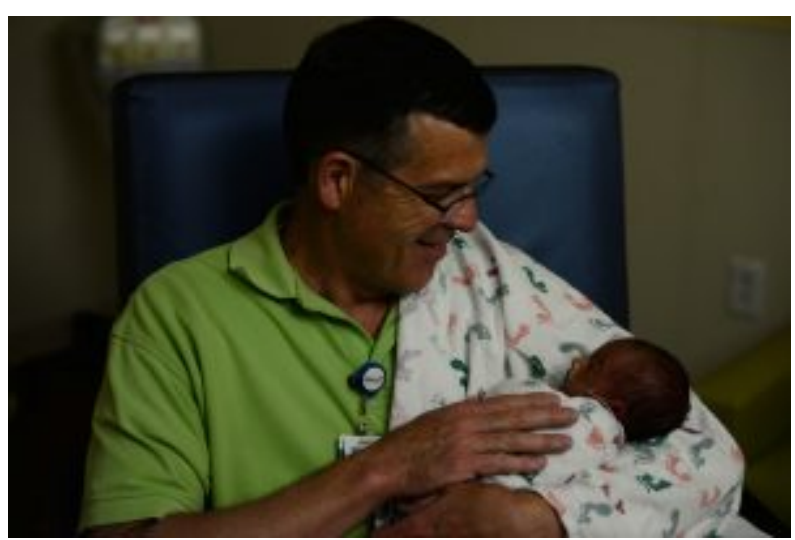

Figure 7. A parent smiling at their child. (Photo Source: Miranda Simpson)
Temperament does not change dramatically as we grow up, but we may learn how to work around and manage our temperamental qualities. Temperament may be one of the things about us that stays the same throughout development. In contrast, personality, defined as an individual's consistent pattern of feeling, thinking, and behaving, is the result of the continuous interplay between biological disposition and experience.

Personality also develops from temperament in other ways. ${ }^{51}$ As children mature biologically, temperamental characteristics emerge and change over time. A newborn is not capable of much selfcontrol, but as brain-based capacities for self- control advance, temperamental changes in selfregulation become more apparent. For example, a newborn who cries frequently doesn't necessarily have a grumpy personality; over time, with sufficient parental support and an increased sense of security, the child might be less likely to cry.

In addition, personality is made up of many other features besides temperament. Children's developing self-concept, their motivations to achieve or to socialize, their values and goals, their coping styles, their sense of responsibility and conscientiousness, and many other qualities are encompassed into personality. These qualities are influenced by biological dispositions, but even more by the child's experiences with others, particularly in close relationships, that guide the growth of individual characteristics. Indeed, personality development begins with the biological foundations of temperament but becomes increasingly elaborated, extended, and refined over time. The newborn that parents gazed upon thus becomes an adult with a personality of depth and nuance.

51. Thompson, R. A., Winer, A. C., \& Goodvin, R. (2010). The individual child: Temperament, emotion, self, and personality. In M. Bornstein \& M. E. Lamb (Eds.), Developmental science: An advanced textbook (6th ed., pp. 423-464). New York, NY: Psychology Press/Taylor \& Francis. 


\section{Erikson: Trust vs Mistrust}

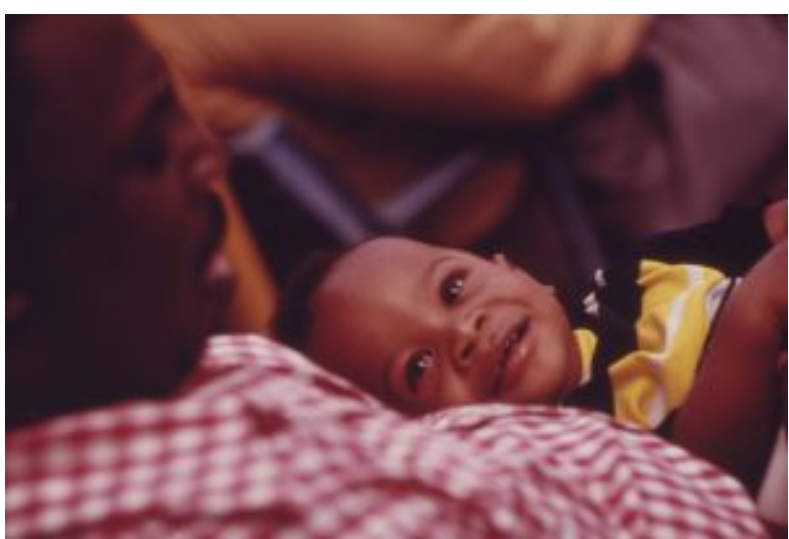

Figure 8. A happy child. (Photo Source: John H. White, public domain)
As we previously discussed in the Theories section, Erikson formulated an eight-stage theory of psychosocial development. Erikson was in agreement on the importance of a secure base, arguing that the most important goal of infancy was the development of a basic sense of trust in one's caregivers. Consequently, the first stage, trust vs. mistrust, highlights the importance of attachment. Erikson maintained that the first year to year and a half of life involves the establishment of a sense of trust. ${ }^{52}$ Infants are dependent and must rely on others to meet their basic physical needs as well as their needs for stimulation and comfort. A caregiver

who consistently meets these needs instills a sense of trust or the belief that the world is a trustworthy place. The caregiver should not worry about overindulging a child's need for comfort, contact, or stimulation.

Erikson (1982) believed that mistrust could contaminate all aspects of one's life and deprive the individual of love and fellowship with others. ${ }^{53}$ Consider the implications for establishing trust if a caregiver is unavailable or is upset and ill-prepared to care for a child. Or if a child is born prematurely, is unwanted, or has physical problems that make him or her less desirable to a parent. Under these circumstances, we cannot assume that the parent is going to provide the child with a feeling of trust.

\section{Mary Ainsworth and the Strange Situation}

Developmental psychologist Mary Ainsworth, a student of John Bowlby, continued studying the development of attachment in infants. Ainsworth and her colleagues created a laboratory test that measured an infant's attachment to his or her parent. The test is called The Strange Situation Technique because it is conducted in a context that is unfamiliar to the child and therefore likely to heighten the child's need for his or her parent. ${ }^{54}$

During the procedure, that lasts about 20 minutes, the parent and the infant are first left alone, while the infant explores the room full of toys. Then a strange adult enters the room and talks for a minute 
to the parent, after which the parent leaves the room. The stranger stays with the infant for a few minutes, and then the parent again enters and the stranger leaves the room. During the entire session, a video camera records the child's behaviors, which are later coded by trained coders. The investigators were especially interested in how the child responded to the caregiver leaving and returning to the room, referred to as the "reunion." On the basis of their behaviors, the children are categorized into one of four groups where each group reflects a different kind of attachment relationship with the caregiver. One style is secure and the other three styles are referred to as insecure.

- A child with a secure attachment style usually explores freely while the caregiver is present and may engage with the stranger. The child will typically play with the toys and bring one to the caregiver to show and describe from time to time. The child may be upset when the caregiver departs but is also happy to see the caregiver return.

- A child with an ambivalent (sometimes called resistant) attachment style is wary about the situation in general, particularly the stranger, and stays close or even clings to the caregiver rather than exploring the toys. When the caregiver leaves, the child is extremely distressed and is ambivalent when the caregiver returns. The child may rush to the caregiver but then fails to be comforted when picked up. The child may still be angry and even resist attempts to be soothed.

- A child with an avoidant attachment style will avoid or ignore the mother, showing little emotion when the mother departs or returns. The child may run away from the mother when she approaches. The child will not explore very much, regardless of who is there, and the stranger will not be treated much differently from the mother.

- A child with a disorganized/disoriented attachment style seems to have an inconsistent way of coping with the stress of the strange situation. The child may cry during the separation, but avoid the mother when she returns, or the child may approach the mother but then freeze or fall to the floor.

How common are the attachment styles among children in the United States? It is estimated that about 65 percent of children in the United States are securely attached. Twenty percent exhibit avoidant styles and 10 to 15 percent are ambivalent. Another 5 to 10 percent may be characterized as disorganized.

Some cultural differences in attachment styles have been found. ${ }^{55}$ For example, German parents value independence and Japanese mothers are typically by their children's sides. As a result, the rate

55. Rothbaum, F., Weisz, J., Pott, M., Miyake, K., \& Morelli, G. (2010). Attachment and culture: Security in the United States and Japan. American Psychologist, 55, 1093-1104. 
of insecure-avoidant attachments is higher in Germany and insecure-resistant attachments are higher in Japan. These differences reflect cultural variation rather than true insecurity, however. ${ }^{56}$

Keep in mind that methods for measuring attachment styles have been based on a model that reflects middle-class, U. S. values and interpretation. Newer methods for assessment attachment styles involve using a $\mathbf{Q}$-sort technique in which a large number of behaviors are recorded on cards and the observer sorts the cards in a way that reflects the type of behavior that occurs within the situation. ${ }^{57}$ There are 90 items in the third version of the Q-sort technique, and examples of the behaviors assessed include:

- When child returns to mother after playing, the child is sometimes fussy for no clear reason.

- When the child is upset or injured, the child will accept comforting from adults other than mother.

- Child often hugs or cuddles against mother, without her asking or inviting the child to do so

- When the child is upset by mother's leaving, the child continues to cry or even gets angry after she is gone.

At least two researchers observe the child and parent in the home for 1.5-2 hours per visit. Usually two visits are sufficient to gather adequate information. The parent is asked if the behaviors observed are typical for the child. This information is used to test the validity of the Strange Situation classifications across age, cultures, and with clinical populations.

\section{Caregiver Interactions and the Formation of Attachment}

Most developmental psychologists argue that a child becomes securely attached when there is consistent contact from one or more caregivers who meet the physical and emotional needs of the child in a responsive and appropriate manner. However, even in cultures where mothers do not talk, cuddle, and play with their infants, secure attachments can develop. ${ }^{58}$

- The insecure ambivalent style occurs when the parent is insensitive and responds inconsistently to the child's needs. Consequently, the infant is never sure that the world is a trustworthy place or that he or she can rely on others without some anxiety. A caregiver who is unavailable, perhaps because of marital tension, substance abuse, or preoccupation with work, may send a message to the infant he or she cannot rely on having needs met. An infant who receives only sporadic attention when experiencing discomfort may not learn how to calm

56. Van Ijzendoorn, M. H., \& Sagi, A. (1999). Cross-cultural patterns of attachment. In J. Cassidy \& P. R. Shaver (Eds.), Handbook of attachment: Theory, research, and clinical applications (pp. 713-734). New York: Guilford.

57. Waters, E. (1987). Attachment Q-set (Version 3). Retrieved from http://www.johnbowlby.com.

58. LeVine, R. A., Dixon, S., LeVine, S., Richman, A., Leiderman, P. H., Keefer, C. H., \& Brazelton, T. B. (1994). Child care and culture: Lessons from Africa. New York: Cambridge University Press. 
down. The child may cry if separated from the caregiver and also cry upon their return. They seek constant reassurance that never seems to satisfy their doubt. Keep in mind that clingy behavior can also just be part of a child's natural disposition or temperament and does not necessarily reflect some kind of parental neglect. Additionally, a caregiver that attends to a child's frustration can help teach them to be calm and to relax.

- The insecure avoidant style is marked by insecurity, but this style is also characterized by a tendency to avoid contact with the caregiver and with others. This child may have learned that needs typically go unmet and learns that the caregiver does not provide care and cannot be relied upon for comfort, even sporadically. An insecure avoidant child learns to be more independent and disengaged.

- The insecure disorganized/disoriented style represents the most insecure style of attachment and occurs when the child is given mixed, confused, and inappropriate responses from the caregiver. For example, a mother who suffers from schizophrenia may laugh when a child is hurting or cry when a child exhibits joy. The child does not learn how to interpret emotions or to connect with the unpredictable caregiver. This type of attachment is also often seen in children who have been abused. Research has shown that abuse disrupts a child's ability to regulate their emotions. ${ }^{59}$

Having a consistent caregiver may be jeopardized if the infant is cared for in a daycare setting with a high turn-over of staff or if institutionalized and given little more than basic physical care. Infants who, perhaps because of being in orphanages with inadequate care, have not had the opportunity to attach in infancy may still form initial secure attachments several years later. However, they may have more emotional problems of depression, anger, or be overly friendly as they interact with others. ${ }^{60}$

\section{Social Deprivation}

Severe deprivation of parental attachment can lead to serious problems. According to studies of children who have not been given warm, nurturing care, they may show developmental delays, failure to thrive, and attachment disorders. ${ }^{61}$ Non-organic failure to thrive is the diagnosis for an infant who does not grow, develop, or gain weight on schedule. In addition, postpartum depression can cause even a well-intentioned mother to neglect her infant.

Children who experience social neglect or deprivation, repeatedly change primary caregivers that

59. Main, M., \& Solomon, J. (1990). Procedures for identifying infants as disorganized/disoriented during the Ainsworth Strange Situation. In M. T. Greenberg, D. Cicchetti, \& E. M. Cummings (Eds.), Attachment in the Preschool Years (pp.121- 160).Chicago, IL: University of Chicago Press.

60. O'Connor, T.G., Marvin, R., Rutter, M., Olrick, J., \& Britner, P. (2003). Child-parent attachment following early institutional deprivation. Development and Psychopathology, 15, 19-38. https://doi.org/10.1017/S0954579403000026

61. Bowlby, J. (1982). Attachment (2nd ed.). New York: Basic Books. 
limit opportunities to form stable attachments, or are reared in unusual settings (such as institutions) that limit opportunities to form stable attachments can certainly have difficulty forming attachments. According to the Diagnostic and Statistical Manual of Mental Disorders, 5th edition, those children experiencing neglectful situations and also displaying markedly disturbed and developmentally inappropriate attachment behavior, such as being inhibited and withdrawn, minimal social and emotional responsiveness to others, and limited positive affect, may be diagnosed with Reactive Attachment Disorder. ${ }^{62}$ This disorder often occurs with developmental delays, especially in cognitive and language areas. Fortunately, the majority of severely neglected children do not develop Reactive Attachment Disorder, which occurs in less than $10 \%$ of such children. The quality of the caregiving environment after serious neglect affects the development of this disorder.

Being able to overcome challenges and successfully adapt is Resiliency. Even young children can exhibit strong resiliency to harsh circumstances. Resiliency can be attributed to certain personality factors, such as an easy-going temperament. Some children are warm, friendly, and responsive, whereas others tend to be more irritable, less manageable, and difficult to console, and these differences play a role in attachment. ${ }^{63} 64$ It seems safe to say that attachment, like most other developmental processes, is affected by an interplay of genetic and socialization influences.

Receiving support from others also leads to resiliency. A positive and strong support group can help a parent and child build a strong foundation by offering assistance and positive attitudes toward the newborn and parent. In a direct test of this idea, Dutch researcher van den Boom (1994) randomly assigned some babies' mothers to a training session in which they learned to better respond to their children's needs. ${ }^{65}$ The research found that these mothers' babies were more likely to show a secure attachment style in comparison to the mothers in a control group that did not receive training.

\section{Erikson: Autonomy vs Shame and Doubt}

As the child begins to walk and talk, an interest in independence or autonomy replaces a concern for trust. The toddler tests the limits of what can be touched, said, and explored. Erikson (1982) believed that toddlers should be allowed to explore their environment as freely as safety allows and in so doing will develop a sense of independence that will later grow to self-esteem, initiative, and overall

62. American Psychiatric Association. (2013). Diagnostic and statistical manual of mental disorders, 5th edition (DSM-V). Washington, DC: Author.

63. Gillath, O., Shaver, P. R., Baek, J. M., \& Chun, D. S. (2008). Genetic correlates of adult attachment style. Personality \& Social Psychology Bulletin, 34, 1396-1405.

64. Seifer, R., Schiller, M., Sameroff, A., Resnick, S., \& Riordan, K. (1996). Attachment, maternal sensitivity, and infant temperament during the first year of life. Developmental Psychology, 32, 12-25.

65. Van den Boom, D. C. (1994). The influence of temperament and mothering on attachment and exploration: An experimental manipulation of sensitive responsiveness among lower-class mothers with irritable infants. Child Development, 65, $1457-1477$. 
confidence. ${ }^{66}$ If a caregiver is overly anxious about the toddler's actions for fear that the child will get hurt or violate other's expectations, the caregiver can give the child the message that he or she should be ashamed of their behavior and instill a sense of doubt in their own abilities. Parenting advice based on these ideas would be to keep your toddler safe, but let them learn by doing.

\section{Conclusion}

We have explored the dramatic story of the first two years of life. Rapid physical growth, neurological development, language acquisition, the movement from hands on to mental learning, an expanding emotional repertoire, and the initial conceptions of self and others make this period of life very exciting. These abilities are shaped into more sophisticated mental processes, self-concepts, and social relationships during the years of early childhood.

\section{(c) (1) (2) (2)}

Infancy and Toddlerhood by Suzanne Valentine-French; Martha Lally; and Diana Lang is licensed under a Creative Commons Attribution-NonCommercial-ShareAlike 4.0 International License, except where otherwise noted. 


\title{
EARLY CHILDHOOD
}

\author{
Martha Lally; Suzanne Valentine-French; and Diana Lang
}

Our discussion will now focus on the physical, cognitive, and socioemotional development during the ages from two to six, referred to as early childhood. Early childhood represents a time period of continued rapid growth, especially in the areas of language and cognitive development. Those in early childhood have more control over their emotions and begin to pursue a variety of activities that reflect their personal interests. Parents continue to be very important in the child's development, but now teachers and peers exert an influence not seen with infants and toddlers. ${ }^{1}$

Children between the ages of two and six years tend to grow about 3 inches in height and gain about 4 to 5 pounds in weight each year. Just as in infancy, growth occurs in spurts rather than continually. According to the Centers for Disease Control and Prevention (2000) the average 2-year-old weighs between 23 and 28 pounds and stands between 33 and 35 inches tall. $^{2}$ The average 6 -year-old weighs between 40 and 50 pounds and is about 44 to 47 inches in height. The 3-year-old is still very similar to a

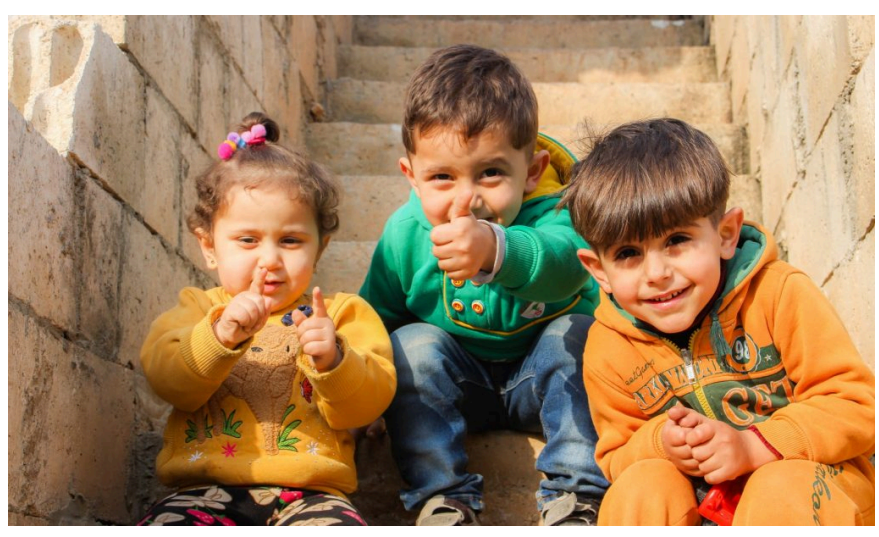

Figure 1. Children sitting on a staircase. (Image Source: $\underline{\text { Samer Daboul, }} \underline{\text { Pexels) }}$ toddler with a large head, large stomach, and short arms and legs. By the time the child reaches age 6, however, the torso has lengthened and body proportions have become more like those of adults.

This growth rate is slower than that of infancy and is accompanied by a reduced appetite between the ages of 2 and 6 . This change can sometimes be surprising to parents and lead to the development of poor eating habits. However, children between the ages of 2 and 3 need 1,000 to 1,400 calories, while children between the ages of 4 and 8 need 1,200 to 2,000 calories. ${ }^{3}$

1. This chapter is adapted from Lifespan Development by Martha Lally and Suzanne Valentine-French, licensed CC BY NC

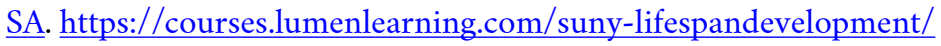

2. Centers for Disease Control and Prevention. (2000). 2000 CDC Growth Charts for the United States: Methods and Development. Retrieved from http://www.cdc.gov/nchs/data/series/sr_11/sr11_246.pdf

3. Mayo Clinic Staff. (2016a). Nutrition for kids: Guidelines for a healthy diet. Retrieved from http://www.mayoclinic.org/healthylifestyle/childrens-health/in-depth/nutrition-for-kids/art-20049335 


\section{Toilet Training}

Toilet training typically occurs during the first two years of early childhood (24-36 months). Some children show interest by age 2 , but others may not be ready until months later. The average age for girls to be toilet trained is 29 months and for boys it is 31 months, and $98 \%$ of children are trained by 36 months. ${ }^{4}$ The child's age is not as important as his/her physical and emotional readiness. If started too early, it might take longer to train a child. According to The Mayo Clinic (2016b) the following questions can help parents determine if a child is ready for toilet training:

- Does your child seem interested in the potty chair or toilet, or in wearing underwear?

- Can your child understand and follow basic directions?

- Does your child tell you through words, facial expressions or posture when he or she needs to go?

- Does your child stay dry for periods of two hours or longer during the day?

- Does your child complain about wet or dirty diapers?

- Can your child pull down his or her pants and pull them up again?

- Can your child sit on and rise from a potty chair? (p. 1$)^{5}$

If a child resists being trained or is not successful after a few weeks, it is best to take a break and try again later. Most children master daytime bladder control first, typically within two to three months of consistent toilet training. However, nap and nighttime training might take months or even years.

Some children experience elimination disorders that may require intervention by the child's pediatrician or a trained mental health practitioner. Elimination disorders include enuresis, or the repeated voiding of urine into bed or clothes (involuntary or intentional) and encopresis, the repeated passage of feces into inappropriate places (involuntary or intentional). ${ }^{6}$ The prevalence of enuresis is $5 \%-10 \%$ for 5 year-olds, $3 \%-5 \%$ for 10 year-olds, and approximately $1 \%$ for those 15 years of age or older. Around 1\% of 5 year- olds have encopresis, and it is more common in males than females.

\section{Sleep}

During early childhood, there is wide variation in the number of hours of sleep recommended per

4. Boyse, K., \& Fitgerald, K. (2010). Toilet training. University of Michigan Health System. Retrieved from http://www.med.umich.edu/yourchild/topics/toilet.htm

5. Mayo Clinic Staff. (2016b). Potty training: How to get the job done. Retrieved from http://www.mayoclinic.org/healthy- lifestyle/ infant-and-toddler-health/indepth/potty-training/art-20045230

6. American Psychiatric Association. (2013). Diagnostic and statistical manual of mental disorders, 5th edition (DSM-V). Washington, DC: Author. 
day. For example, two-year-olds may still need 15-16 hours per day, while a six-year-old may only need 7-8 hours. The National Sleep Foundation's 2015 recommendations based on age are listed in the figure below.

\section{SLEEP DURATION RECOMMENDATIONS}

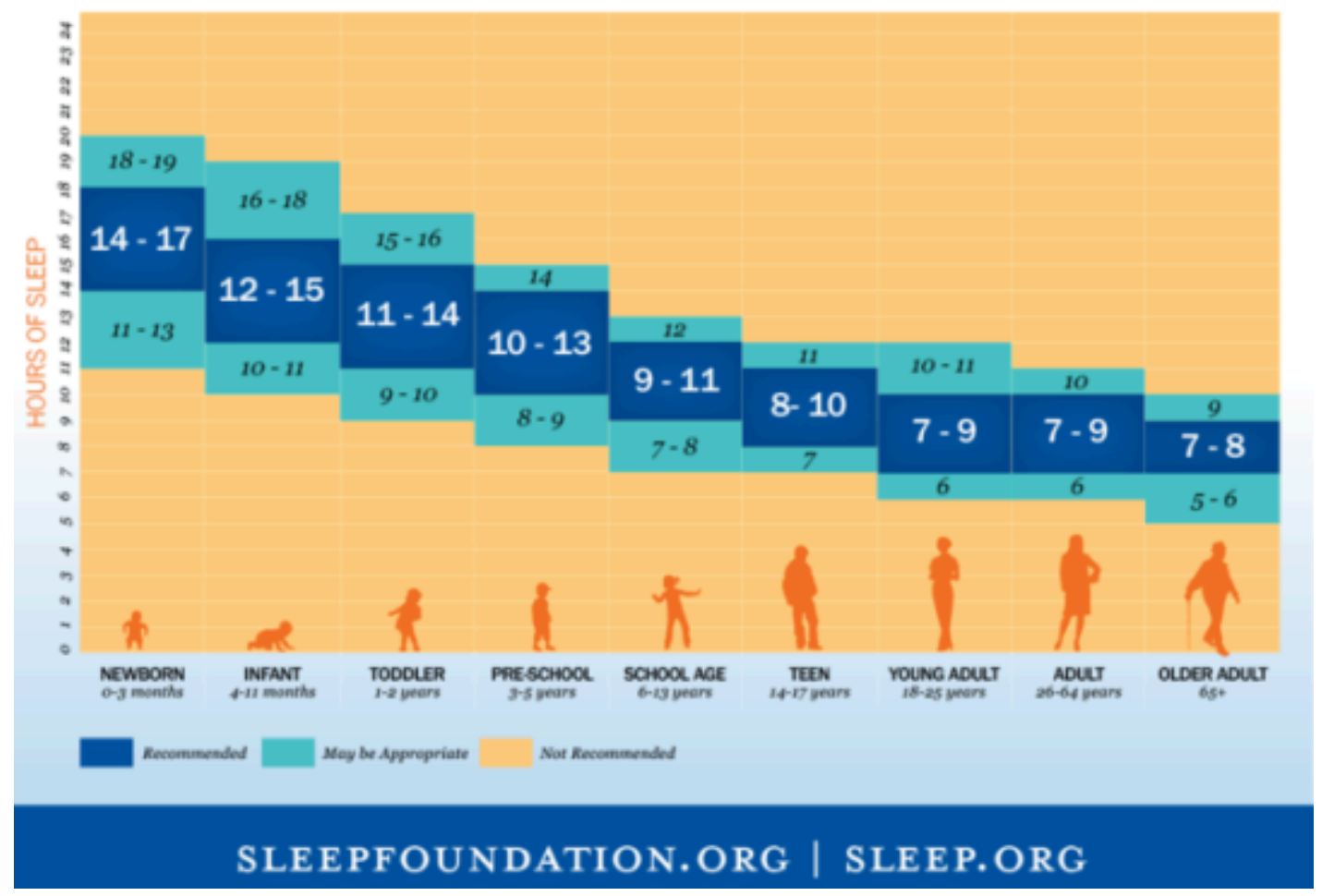

Figure 2. As we age, the amount of sleep recommended for our health decreases steadily.

\section{Piaget}

According to Piaget, the preoperational stage is associated with early childhood and occurs from 2 to 7 years of age. In this stage, children use symbols to represent words, images, and ideas, which is why children in this stage tend to engage in pretend play. A child's arms might become airplane wings as she zooms around the room, or a child with a stick might become a brave knight with a sword. Children also begin to use language in the preoperational stage, but they cannot typically understand adult logic. The term operational refers to logical manipulation of information, so children at this stage are considered pre-operational. Children's logic is based on their own personal knowledge of the world so far, rather than on conventional knowledge.

7. Adapted from https://courses.lumenlearning.com/suny-lifespandevelopment/chapter/piagets-preoperational-stage-ofcognitive-development/ 


\section{Video Example}

Watch this video illustrating children's accurate portrayal of Piaget's preoperational thinking

The preoperational period is divided into two stages: The Symbolic Function Substage occurs between 2 and 4 years of age and is characterized by the child being able to mentally represent an object that is not present and a dependence on perception in problem solving. The Intuitive Thought Substage, lasting from 4 to 7 years, is marked by greater dependence on intuitive thinking rather than just perception. ${ }^{8}$ At this stage, children ask many questions as they attempt to understand the world around them using immature reasoning. Let's examine some of Piaget's assertions about children's cognitive abilities at this age.

\section{Pretend Play}

Pretending is a favorite activity at this time. A toy has qualities beyond the way it was designed to function and can now be used to stand for a character or object unlike anything originally intended. A teddy bear, for example, can be a baby or the queen of a faraway land. Piaget believed that children's pretend play helped children solidify new schemata they were developing cognitively. This play, then, reflected changes in their conceptions or thoughts. However, children also learn as they pretend
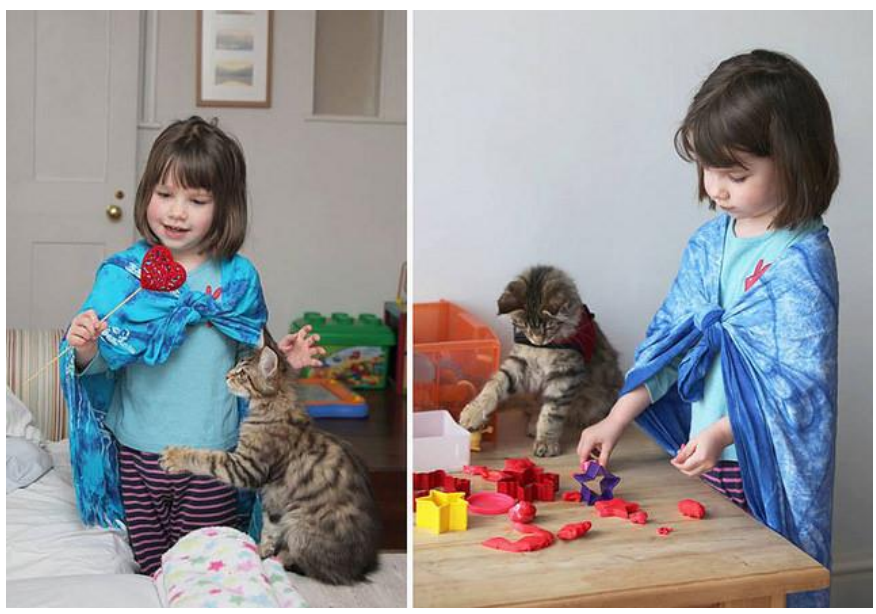

Figure 3. Children learn to use pretend play to mode behaviors they have observed and to devise scenarios they haven't encountered. and experiment. Their play does not simply represent what they have learned. ${ }^{9}$

\section{Egocentrism}

Egocentrism in early childhood refers to the tendency of young children not to be able to take the perspective of others. Instead, the child thinks that everyone sees, thinks, and feels just as they do. An 
egocentric child is not able to infer the perspective of other people and instead attributes his own perspective to situations. For example, ten-year-old Keiko's birthday is coming up, so her mom takes 3 -year-old Kenny to the toy store to choose a present for his sister. He selects an Iron Man action figure for her, thinking that if he likes the toy, his sister will too.

Piaget's classic experiment on egocentrism involved showing children a three dimensional model of a mountain and asking them to describe what a doll that is looking at the mountain from a different angle might see (see Figure 4.9). Children tend to choose a picture that represents their own, rather than the doll's view. By age 7 children are less self-centered.

However, even younger children when speaking to others tend to use different sentence structures and vocabulary when addressing a younger child or an older adult. This indicates some awareness of the views of others.

\section{Conservation Errors}

Conservation refers to the ability to recognize that moving or rearranging matter does not change the quantity. Let's look at Kenny and Keiko again. Dad gave a slice of pizza to 10-year-old Keiko and another slice to 3-year-old Kenny. Kenny's pizza slice was cut into five pieces, so Kenny told his sister that he got more pizza than she did. Kenny did not understand that cutting the pizza into smaller pieces did not increase the overall amount. This was because Kenny exhibited Centration, or focused on only one characteristic of an object to the exclusion of others. Kenny focused on the five pieces of pizza to his sister's one piece even though the total amount was the same. Keiko was able to consider several characteristics of an object than just one. Because children have not developed this understanding of conservation, they cannot perform mental operations.

The classic Piagetian experiment associated with conservation involves liquid. ${ }^{10}$ As seen in Figure 4.10, the child is shown two glasses (as shown in a) which are filled to the same level and asked if they have the same amount. Usually the child agrees they have the same amount.

The experimenter then pours the liquid in one glass to a taller and thinner glass (as shown in b). The child is again asked if the two glasses have the same amount of liquid. The preoperational child will typically say the taller glass now has more liquid because it is taller (as shown in c). The child has centrated on the height of the glass and fails to conserve.

10. Crain, W. (2005). Theories of development concepts and applications (5th ed.). New Jersey: Pearson. 


\section{Video Example}

Watch this video illustrating children's classification errors (they have not yet mastered all parts of Piaget's conservation tasks)

Classification Errors: Preoperational children have difficulty understanding that an object can be classified in more than one way. For example, if shown three white buttons and four black buttons and asked whether there are more black buttons or buttons, the child is likely to respond that there are more black buttons. They do not consider the general class of buttons. As the child's vocabulary improves and more schemata are developed, the ability to classify objects improves.

Animism refers to attributing life-like qualities to objects. The cup is alive, the chair that falls down and hits the child's ankle is mean, and the toys need to stay home because they are tired. Cartoons frequently show objects that appear alive and take on lifelike qualities. Young children do seem to think that objects that move may be alive, but after age three, they seldom refer to objects as being alive. $^{11}$

\section{Critiques of Piaget}

Similar to the critique of the sensorimotor period, several psychologists have attempted to show that Piaget also underestimated the intellectual capabilities of the preoperational child. For example, children's specific experiences can influence when they are able to conserve. Children of pottery makers in Mexican villages know that reshaping clay does not change the amount of clay at much younger ages than children who do not have similar experiences. ${ }^{12}$ Crain (2005) indicated that preoperational children can think rationally on mathematical and scientific tasks, and they are not as egocentric as Piaget implied. ${ }^{13}$ Research on Theory of Mind (discussed later in the chapter) has demonstrated that children overcome egocentrism by 4 or 5 years of age, which is sooner than Piaget indicated.

11. Berk, L. E. (2007). Development through the life span (4th ed.). Boston: Allyn and Bacon.

12. Price-Williams, D.R., Gordon, W., \& Ramirez, M. (1969). Skill and conservation: A study of pottery making children. Developmental Psychology, 1, 769.

13. Crain, W. (2005). Theories of development concepts and applications (5th ed.). New Jersey: Pearson. 


\section{Children's Understanding of the World}

Both Piaget and Vygotsky believed that children actively try to understand the world around them. More recently, developmentalists have added to this understanding by examining how children organize information and develop their own theories about the world.

Theory of mind refers to the ability to think about other people's thoughts. This mental mind reading helps humans to understand and predict the reactions of others, thus playing a crucial role in social development. One common method for determining if a child has reached this mental milestone is the false belief task, described below.

The research began with a clever experiment by Wimmer and Perner (1983), who tested whether children can pass a false-belief test. ${ }^{14}$ The child is shown a picture story of Sally, who puts her ball in a basket and leaves the room. While Sally is out of the room, Anne comes along and takes the ball from the basket and puts it inside a box. The child is then asked where Sally thinks the ball is located when she comes back to the room. Is she going to look first in the box or in the basket? The right answer is that she will look in the basket, because that's where she put it and thinks it is; but we have to infer this false belief against our own better knowledge that the ball is in the box. This is very difficult for children before the age of four because of the cognitive effort it takes. Threeyear-olds have difficulty distinguishing between what
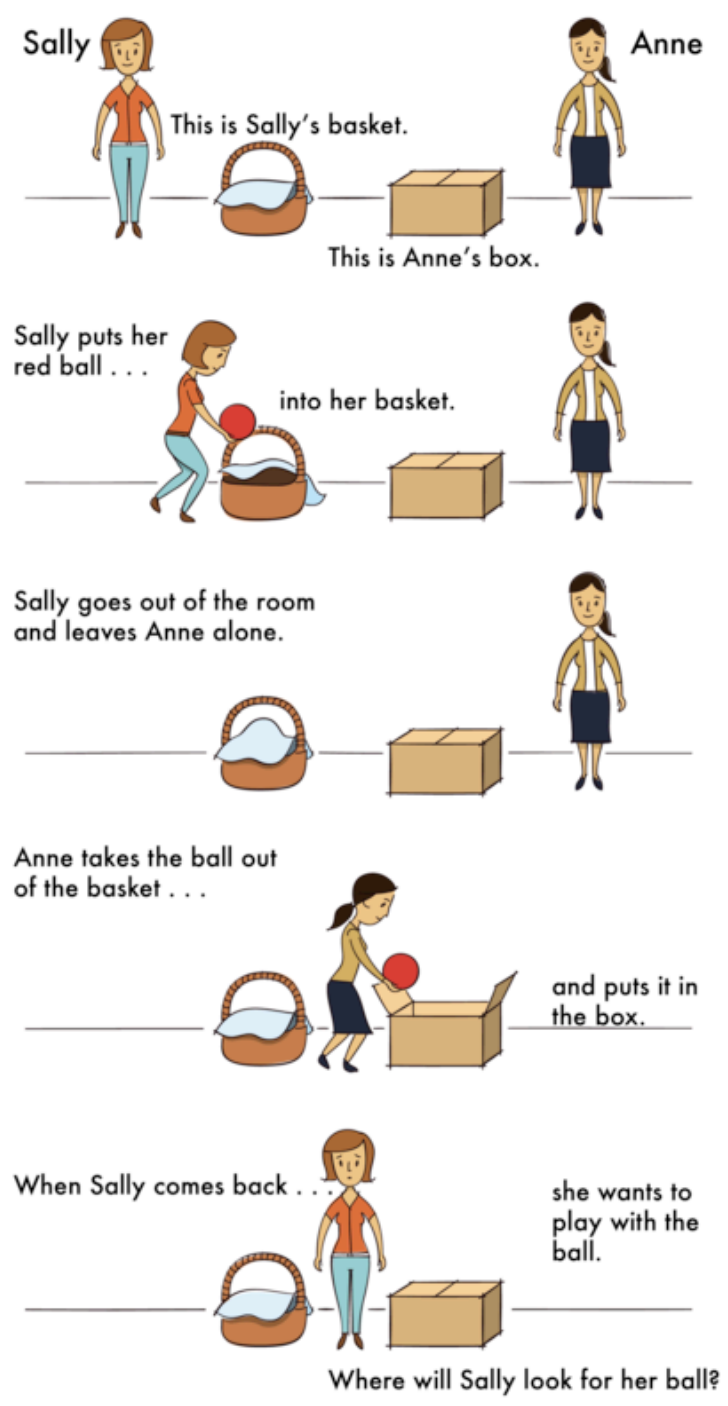

Figure 4. Object permanence comic.

14. Wimmer, H., \& Perner, J. (1983). Beliefs about beliefs: Representation and constraining function of wrong beliefs in young children's understanding of deception. Cognition, 13, 103-128. 
they once thought was true and what they now know to be true. They feel confident that what they know now is what they have always known. ${ }^{15}$

Even adults need to think through this task. ${ }^{16}$ To be successful at solving this type of task the child must separate what he or she "knows" to be true from what someone else might "think" is true. In Piagetian terms, they must give up a tendency toward egocentrism. The child must also understand that what guides people's actions and responses are what they "believe" rather than what is reality. In other words, people can mistakenly believe things that are false and will act based on this false knowledge. Consequently, prior to age four children are rarely successful at solving such a task. ${ }^{17}$

\section{Language Development}

A child's vocabulary expands between the ages of two to six from about 200 words to over 10,000 words. This "vocabulary spurt" typically involves 10-20 new words per week and is accomplished through a process called fast-mapping. Words are easily learned by making connections between new words and concepts already known. The parts of speech that are learned depend on the language and what is emphasized. Children speaking verb-friendly languages, such as Chinese and Japanese, learn verbs more readily, while those speaking English tend to learn nouns more readily. However, those learning less verb-friendly languages, such as English, seem to need assistance in grammar to master the use of verbs. ${ }^{18}$

\section{Literal meanings}

Children can repeat words and phrases after having heard them only once or twice, but they do not always understand the meaning of the words or phrases. This is especially true of expressions or figures of speech which are taken literally. For example, a classroom full of preschoolers hears the teacher say, "Wow! That was a piece of cake!" The children began asking "Cake? Where is my cake? I want cake!"

15. Birch, S., \& Bloom, P. (2003). Children are cursed: An asymmetric bias in mental-state attribution. Psychological Science, 14(3), 283-286.

16. Epley, N., Morewedge, C. K., \& Keysar, B. (2004). Perspective taking in children and adults: Equivalent egocentrism but differential correction. Journal of Experimental Social Psychology, 40, 760-768.

17. Wellman, H.M., Cross, D., \& Watson, J. (2001). Meta-analysis of theory of mind development: The truth about false belief. Child Development, 72(3), 655-684.

18. Imai, M., Li, L., Haryu, E., Hirsh-Pasek, K., Golinkoff, R. M., \& Shigematsu, J. (2008). Novel noun and verb learning in Chinese, English, and Japanese children: Universality and language-specificity in novel noun and verb learning. Child Development, 79, 979-1000. 


\section{Overregularization}

Children learn rules of grammar as they learn language but may apply these rules inappropriately at first. For instance, a child learns to add "ed" to the end of a word to indicate past tense. Then form a sentence such as "I goed there. I doed that." This is typical at ages two and three. They will soon learn new words such as "went" and "did" to be used in those situations.

\section{The Impact of Training}

Remember Vygotsky and the Zone of Proximal Development? Children can be assisted in learning language by others who listen attentively, model more accurate pronunciations, and encourage elaboration. The child exclaims, "I'm goed there!" and the adult responds, "You went there? Say, 'I went there.' Where did you go?" Children may be ripe for language as Chomsky suggests, but active participation in helping them learn is important for language development as well. The process of scaffolding is one in which the guide provides needed assistance to the child as a new skill is learned.

\section{Preschool}

Providing universal preschool has become an important lobbying point for federal, state, and local leaders throughout our country. In his 2013 State of the Union address, President Obama called upon Congress to provide high-quality preschool for all children. He continued to support universal preschool in his legislative agenda, and in December 2014 the President convened state and local policymakers for the White House Summit on Early Education. ${ }^{19}$ However, universal preschool covering all four-year-olds in the country would require significant funding. Further, how effective preschools are in preparing children for elementary school, and what constitutes high-quality preschool have been debated. To set criteria for designation as a high quality preschool, the National Association for the Education of Young Children (NAEYC) identifies 10 standards. ${ }^{20}$ These include:

- Positive relationships among all children and adults are promoted.

- A curriculum that supports learning and development in social, emotional, physical, language, and cognitive areas.

- Teaching approaches that are developmentally, culturally, and linguistically appropriate.

- Assessment of children's progress to provide information on learning and development.

- The health and nutrition of children are promoted, while they are protected from illness and

19. White House Press Secretary. (2014). Fact Sheet: Invest in US: The White House Summit on Early Childhood Education. Retrieved from https://www.whitehouse.gov/the-press-office/2014/12/10/fact-sheet-invest-us-white-house-summit- earlychildhood-education

20. National Association for the Education of Young Children. (2016). The 10 NAEYC program standards. Retrieved from http://families.naeyc.org/accredited-article/10-naeyc-program-standards 
injury.

- Teachers possess the educational qualifications, knowledge, and commitment to promote children's learning.

- Collaborative relationships with families are established and maintained.

- Relationships with agencies and institutions in the children's communities are established to support the program's goals.

- Indoor and outdoor physical environments are safe and well-maintained.

- Leadership and management personnel are well qualified, effective, and maintain licensure status with the applicable state agency.

Primary caregivers should review preschool programs using the NAEYC criteria as a guide and template for asking questions that will assist them in choosing the best program for their child. Selecting the right preschool is also difficult because there are so many types of preschools available. Zachry (2013) identified Montessori, Waldorf, Reggio Emilia, High Scope, Parent Co-Ops, and Bank Street as types of preschool programs that focus on children learning through discovery. Teachers act as guides and create activities based on the child's developmental level. ${ }^{21}$

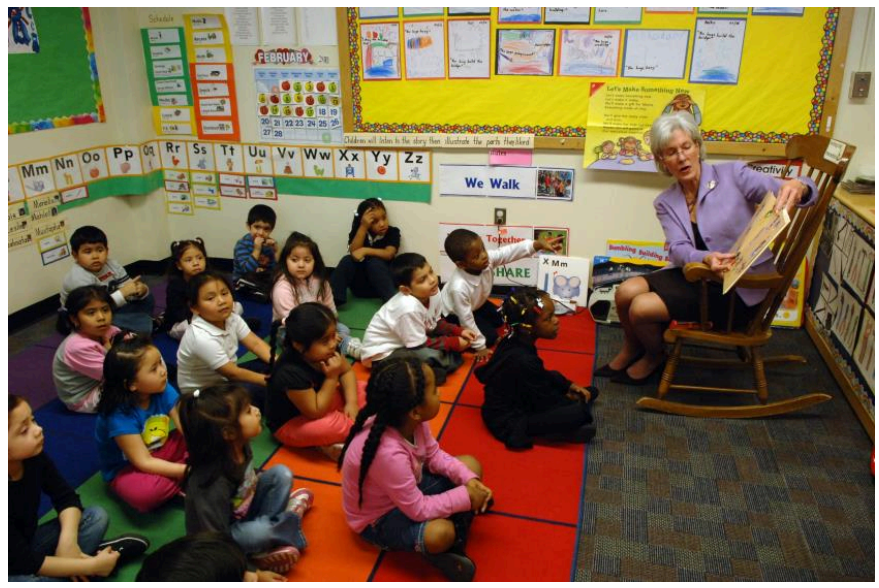

Figure 5. Head Start students learning in class.

\section{Head Start}

For children who live in poverty, Head Start has been providing preschool education since 1965 when it was begun by President Lyndon Johnson as part of his war on poverty. In 2013, research revealed that Head Start served nearly one million children and annually costs approximately 7.5 billion dollars. ${ }^{22}$

However, concerns about the effectiveness of Head Start have been ongoing since the program began. Armor (2015) reviewed existing research on Head Start and found there were no lasting gains,

21. Zachry, A. (2013). 6 Types of Preschool Programs. Retrieved from http://www.parents.com/toddlers-preschoolers/starting preschool/preparing/types-of-preschool-programs/

22. United States Department of Health and Human Services. (2015). Head start program facts fiscal year 2013. Retrieved from http://eclkc.ohs.acf.hhs.gov/hslc/data/factsheets/docs/hs-program-fact-sheet-2013.pdf 
and the average child in Head Start had not learned more than children who did not receive preschool education. $^{23}$

A recent report dated July 2015 evaluating the effectiveness of Head Start comes from the What Works Clearinghouse. The What Works Clearinghouse identifies research that provides reliable evidence of the effectiveness of programs and practices in education and is managed by the Institute of Education Services for the United States Department of Education. After reviewing 90 studies on the effectiveness of Head Start, only one study was deemed scientifically acceptable and this study showed disappointing results. ${ }^{24}$ This study showed that 3 and 4 -year-old children in Head Start received "potentially positive effects" on general reading achievement, but no noticeable effects on math achievement and social-emotional development.

Nonexperimental designs are a significant problem in determining the effectiveness of Head Start programs because a control group is needed to show group differences that would demonstrate educational benefits. Because of ethical reasons, low-income children are usually provided with some type of preschool programming in an alternative setting. Additionally, head Start programs are different depending on the location, and these differences include the length of the day or qualification of the teachers. Lastly, testing young children is difficult and strongly dependent on their language skills and comfort level with an evaluator. ${ }^{25}$

\section{Autism Spectrum Disorder in Early Childhood}

A greater discussion on disorders affecting children and special educational services to assist them will occur in chapter 5 . However, because characteristics of Autism Spectrum Disorder must be present in the early developmental period, as established by the Diagnostic and Statistical Manual of Mental Disorders (DSM-5), this disorder will be presented here. ${ }^{26}$

Autism spectrum disorder is probably the most misunderstood and puzzling of neurodevelopmental disorders. Children with this disorder show signs of significant disturbances in three main areas: (a) deficits in social interaction, (b) deficits in communication, and (c) repetitive

23. Armor, D. J. (2015). Head start or false start. USA Today Magazine. Retrieved from https://www.questia.com/magazine/ 1G1-429736352/head-start-or-false-start

24. Barshay, J. (2015). Report: Scant scientific evidence for Head Start programs' effectiveness. U.S. News and World Report. Retrieved from http://www.usnews.com/news/articles/2015/08/03/report-scant-scientific-evidence-for-head-startprograms-effectiveness

25. Barshay, J. (2015). Report: Scant scientific evidence for Head Start programs' effectiveness. U.S. News and World Report. Retrieved from http://www.usnews.com/news/articles/2015/08/03/report-scant-scientific-evidence-for-head-startprograms-effectiveness

26. American Psychiatric Association. (2013). Diagnostic and statistical manual of mental disorders, 5th edition (DSM-V). Washington, DC: Author. 
patterns of behavior or interests. These disturbances appear early in life and cause serious impairments in functioning. ${ }^{27}$ The child with autism spectrum disorder might exhibit deficits in social interaction by not initiating conversations with other children or turning their head away when spoken to. These children do not make eye contact with others and seem to prefer playing alone rather than with others. In a certain sense, it is almost as though these individuals live in a personal and isolated social world others are simply not privy to or able to penetrate.

Communication deficits can range from a complete lack of speech, to one word responses (e.g., saying "Yes" or "No" when replying to questions or statements that require additional elaboration), to echoed speech (e.g., parroting what another person says, either immediately or several hours or even days later), to difficulty maintaining a conversation because of an inability to reciprocate others' comments. These deficits can also include problems in using and understanding nonverbal cues (e.g., facial expressions, gestures, and postures) that facilitate normal communication.

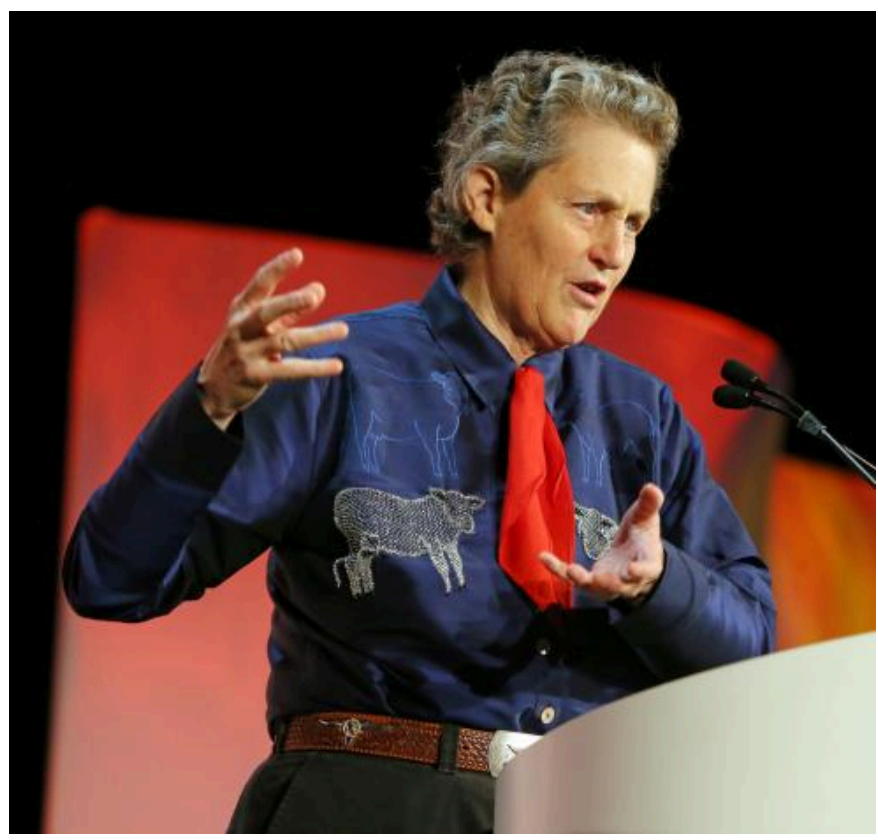

Figure 6. Dr. Temple Grandin, an advocate for individuals with autism.
Repetitive patterns of behavior or interests can be exhibited a number of ways. The child might engage in stereotyped, repetitive movements (rocking, head-banging, or repeatedly dropping an object and then picking it up), or she might show great distress at small changes in routine or the environment. For example, the child might throw a temper tantrum if an object is not in its proper place or if a regularlyscheduled activity is rescheduled. In some cases, the person with autism spectrum disorder might show highly restricted and fixated interests that appear to be abnormal in their intensity. For instance, the child might learn and memorize every detail about something even though doing so serves no apparent purpose. Importantly, autism spectrum disorder is not the same thing as intellectual disability, although these two conditions can occur together. The DSM-5 specifies that the symptoms of autism spectrum disorder are not caused or explained by intellectual disability.

The qualifier "spectrum" in autism spectrum disorder is used to indicate that individuals with the disorder can show a range, or spectrum, of symptoms that vary in their magnitude and severity: Some severe, others less severe. The previous edition of the DSM included a diagnosis of Asperger's 
disorder, generally recognized as a less severe form of autistic disorder; individuals diagnosed with Asperger's disorder were described as having average or high intelligence and a strong vocabulary, but exhibiting impairments in social interaction and social communication, such as talking only about their special interests. ${ }^{28}$ However, because research has failed to demonstrate that Asperger's disorder differs qualitatively from autistic disorder, the DSM-5 does not include it. Some individuals with autism spectrum disorder, particularly those with better language and intellectual skills, can live and work independently as adults. However, most do not because the symptoms remain sufficient to cause serious impairment in many realms of life. ${ }^{29}$

Currently, estimates indicate that nearly 1 in 88 children in the United States has autism spectrum disorder; the disorder is 5 times more common in boys ( 1 out of 54 ) than girls (1 out of 252$).{ }^{30}$ Rates of autistic spectrum disorder have increased dramatically since the 1980s. Although it is difficult to interpret this increase, it is possible that the rise in prevalence is the result of the broadening of the diagnosis, increased efforts to identify cases in the community, and greater awareness and acceptance of the diagnosis. In addition, mental health professionals are now more knowledgeable about autism spectrum disorder and are better equipped to make the diagnosis, even in subtle cases. $^{31}$

The exact causes of autism spectrum disorder remain unknown despite massive research efforts over the last two decades. ${ }^{32}$ Autism appears to be strongly influenced by genetics, as identical twins show concordance rates of $60 \%-90 \%$, whereas concordance rates for fraternal twins and siblings are $5 \%-10 \% .{ }^{33}$ Many different genes and gene mutations have been implicated in autism. ${ }^{34}$ Among the genes involved are those important in the formation of synaptic circuits that facilitate communication between different areas of the brain. ${ }^{35}$ A number of environmental factors are also thought to possibly be associated with increased risk for autism spectrum disorder, at least in part,

28. Wing, L., Gould, J., \& Gillberg, C. (2011). Autism spectrum disorders in the DSM-V: Better or worse than the DSM IV? Research in Developmental Disabilities, 32, 768-773.

29. American Psychiatric Association. (2013). Diagnostic and statistical manual of mental disorders, 5th edition (DSM-V). Washington, DC: Author.

30. Centers for Disease Control and Prevention. (2012). Prevalence of autism spectrum disorders, autism and developmental disabilities monitoring network, 14 sites, United States, 2008. Morbidity and Mortality Weekly Report: Surveillance Summaries, 61(3), 1-19. Retrieved from http://www.cdc.gov/mmwr/pdf/ss/ss6103.pdf

31. Novella, S. (2008). The increase in autism diagnoses: Two hypotheses. Retrieved from http://www.sciencebasedmedicine.org/theincrease-in-autism-diagnoses-two-hypotheses/

32. Meek, S. E., Lemery-Chalfant, K., Jahromi, L. D., \& Valiente, C. (2013). A review of gene-environment correlations and their implications for autism: A conceptual model. Psychological Review, 120, 497-521.

33. Autism Genome Project Consortium. (2007). Mapping autism risk loci using genetic linkage and chromosomal rearrangements. Nature Genetics, 39, 319-328.

34. Meek, S. E., Lemery-Chalfant, K., Jahromi, L. D., \& Valiente, C. (2013). A review of gene-environment correlations and their implications for autism: A conceptual model. Psychological Review, 120, 497-521.

35. Gauthier, J., Siddiqui, T. J., Huashan, P., Yokomaku, D., Hamdan, F. F., Champagne, N., . . Rouleau, G.A. (2011). Truncating mutations in NRXN2 and NRXN1 in autism spectrum disorders and schizophrenia. Human Genetics, 130, 563-573. 
because they contribute to new mutations. These factors include exposure to pollutants, such as plant emissions and mercury, urban versus rural residence, and vitamin D deficiency. ${ }^{36}$

There is no scientific evidence that a link exists between autism and vaccinations. ${ }^{37}$ Indeed, a recent study compared the vaccination histories of 256 children with autism spectrum disorder with that of 752 control children across three time periods during their first two years of life (birth to 3 months, birth to 7 months, and birth to 2 years). ${ }^{38}$ At the time of the study, the children were between 6 and 13 years old, and their prior vaccination records were obtained. Because vaccines contain immunogens (substances that fight infections), the investigators examined medical records to see how many immunogens children received to determine if those children who received more immunogens were at greater risk for developing autism spectrum disorder. The results of this study clearly demonstrated that the quantity of immunogens from vaccines received during the first two years of life were not at all related to the development of autism spectrum disorder.

\section{Erikson: Initiative versus Guilt}

The trust and autonomy of previous stages develop into a desire to take initiative or to think of ideas and initiative action. ${ }^{39}$ Children may want to build a fort with the cushions from the living room couch or open a lemonade stand in the driveway or make a zoo with their stuffed animals and issue tickets to those who want to come. Or they may just want to get themselves ready for bed without any assistance. To reinforce taking initiative, caregivers should offer praise for the child's efforts and avoid being critical of messes or mistakes. Placing pictures of drawings on the refrigerator, purchasing mud pies for dinner, and admiring towers of legos will facilitate the child's sense of initiative.

36. Kinney, D. K., Barch, D. H., Chayka, B., Napoleon, S., \& Munir, K. M. (2009). Environmental risk factors for autism: Do they help or cause de novo genetic mutations that contribute to the disorder? Medical Hypotheses, 74, $102-106$.

37. Hughes, V. (2007). Mercury rising. Nature Medicine, 13, 896-897.

38. DeStefano, F., Price, C. S., \& Weintraub, E. S. (2013). Increasing exposures to antibody-stimulating proteins and polysaccharides in vaccines is not associated with risk of autism. The Journal of Pediatrics, 163, 561-567.

39. Erikson, E. (1982). The life cycle completed. NY: Norton \& Company. 


\section{Sibling Relationships}

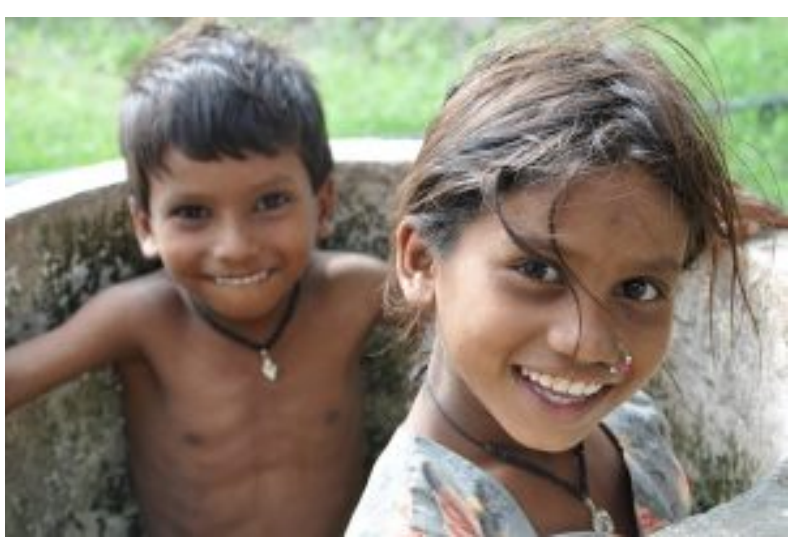

Figure 7. Siblings playing together (Photo Source: Pikrepo , DMCA)
Siblings spend a considerable amount of time with each other and offer a unique relationship that is not found with same-age peers or with adults. Siblings play an important role in the development of social skills. Cooperative and pretend play interactions between younger and older siblings can teach empathy, sharing, and cooperation, ${ }^{40}$ as well as, negotiation and conflict resolution. ${ }^{41}$ However, the quality of sibling relationships is often mediated by the quality of the parent-child relationship and the psychological adjustment of the child (Pike et al., 2005). For instance, more negative interactions between siblings have been reported in families where parents had poor patterns of communication with their children. ${ }^{42}$ Children who have emotional and behavioral problems are also more likely to have negative interactions with their siblings. However, the psychological adjustment of the child can sometimes be a reflection of the parent-child relationship. Thus, when examining the quality of sibling interactions, it is often difficult to tease out the separate effect of adjustment from the effect of the parent-child relationship.

While parents want positive interactions between their children, conflicts are going to arise, and some confrontations can be the impetus for growth in children's social and cognitive skills. The sources of conflict between siblings often depend on their respective ages. Dunn and Munn (1987) revealed that over half of all sibling conflicts in early childhood were disputes about property rights. ${ }^{43}$ By middle childhood this starts shifting toward control over social situations, such as what games to play, disagreements about facts or opinions, or rude behavior. ${ }^{44}$ Researchers have also found that the strategies children use to deal with conflict change with age, but that this is also tempered by the nature of the conflict. Abuhatoum and Howe (2013) found that coercive strategies (e.g., threats) were preferred when the dispute centered on property rights, while reasoning was

40. Pike, A., Coldwell, J., \& Dunn, J. F. (2005). Sibling relationships in early/middle childhood: Links with individual adjustment. Journal of Family Psychology, 19(4), 523-532.

41. Abuhatoum, S., \& Howe, N. (2013). Power in sibling conflict during early and middle childhood. Social Development, 22, 738754.

42. Brody, G. H., Stoneman, Z., \& McCoy, J. K. (1994). Forecasting sibling relationships in early adolescence from child temperament and family processes in middle childhood. Child development, 65, 771-784.

43. Dunn, J., \& Munn, P. (1987). Development of justification in disputes with mother and sibling. Developmental Psychology, 23, 791-798.

44. Howe, N., Rinaldi, C. M., Jennings, M., \& Petrakos, H. (2002). "No! The lambs can stay out because they got cozies": Constructive and destructive sibling conflict, pretend play, and social understanding. Child Development, 73, 1406- 1473. 
more likely to be used by older siblings and in disputes regarding control over the social situation. ${ }^{45}$ However, younger siblings also use reasoning, frequently bringing up the concern of legitimacy (e.g., "You're not the boss") when in conflict with an older sibling. This is a very common strategy used by younger siblings and is possibly an adaptive strategy in order for younger siblings to assert their autonomy. A number of researchers have found that children who can use non-coercive strategies are more likely to have a successful resolution, whereby a compromise is reached and neither child feels slighted. ${ }^{46} 47$

Not surprisingly, friendly relationships with siblings often lead to more positive interactions with peers. The reverse is also true. A child can also learn to get along with a sibling, with, as the song says "a little help from my friends." ${ }^{8}$

\section{() (1) $\circledast(2)$}

Early Childhood by Martha Lally; Suzanne Valentine-French; and Diana Lang is licensed under a Creative Commons AttributionNonCommercial-ShareAlike 4.0 International License, except where otherwise noted.

45. Abuhatoum, S., \& Howe, N. (2013). Power in sibling conflict during early and middle childhood. Social Development, 22, 738754.

46. Ram, A., \& Ross, H. (2008). "We got to figure it out": Information-sharing and siblings' negotiations of conflicts of interest. Social Development, 17, 512-527.

47. Abuhatoum, S., \& Howe, N. (2013). Power in sibling conflict during early and middle childhood. Social Development, 22, 738754.

48. Kramer, L., \& Gottman, J. M. (1992). Becoming a sibling: "With a little help from my friends.” Developmental Psychology, 28, 685-699. 


\title{
MIDDLE AND LATE CHILDHOOD
}

\author{
Martha Lally; Suzanne Valentine-French; and Diana Lang
}

Middle and late childhood spans the ages between early childhood and adolescence, approximately ages 6 to 11 years. Children gain greater control over the movement of their bodies, mastering many gross and fine motor skills that eluded the younger child. Changes in the brain during this age enable not only physical development, but contributes to greater reasoning and flexibility of thought. School becomes a big part of middle and late childhood, and it expands their world beyond the boundaries of their own family. Peers start to take center-stage, often prompting changes in the parent-child relationship. Peer acceptance also influences children's perception of self and may have consequences for emotional development beyond these years. ${ }^{1}$

Rates of growth generally slow during these years. Typically, a child will gain about 5-7 pounds a year and grow about 2-3 inches per year. ${ }^{2}$ They also tend to slim down and gain muscle strength and lung capacity making it possible to engage in strenuous physical activity for long periods of time. The beginning of the growth spurt, which occurs prior to puberty, begins two years earlier for females than males. The mean age for the beginning of the growth spurt for girls is nine, while for boys it is eleven. Children of this age tend to sharpen their abilities to perform both gross motor skills, such as riding a bike, and fine motor skills, such as cutting their fingernails. In gross motor skills (involving large muscles) boys typically outperform girls, while with fine motor skills (small muscles) girls outperform the boys. These improvements in motor skills are related to brain growth and experience during this developmental period.

Two major brain growth spurts occur during middle/late childhood. ${ }^{3}$ Between ages 6 and 8 , significant improvements in fine motor skills and eye-hand coordination are noted. Then between 10 and 12 years of age, the frontal lobes become more developed and improvements in logic, planning, and memory are evident. ${ }^{4}$ Children in middle to late childhood are also better able to plan,

1. This chapter is adapted from Lifespan Development by Martha Lally and Suzanne Valentine-French, licensed CC BY NC SA. https://courses.lumenlearning.com/suny-lifespandevelopment/

2. Centers for Disease Control and Prevention. (2000). 2000 CDC growth charts for the United States: Methods and development. Retrieved from $\underline{\text { http://www.cdc.gov/nchs/data/series/sr_11/sr11_246.pdf }}$

3. Spreen, O., Rissser, A., \& Edgell, D. (1995). Developmental neuropsychology. New York: Oxford University Press. Sternberg, R. J. (1985). Beyond IQ: A triarchic theory of human intelligence. New York, NY: Cambridge University Press.

4. van der Molen, M., \& Molenaar, P. (1994). Cognitive psychophysiology: A window to cognitive development and brain maturation. In G. Dawson \& K. Fischer (Eds.), Human behavior and the developing brain. New York: Guilford. 
coordinate activity using both left and right hemispheres of the brain, and to control emotional outbursts. Paying attention is also improved as the prefrontal cortex matures. ${ }^{5}$

\section{Video Example}

Watch Dr. Dan Siegel describe adolescent brain development.

\section{Childhood Obesity}

The decreased participation in school physical education and youth sports is just one of many factors that has led to an increase in children being overweight or obese. The current measurement for determining excess weight is the Body Mass Index (BMI) which expresses the relationship of height to weight. According to the Centers for Disease Control and Prevention (CDC), children's whose BMI is at or above the 85 th percentile for their age are considered overweight, while children who are at or above the 95th percentile are considered obese. Excess weight and obesity in children are associated with a variety of medical and cognitive conditions including high blood pressure, insulin resistance, inflammation, depression, and lower academic achievement. ${ }^{6}$

Being overweight has also been linked to impaired brain functioning, which includes deficits in executive functioning, working memory, mental flexibility, and decision making. ${ }^{7}$ Children who ate more saturated fats performed worse on relational memory tasks while eating a diet high in omega-3 fatty acids promoted relational memory skills. ${ }^{8}$ Using animal studies Davidson et al. (2013) found that large amounts of processed sugars and saturated fat weakened the blood-brain barrier, especially in the hippocampus. ${ }^{9}$ This can make the brain more vulnerable to harmful substances that

5. Markant, J. C., \& Thomas, K. M. (2013). Postnatal brain development. In P. D. Zelazo (Ed.), Oxford handbook of developmental psychology. New York: Oxford University Press.

6. Lu, S. (2016). Obesity and the growing brain. Monitor on Psychology, 47(6), 40-43.

7. Liang, J., Matheson, B., Kaye, W., \& Boutelle, K. (2014). Neurocognitive correlates of obesity and obesity-related behaviors in children and adolescents. International Journal of Obesity, 38(4), 494-506

8. Davidson, T. L. (2014). Do impaired memory and body weight regulation originate in childhood with diet-induced hippocampal dysfunction? The American Journal of Clinical Nutrition, 99(5), 971-972.

9. Davidson, T. L., Hargrave, S. L., Swithers, S. E., Sample, C. H., Fu, X., Kinzig, K. P., \& Zheng, W. (2013). Inter-relationships among diet, obesity, and hippocampal-dependent cognitive function. Neuroscience, 253, 110-122. 
can impair its functioning. Another important executive functioning skill is controlling impulses and delaying gratification. Children who are overweight show less inhibitory control than normalweight children, which may make it more difficult for them to avoid unhealthy foods. ${ }^{10}$ Overall, being overweight as a child increases the risk for cognitive decline as one ages. Visit this link from the CDC to learn more about childhood overweight and obesity.

An added concern is that the children themselves are not accurately identifying if they are overweight. In a United States sample of 8-15 year-olds, more than 80\% of overweight boys and 70\% of overweight girls misperceived their weight as normal. ${ }^{11}$ Also noted was that as the socioeconomic status of the children rose, the frequency of these misconceptions decreased. It appeared that families with more resources were more conscious of what defines a healthy weight.

Children who are overweight tend to be rejected, ridiculed, teased and bullied by others more than their peer counterparts. ${ }^{12}$ This can certainly be damaging to their self-image and popularity. In addition, children who are obese run the risk of suffering orthopedic problems such as knee injuries, and they have an increased risk of heart disease and stroke in adulthood. It is hard for a child who is obese to become a non-obese adult. In addition, the number of cases of pediatric diabetes has risen dramatically in recent years.

Behavioral interventions, including training children to overcome impulsive behavior, are being researched to help children achieve and maintain a healthy weight. ${ }^{13}$ Practicing inhibition has been shown to strengthen the ability to resist unhealthy foods. Parents can help their children the best when they are warm and supportive without using shame or guilt. Parents can also act like the child's frontal lobe until it is developed by helping them make correct food choices and praising their efforts. ${ }^{14}$ Research also shows that exercise, especially aerobic exercise, can help improve cognitive functioning in children. ${ }^{15}$ Parents should take caution against emphasizing diet alone to avoid the development of any obsession about dieting that can lead to eating disorders. Instead, increasing a child's activity level is most helpful.

Recall from earlier chapters that children in early childhood are in Piaget's preoperational stage, and during this stage, children are learning to think symbolically about the world. Cognitive skills continue to expand in middle and late childhood as thought processes become more logical and organized when dealing with concrete information. Children at this age understand concepts such as

10. Lu, S. (2016). Obesity and the growing brain. Monitor on Psychology, 47(6), 40-43.

11. Sarafrazi, N., Hughes, J. P., \& Borrud, L. (2014). Perception of weight status in U.S. children and adolescents aged 8-15 years, 2005-2012. NCHS Data Brief, 158, 1-8.

12. (Stopbullying.gov).

13. Lu, S. (2016). Obesity and the growing brain. Monitor on Psychology, 47(6), 40-43.

14. Liang, J., Matheson, B., Kaye, W., \& Boutelle, K. (2014). Neurocognitive correlates of obesity and obesity-related behaviors in children and adolescents. International Journal of Obesity, 38(4), 494-506

15. Lu, S. (2016). Obesity and the growing brain. Monitor on Psychology, 47(6), 40-43. 
past, present, and future, giving them the ability to plan and work toward goals. Additionally, they can process complex ideas such as addition and subtraction and cause-and-effect relationships.

\section{Concrete Operational Thought}

From ages 7 to 11, children are in what Piaget referred to as the Concrete Operational Stage of cognitive development. ${ }^{16}$ This involves mastering the use of logic in concrete ways. The word concrete refers to that which is tangible; that which can be seen, touched, or experienced directly. The concrete operational child is able to make use of logical principles in solving problems involving the physical world. For example, the child can understand the principles of cause and effect, size, and distance.

The child can use logic to solve problems tied to their own direct experience, but has trouble solving hypothetical problems or considering more abstract problems. The child uses Inductive Reasoning, which is a logical process in which multiple premises believed to be true are combined to obtain a specific conclusion. For example, a child has one friend who is rude, another friend who is also rude, and the same is true for a third friend. The child may conclude that friends are rude. We will see that this way of thinking tends to change during adolescence being replaced with deductive reasoning. We will now explore some of the major abilities that the concrete child exhibits.
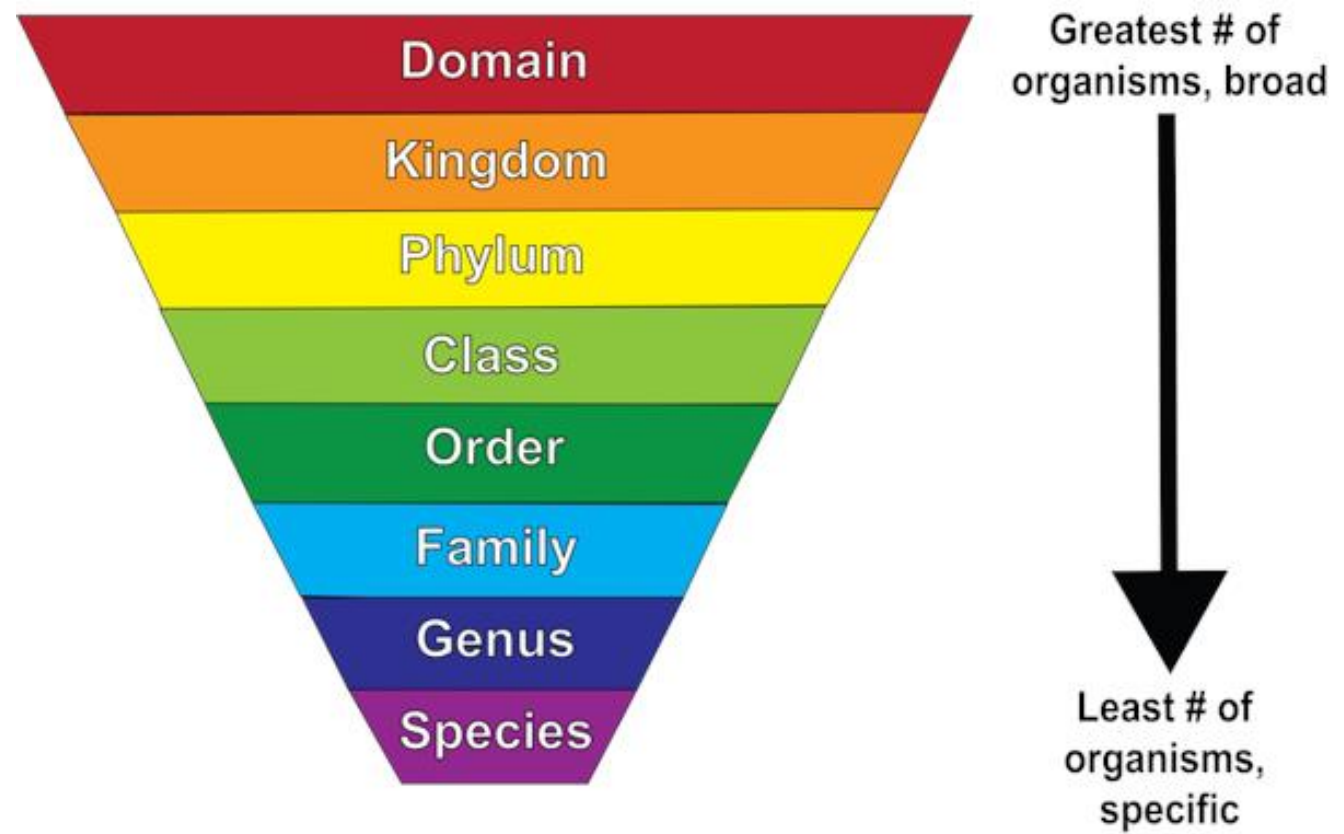

Figure 2. Children in the concrete operational stage understand how to classify organisms

16. Crain, W. (2005). Theories of development (5th ed.). Upper Saddle River, NJ: Pearson. 
- Classification: As children's experiences and vocabularies grow, they build schemata and are able to organize objects in many different ways. They also understand classification hierarchies and can arrange objects into a variety of classes and subclasses.

- Identity: One feature of concrete operational thought is the understanding that objects have qualities that do not change even if the object is altered in some way. For instance, mass of an object does not change by rearranging it. A piece of chalk is still chalk even when the piece is broken in two.

- Reversibility: The child learns that some things that have been changed can be returned to their original state. Water can be frozen and then thawed to become liquid again. But eggs cannot be unscrambled. Arithmetic operations are reversible as well: $2+3=5$ and $5-3=2$.

Many of these cognitive skills are incorporated into the school's curriculum through mathematical problems and in worksheets about which situations are reversible or irreversible.

- Conservation: Remember the example in our last chapter of preoperational children thinking that a tall beaker filled with 8 ounces of water was "more" than a short, wide bowl filled with 8 ounces of water? Concrete operational children can understand the concept of conservation which means that changing one quality (in this example, height or water level) can be compensated for by changes in another quality (width). Consequently, there is the same amount of water in each container, although one is taller and narrower and the other is shorter and wider.

- Decentration: Concrete operational children no longer focus on only one dimension of any object (such as the height of the glass) and instead consider the changes in other dimensions too (such as the width of the glass). This allows for conservation to occur.

- Seriation: Arranging items along a quantitative dimension, such as length or weight, in a methodical way is now demonstrated by the concrete operational child. For example, they can methodically arrange a series of different-sized sticks in order by length, while younger children approach a similar task in a haphazard way.

These new cognitive skills increase the child's understanding of the physical world, however according to Piaget, they still cannot think in abstract ways. Additionally, they do not think in systematic scientific ways. For example, when asked which variables influence the period that a pendulum takes to complete its arc, and given weights they can attach to strings in order to do experiments, most children younger than 12 perform biased experiments from which no conclusions can be drawn. ${ }^{17}$

17. Inhelder, B., \& Piaget, J. (1958). The growth of logical thinking from childhood to adolescence. New York: Basic Books. Jaffee, S., \& Hyde, J. S. (2000). Gender differences in moral orientation: A meta-analysis. Psychological Bulletin, 126(5), $703-726$. 


\section{Education}

Remember the ecological systems model that we explored? This model helps us understand an individual by examining the contexts in which the person lives and the direct and indirect influences on that person's life. School becomes a very important component of children's lives during middle and late childhood, and parents and the culture contribute to children's experiences in school as indicated by the ecological systems model through their interaction with the school.

\section{Parental Involvement in School}

Parents and caregivers vary in their level of involvement with their children's schools. Teachers often complain that they have difficulty getting parents/caregivers to participate in their child's education and devise a variety of techniques to keep parents in touch with daily and overall progress. For example, parents may be required to sign a behavior chart each evening to be returned to school or may be given information about the school's events through websites and newsletters. There are other factors that need to be considered when looking at parental involvement. To explore these, first ask yourself if all parents who enter the school with concerns about their child be received in the same way?

Horvat (2004) found that teachers seek a particular type of involvement from particular types of parents. ${ }^{18}$ While teachers thought they were open and neutral in their responses to parental involvement, in reality teachers were most receptive to support, praise and agreement coming from parents who were most similar in race and social class with the teachers. Parents who criticized the school or its policies were less likely to be given voice. Parents who have higher levels of income, occupational status, and other qualities favored in society have family capital. This is a form of power that can be used to improve a child's education. Caregivers who do not have these qualities may find it more difficult to be effectively involved. The authors suggest that teachers closely examine their biases. Schools may also need to examine their ability to dialogue with parents about school policies in more open ways. Any efforts to improve effective parental involvement should address these concerns.

\section{Erikson: Industry vs. Inferiority}

According to Erikson, children in middle and late childhood are very busy or industrious. ${ }^{19}$ They are constantly doing, planning, playing, getting together with friends, and achieving. This is a very active

18. Horvat, E. M. (2004). Moments of social inclusion and exclusion: Race, class, and cultural capital in family-school relationships. In A. Lareau (Author) \& J. H. Ballantine \& J. Z. Spade (Eds.), Schools and society: A sociological approach to education (2nd ed., pp. 276-286). Belmont, CA: Wadsworth.

19. Erikson, E. (1982). The life cycle completed. NY: Norton \& Company. 
time, and a time when they are gaining a sense of how they measure up when compared with peers. Erikson believed that if these industrious children can be successful in their endeavors, they will get a sense of confidence for future challenges. If not, a sense of inferiority can be particularly haunting during middle and late childhood.

\section{Bullying}

According to Stopbullying.gov, a federal government website managed by the U.S. Department of Health \& Human Services, Bullying is defined as unwanted, aggressive behavior among school-aged children that involves a real or perceived power imbalance. Further, aggressive behavior happens more than once or has the potential to be repeated. There are different types of bullying, including verbal bullying, which is saying or writing mean things, teasing, name calling, taunting, threatening, or making inappropriate sexual comments. Social bullying, also referred to as relational bullying, involves spreading rumors, purposefully excluding someone from a group, or embarrassing someone on purpose. Physical Bullying involves hurting a person's body or possessions.

A more recent form of bullying is Cyberbullying, which involves electronic technology. Examples of cyberbullying include sending mean text messages or emails, creating fake profiles, and posting embarrassing pictures, videos, or rumors on social networking sites. Children who experience cyberbullying have a harder time getting away from the behavior because it can occur at any time of day and without being in the presence of others. Additional concerns of cyberbullying include that messages and images can be posted anonymously, distributed quickly, and be difficult to trace or delete. Children who are cyberbullied are more likely to experience in-person bullying, be unwilling to attend school, receive poor grades, use alcohol and drugs, skip school, have lower self-esteem, and have more health problems. ${ }^{20}$

Bullying can happen to anyone, but some students are at an increased risk for being bullied including lesbian, gay, bisexual, transgendered (LGBT) youth, those with disabilities, and those who are socially isolated. Additionally, those who are perceived as different, weak, less popular, overweight, or having low self-esteem, have a higher likelihood of being bullied.

Bullies are often thought of as having low self-esteem, and then bully others to feel better about themselves. Although this can occur, many bullies in fact have high levels of self-esteem. They possess considerable popularity and social power and have well-connected peer relationships. They do not lack self-esteem, and instead lack empathy for others. They like to dominate or be in charge of others.

Unfortunately, most children do not let adults know that they are being bullied. Some fear retaliation 
from the bully, while others are too embarrassed to ask for help. Those who are socially isolated may not know who to ask for help or believe that no one would care or assist them if they did ask for assistance. Consequently, it is important for parents and teachers to know the warning signs that may indicate a child is being bullied. These include unexplainable injuries, lost or destroyed possessions, changes in eating or sleeping patterns, declining school grades, not wanting to go to school, loss of friends, decreased self-esteem and/or self-destructive behaviors.

\section{() (1) (2) (2)}




\title{
ADOLESCENCE
}

\author{
Martha Lally; Suzanne Valentine-French; and Diana Lang
}

Adolescence is a period that begins with puberty and ends with the transition to adulthood (approximately ages 10-18). Physical changes associated with puberty are triggered by hormones. Changes happen at different rates in distinct parts of the brain and increase adolescents' propensity for risky behavior. Cognitive changes include improvements in complex and abstract thought. Adolescents' relationships with parents go through a period of redefinition in which many adolescents become more autonomous. Peer relationships are important sources of support, but companionship during adolescence can also promote problem behaviors. Identity formation occurs as adolescents explore and commit to different roles and ideological positions. Because so much is happening in these years, psychologists have focused a great deal of attention on the period of adolescence. $^{1}$

\section{The Adolescent Brain}

The brain undergoes dramatic changes during adolescence. Although it does not get larger, it matures by becoming more interconnected and specialized. ${ }^{2}$ The myelination and development of connections between neurons continues. This results in an increase in the white matter of the brain, and allows the adolescent to make significant improvements in their thinking and processing skills. Different brain areas become myelinated at different times. For example, the brain's language areas undergo myelination during the first 13 years. Completed insulation of the axons consolidates these language skills, but makes it more difficult to learn a second language. With greater myelination, however, comes diminished plasticity as a myelin coating inhibits the growth of new connections. ${ }^{3}$

Even as the connections between neurons are strengthened, synaptic pruning occurs more than during childhood as the brain adapts to changes in the environment. This synaptic pruning causes the gray matter of the brain, or the cortex, to become thinner but more efficient. ${ }^{4}$ The corpus callosum, which connects the two hemispheres, continues to thicken allowing for stronger connections between brain areas. Additionally, the hippocampus becomes more strongly connected

1. This chapter is adapted from Lifespan Development by Martha Lally and Suzanne Valentine-French, licensed $\underline{\text { CC BY NC }}$ SA. https://courses.lumenlearning.com/suny-lifespandevelopment/

2. Giedd, J. N. (2015). The amazing teen brain. Scientific American, 312(6), 32-37.

3. Dobbs, D. (2012). Beautiful brains. National Geographic, 220(4), 36.

4. Dobbs, D. (2012). Beautiful brains. National Geographic, 220(4), 36. 
to the frontal lobes, allowing for greater integration of memory and experiences into our decision making.

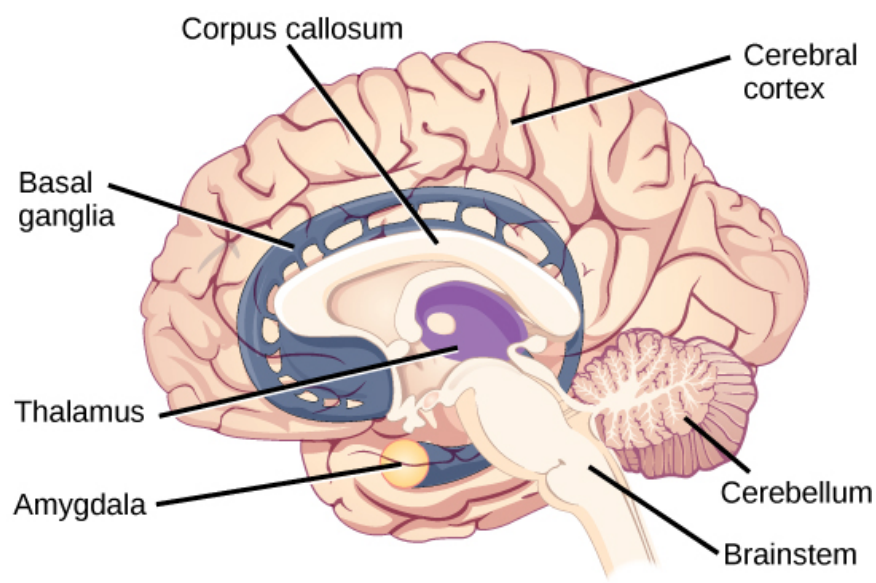

(b) Sagittal section

The limbic system, which regulates emotion and reward, is linked to the hormonal changes that occur at puberty. The limbic system is also related to novelty seeking and a shift toward interacting with peers. In contrast, the prefrontal cortex which is involved in the control of impulses, organization, planning, and making good decisions, does not fully develop until the mid-20s. According to Giedd (2015) the significant aspect of the later developing prefrontal cortex and early development of the limbic system is the "mismatch" in timing between the two. ${ }^{5}$ The approximately ten years

Figure 1. The Limbic System.

that separates the development of these two brain areas can result in risky behavior, poor decision making, and weak emotional control for the adolescent. When puberty begins earlier, this mismatch extends even further.

Teens often take more risks than adults and according to research, it is because they weigh risks and rewards differently than adults do. ${ }^{6}$ For adolescents, the brain's sensitivity to the neurotransmitter dopamine peaks, and dopamine is involved in reward circuits so the possible rewards outweigh the risks. Adolescents respond especially strongly to social rewards during activities, and they prefer the company of others their same age. In addition to dopamine, the adolescent brain is affected by oxytocin which facilitates bonding and makes social connections more rewarding. With both dopamine and oxytocin engaged, it is no wonder that adolescents seek peers and excitement in their lives that could end up actually harming them.

Because of all the changes that occur in the adolescent brain, the chances for abnormal development can occur, including mental illness. In fact, 50\% of the mental illness occurs by the age 14 and $75 \%$ occurs by age $24 .^{7}$ Additionally, during this period of development the adolescent brain is especially vulnerable to damage from drug exposure. For example, repeated exposure to marijuana can affect cellular activity in the endocannabinoid system. Consequently, adolescents are more sensitive to the effects of repeated marijuana exposure. ${ }^{8}$

5. Giedd, J. N. (2015). The amazing teen brain. Scientific American, 312(6), 32-37.

6. Dobbs, D. (2012). Beautiful brains. National Geographic, 220(4), 36.

7. Giedd, J. N. (2015). The amazing teen brain. Scientific American, 312(6), 32-37.

8. Weir, K. (2015). Marijuana and the developing brain. Monitor on Psychology, 46(10), 49-52. 
However, researchers have also focused on the highly adaptive qualities of the adolescent brain which allow the adolescent to move away from the family towards the outside world. ${ }^{9}{ }^{10}$ Novelty seeking and risk-taking can generate positive outcomes including meeting new people and seeking out new situations. Separating from the family and moving into new relationships and different experiences are actually quite adaptive for society.

\section{Adolescent Sleep}

According to the National Sleep Foundation (NSF) (2016), adolescents need about 8 to 10 hours of sleep each night to function best. ${ }^{11}$ The most recent Sleep in America poll in 2006 indicated that adolescents between sixth and twelfth grade were not getting the recommended amount of sleep. On average adolescents only received $71 / 2$ hours of sleep per night on school nights with younger adolescents getting more than older ones (8.4 hours for sixth graders and only 6.9 hours for those in twelfth grade). For older adolescents, only about one in ten (9\%) get an optimal amount of sleep, and they are more likely to experience negative consequences the following day. These include feeling too tired or sleepy, being cranky or irritable, falling asleep in school, having a depressed mood, and drinking caffeinated beverages (NSF, 2016). Additionally, they are at risk for substance abuse, car crashes, poor academic performance, obesity, and a weakened immune system. ${ }^{12}$

Why don't adolescents get adequate sleep? In addition to known environmental and social factors, including work, homework, media, technology, and socializing, the adolescent brain is also a factor. As adolescents go through puberty, their circadian rhythms change and push back their sleep time until later in the evening. ${ }^{13}$ This biological change not only keeps adolescents awake at night, but it also makes it difficult for them to get up in the morning. When they are awake too early, their brains do not function optimally. Impairments are noted in attention, behavior, and academic achievement, while increases in tardiness and absenteeism are also demonstrated.

\section{Adolescent Sexual Activity}

By about age ten or eleven, most children experience increased sexual attraction to others that affects their social life, both in school and out. ${ }^{14}$

9. Giedd, J. N. (2015). The amazing teen brain. Scientific American, 312(6), 32-37.

10. Dobbs, D. (2012). Beautiful brains. National Geographic, 220(4), 36.

11. National Sleep Foundation (2016). Teens and Sleep. Retrieved from https://sleepfoundation.org/sleep topics/teens-and-sleep

12. Weintraub, K. (2016). Young and sleep-deprived. Monitor on Psychology, 47(2), 46-50.

13. Weintraub, K. (2016). Young and sleep-deprived. Monitor on Psychology, 47(2), 46-50.

14. McClintock, M. \& Herdt, G. (1996). Rethinking puberty: The development of sexual attraction. Current Directions in Psychological Science, 5, 178-183. 


\section{Adolescent Pregnancy}

Although adolescent pregnancy rates have declined since 1991, teenage birth rates in the United States are higher than most developed countries. In 2014 females aged 15-19 years experienced a birth rate of 24.2 per 1,000 women. This is a drop of $9 \%$ from 2013 . Birth rates fell $11 \%$ for those aged 15-17 years and 7\% for 18-19 year-olds. It appears that adolescents seem to be less sexually active than in previous years, and those who are sexually active seem to be using birth control. ${ }^{15}$

\section{Risk Factors for Adolescent Pregnancy}

Miller, Benson, and Galbraith (2001) found that parent/child closeness, parental supervision, and parents' values against teen intercourse (or unprotected intercourse) decreased the risk of adolescent pregnancy ${ }^{16}$ In contrast, residing in disorganized/dangerous neighborhoods, living in a lower SES family, living with a single parent, having older sexually active siblings or pregnant/parenting teenage sisters, early puberty, and being a victim of sexual abuse place adolescents at an increased risk of adolescent pregnancy.

\section{Consequences of Adolescent Pregnancy}

After the child is born life can be difficult for a teenage mother. Teenagers who have a child before age 18 years of age are less likely to graduate from high school. Without a high school degree, job prospects are limited and economic independence is difficult. Teen mothers are more likely to live in poverty, and more than $75 \%$ of all unmarried teen mothers receive public assistance within 5 years of the birth of their first child. Approximately, $64 \%$ of children born to an unmarried teenage highschool dropout live in poverty. Further, a child born to a teenage mother is $50 \%$ more likely to repeat a grade in school and is more likely to perform poorly on standardized tests and drop out before finishing high school. ${ }^{17}$ Research analyzing the age that men father their first child and how far they complete their education have been summarized by the Pew Research Center (2015) and reflect the research for females. ${ }^{18}$ Among dads ages 22 to $44,70 \%$ of those with less than a high school diploma say they fathered their first child before the age of 25 . In comparison, less than half (45\%) of fathers with some college experience became dads by that age. Additionally, becoming a young father occurs

15. Center for Disease Control. (2016). Birth rates (live births) per 1,000 females aged 15-19 years, by race and Hispanic ethnicity, select years. Retrieved from http://www.cdc.gov/teenpregnancy/about/birth-rates-chart-2000-2011-text.htm

16. Miller, B. C., Benson, B., \& Galbraith, K. A. (2001). Family relationships and adolescent pregnancy risk: A research synthesis. Developmental Review, 21(1), 1-38. doi:10.1006/drev.2000.0513

17. March of Dimes. (2012). Teenage pregnancy. Retrieved from http://www.marchofdimes.org/materials/teenage-pregnancy.pdf

18. Pew Research Center. (2015). College-educated men taking their time becoming dads. Retrieved from http://www.pewresearch.org/fact-tank/2015/06/19/college-educated-men-take-their-time-becoming-dads/ 
much less for those with a bachelor's degree or higher as just $14 \%$ had their first child prior to age 25 . Like men, women with more education are likely to be older when they become mothers.

\section{Piaget’s Formal Operational Stage}

During the formal operational stage, adolescents are able to understand abstract principles which have no physical reference. They can now contemplate such abstract constructs as beauty, love, freedom, and morality. The adolescent is no longer limited by what can be directly seen or heard. Additionally, while younger children solve problems through trial and error, adolescents demonstrate hypothetical-deductive reasoning, which is developing hypotheses based on what might logically occur. They are able to think about all the possibilities in a situation beforehand, and then test them systematically. ${ }^{19}$ Now they are able to engage in true scientific thinking. Formal operational thinking also involves accepting hypothetical situations. Adolescents understand the concept of transitivity, which means that a relationship between two elements is carried over to other elements logically related to the first two, such as if $\mathrm{A}<\mathrm{B}$ and $\mathrm{B}<\mathrm{C}$, then $\mathrm{A}<\mathrm{C} .{ }^{20}$ For example, when asked: If Maria is shorter than Alicia and Alicia is shorter than Caitlyn, who is the shortest? Adolescents are able to answer the question correctly as they understand the transitivity involved.

According to Piaget, most people attain some degree of formal operational thinking, but use formal operations primarily in the areas of their strongest interest. ${ }^{21}$ In fact, most adults do not regularly demonstrate formal operational thought, and in small villages and tribal communities, it is barely used at all. A possible explanation is that an individual's thinking has not been sufficiently challenged to demonstrate formal operational thought in all areas.

\section{Adolescent Egocentrism}

Once adolescents can understand abstract thoughts, they enter a world of hypothetical possibilities and demonstrate egocentrism or a heightened self-focus. The egocentricity comes from attributing unlimited power to their own thoughts. ${ }^{22}$ Piaget believed it was not until adolescents took on adult roles that they would be able to learn the limits to their own thoughts.

David Elkind (1967) expanded on the concept of Piaget's adolescent egocentricity. ${ }^{23}$ Elkind theorized

19. Crain, W. (2005). Theories of development concepts and applications (5th ed.). New Jersey: Pearson. Crooks, K. L., \& Baur, K. (2007). Our sexuality (10th ed.). Belmont, CA: Wadsworth.

20. Thomas, R. M. (1979). Comparing theories of child development. Santa Barbara, CA: Wadsworth.

21. Crain, W. (2005). Theories of development concepts and applications (5th ed.). New Jersey: Pearson. Crooks, K. L., \& Baur, K. (2007). Our sexuality (10th ed.). Belmont, CA: Wadsworth.

22. Crain, W. (2005). Theories of development concepts and applications (5th ed.). New Jersey: Pearson. Crooks, K. L., \& Baur, K. (2007). Our sexuality (10th ed.). Belmont, CA: Wadsworth.

23. Elkind, D. (1967). Egocentrism in adolescence. Child Development, 38, 1025-1034. 
that the physiological changes that occur during adolescence result in adolescents being primarily concerned with themselves. Additionally, since adolescents fail to differentiate between what others are thinking and their own thoughts, they believe that others are just as fascinated with their behavior and appearance. This belief results in the adolescent anticipating the reactions of others, and consequently constructing an imaginary audience. "The imaginary audience is the adolescent's belief that those around them are as concerned and focused on their appearance as they themselves are" (p. 441). ${ }^{24}$ Elkind thought that the imaginary audience contributed to the self-consciousness that occurs during early adolescence. The desire for privacy and reluctance to share personal information may be a further reaction to feeling under constant observation by others.

Another important consequence of adolescent egocentrism is the personal fable or a belief that one is unique, special, and invulnerable to harm. Elkind (1967) explains that because adolescents feel so important to others (imaginary audience) they regard themselves and their feelings as being special and unique. ${ }^{25}$ Adolescents believe that only they have experienced strong and diverse emotions, and therefore others could never understand how they feel. This uniqueness in one's emotional experiences reinforces the adolescent's belief of invulnerability, especially to death. Adolescents will engage in risky behaviors, such as drinking and driving or unprotected sex, and feel they will not suffer any negative consequences. Elkind believed that adolescent egocentricity emerged in early adolescence and declined in middle adolescence, however, recent research has also identified egocentricity in late adolescence. ${ }^{26}$

\section{Consequences of Formal Operational Thought}

As adolescents are now able to think abstractly and hypothetically, they exhibit many new ways of reflecting on information. ${ }^{27}$ For example, they demonstrate greater introspection or thinking about one's thoughts and feelings. They begin to imagine how the world could be which leads them to become idealistic or insisting upon high standards of behavior. Because of their idealism, they may become critical of others, especially adults in their life. Additionally, adolescents can demonstrate hypocrisy, or pretend to be what they are not. Since they are able to recognize what others expect of them, they will conform to those expectations for their emotions and behavior seemingly hypocritical to themselves.

24. Schwartz, P. D., Maynard, A. M., \& Uzelac, S. M. (2008). Adolescent egocentrism: A contemporary view. Adolescence, 43, 441447.

25. Elkind, D. (1967). Egocentrism in adolescence. Child Development, 38, 1025-1034.

26. Schwartz, P. D., Maynard, A. M., \& Uzelac, S. M. (2008). Adolescent egocentrism: A contemporary view. Adolescence, 43, 441447.

27. Dolgin, K. G. (2011). The adolescent: Development, relationships, and culture (13th ed.). Boston, MA: Pearson. 


\section{Information Processing}

Executive functions, such as attention, increases in working memory, and cognitive flexibility have been steadily improving since early childhood. Studies have found that executive function is very competent in adolescence. However, self-regulation, or the ability to control impulses, may still fail. A failure in self- regulation is especially true when there is high stress or high demand on mental functions. ${ }^{28}$ While high stress or demand may tax even an adult's self-regulatory abilities, neurological changes in the adolescent brain may make teens particularly prone to more risky decision making under these conditions.

\section{Inductive and Deductive Reasoning}

Inductive reasoning emerges in childhood, and is a type of reasoning that is sometimes characterized as "bottom-up- processing" in which specific observations, or specific comments from those in authority, may be used to draw general conclusions. However, in inductive reasoning the veracity of the information that created the general conclusion does not guarantee the accuracy of that conclusion. For instance, a child who has only observed thunder on summer days may conclude that it only thunders in the summer.
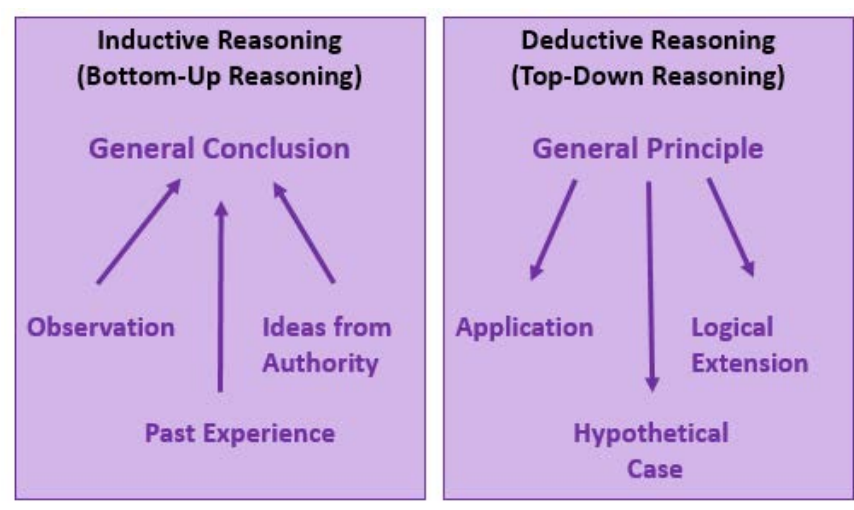

Figure 3. Inductive reasoning and deductive reasoning visualized.

In contrast, deductive reasoning, sometimes called "top-down-processing", emerges in adolescence. This type of reasoning starts with some overarching principle, and based on this propose specific conclusions. Deductive reasoning guarantees a truthful conclusion if the premises on which it is based are accurate.

Intuitive versus Analytic Thinking: Cognitive psychologists often refer to intuitive and analytic thought as the Dual-Process Model; the notion that humans have two distinct networks for processing information. ${ }^{29}$ Intuitive thought is automatic, unconscious, and fast, ${ }^{30}$ and it is more experiential and emotional. In contrast, Analytic thought is deliberate, conscious, and rational.

28. Luciano, M., \& Collins, P. F. (2012). Incentive motivation, cognitive control, and the adolescent brain: Is it time for a paradigm shift. Child Development Perspectives, 6 (4), 394-399.

29. Albert, D., \& Steinberg, L. (2011). Adolescent judgment and decision making. Journal of Research on Adolescence, 21, $211-224$. 30. Kahneman, D. (2011). Thinking, fast and slow. New York NY: Farrar, Straus and Giroux. 
While these systems interact, they are distinct. ${ }^{31}$ Intuitive thought is easier and more commonly used in everyday life. It is also more commonly used by children and teens than by adults. ${ }^{32}$ The quickness of adolescent thought, along with the maturation of the limbic system, may make teens more prone to emotional intuitive thinking than adults.

\section{Erikson: Identity vs. Role Confusion}

Erikson believed that the primary psychosocial task of adolescence was establishing an identity. Teens struggle with the question "Who am I?" This includes questions regarding their appearance, vocational choices and career aspirations, education, relationships, sexuality, political and social views, personality, and interests. Erikson saw this as a period of confusion and experimentation regarding identity and one's life path. During adolescence we experience psychological

moratorium, where teens put on hold commitment to an identity while exploring the options. The culmination of this exploration is a more coherent view of oneself. Those who are unsuccessful at resolving this stage may either withdraw further into social isolation or become lost in the crowd. However, more recent research, suggests that few leave this age period with identity achievement and that most identity formation occurs during young adulthood. ${ }^{33}$

Developmental psychologists have researched several different areas of identity development and some of the main areas include:

- Religious identity: The religious views of teens are often similar to that of their families. ${ }^{34}$ Most teens may question specific customs, practices, or ideas in the faith of their parents, but few completely reject the religion of their families.

- Political identity: The political ideology of teens is also influenced by their parents' political beliefs. A new trend in the 21 st century is a decrease in party affiliation among adults. Many adults do not align themselves with either the democratic or republican party, but view themselves as more of an "independent". Their teenage children are often following suit or become more apolitical. ${ }^{35}$

31. Kuhn, D. (2013). Reasoning. In. P.D. Zelazo (Ed.), The Oxford handbook of developmental psychology. (Vol. 1, pp. 744-764). New York NY: Oxford University Press.

32. Klaczynski, P. (2001). Analytic and heuristic processing influences on adolescent reasoning and decision-making. Child Development, $72(3), 844-861$.

33. Co tè, J. E. (2006). Emerging adulthood as an institutionalized moratorium: Risks and benefits to identity formation. In J. J. Arnett \& J. T. Tanner (Eds.), Emerging adults in America: Coming of age in the 21st century, (pp. 85-116). Washington D.C.: American Psychological Association Press.

34. Kim-Spoon, J., Longo, G.S., \& McCullough, M.E. (2012). Parent-adolescent relationship quality as moderator for the influences of parents' religiousness on adolescents' religiousness and adjustment. Journal or Youth \& Adolescence, 41 (12), $1576-1578$.

35. Co tè, J. E. (2006). Emerging adulthood as an institutionalized moratorium: Risks and benefits to identity formation. In J. J. 
- Vocational identity: While adolescents in earlier generations envisioned themselves as working in a particular job, and often worked as an apprentice or part-time in such occupations as teenagers, this is rarely the case today. Vocational identity takes longer to develop, as most of today's occupations require specific skills and knowledge that will require additional education or are acquired on the job itself. In addition, many of the jobs held by teens are not in occupations that most teens will seek as adults.

- Gender identity: This is also becoming an increasingly prolonged task as attitudes and norms regarding gender keep changing. The roles appropriate for males and females are evolving. Some teens may foreclose on a gender identity as a way of dealing with this uncertainty, and they may adopt more stereotypic male or female roles. ${ }^{36}$

- Ethnic identity refers to how people come to terms with who they are based on their ethnic or racial ancestry. "The task of ethnic identity formation involves sorting out and resolving positive and negative feelings and attitudes about one's own ethnic group and about other groups and identifying one's place in relation to both" (p. 119). ${ }^{37}$ When groups differ in status in a culture, those from the non- dominant group have to be cognizant of the customs and values of those from the dominant culture. The reverse is rarely the case. This makes ethnic identity far less salient for members of the dominant culture. In the United States, those of European ancestry engage in less exploration of ethnic identity, than do those of non-European ancestry. ${ }^{38}$ However, according to the U.S. Census (2012) more than 40\% of Americans under the age of 18 are from ethnic minorities. ${ }^{39}$ For many ethnic minority teens, discovering one's ethnic identity is an important part of identity formation.

Phinney's model of ethnic identity formation is based on Erikson's and Marcia's model of identity formation. ${ }^{40} 41$ Through the process of exploration and commitment, individuals come to understand and create an ethnic identity. Phinney suggests three stages or statuses with regard to ethnic identity:

1. Unexamined Ethnic Identity: Adolescents and adults who have not been exposed to ethnic

Arnett \& J. T. Tanner (Eds.), Emerging adults in America: Coming of age in the 21st century, (pp. 85-116). Washington D.C.: American Psychological Association Press.

36. Sinclair, S., \& Carlsson, R. (2013). What will I be when I grow up? The impact of gender identity threat on adolescents' occupational preferences. Journal of Adolescence, 36(3), 465-474.

37. Phinney, J. S. (2006). Ethnic identity exploration. In J. J. Arnett \& J. L. Tanner (Eds.) Emerging adults in America: Coming of age in the 21st Century. (pp. 117-134) Washington DC: American Psychological Association.

38. Phinney, J. S. (1989). Stages of ethnic identity development in minority group adolescents. Journal of Early Adolescence, 9, 3449.

39. United States Census. (2012). 2000-2010 Intercensal estimates. Retrieved from http://www.census.gov/popest/data/index.html

40. Phinney, J. S. (1990). Ethnic identity in adolescents and adults: Review of research. Psychological Bulletin, 108(3), $499-514$. doi:10.1037/0033-2909.108.3.499

41. Syed, M., \& Juang, L. P. (2014). Ethnic identity, identity coherence, and psychological functioning: Testing basic assumptions of the developmental model. Cultural Diversity and Ethnic Minority Psychology, 20(2), 176-190. doi:10.1037/a0035330 
identity issues may be in the first stage, unexamined ethnic identity. This is often characterized by a preference for the dominant culture, or where the individual has given little thought to the question of their ethnic heritage. This is similar to diffusion in Marcia's model of identity. ${ }^{42}$ Included in this group are also those who have adopted the ethnicity of their parents and other family members with little thought about the issues themselves, similar to Marcia's foreclosure status. $^{43}$

2. Ethnic Identity Search: Adolescents and adults who are exploring the customs, culture, and history of their ethnic group are in the ethnic identity search stage, similar to Marcia's moratorium status. ${ }^{44}$ Often some event "awakens" a teen or adult to their ethnic group; either personal experience with prejudice, a highly profiled case in the media, or even a more positive event that recognizes the contribution of someone from the individual's ethnic group. Teens and adults in this stage will immerse themselves in their ethnic culture. For some, "it may lead to a rejection of the values of the dominant culture" (p. 503). ${ }^{45}$

3. Achieved Ethnic Identity: Those who have actively explored their culture are likely to have a deeper appreciation and understanding of their ethnic heritage, leading to progress toward an achieved ethnic identity. ${ }^{46}$ An achieved ethnic identity does not necessarily imply that the individual is highly involved in the customs and values of their ethnic culture. One can be confident in their ethnic identity without wanting to maintain the language or other customs.

The development of ethnic identity takes time, with about $25 \%$ of tenth graders from ethnic minority backgrounds having explored and resolved the issues. ${ }^{47}$ The more ethnically homogeneous the high school, the less identity exploration and achievement. ${ }^{48}$ Moreover, even in more ethnically diverse high schools, teens tend to spend more time with their own group, reducing exposure to other ethnicities. This may explain why, for many, college becomes the time of ethnic identity

42. Marcia, J. (2010). Life transitions and stress in the context of psychosocial development. In T.W. Miller (Ed.), Handbook of stressful transitions across the lifespan (Part 1, pp. 19-34). New York, NY: Springer Science \& Business Media.

43. Phinney, J. S. (1990). Ethnic identity in adolescents and adults: Review of research. Psychological Bulletin, 108(3), 499-514. doi:10.1037/0033-2909.108.3.499

44. Phinney, J. S. (1990). Ethnic identity in adolescents and adults: Review of research. Psychological Bulletin, 108(3), $499-514$. doi:10.1037/0033-2909.108.3.499

45. Phinney, J. S. (1990). Ethnic identity in adolescents and adults: Review of research. Psychological Bulletin, 108(3), $499-514$. doi:10.1037/0033-2909.108.3.499

46. Phinney, J. S. (1990). Ethnic identity in adolescents and adults: Review of research. Psychological Bulletin, 108(3), $499-514$. doi:10.1037/0033-2909.108.3.499

47. Phinney, J. S. (1989). Stages of ethnic identity development in minority group adolescents. Journal of Early Adolescence, 9, 3449.

48. Umana-Taylor, A. (2003). Ethnic identity and self-esteem. Examining the roles of social context. Journal of Adolescence, 27, 139-146. 
exploration. "[The] transition to college may serve as a consciousness-raising experience that triggers exploration." ${ }^{49}$

It is also important to note that those who do achieve ethnic identity may periodically reexamine the issues of ethnicity. This cycling between exploration and achievement is common not only for ethnic identity formation but in other aspects of identity development. ${ }^{50}$

\section{Bicultural/Multiracial Identity}

Some who identify as ethnic minorities may wrestle with the question of how, and to what extent, they will identify with the culture of the surrounding society and with the culture of their family. Phinney (2006) suggests that people may handle it in different ways. ${ }^{51}$ Some may keep the identities separate, others may combine them in some way, while others may reject some of them. Bicultural identity means the individual sees oneself as part of both the ethnic minority group and the larger society. Those who are multiracial, that is whose parents come from two or more ethnic or racial groups, may have a more challenging task. In some cases their appearance may be ambiguous. This can lead to others constantly asking them to categorize themselves. Phinney (2006) notes that the process of identity formation may start earlier and take longer to accomplish in those who are not mono-racial. ${ }^{52}$

\section{Individual Identity Development within the Family Context}

An individual's identity forms in part from being a member of a family. In other words, an individual's personal identity emerges within the context of the family. It is not a neutral environment and family can greatly affect an individual's identity development. ${ }^{53}$ Recall the definition of family from the key concepts at the beginning of this book, that family can include various people who have relationship with an individual beyond just legal or biological ties. Many families are also a well-organized group with a high degree of unity that interacts with its social and

49. Syed, M., \& Azmitia, M. (2009). Longitudinal trajectories of ethnic identity during the college years. Journal of Research on Adolescence, 19, 618. doi:10.1111/j.1532-7795.2009.00609.x

50. Grotevant, H. (1987). Toward a process model of identity formation. Journal of Adolescent Research, 2, 203-222

51. Phinney, J. S. (2006). Ethnic identity exploration. In J. J. Arnett \& J. L. Tanner (Eds.) Emerging adults in America: Coming of age in the 21st Century. (pp. 117-134) Washington DC: American Psychological Association.

52. Phinney, J. S. (2006). Ethnic identity exploration. In J. J. Arnett \& J. L. Tanner (Eds.) Emerging adults in America: Coming of age in the 21st Century. (pp. 117-134) Washington DC: American Psychological Association.

53. Scabini, E., \& Manzi, C. (2011). Family processes and identity. In S.J. Schwartz et al. (eds.), Handbook of Identity Theory and Research (pp. 569 - 588). Springer Science+Business Media, LLC 2011. DOI 10.1007/978-1-4419-7988-9_2 
cultural context. It is different from other social groups because it typically does not have a limited lifetime similar to most social groups, but rather most families have a past, present, and future. ${ }^{54}$

Based on the family systems theory (visit the family systems chapter for more information) the family is considered a system (or unit) which is also made up of subsystems that inform one's individual identity. These subsystems may include couple relationships, sibling relationships, parentchild relationships, and so on. ${ }^{55}$ Individuals within these systems have separate individual identities as well as the shared identity of a subsystem or family system. This means that individuals' role identities, such as being a sibling, spouse, parent, and/or child are interdependent with one another. One's identity in multiple domains such as the identity of being both a parent and child are linked, meaning that parents are also children of the preceding generation. ${ }^{56}$ Thus, one's identity formed in part by one identity role, such as being a child of a parent can influence later identity roles such as becoming a parent. Parenting style can also influence identity development. For example, those who experience significant abuse within their family may not achieve as clear of an identity compared to those who do not experience any abuse within their family. ${ }^{57}$

\section{Parents/Caregivers and Teens: Autonomy and Attachment}

While most adolescents tend to get along with their parents or primary caregivers, many tend to spend less time with them. ${ }^{58}$ This decrease in the time spent with families may be a reflection of a teenager's greater desire for independence or autonomy. It can be difficult for many parents to deal with this desire for autonomy. However, it is likely adaptive for teenagers to increasingly distance themselves and establish relationships outside of their families in preparation for adulthood. This means that both parents and teenagers need to strike a balance between autonomy, while still maintaining close and supportive familial relationships.

Children in middle and late childhood are increasingly granted greater freedom regarding momentto-moment decision making. This continues in adolescence, as teens are demanding greater control in decisions that affect their daily lives. This can increase conflict between parents and their teenagers. For many adolescents, this conflict centers on chores, homework, curfew, dating, and personal appearance. These are all things many teens believe they should manage that parents

54. Scabini, E., \& Manzi, C. (2011). Family processes and identity. In S.J. Schwartz et al. (eds.), Handbook of Identity Theory and Research (pp. 569 - 588). Springer Science+Business Media, LLC 2011. DOI 10.1007/978-1-4419-7988-9_2

55. Scabini, E., \& Manzi, C. (2011). Family processes and identity. In S.J. Schwartz et al. (eds.), Handbook of Identity Theory and Research (pp. 569 - 588). Springer Science+Business Media, LLC 2011. DOI 10.1007/978-1-4419-7988-9_2

56. Cigoli, V., \& Scabini, E. (2006). Family identity: Ties, symbols, and transitions. Mahwah, NJ: Lawrence Erlbaum Associates. ISBN 9780805863185

57. Hasanah, U., Susanti, H., \& Panjaitan, R. U. (2019). Family experience in facilitating adolescents during self-identity development in ex-localization in Indonesia. BMC Nursing, 18(35). https://doi.org/10.1186/s12912-019-0358-7

58. Smetana, J. G. (2011). Adolescents, families, and social development. Chichester, UK: Wiley-Blackwell. 
previously had considerable control over. Teens report more conflict with their mothers, as many mothers believe they should still have some control over many of these areas, yet often report their mothers to be more encouraging and supportive. ${ }^{59}$ As teens grow older, more compromise is reached between parents and teenagers. ${ }^{60}$ In addition, culture and ethnicity also play a role in how restrictive parents/caregivers are with the daily lives of their children. ${ }^{61}$

Having supportive, less conflict-ridden relationships with primary caregivers also benefits teenagers. Research on attachment in adolescence find that teens who are still securely attached to their parents have less emotional problems, ${ }^{62}$ are less likely to engage in drug abuse and other criminal behaviors, ${ }^{63}$ and have more positive peer relationships. ${ }^{64}$

\section{(ㄷ) (1) (2) (2)}

Adolescence by Martha Lally; Suzanne Valentine-French; and Diana Lang is licensed under a Creative Commons Attribution-

NonCommercial-ShareAlike 4.0 International License, except where otherwise noted.

59. Costigan, C. L., Cauce, A. M., \& Etchinson, K. (2007). Changes in African American mother-daughter relationships during adolescence: Conflict, autonomy, and warmth. In B. J. R. Leadbeater \& N. Way (Eds.), Urban girls revisited: Building strengths (pp. 177-201). New York NY: New York University Press.

60. Smetana, J. G. (2011). Adolescents, families, and social development. Chichester, UK: Wiley-Blackwell.

61. Chen, B., Vansteenkiste, M., Beyers, W., Soensens, B., \& Van Petegem, S. (2013). Autonomy in family decision making for Chinese adolescents: Disentangling the dual meaning of autonomy. Journal of Cross-Cultural Psychology, 44, 1184- 1209.

62. Rawatlal, N., Kliewer, W., \& Pillay, B. J. (2015). Adolescent attachment, family functioning and depressive symptoms. South African Journal of Psychiatry, 21(3), 80-85. doi:10.7196/SAJP.8252

63. Meeus, W., Branje, S., \& Overbeek, G. J. (2004). Parents and partners in crime: a six-year longitudinal study on changes in supportive relationships and delinquency in adolescence and young adulthood. Journal of Child Psychology \& Psychiatry, 45(7), 1288-1298. doi:10.1111/j.1469-7610.2004.00312.x

64. Shomaker, L. B., \& Furman, W. (2009). Parent-adolescent relationship qualities, internal working models, and attachment styles as predictors of adolescents' interactions with friends. Journal or Social and Personal Relationships, 2, 579-603. 


\title{
EMERGING AND EARLY ADULTHOOD
}

\author{
Martha Lally and Suzanne Valentine-French
}

Historically, early adulthood spanned from approximately 18 years (the end of adolescence) until 40 to 45 years (beginning of middle adulthood). More recently, developmentalists have divided this age period into two separate stages: Emerging adulthood followed by early adulthood. Although these age periods differ in their physical, cognitive, and social development, overall the age period from 18 years to 45 years is a time of peak physical capabilities and the emergence of more mature cognitive development, financial independence, and intimate relationships. ${ }^{1}$

\section{Emerging Adulthood}

Emerging adulthood is the period between the late teens and early twenties; ages 18-25 years, although some researchers have included up to age 29 years in the definition. ${ }^{2}$ Jeffrey Arnett (2000) argues that emerging adulthood is neither adolescence nor is it young adulthood. ${ }^{3}$ Individuals in this age period have left behind the relative dependency of childhood and adolescence, but have not yet taken on the responsibilities of adulthood. "Emerging adulthood is a time of life when many different directions remain possible, when little about the future is decided for certain, when the scope of independent exploration of life's possibilities is greater for most people than it will be at any other period of the life course" (p. 469). ${ }^{4}$

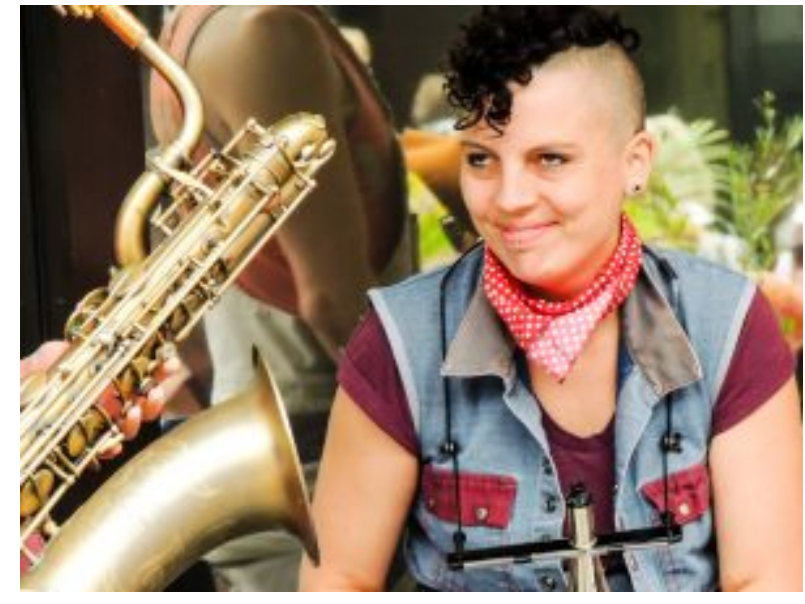

Figure 1. A young adult enjoying a saxophonist performance. (Photo Source: pxfuel, DMCA)

1. This chapter is adapted from Lifespan Development by Martha Lally and Suzanne Valentine-French, licensed CC BY NC SA. https://courses.lumenlearning.com/suny-lifespandevelopment/

2. Society for the Study of Emerging Adulthood (SSEA). (2016). Overview. Retrieved from http://ssea.org/about/index.htm

3. Arnett, J. J. (2000). Emerging adulthood: A theory of development from late teens through the twenties. American Psychologist, $55,469-480$.

4. Arnett, J. J. (2000). Emerging adulthood: A theory of development from late teens through the twenties. American Psychologist, $55,469-480$. 
Arnett has identified five characteristics of emerging adulthood that distinguishes it from adolescence and young adulthood. ${ }^{5}$

1. It is the age of identity exploration. In 1950, Erik Erikson proposed that it was during adolescence that humans wrestled with the question of identity. Yet, even Erikson (1968) commented on a trend during the 20th century of a "prolonged adolescence" in industrialized societies. Today, most identity development occurs during the late teens and early twenties rather than adolescence. It is during emerging adulthood that people are exploring their career choices and ideas about intimate relationships, setting the foundation for adulthood.

2. Arnett also described this time period as the age of instability. ${ }^{6}$ Exploration generates uncertainty and instability. Emerging adults change jobs, relationships, and residences more frequently than other age groups.

3. This is also the age of self-focus. Being self-focused is not the same as being "self- centered." Adolescents are more self-centered than emerging adults. Arnett reports that in his research, he found emerging adults to be very considerate of the feelings of others, especially their parents. They now begin to see their parents as people not just parents, something most adolescents fail to do. ${ }^{7}$ Nonetheless, emerging adults focus more on themselves, as they realize that they have few obligations to others and that this is the time where they can do what they want with their life.

4. This is also the age of feeling in-between. When asked if they feel like adults, more 18 to 25 year-olds answer "yes and no" than do teens or adults over the age of $25 .^{8}$ Most emerging adults have gone through the changes of puberty, are typically no longer in high school, and many have also moved out of their parents' home. Thus, they no longer feel as dependent as they did as teenagers. Yet, they may still be financially dependent on their parents to some degree, and they have not completely attained some of the indicators of adulthood, such as finishing their education, obtaining a good full-time job, being in a committed relationship, or being responsible for others. It is not surprising that Arnett found that $60 \%$ of 18 to 25 year-olds felt that in some ways they were adults, but in some ways they were not. ${ }^{9}$

5. Finally, emerging adulthood is the age of possibilities. It is a time period of optimism as more 18 to 25 year-olds feel that they will someday get to where they want to be in life. Arnett suggests that this optimism is because these dreams have yet to be tested. ${ }^{10}$,

5. Arnett, J. J. (2006). G. Stanley Hall's adolescence: Brilliance and non-sense. History of Psychology, 9, 186-197.

6. Arnett, J. J. (2000). Emerging adulthood: A theory of development from late teens through the twenties. American Psychologist, $55,469-480$.

7. Arnett, J. J. (2006). G. Stanley Hall's adolescence: Brilliance and non-sense. History of Psychology, 9, 186-197.

8. Arnett, J. J. (2001). Conceptions of the transitions to adulthood: Perspectives from adolescence to midlife. Journal of Adult Development, 8, 133-143.

9. Arnett, J. J. (2001). Conceptions of the transitions to adulthood: Perspectives from adolescence to midlife. Journal of Adult Development, 8, 133-143.

10. Arnett, J. J. (2000). Emerging adulthood: A theory of development from late teens through the twenties. American Psychologist, 
For example, it is easier to believe that you will eventually find your soul mate when you have yet to have had a serious relationship. It may also be a chance to change directions, for those whose lives up to this point have been difficult. The experiences of children and teens are influenced by the choices and decisions of their parents. If the parents are dysfunctional, there is little a child can do about it. In emerging adulthood, people can move out and move on. They have the chance to transform their lives and move away from unhealthy environments. Even those whose lives were happier and more fulfilling as children, now have the opportunity in emerging adulthood to become independent and make decisions about the direction they would like their life to take.

\section{Cultural Variations}

The five features proposed in the theory of emerging adulthood originally were based on research involving about 300 Americans between ages 18 and 29 from various ethnic groups, social classes, and geographical regions. ${ }^{11}$ To what extent does the theory of emerging adulthood apply internationally?

The answer to this question depends greatly on what part of the world is considered. Demographers make a useful distinction between the developing countries that comprise the majority of the world's population and the economically developed countries that are part of the Organization for Economic Co- operation and Development (OECD), including the United States, Canada, Western Europe, Japan, South Korea, Australia, and New Zealand. The current population of OECD countries (also called developed countries) is 1.2 billion, about $18 \%$ of the total world population. ${ }^{12}$ The rest of the human population resides in developing countries, which have much lower median incomes, much lower median educational attainment, and much higher incidence of illness, disease, and early death. Let us consider emerging adulthood in other OECD countries as little is known about the experiences of 18- 25 year-olds in developing countries.

The same demographic changes as described above for the United States have taken place in other OECD countries as well. This is true of participation in postsecondary education, as well as median ages for entering marriage and parenthood. ${ }^{13}$ However, there is also substantial variability in how emerging adulthood is experienced across OECD countries. Europe is the region where emerging

$55,469-480$.

11. Arnett, J. J. (2004). Conceptions of the transition to adulthood among emerging adults in American ethnic groups. In J. J. Arnett \& N. Galambos (Eds.), Cultural conceptions of the transition to adulthood: New directions in child and adolescent development. San Francisco: Jossey-Bass.

12. United Nations Development Programme (UNDP). (2011). Human development report. NY: Oxford University Press.

13. UNdata (2010). Gross enrollment ratio in tertiary education. United Nations Statistics Division. Retrieved November 5, 2010, from http://data.un.org/Data.aspx?d=GenderStat\&f=inID:68 
adulthood is longest and most leisurely. The median ages for entering marriage and parenthood are near 30 in most European countries. ${ }^{14}$

Europe today is the location of the most affluent, generous, and egalitarian societies in the world, in fact, in human history. ${ }^{15}$ Governments pay for tertiary education, assist young people in finding jobs, and provide generous unemployment benefits for those who cannot find work. In northern Europe, many governments also provide housing support. Emerging adults in European societies make the most of these advantages, gradually making their way to adulthood during their twenties while enjoying travel and leisure with friends.

The lives of emerging adults in developed Asian countries, such as Japan and South Korea, are in some ways similar to the lives of emerging adults in Europe and in some ways strikingly different. Like emerging European adults, emerging adults in Asian tend to enter marriage and parenthood around age 30 years. ${ }^{16}$ Like emerging adults in Europe, emerging adults in Japan and South Korea enjoy the benefits of living in affluent societies with generous social welfare systems that provide support for them in making the transition to adulthood, including free university education and substantial unemployment benefits.

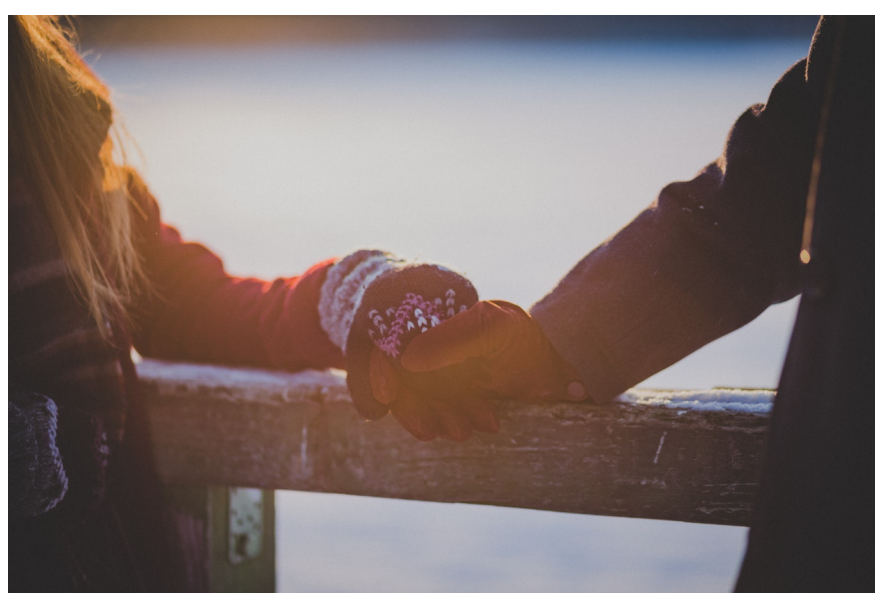

Figure 2. Is your culture one that promotes romantic relationships for emerging adults? Or does it encourage you to wait till you're older? What would it be like to live in the opposite culture?

However, in other ways, the experience of emerging adulthood in Asian OECD countries is markedly different than in Europe. Europe has a long history of individualism, and today's emerging adults carry that legacy with them in their focus on self-development and leisure during emerging adulthood. In contrast, most Asian cultures have a shared cultural history emphasizing collectivism and family obligations.

Although Asian cultures have become more individualistic in recent decades, as a consequence of globalization, the legacy of collectivism persists in the lives of emerging adults. They pursue identity explorations and self-development during emerging adulthood, like their American and European counterparts, but within narrower boundaries set by their sense of obligations to others, especially

14. Douglass, C. B. (2007). From duty to desire: Emerging adulthood in Europe and its consequences. Child Development Perspectives, 1, 101-108.

15. Arnett, J.J. (2007). The long and leisurely route: Coming of age in Europe today. Current History, 106, $130-136$.

16. Arnett, J. J. (2011). Emerging adulthood(s): The cultural psychology of a new life stage. In L.A. Jensen (Ed.), Bridging cultural and developmental psychology: New syntheses in theory, research, and policy (pp. 255-275). New York, NY: Oxford University Press. 
their parents. ${ }^{17}$ For example, in their views of the most important criteria for becoming an adult, emerging adults in the United States and Europe consistently rank financial independence among the most important markers of adulthood. In contrast, emerging adults with an Asian cultural background especially emphasize becoming capable of supporting parents financially as among the most important criteria. ${ }^{18} 19$ This sense of family obligation may curtail their identity explorations in emerging adulthood to some extent, as they pay more heed to their parents' wishes about what they should study, what job they should take, and where they should live than emerging adults do in the West. $^{20}$

\section{When Does Adulthood Begin?}

According to Rankin and Kenyon (2008), historically the process of becoming an adult was more clearly marked by rites of passage. ${ }^{21}$ For many individuals, marriage and becoming a parent were considered entry into adulthood. However, these role transitions are no longer considered as the important markers of adulthood. ${ }^{22}$ Economic and social changes have resulted in increase in young adults attending college and a delay in marriage and having children. ${ }^{23}{ }^{24}$ Consequently, current research has found financial independence and accepting responsibility for oneself to be the most important markers of adulthood in Western culture across age and ethnic groups. ${ }^{25}$

In looking at college students' perceptions of adulthood, Rankin and Kenyon (2008) found that some

17. Phinney, J. S. \& Baldelomar, O. A. (2011). Identity development in multiple cultural contexts. In L. A. Jensen (Ed.), Bridging cultural and developmental psychology: New syntheses in theory, research and policy (pp. 161-186). New York, NY: Oxford University Press.

18. Arnett, J. J. (2003). Conceptions of the transition to adulthood among emerging adults in American ethnic groups. New Directions for Child and Adolescent Development, 100, 63-75.

19. Nelson, L. J., Badger, S., \& Wu, B. (2004). The influence of culture in emerging adulthood: Perspectives of Chinese college students. International Journal of Behavioral Development, 28, 26-36.

20. Rosenberger, N. (2007). Rethinking emerging adulthood in Japan: Perspectives from long-term single women. Child Development Perspectives, 1, 92-95.

21. Rankin, L. A. \& Kenyon, D. B. (2008). Demarcating role transitions as indicators of adulthood in the 21 st century. Who are they? Journal of Adult Development, 15(2), 87-92. doi: 10.1007/s10804-007-9035-2

22. Arnett, J. J. (2001). Conceptions of the transitions to adulthood: Perspectives from adolescence to midlife. Journal of Adult Development, 8, 133-143.

23. Rankin, L. A. \& Kenyon, D. B. (2008). Demarcating role transitions as indicators of adulthood in the 21 st century. Who are they? Journal of Adult Development, 15(2), 87-92. doi: 10.1007/s10804-007-9035-2

24. Arnett, J. J., \& Taber, S. (1994). Adolescence terminable and interminable: When does adolescence end? Journal of Youth and Adolescence, 23, 517-537.

25. Arnett, J. J. (2004). Conceptions of the transition to adulthood among emerging adults in American ethnic groups. In J. J. Arnett \& N. Galambos (Eds.), Cultural conceptions of the transition to adulthood: New directions in child and adolescent development. San Francisco: Jossey-Bass. 
students still view rites of passage as important markers. ${ }^{26}$ College students who had placed more importance on role transition markers, such as parenthood and marriage, belonged to a fraternity/ sorority, were traditionally aged (18-25), belonged to an ethnic minority, were of a traditional marital status; i.e., not cohabitating, or belonged to a religious organization, particularly for men. These findings supported the view that people holding collectivist or more traditional values place more importance on role transitions as markers of adulthood. In contrast, older college students and those cohabitating did not value role transitions as markers of adulthood as strongly.

\section{Obesity}

Although at the peak of physical health, a concern for early adults is the current rate of obesity. Results from the 2015 National Center for Health Statistics indicate that an estimated 70.7\% of U.S. adults aged 20 and over are overweight and $37.9 \%$ are obese. ${ }^{27}$ Body mass index (BMI), expressed as weight in kilograms divided by height in meters squared $(\mathrm{kg} / \mathrm{m} 2)$, is commonly used to classify overweight (BMI 25.0-29.9), obesity (BMI greater than or equal to 30.0), and extreme obesity (BMI greater than or equal to 40.0). The 2015 statistics are an increase from the 2013-2014 statistics that indicated that an estimated $35.1 \%$ were obese, and $6.4 \%$ extremely obese. ${ }^{28}$ In $2003-2004,32 \%$ of American adults were identified as obese. The CDC also indicated that one's 20 s are the prime time to gain weight as the average person gains one to two pounds per year from early adulthood into middle adulthood. The average man in his 20s weighs around 185 pounds and by his 30s weighs approximately 200 pounds. The average American woman weighs 162 pounds in her 20s and 170 pounds in her 30 s.

26. Rankin, L. A. \& Kenyon, D. B. (2008). Demarcating role transitions as indicators of adulthood in the 21 st century. Who are they? Journal of Adult Development, 15(2), 87-92. doi: 10.1007/s10804-007-9035-2

27. Centers for Disease Control and Prevention. (2015). Obesity and overweight. Retrieved from http://www.cdc.gov/nchs/fastats/ obesity-overweight.htm

28. Fryar, C. D., Carroll, M. D., \& Ogden, C. L. (2014). Prevalence of overweight, obesity, and extreme obesity among adults: United States, 1960-1962 through 2011-2012. Retrieved from http://www.cdc.gov/nchs/data/hestat/obesity_adult_11_12/

obesity_adult_11_12.htm 
The American obesity crisis is also reflected worldwide. ${ }^{29}$ Although obesity is seen throughout the world, more obese men and women live in China and the USA than in any other country. Figure 2 illustrates how waist circumference is also used as a measure of obesity. Figure 3 demonstrates the percentage of growth for males and females identified as obese between 1960 and 2012.

\section{Causes of Obesity}

According to the Centers for Disease Control and Prevention (CDC) (2016), obesity originates from a complex set of contributing factors, including one's

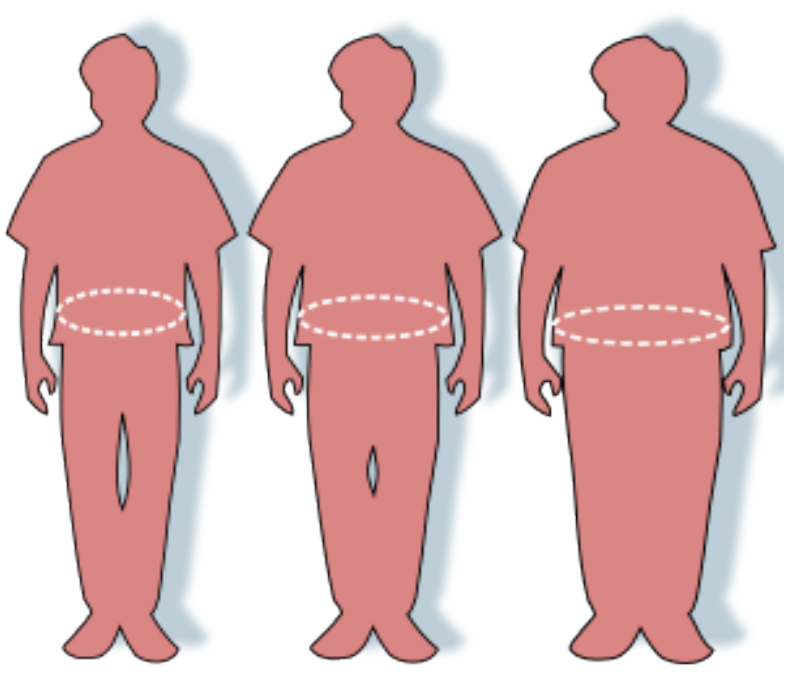
environment, behavior, and genetics. Societal factors

Figure 3. Waist Circumference include culture, education, food marketing and promotion, the quality of food, and the physical activity environment available. Behaviors leading to obesity include diet, the amount of physical activity, and medication use. Lastly, there does not appear to be a single gene responsible for obesity. Rather, research has identified variants in several genes that may contribute to obesity by increasing hunger and food intake. Another genetic explanation is the mismatch between today's environment and "energy-thrifty genes" that multiplied in the distant past, when food sources were unpredictable. The genes that helped our ancestors survive occasional famines are now being challenged by environments in which food is plentiful all the time. Overall, obesity most likely results from complex interactions among the environment and multiple genes.

\section{Obesity Health Consequences}

Obesity is considered to be one of the leading causes of death in the United States and worldwide. According to the CDC (2016) compared to those with a normal or healthy weight, people who are obese are at increased risk for many serious diseases and health conditions including: ${ }^{30}$

- All-causes of death (mortality)

- High blood pressure (Hypertension)

- High LDL cholesterol, low HDL cholesterol, or high levels of triglycerides (Dyslipidemia)

- Type 2 diabetes

29. Wighton, K. (2016). World's obese population hits 640 million, according to largest ever study. Imperial College. Retrieved from http://www3.imperial.ac.uh/newsandeventspggrp/imperialcollege/newssummary/news_311-3-2016-22-34-39

30. Centers for Disease Control and Prevention. (2016). Adult obesity causes and consequences. Retrieved from http://www.cdc.gov/ obesity/adult/causes.html 
- Coronary heart disease

- Stroke

- Gallbladder disease

- Osteoarthritis (a breakdown of cartilage and bone within a joint)

- Sleep apnea and breathing problems

- Some cancers (endometrial, breast, colon, kidney, gallbladder, and liver)

- Low quality of life

- Mental illness such as clinical depression, anxiety, and other mental disorders

- Body pain and difficulty with physical functioning

\section{A Healthy, but Risky Time}

Doctor's visits are less frequent in early adulthood than for those in midlife and late adulthood and are necessitated primarily by injury and pregnancy. ${ }^{31}$ However, the top five causes of death in emerging and early adulthood are non-intentional injury (including motor vehicle accidents), homicide, and suicide with cancer and heart disease completing the list. ${ }^{32}$ Rates of violent death (homicide, suicide, and accidents) are highest among young adult males, and vary by race and ethnicity. Rates of violent death are higher in the United States than in Canada, Mexico, Japan, and other selected countries. Males are more likely to die in auto accidents than are females. ${ }^{33}$

\section{Alcohol Abuse}

A significant contributing factor to risky behavior is alcohol. According to the 2014 National Survey on Drug Use and Health (National Institute on Alcohol Abuse and Alcoholism (NIAAA), 88\% of people ages 18 or older reported that they drank alcohol at some point in their lifetime; $71 \%$ reported that they drank in the past year; and 57\% reported drinking in the past month. ${ }^{34}$ Additionally, 6.7\% reported that they engaged in heavy drinking in the past month. Heavy drinking is defined as drinking five or more drinks on the same occasion on each of five or more days in the past 30 days. Nearly 88,000 people (approximately 62,000 men and 26,000 women) die from alcoholrelated causes annually, making it the fourth leading preventable cause of death in the United States. In 2014, alcohol-impaired driving fatalities accounted for 9,967 deaths (31\% of overall driving fatalities).

31. Berger, K. S. (2005). The developing person through the life span (6th ed.). New York: Worth.

32. Heron, M. P., \& Smith, B. L. (2007). Products - Health E Stats - Homepage. Centers for Disease Control and Prevention. Retrieved from

33. Frieden, T. (2011, January 14). Morbidity and Mortality Weekly Report for the Centers for Disease Control. Center for Disease Control. Retrieved from http://www.cdc.gov/mmwr/preview/mmwrhtml/su6001al.htm?s_su6001al_w

34. National Institute on Alcohol Abuse and Alcoholism. (2016). Alcohol facts and statistics. Retrieved from http://pubs.niaaa.nih.gov/publications/AlcoholFacts\&Stats/AlcoholFacts\&Stats.htm 
The NIAAA defines binge drinking when blood alcohol concentration levels reach $0.08 \mathrm{~g} / \mathrm{dL}$. This typically occurs after four drinks for women and five drinks for men in approximately two hours. In 2014, 25\% of people ages 18 or older reported that they engaged in binge drinking in the past month. According to the NIAAA (2015) "Binge drinking poses serious health and safety risks, including car crashes, drunk-driving arrests, sexual assaults, and injuries. Over the long term, frequent binge drinking can damage the liver and other organs," (p. 1). ${ }^{35}$

\section{Alcohol and College Students}

Results from the 2014 survey demonstrated a difference between the amount of alcohol consumed by college students and those of the same age who are not in college. ${ }^{36}$ Specifically, $60 \%$ of full-time college students' ages 18-22 drank alcohol in the past month compared with $51.5 \%$ of other persons of the same age not in college. In addition, 38\% of college students' ages 18-22 engaged in binge drinking; that is, five or more drinks on one occasion in the past month, compared with $33.5 \%$ of other persons of the same age. Lastly, 12\% of college students' (ages 18-22) engaged in heavy drinking; that is, binge drinking on five or more occasions per month, in the past month. This compares with $9.5 \%$ of other emerging adults not in college.

The consequences for college drinking are staggering, and the NIAAA (2016) estimates that each year the following occur:

- 1,825 college students between the ages of 18 and 24 die from alcohol-related unintentional injuries, including motor-vehicle crashes.

- 696,000 students between the ages of 18 and 24 are assaulted by another student who has been drinking.

- Roughly 1 in 5 college students meet the criteria for an Alcohol Use Disorder.

- About 1 in 4 college students report academic consequences from drinking, including missing class, falling behind in class, doing poorly on exams or papers, and receiving lower grades overall. (p. 1)

- 97,000 students between the ages of 18 and 24 report experiencing alcohol-related sexual assault or date rape.

The role alcohol plays in predicting acquaintance rape on college campuses is of particular concern. "Alcohol use in one the strongest predictors of rape and sexual assault on college campuses," (p.

35. National Institute on Alcohol Abuse and Alcoholism. (2015). College Drinking. Retrieved from http://pubs.niaaa.nih.gov/ publications/CollegeFactSheet/CollegeFact.htm

36. National Institute on Alcohol Abuse and Alcoholism. (2016). Alcohol facts and statistics. Retrieved from http://pubs.niaaa.nih.gov/publications/AlcoholFacts\&Stats/AlcoholFacts\&Stats.htm 
454). ${ }^{37}$ Krebs, Lindquist, Warner, Fisher and Martin (2009) found that over $80 \%$ of sexual assaults on college campuses involved alcohol. ${ }^{38}$ Being intoxicated increases a female's risk of being the victim of date or acquaintance rape ${ }^{39}$ Females are more likely to blame themselves and to be blamed by others if they were intoxicated when raped. College students view perpetrators who were drinking as less responsible, and victims who were drinking as more responsible for the assaults. ${ }^{40}$

\section{Factors Affecting College Students' Drinking}

Several factors associated with college life affect a student's involvement with alcohol. ${ }^{41}$ These include the pervasive availability of alcohol, inconsistent enforcement of underage drinking laws, unstructured time, coping with stressors, and limited interactions with parents and other adults. Due to social pressures to conform and expectations when entering college, the first six weeks of freshman year are an especially susceptible time for students. Additionally, more drinking occurs in colleges with active Greek systems and athletic programs. Alcohol consumption is lowest among students living with their families and commuting, while it is highest among those living in fraternities and sororities.

\section{College Strategies to Curb Drinking}

Strategies to address college drinking involve the individual-level and campus community as a whole. Identifying at-risk groups, such as first year students, members of fraternities and sororities, and athletes has proven helpful in changing students' knowledge, attitudes, and behavior regarding alcohol. ${ }^{42}$ Interventions include education and awareness programs, as well as intervention by health professionals. At the college-level, reducing the availability of alcohol has proven effective by decreasing both consumption and negative consequences.

\section{Non-Alcohol Substance Use}

Illicit drug use peaks between the ages of 19 and 22 and then begins to decline. Additionally, 25\% of

37. Carroll, J. L. (2016). Sexuality now: Embracing diversity (5th ed.). Boston, MA: Cengage Learning.

38. Krebs, C., Lindquist, C., Warner, T., Fisher, B., \& Martin, S. (2009). College women's experiences with physically forced, alcohol or other drug-enabled, and drug-facilitated sexual assault before and since entering college. Journal of American College Health, 57(6), 639-649.

39. Carroll, J. L. (2007). Sexuality now: Embracing diversity (2nd ed.). Belmont, CA: Thomson Learning.

40. Untied, A., Orchowski, L., Mastroleo, N., \& Gidycz, C. (2012). College students' social reactions to the victim in a hypothetical sexual assault scenario: The role of victim and perpetrator alcohol use. Violence and Victims, 27(6), 957-972.

41. National Institute on Alcohol Abuse and Alcoholism. (2015). College Drinking. Retrieved from http://pubs.niaaa.nih.gov/ publications/CollegeFactSheet/CollegeFact.htm

42. National Institute on Alcohol Abuse and Alcoholism. (2015). College Drinking. Retrieved from http://pubs.niaaa.nih.gov/ publications/CollegeFactSheet/CollegeFact.htm 
those who smoke cigarettes, 33\% of those who smoke marijuana, and 70\% of those who abuse cocaine began using after age $17 .{ }^{43}$ Emerging adults (18 to 25 ) are the largest abusers of prescription opioid pain relievers, anti-anxiety medications, and Attention Deficit Hyperactivity Disorder medication. ${ }^{44}$ In 2014 more than 1700 emerging adults died from a prescription drug overdose. This is an increase of four times since 1999. Additionally, for every death there were 119 emergency room visits.

Daily marijuana use is at the highest level in three decades. ${ }^{45}$ For those in college, 2019 data indicate that $5.9 \%$ of college students smoke marijuana daily, while only $2 \%$ smoked daily in 1994 . For noncollege students of the same age, the daily percentage is over twice as high (approximately 15\%). Additionally, daily cigarette smoking is lower for those in college as only $7.9 \%$ smoked in the past month, while for those not in college was $16 \%{ }^{46}$

Rates of violent death are influenced by substance use which peaks during emerging and early adulthood. Drugs impair judgment, reduce inhibitions, and alter mood, all of which can lead to dangerous behavior. Reckless driving, violent altercations, and forced sexual encounters are some examples. Drug and alcohol use increase the risk of sexually transmitted infections because people are more likely to engage in risky sexual behavior when under the influence. This includes having sex with someone who has had multiple partners, having anal sex without the use of a condom, having multiple partners, or having sex with someone whose history is unknown. Lastly, as previously discussed, drugs and alcohol ingested during pregnancy have a teratogenic effect on the developing embryo and fetus.

\section{Beyond Formal Operational Thought}

According to Piaget's theory, adolescents acquire formal operational thought as they. The hallmark of this type of thinking is the ability to think abstractly or to consider possibilities and ideas about circumstances never directly experienced. Thinking abstractly is only one characteristic of adult thought, however. If you compare a 15 year-old with someone in their late 30 s, you would probably find that the latter considers not only what is possible, but also what is likely. Why the change? The adult has gained experience and understands why possibilities do not always become realities. They learn to base decisions on what is realistic and practical, not idealistic, and can make adaptive

43. Volkow, N. D. (2004). Exploring the Whys of Adolescent Drug Use. United States, National Institute on Drug Abuse. Retrieved from http://www.drugabuse.gov/NIDA_notes/NNvol19N3/DirRepVol19N3.html

44. National Institute on Drug Abuse. (2015). College-age and young adults. Retrieved from https://www.drugabuse.gov/relatedtopics/college-age-young-adults/college-addiction-studies-programs

45. National Institute on Drug Abuse. (2015). College-age and young adults. Retrieved from https://www.drugabuse.gov/relatedtopics/college-age-young-adults/college-addiction-studies-programs

46. National Institutes of Health. (2020). Vaping, marijuana use in 2019 rose in college age adults. Retrieved from https://www.nih.gov/news-events/news-releases/vaping-marijuana-use-2019-rose-college-age-adults 
choices. Adults are also not as influenced by what others think. This advanced type of thinking is referred to as postformal Thought. ${ }^{47}$

In addition to moving toward more practical considerations, thinking in early adulthood may also become more flexible and balanced. Abstract ideas that the adolescent believes in firmly may become standards by which the adult evaluates reality. Adolescents tend to think in dichotomies; ideas are true or false; good or bad; and there is no middle ground. However, with experience, the adult comes to recognize that there is some right and some wrong in each position, some good or some bad in a policy or approach, some truth and some falsity in a particular idea. This ability to bring together salient aspects of two opposing viewpoints or positions is referred to as dialectical thought and is considered one of the most advanced aspects of postformal thinking. ${ }^{48}$ Such thinking is more realistic because very few positions, ideas, situations, or people are completely right or wrong. So, for example, parents who were considered angels or devils by the adolescent eventually become just people with strengths and weaknesses, endearing qualities, and faults to the adult.

\section{Does everyone reach post-formal or even formal operational thought?}

Formal operational thought involves being able to think abstractly; however, this ability does not apply to all situations or all adults. Formal operational thought is influenced by experience and education. Some adults lead lives in which they are not challenged to think abstractly about their world. Many adults do not receive any formal education and are not taught to think abstractly about situations they have never experienced. Further, they are also not exposed to conceptual tools used to formally analyze hypothetical situations. Those who do think abstractly, in fact, may be able to do so more easily in some subjects than others. For example, psychology majors may be able to think abstractly about psychology, but be unable to use abstract reasoning in physics or chemistry.

Abstract reasoning in a particular field requires a knowledge base that we might not have in all areas. Consequently, our ability to think abstractly depends to a large extent on our experiences.

\section{Attachment in Young Adulthood}

Hazan and Shaver (1987) described the attachment styles of adults, using the same three general categories proposed by Ainsworth's research on young children; secure, avoidant, and anxious/ ambivalent. ${ }^{49}$ Hazan and Shaver developed three brief paragraphs describing the three adult attachment styles. Adults were then asked to think about romantic relationships they were in and

47. Sinnott, J. D. (1998). The development of logic in adulthood. NY: Plenum Press.

48. Basseches, M. (1984). Dialectical thinking and adult development. Norwood, NJ: Ablex Pub.

49. Hazan, C., \& Shaver, P. (1987). Romantic love conceptualized as an attachment process. Journal of Personality and Social Psychology, 52 (3), 511-524. 
select the paragraph that best described the way they felt, thought, and behaved in these relationships (See Table 1).

Table 1. Which of the following best describes you in your romantic relationships?50

\begin{tabular}{c|l}
\hline Secure & $\begin{array}{l}\text { I find it relatively easy to get close to others and am comfortable depending on them and } \\
\text { having them depend on me. I don't often worry about being abandoned or about someone } \\
\text { getting too close to me. }\end{array}$ \\
$\begin{array}{l}\text { I am somewhat uncomfortable being close to others; I find it difficult to trust them } \\
\text { completely, difficult to allow myself to depend on them. I am nervous when anyone gets } \\
\text { too close, and often, love partners want me to be more intimate than I feel comfortable } \\
\text { being. }\end{array}$ \\
$\begin{array}{l}\text { Anxious/ } \\
\text { Ambivalent }\end{array}$ & $\begin{array}{l}\text { I find that others are reluctant to get as close as I would like. I often worry that my partner } \\
\text { doesn't really love me or won't stay with me. I want to merge completely with another } \\
\text { person, and this sometimes scares people away. }\end{array}$ \\
\hline
\end{tabular}

Bartholomew (1990) challenged the categorical view of attachment in adults and suggested that adult attachment was best described as varying along two dimensions; attachment relatedanxiety and attachment-related avoidance. ${ }^{51}$ Attachment-related anxiety refers to the extent to which an adult worries about whether their partner really loves them. Those who score high on this dimension fear that their partner will reject or abandon them. ${ }^{52}$ Attachment-related avoidance refers to whether an adult can open up to others, and whether they trust and feel

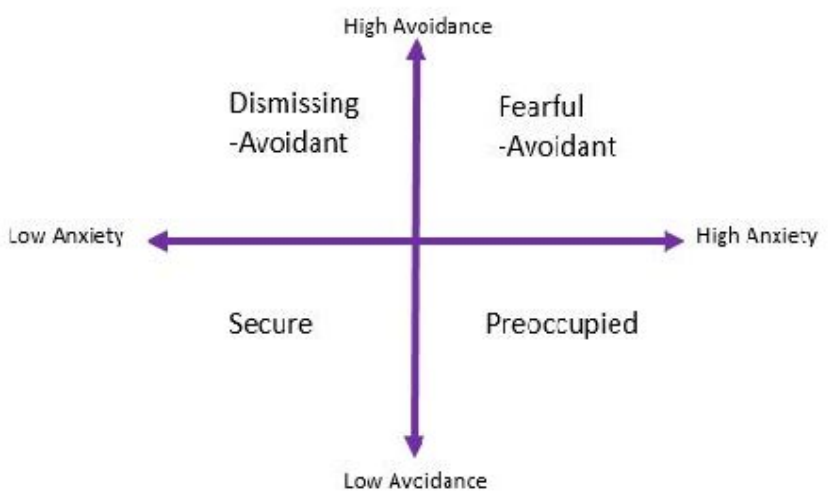

Figure 5. Four-Category Model with the TwoDimensions of Attachment they can depend on others. Those who score high on attachment-related avoidance are uncomfortable with opening up and may fear that such dependency may limit their sense of autonomy. According to Bartholomew (1990) this would yield four possible attachment styles in adults; secure, dismissing, preoccupied, and fearful-avoidant (see Figure 5). ${ }^{53}$

50. Adapted from Hazan, C., \& Shaver, P. (1987) Romantic love conceptualized as an attachment process. Journal of Personality and Social Psychology, 52, 511-524. http://dx.doi.org/10.1037/0022-3514.52.3.511

51. Bartholomew, K. (1990). Avoidance of intimacy: An attachment perspective. Journal of Social and Personal Relationships, 7 , 147-178. DOI: 10.1037/0022-3524.61.2.226.

52. Fraley, R. C., Hudson, N. W., Heffernan, M. E., \& Segal, N. (2015). Are adult attachment styles categorical or dimensional? A taxometric analysis of general and relationship-specific attachment orientations. Journal of Personality and Social Psychology, 109 (2), 354-368.

53. Bartholomew, K. (1990). Avoidance of intimacy: An attachment perspective. Journal of Social and Personal Relationships, 7 , 147-178. DOI: 10.1037/0022-3524.61.2.226. 
Securely attached adults score lower on both dimensions. They are comfortable trusting their partners and do not worry excessively about their partner's love for them. Adults with a dismissing style score low on attachment-related anxiety, but higher on attachment-related avoidance. Such adults dismiss the importance of relationships. They trust themselves but do not trust others, thus do not share their dreams, goals, and fears with others. They do not depend on other people and feel uncomfortable when they have to do so.

Those with a preoccupied attachment are low in attachment-related avoidance, but high in attachment-related anxiety. Such adults are often prone to jealousy and worry that their partner does not love them as much as they need to be loved. Adults whose attachment style is fearful-avoidant score high on both attachment-related avoidance and attachment-related anxiety. These adults want close relationships, but do not feel comfortable getting emotionally close to others. They have trust issues with others and often do not trust their own social skills in maintaining relationships.

Research on attachment in adulthood has found that:

- Adults with insecure attachments report lower satisfaction in their relationships. ${ }^{54}$

- Those high in attachment-related anxiety report more daily conflict in their relationships. ${ }^{55}$

- Those with avoidant attachment exhibit less support to their partners. ${ }^{56}$

- Young adults show greater attachment-related anxiety than do middle-aged or older adults. ${ }^{57}$

- Some studies report that young adults show more attachment-related avoidance, ${ }^{58}$ while other studies find that middle-aged adults show higher avoidance than younger or older adults. ${ }^{59}$

- Young adults with more secure and positive relationships with their parents make the transition to adulthood more easily than do those with more insecure attachments. ${ }^{60}$

54. Butzer, B., \& Campbell, L. (2008). Adult attachment, sexual satisfaction, and relationship satisfaction: A study of married couples. Personal Relationships, 15, 141-154.

55. Campbell, L., Simpson, J. A., Boldry, J., \& Kashy, D. A. (2005). Perceptions of conflict and support in romantic relationships: The role of attachment anxiety. Journal of Personality and Social Psychology, 88, 510-532.

56. Simpson, J. A., Rholes, W. S., Oriña, M. M., \& Grich, J. (2002). Working models of attachment, support giving, and support seeking in a stressful situation. Personality and Social Psychology Bulletin, 28, 598-608.

57. Chopik, W. J., Edelstein, R. S., \& Fraley, R. C. (2013). From the cradle to the grave: Age differences in attachment from early adulthood to old age. Journal or Personality, 81 (2), 171-183 DOI: 10.1111/j. 1467-6494.2012.00793

58. Schindler, I., Fagundes, C. P., \& Murdock, K. W. (2010). Predictors of romantic relationship formation: Attachment style, prior relationships, and dating goals. Personal Relationships, 17, 97-105.

59. Chopik, W. J., Edelstein, R. S., \& Fraley, R. C. (2013). From the cradle to the grave: Age differences in attachment from early adulthood to old age. Journal or Personality, 81 (2), 171-183 DOI: 10.1111/j. 1467-6494.2012.00793

60. Fraley, R. C. (2013). Attachment through the life course. In R. Biswas-Diener \& E. Diener (Eds), Noba textbook series: Psychology. Champaign, IL: DEF publishers. Retrieved from nobaproject.com. 


\section{Do people with certain attachment styles attract those with similar styles?}

When people are asked what kinds of psychological or behavioral qualities they are seeking in a romantic partner, a large majority of people indicate that they are seeking someone who is kind, caring, trustworthy, and understanding, that is the kinds of attributes that characterize a "secure" caregiver. ${ }^{61}$ However, we know that people do not always end up with others who meet their ideals. Are secure people more likely to end up with secure partners, and, vice versa, are insecure people more likely to end up with insecure partners? The majority of the research that has been conducted to date suggests that the answer is “yes." Frazier, Byer, Fischer, Wright, and DeBord (1996) studied the attachment patterns of more than 83 heterosexual couples and found that, if the man was relatively secure, the woman was also likely to be secure. ${ }^{62}$

One important question is whether these findings exist because (a) secure people are more likely to be attracted to other secure people, (b) secure people are likely to create security in their partners over time, or (c) some combination of these possibilities. Existing empirical research strongly supports the first alternative. For example, when people have the opportunity to interact with individuals who vary in security in a speed-dating context, they express a greater interest in those who are more secure rather than those who are more insecure. ${ }^{63}$ However, there is also some evidence that people's attachment styles mutually shape one another in close relationships. For example, in a longitudinal study, Hudson, Fraley, Vicary, and Brumbaugh (2012) found that, if one person in a relationship experienced a change in security, the person's partner was likely to experience a change in the same direction. ${ }^{64}$

\section{Do early experiences as children shape adult attachment?}

The majority of research on this issue is retrospective; that is, it relies on adults' reports of what they recall about their childhood experiences. This kind of work suggests that secure adults are more likely to describe their early childhood experiences with their parents as being supportive, loving, and kind. ${ }^{65}$ A number of longitudinal studies are emerging that demonstrate prospective associations between early attachment experiences and adult attachment styles and/or interpersonal functioning

61. Chappell, K. D., \& Davis, K. E. (1998). Attachment, partner choice, and perception of romantic partners: An experimental test of the attachment-security hypothesis. Personal Relationships, 5, 327-342.

62. Frazier, P. A, Byer, A. L., Fischer, A. R., Wright, D. M., \& DeBord, K. A. (1996). Adult attachment style and partner choice: Correlational and experimental findings. Personal Relationships, 3, 117-136.

63. McClure, M. J., Lydon., J. E., Baccus, J., \& Baldwin, M. W. (2010). A signal detection analysis of the anxiously attached at speeddating: Being unpopular is only the first part of the problem. Personality and Social Psychology Bulletin, 36, 1024-1036.

64. Hudson, N. W., Fraley, R. C., Vicary, A. M., \& Brumbaugh, C. C. (2012). Attachment coregulation: A longitudinal investigation of the coordination in romantic partners' attachment styles. Manuscript under review.

65. Hazan, C., \& Shaver, P. (1987). Romantic love conceptualized as an attachment process. Journal of Personality and Social Psychology, 52 (3), 511-524. 
in adulthood. For example, Fraley, Roisman, Booth-LaForce, Owen, and Holland (2013) found in a sample of more than 700 individuals studied from infancy to adulthood that maternal sensitivity across development prospectively predicted security at age $18 .{ }^{66}$ Simpson, Collins, Tran, and Haydon (2007) found that attachment security, assessed in infancy in the strange situation, predicted peer competence in grades one to three, which, in turn, predicted the quality of friendship relationships at age 16, which, in turn, predicted the expression of positive and negative emotions in their adult romantic relationships at ages 20 to $23 .^{67}$

It is easy to come away from such findings with the mistaken assumption that early experiences "determine" later outcomes. To be clear: Attachment theorists assume that the relationship between early experiences and subsequent outcomes is probabilistic, not deterministic. Having supportive and responsive experiences with caregivers early in life is assumed to set the stage for positive social development. But that does not mean that attachment patterns are set in stone. In short, even if an individual has far from optimal experiences in early life, attachment theory suggests that it is possible for that individual to develop well-functioning adult relationships through a number of corrective experiences, including relationships with siblings, other family members, teachers, and close friends. Security is best viewed as a culmination of a person's attachment history rather than a reflection of his or her early experiences alone. Those early experiences are considered important, not because they determine a person's fate, but because they provide the foundation for subsequent experiences.

\section{Relationships with Parents/Caregivers and Siblings}

In early adulthood the parent-child relationship has to transition toward a relationship between two adults. This involves a reappraisal of the relationship by both parents and young adults. One of the biggest challenges for parents/caregivers, especially during emerging adulthood, is coming to terms with the adult status of their children. Aquilino (2006) suggests that parents who are reluctant or unable to do so may hinder young adults' identity development. ${ }^{68}$ This problem becomes more pronounced when young adults still reside with their parents. Arnett (2004) reported that leaving home often helped promote psychological growth and independence in early adulthood. ${ }^{69}$

66. Fraley, R. C., Roisman, G. I., Booth-LaForce, C., Owen, M. T., \& Holland, A. S. (2013). Interpersonal and genetic origins of adult attachment styles: A longitudinal study from infancy to early adulthood. Journal of Personality and Social Psychology, 104, 8817-838.

67. Simpson, J. A., Collins, W. A., Tran, S., \& Haydon, K. C. (2007). Attachment and the experience and expression of emotions in adult romantic relationships: A developmental perspective. Journal of Personality and Social Psychology, 92, 355-367.

68. Aquilino, W. S. (2006). Family relationships and support systems in emerging adulthood. In J. J. Arnett \& J. L. Tanner (Eds.), Emerging adults in America: Coming of age in the 21st century (pp. 193-217). Washington, DC: American Psychological Association.

69. Arnett, J. J. (2004). Conceptions of the transition to adulthood among emerging adults in American ethnic groups. In J. J. 
Sibling relationships are one of the longest-lasting bonds in people's lives. Yet, there is little research on the nature of sibling relationships in adulthood. ${ }^{70}$ What is known is that the nature of these relationships change, as adults have a choice as to whether they will maintain a close bond and continue to be a part of the life of a sibling. Siblings must make the same reappraisal of each other as adults, as parents have to with their adult children. Research has shown a decline in the frequency of interactions between siblings during early adulthood, as presumably peers, romantic relationships, and children become more central to the lives of young adults. Aquilino (2006) suggests that the task in early adulthood may be to maintain enough of a bond so that there will be a foundation for this relationship in later life. ${ }^{71}$ Those who are successful can often move away from the "older-younger" sibling conflicts of childhood, toward a more equal relationship between two adults. Siblings that were close to each other in childhood are typically close in adulthood, ${ }^{72}$ and in fact, it is unusual for siblings to develop closeness for the first time in adulthood. Overall, the majority of adult sibling relationships are close. ${ }^{73}$

\section{Erikson: Intimacy versus Isolation}

Erikson's sixth stage focuses on establishing intimate relationships or risking social isolation. ${ }^{74}$ Intimate relationships are more difficult if one is still struggling with identity. Achieving a sense of identity is a life-long process, as there are periods of identity crisis and stability. However, once identity is established intimate relationships can be pursued. ${ }^{75}$

These intimate relationships include acquaintanceships and friendships, but also the more

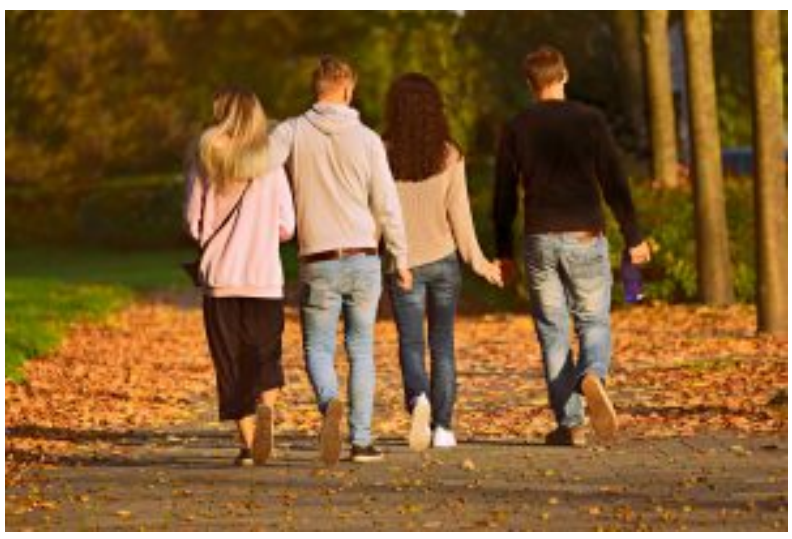

Figure 6. Young adults find companionship in both friend groups and prospective partners. (Photo Source: Pikrepo, DMCA)

Arnett \& N. Galambos (Eds.), Cultural conceptions of the transition to adulthood: New directions in child and adolescent development. San Francisco: Jossey-Bass.

70. Aquilino, W. S. (2006). Family relationships and support systems in emerging adulthood. In J. J. Arnett \& J. L. Tanner (Eds.), Emerging adults in America: Coming of age in the 21st century (pp. 193-217). Washington, DC: American Psychological Association.

71. Aquilino, W. S. (2006). Family relationships and support systems in emerging adulthood. In J. J. Arnett \& J. L. Tanner (Eds.), Emerging adults in America: Coming of age in the 21st century (pp. 193-217). Washington, DC: American Psychological Association.

72. Dunn, J. (1984). Sibling studies and the developmental impact of critical incidents. In P.B. Baltes \& O.G. Brim (Eds.), Life-span development and behavior (Vol 6). Orlando, FL: Academic Press.

73. Cicirelli, V. (2009). Sibling relationships, later life. In D. Carr (Ed.), Encyclopedia of the life course and human development. Boston, MA: Cengage.

74. Erikson, E. H. (1950). Childhood and society. New York: Norton.

75. Erikson, E. H. (1968). Identity: Youth and crisis. New York: Norton. 
276 | EMERGING AND EARLY ADULTHOOD

important close relationships, which are the long-term romantic relationships that we develop with another person, for instance, in a marriage. ${ }^{76}$

\section{(ㅇ)(1) $(0$}

Emerging and Early Adulthood by Martha Lally and Suzanne Valentine-French is licensed under a Creative Commons AttributionNonCommercial-ShareAlike 4.0 International License, except where otherwise noted.

76. Hendrick, C., \& Hendrick, S. S. (Eds.). (2000). Close relationships: A sourcebook. Thousand Oaks, CA: Sage. 